\title{
Grupos Finitos e Quebra de Simetria no Código Genético
}

\author{
Fernando Martins Antoneli Júnior
}

\author{
TESE APRESENTADA \\ $\mathrm{AO}$ \\ INSTITUTO DE MATEMÁTICA E ESTATÍSTICA \\ DA \\ UNIVERSIDADE DE SÃO PAULO \\ PARA \\ OBTENÇÃO DO GRAU DE DOUTOR \\ EM \\ MATEMÁTICA APLICADA
}

\section{Área de Concentração: Matemática Aplicada Orientador: Prof. Dr. Michael Forger}

Durante a elaboração deste trabalho o autor recebeu apoio financeiro da FAPESP

-São Paulo, janeiro de 2003- 



\title{
Grupos Finitos e Quebra de Simetria no Código Genético
}

\author{
Este exemplar corresponde à redação final da \\ tese devidamente corrigida e defendida \\ por Fernando Martins Antoneli Júnior \\ e aprovada pela comissão julgadora.
}

São Paulo, 24 de janeiro de 2003.

\section{COMISSÃO JULGADORA}

- Prof. Dr. Frank Michael Forger (orientador) - IME-USP

- Prof. Dr. Francisco Cesar Polcino Milies - IME-USP

- Prof. Dr. Said Najati Sidki - DM-UnB

- Prof. Dr. Norai Romeu Rocco - DM-UnB

- Prof. Dr. José Eduardo Martinho Hornos - IFSC-USP 



\title{
Resumo
}

Neste trabalho resolvemos o problema da classificação dos possíveis esquemas de quebra de simetria que reproduzem as degenerescências do código genético na categoria dos grupos finitos simples, contribuindo assim para a busca de modelos algébricos para a evolução do código genético, iniciada por Hornos \& Hornos em [80].

\begin{abstract}
In this work we solve the problem of classifying the possible symmetry breaking schemes based on simple finite groups that reproduce the degeneracies of the genetic code, thus contributing to the search for algebraic models that describe the evolution of the genetic code, initiated by Hornos \& Hornos in [80].
\end{abstract}



Aos meus pais,

Fernando e Eideni. 

A evolução pára quando a estupidez não é mais fatal.

Autor desconhecido. 



\section{Agradecimentos}

Ao Prof. Michael Forger, meu orientador, pelo incentivo, confiança, compreensão, paciência. A sua experiência como pesquisador e professor tornou possível a realização desta tese e contribuiu para a minha formação matemática e cultural.

Aos meus pais, Fernando e Eideni, a quem também dedico este trabalho, pelo apoio e compreensão desde que eu decidi seguir a carreia acadêmica.

Aos membros da banca examinadora, pelas correções e sugestões que que ajudaram a aumentar a legibilidade e corretude e precisão de nosso trabalho. 



\section{Conteúdo}

Introdução iii

Lista de Notações $\quad$ v

1 Quebra de Simetria e o Código Genético 1

1.1 DNA, RNA, Síntese de Proteínas e o Código Genético . . . . . . . . . . . 2

1.2 Simetria e Quebra de Simetria . . . . . . . . . . . . . . . . . . 7

1.3 Quebra Imperfeita de Simetria e Congelamento . . . . . . . . . . . . . . 11

2 Grupos Finitos $\quad 15$

2.1 Estrutura dos Grupos Finitos _ . . . . . . . . . . . . . . . . 15

2.2 Grupos de Recobrimento e Representações Projetivas . . . . . . . . . . . . . 19

2.3 Extensões por Grupos de Automorfismos . . . . . . . . . . . . . . . . . . . 24

3 Grupos Finitos Simples $\quad 29$

3.1 Grupos Alternados . . . . . . . . . . . . . . . . . . . . . . . . . 32

3.2 Grupos Finitos de Tipo Lie . . . . . . . . . . . . . . . . . . . . . 33

3.3 Grupos Esporádicos . . . . . . . . . . . . . . . . . . . . . . . . . . . . . . . 49

3.4 Classificação dos Grupos Finitos Simples . . . . . . . . . . . . . . . . . 54 
4 Representações de Códons

4.1 Representações, Caracteres e Extensões . . . . . . . . . . . . . . . . . . . . 56

4.2 Grupos Esporádicos . . . . . . . . . . . . . . . . . . . . . . 58

4.3 Grupos Alternados . . . . . . . . . . . . . . . . . . . . . 58

4.4 Grupos de Tipo Lie . . . . . . . . . . . . . . . . . . . 61

$\begin{array}{lll}5 & \text { Regras de Ramificação } & 77\end{array}$

5.1 Representações Permutacionais . . . . . . . . . . . . . . . . . 78

5.2 Classes de Conjugação de Subgrupos . . . . . . . . . . . . . . . . 87

5.3 Restrição de Caracteres e Ramificação . . . . . . . . . . . . . . . . . . 94

5.4 Busca por Quebras de Simetria para o Código Genético . . . . . . . . . . . 97

6 Resultados e Perspectivas $\quad 101$

6.1 Grupos para o código genético . . . . . . . . . . . . . . . . . . . 104

$\begin{array}{ll}\text { A Número de Códigos Genéticos } & 143\end{array}$

$\begin{array}{ll}\text { Bibliografia } & 145\end{array}$ 


\section{Introdução}

A origem da vida é, sem dúvida, uma das questões mais fascinantes - e também uma das mais profundas - já levantadas pelo homem. A resposta ainda esta além da nossa compreensão mas, ao que tudo indica, só poderá ser alcançada através de uma estreita cooperação entre as principais áreas do conhecimento envolvidas: física, química, biologia, geologia, astronomia e até matemática. De fato, entre os vários problemas a serem enfrentados na busca por uma resposta, um dos mais importantes refere-se à origem do código genético, e é neste contexto que a matemática pode fornecer ferramentas e idéias.

É um fato inegável que a área das ciências de maior interação com a matemática é a física. Aplicações da matemática em outros setores, além da utilização de técnicas estatísticas para a análise de dados experimentais, têm menos tradição mas começaram a se intensificar no decorrer do século 20, principalmente nas áreas de economia e finanças e em ciências biológicas e da saúde. A título de exemplo, podemos citar os trabalhos de John von Neumann sobre a teoria dos jogos, a teoria do equilíbrio de John Nash e a equação de Black \& Scholes pedras angulares para o desenvolvimento de métodos matemáticos sofisticados em economia e finanças - ou o modelo de Huxley \& Hodgkin para a transmissão de impulsos elétricos em neurônios, que incentivou o uso de equações diferenciais em problemas de biologia. Uma série de aplicações de métodos matemáticos modernos à biologia pode ser encontrada em [139].

Em 1993, J.E.M. Hornos \& Y.M.M. Hornos [80] propuseram um novo modelo para a evolução do código genético, baseado na hipótese de que o código genético observado hoje foi o resultado de um processo evolutivo acompanhado de uma sequência de quebras de simetria. Usando a teoria dos grupos - mais especificamente a teoria dos grupos de Lie compactos conexos ou, equivalentemente, das álgebras de Lie semisimples - para implementar a idéia de quebra de simetria, eles obtiveram uma descrição explícita de uma sequência de quebras de simetria que pode ter gerado o código genético através de um processo evolutivo. Além disto, em [80] é sugerida a realização do mesmo programa usando-se outras noções de simetria, principalmente a teoria dos grupos finitos, ou ainda extensões da noção de simetria, tais como supersimetria e grupos quânticos. 
O trabalho original de Hornos \& Hornos deu impulso à criação de um projeto temático cujo principal objetivo era a identificação e o estudo de modelos para a evolução do código genético baseados em métodos algébricos. Nesta direção, os principais resultados do projeto foram: a consolidação e extensão da classificação já enunciada no trabalho original de Hornos \& Hornos, com a inclusão de muitos detalhes não apresentados anteriormente $[53,81,3]$ e a implementação do programa de [80] usando o conceito de supersimetria [54, 55]. O presente trabalho, que faz parte deste projeto, apresenta a classificação dos possíveis esquemas de quebra de simetria para o código genético no contexto dos grupos finitos e descreve os conceitos e métodos empregados na sua obtenção, inclusive uma formulação matemática compacta e nova da noção de congelamento originalmente introduzida por Francis Crick [38].

Um dos principais aspectos de todas as investigações desta natureza é a escolha da categoria de objetos algébricos em que a análise será realizada. Por exemplo, no trabalho original de Hornos \& Hornos, a categoria utilizada é a dos grupos de Lie compactos conexos, amplamente usada na física, o que conferiu ao trabalho um impacto além da matemática. No entanto, a escolha mais imediata e natural para um problema de cunho discreto como este é trabalhar na categoria dos grupos finitos, que possui semelhanças formais com a dos grupos de Lie compactos conexos mas que é menos conhecida. Portanto, para que nosso trabalho tenha maior impacto, optamos por incluir uma introdução, numa linguagem não especializada, à teoria dos grupos finitos simples e à sua classificação, que é um dos mais célebres resultados da matemática do século 20 e constitui um dos pilares da classificação aqui apresentada.

Finalmente, gostaríamos de mencionar que, como temos um problema concreto em mãos, optamos por uma apresentação também concreta, mas isto não significa que os métodos aqui utilizados sejam específicos para este problema. Na verdade eles são absolutamente gerais e podem ser adaptados facilmente a qualquer tipo de construção de modelos baseada nas idéias de [80] e [53, 81, 3], sendo limitados apenas pela capacidade computacional disponível. 


\section{Lista de Notações}

$\mathbb{Z}$

$\mathbb{Q}$

$\mathbb{R}$

$\mathbb{C}$

$\mathbb{K}^{\times}$

$\mathbb{Z}_{n}$

Alt

Sym $_{n}$

$G L(V)$

$\operatorname{Aut}(G)$

$\operatorname{Inn}(G)$

$\operatorname{Hom}(G, H)$

$Z(G)$

$G \times H$ anel dos números inteiros

corpo dos números racionais

corpo dos números reais

corpo dos números complexos

grupo multiplicativo do corpo $\mathbb{K}$

grupo cíclico de ordem $n$

grupo alternado em $n$ símbolos

grupo simétrico em $n$ símbolos

grupo geral linear sobre o espaço vetorial $V$

grupo dos automorfismos do grupo $G$

grupo dos automorfismos internos do grupo $G$

conjunto dos homomorfismos do grupo $G$ no grupo $H$

centro do grupo $G$

produto direto dos grupos $G$ e $H$ 

Capítulo 1

\section{Quebra de Simetria e o Código Genético}

A noção de evolução foi introduzida na biologia por Charles Darwin através do seu trabalho sobre "A Origem das Espécies" e se tornou um dos mais importantes paradigmas da ciência moderna, aparecendo sempre quando ocorrem mudanças nas estruturas e padrões em que a matéria se autorganiza. Um dos principais aspectos ligados à evolução é o aumento da complexidade estrutural, no sentido de que estruturas mais simples se agrupam e se combinam, em vários níveis, formando estruturas cada vez mais sofisticadas e variadas. Isto resulta na emergência de novas propriedades qualitativas que não estão presentes nos componentes da estrutura mas só aparecem devido à interação entre eles.

O estudo da formação de padrões é um dos principais objetivos de diversas disciplinas da física e da matemática, e o conceito de simetria desempenha um papel muito importante neste tipo de investigação, uma vez que alguma tendência em direção à regularidade parece inerente à natureza. O fato de que simetrias podem ser usadas para classificar padrões de regularidade foi percebido há algum tempo: exemplos clássicos são a classificação das possíveis estruturas cristalinas em 230 classes distintas de simetria ou a classificação de partículas hadrônicas usando a teoria de representações do grupo $S U(3)$ que levou à descoberta de que essas partículas são compostas de quarks. Porém, neste tipo de descrição de padrões, usa-se apenas o "aspecto estático" das simetrias. Existe também um "aspecto dinâmico" que se revela em contextos tão distintos como as teorias de calibre, que hoje são a base teórica do modelo padrão da física das partículas, ou a teoria de sistemas dinâmicos

e de bifurcações, que se ocupa das transformações entre padrões. É aqui que se observa o fenômeno de quebra de simetria, que parece ser um aspecto importante de processos evolutivos. O fenômeno de quebra de simetria ocorre quando um estado inicial com alto grau de simetria evolve para um estado subsequente com menor grau de simetria. Tal perda de simetria pode ser interpretada como resultado da variação de parâmetros externos do sistema; em outras palavras, bifurcações são acompanhadas por quebras de simetria. 
A hipótese principal deste trabalho e do projeto temático de pesquisa em que está inserido é que o fenômeno de quebra de simetria teve um papel importante na evolução do código genético e que ele pode ser usado para analisar quais foram os passos intermediários e como este processo ocorreu. Aqui, no entanto, trataremos apenas da questão da descrição das possíveis configurações de quebra de simetria, dentro de uma certa categoria de simetrias admissíveis. Neste sentido, nosso trabalho é classificatório, abordando o "aspecto estático" e não o "aspecto dinâmico"; isto é comum em aplicações da teoria dos grupos, como nos exemplos mencionados acima. Tal trabalho de classificação é imprescindível para que seja possível abordar, em trabalhos futuros, o "aspecto dinâmico".

\subsection{DNA, RNA, Síntese de Proteínas e o Código Genético}

Nesta seção, recordaremos brevemente a estrutura do DNA e do RNA, do modo como estes codificam a síntese de proteínas e do papel do código genético neste processo. Maiores detalhes podem ser encontrados em livros texto de genética ou bioquímica, por exemplo $[100,110,111,140]$.

Em todas as formas de vida na Terra, a informação genética é armazenada em dois polímeros chamados ácido desoxiribonucléico ou DNA e ácido ribonucléico ou RNA, que são constituídos de

- açucar (desoxiribose e ribose respectivamente),

- fosfato,

- quatro diferentes bases nucléicas:

A (adenina), C (citosina), G (guanina) e

$\mathrm{T}$ (timina) no DNA, U (uracila) no RNA.

Quimicamente, citosina, timina e uracila são piramidinas, enquanto que adenina e guanina são purinas.

O DNA - o material genético primário - forma a famosa hélice dupla, constituída de duas fitas de bases nucléicas, orientadas em sentidos opostos. Cada bases nucléica é quimicamente ligada a uma molécula de desoxiribose e estas são interligadas por grupos de fosfato para formar uma fita. A sequência das bases nucléicas em qualquer uma das duas fitas determina a outra, pois

- T forma par somente com A e A somente com T (por 2 pontes de hidrogênio),

- C forma par somente com G e G somente com C (por 3 pontes de hidrogênio). 
Estas afirmações são conhecidas como as regras de pareamento de Watson-Crick. Note que matematicamente, elas podem ser vistas como um princípio de dualidade, que chamaremos de dualidade $\boldsymbol{d e}$ Watson-Crick: toda base nucléica $\mathrm{X}$ tem uma base nucléica dual $\mathrm{X}^{\dagger}$ :

$$
\mathrm{A}^{\dagger}=\mathrm{T}, \mathrm{C}^{\dagger}=\mathrm{G}, \mathrm{G}^{\dagger}=\mathrm{C}, \mathrm{T}^{\dagger}=\mathrm{A} .
$$

Como veremos adiante, a unidade de informação do código genético, chamada de códon, consiste de uma sequência de três bases: então cada códon XYZ tem um códon dual ou anticódon canônico

$$
(\mathrm{XYZ})^{\dagger}=\mathrm{Z}^{\dagger} \mathrm{Y}^{\dagger} \mathrm{X}^{\dagger}
$$

Note a inversão de ordem que é matematicamente apelativa e corresponde ao fato biológico de que as duas hélices na molécula de DNA estão orientadas em sentidos opostos.

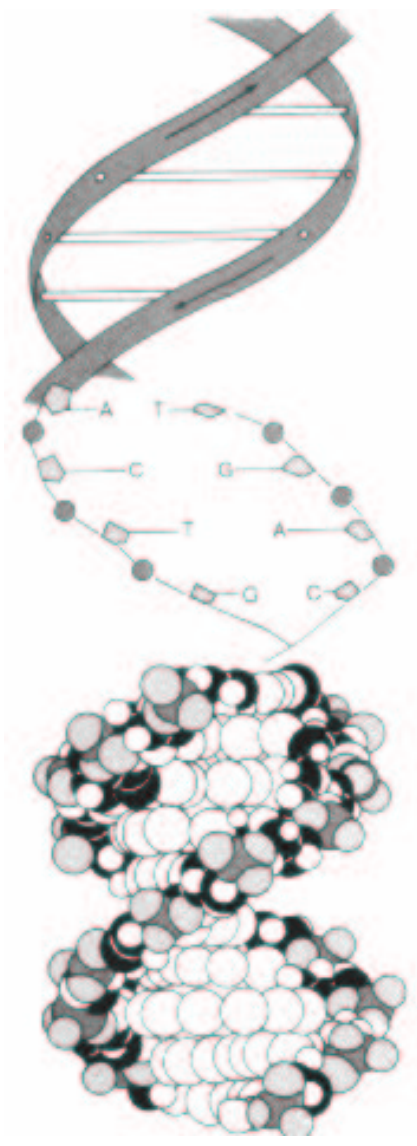

Figura 1.1: DNA e a dualidade de Watson-Crick. 
O RNA - o material genético secundário - consiste em somente uma fita de bases, cada uma quimicamente ligada a uma molécula de ribose e estas são interconectadas por grupos de fosfato. Existem vários tipos de RNA:

- mRNA - RNA mensageiro ou matriz,

- tRNA - RNA de transferência,

- rRNA - RNA ribossômico.

Eles têm funções diferentes, mas todos são importantes na síntese de proteínas. Como no RNA a timina é substituída pela uracila, a dualidade de Watson-Crick para o RNA é completamente análoga à dualidade para o DNA: basta trocar T por U.

A síntese de proteínas nas células procede em basicamente dois estágios:

Transcrição: A informação genética é copiada do DNA para o mRNA: a sequência de bases do mRNA é simplesmente a imagem refletida de uma parte da fita do DNA que é copiada. O mRNA leva esta informação até os ribossomos.

Tradução: No ribossomo (a fábrica de síntese de proteínas dentro das células), a sequência de bases nucléicas é lida do mRNA e traduzida para uma sequência de aminoácidos que formarão a proteína. O mediador deste processo de tradução é o tRNA.

Coloca-se então a questão de quais são as regras que governam este processo de tradução, da linguagem das bases nucléicas para a linguagem dos aminoácidos.

A primeira questão que deve ser respondida refere-se à unidade de informação genética. É óbvio que esta unidade de informação deve ser composta de pelo menos três bases nucléicas, uma vez que há apenas 4 bases nucléicas enquanto que as proteínas são formadas usando 20 diferentes aminoácidos. No final da década de 50, Barnett, Brenner, Crick and Watts-Tobin [17] apresentaram um argumento simples que, combinado com informações experimentais já disponíveis naquela época, permitiu concluir que a solução escolhida pela natureza é a mais simples: a unidade de informação genética, chamada de códon, é uma sequência de três bases. Sendo assim uma contagem elementar revela que há exatamente $4 \times 4 \times 4=64$ códons.

A segunda e mais concreta questão que então se coloca é a seguinte. Qual é o dicionário usado pela natureza para associar a cada códon um aminoácido ? 
Durante a década de 50 houve muita especulação em torno desta questão e vários modelos foram propostos [77]. No entanto a resposta definitiva não correspondeu a nenhum deles; ela foi encontrada experimentalmente [119, 120]. Esta correspondência entre códons (no nível do mRNA) e aminoácidos é o que se chama o código genético padrão, resumido na Tabela 1.1.

\begin{tabular}{|c|c|c|c|c|c|}
\hline \multirow{2}{*}{$\begin{array}{c}\text { primeira } \\
\text { base }\end{array}$} & \multicolumn{4}{|c|}{ segunda base } & terceira \\
\hline \hline \multirow{4}{*}{ U } & C & A & G & base \\
\hline \multirow{4}{*}{ C } & Phe & Ser & Tyr & Cys & U \\
& Phe & Ser & Tyr & Cys & C \\
& Leu & Ser & TERM & TERM & A \\
& Leu & Ser & TERM & Trp & G \\
\hline \multirow{4}{*}{ A } & Leu & Pro & His & Arg & U \\
& Leu & Pro & His & Arg & C \\
& Leu & Pro & Gln & Arg & A \\
& Leu & Pro & Gln & Arg & G \\
\hline \multirow{4}{*}{ A } & Ile & Thr & Asn & Ser & U \\
& Ile & Thr & Asn & Ser & C \\
& Ile & Thr & Lys & Arg & A \\
& Met & Thr & Lys & Arg & G \\
\hline \multirow{4}{*}{ G } & Val & Ala & Asp & Gly & U \\
& Val & Ala & Asp & Gly & C \\
& Val & Ala & Glu & Gly & A \\
& Val & Ala & Glu & Gly & G \\
\hline
\end{tabular}

Tabela 1.1: Código Genético Padrão para o mRNA. 
Um dos aspectos mais marcantes deste código é a sua degenerescência, isto é, a presença de códons que são sinônimos, representando o mesmo aminoácido. De fato, chama a atenção o agrupamento sistemático dos códons em "multipletos" de códons sinônimos, sendo que o esquema subjacente tem resistido, durante décadas, às mais variadas tentativas de encontrar uma explicação simples.

Um outro aspecto importante do código genético apresentado na Tabela 1.1 é sua quase universalidade para os seres vivos do planeta Terra, isto é, o fato de que quase todos os organismos existentes, desde bactérias até células de mamíferos, usam o mesmo código para sintetizar proteínas. Definitivamente estabelecido em 1966, ele foi durante mais de uma década chamado o "código genético universal" mas é hoje conhecido como o "código genético padrão" pois, como foi descoberto em 1979/1980, existem códigos diferentes. No entanto, os desvios são pequenos: em cada caso, a modificação afeta apenas um número pequeno de atribuições códon-aminoácido e ocorre em classes muito restritas de espécies ou, com maior frequência, em certas organelas tais como mitocôndria e cloroplastos - estruturas intracelulares que possuem seu próprio DNA e exercem funções biológicas altamente específicas (a produção de ATP no caso das mitocôndria e a fotossíntese no caso dos cloroplastos).

O argumento normalmente empregado por biólogos e geneticistas para explicar a quase universalidade do código genético padrão foi formulado pela primeira vez por Crick, através da sua famosa hipótese do "acidente de congelamento". De acordo com esta hipótese, o código genético, depois de passar por uma fase primordial de evolução, foi congelado na sua forma observada hoje, quando o mecanismo de síntese de proteínas nos organismos havia se tornado tão complexo que qualquer outra modificação seria letal; universalidade então seria uma consequência do fato de que este congelamento tenha acontecido muito cedo na evolução, antes mesmo da bifurcação das formas de vida em diferentes reinos. Até os desvios encontrados posteriormente reforçam este argumento, pois as variações são observadas, na sua grande maioria, em situações onde a pressão evolutiva no sentido de manutenção do código padrão está reduzida.

Por outro lado, a simples afirmação de que a evolução do código genético foi congelada em algum estágio não fornece nenhuma indicação sobre quais foram as leis que regeram esta evolução antes do congelamento. Na sua forma extrema, a hipótese do "acidente de congelamento" postula que a evolução primordial foi inteiramente uma questão de acaso Um simples argumento combinatório mostra, no entanto, que o número de possíveis códigos genéticos é da ordem de $10^{99}$, sendo que a esmagadora maioria não exibe nenhum tipo de regularidade. (Veja Apêndice A.) Portanto, deste ponto de vista, o surgimento de um código genético com regularidade marcante é extremamente improvável.

A abordagem algébrica ao problema da evolução do código genético trata exatamente esta questão. Baseia-se na idéia de que as degenerescências observadas no código genético são reflexo de uma simetria primordial que foi quebrada no curso de sua evolução, em uma 
sequência de passos. Uma das principais vantagens desta abordagem é que a imposição de compatibilidade com alguma simetria reduz drasticamente o número de possibilidades mencionado anteriormente, levando a uma probabilidade não-desprezível para que o código genético seja justamente como ele é hoje. Neste sentido, a abordagem algébrica é compatível com uma idéia de congelamento mais brando.

\subsection{Simetria e Quebra de Simetria}

De forma intuitiva, o uso de simetrias é um fenômeno cultural muito antigo: observam-se princípios de simetria subjacentes à construção das pirâmides do Egito e independentemente da civilização Maia, na arquitetura dos templos gregos, na ornamentação árabe, etc.. Aparentemente, a presença de simetrias está ligada ao nosso senso estético ${ }^{1}$. Observa-se também que muitas vezes, as simetrias observadas na natureza não são exatas, mas são quebradas. Geralmente, uma simetria quebrada manifesta-se de forma aproximada, isto é, ocorre um desvio da simetria exata que no entanto é suficientemente pequeno para que ela ainda possa ser claramente percebida. Um exemplo típico é a simetria quiral que tem um papel igualmente importante em física, química e biologia e que aparece sempre quando os objetos considerados admitem duas formas distintas de configuração espacial - a levógena e a destrógena. Em termos matemáticos esta simetria corresponde à troca de orientação no espaço e sua quebra indica a possibilidade de que as formas levógenas e destrógenas se comportam de maneiras distintas.

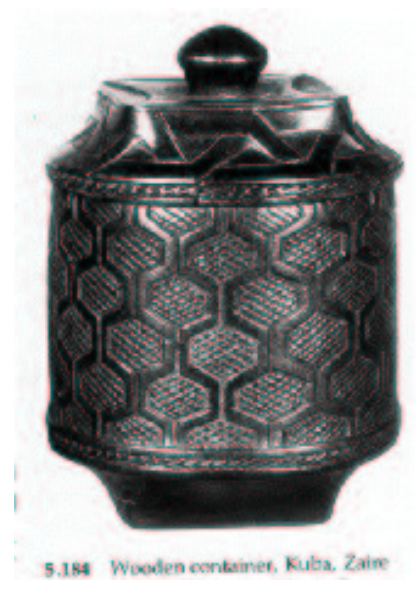

Figura 1.2: Vaso de madeira exibindo simetria ornamental (Kuba, Zaire).

\footnotetext{
${ }^{1}$ Uma bela apresentação destas idéias encontra-se no livro clássico "Symmetry" de Hermann Weyl [155].
} 
A formalização da noção de simetria em linguagem matemática moderna foi iniciada com a definição do conceito de grupo devido a Evariste Galois (grupos discretos) e Sophus Lie (grupos contínuos). Do ponto de vista abstrato, o estudo da teoria dos grupos consiste em obter suas propriedades a partir dos axiomas que os definem, enquanto que do ponto de vista concreto grupos são realizados através de transformações em algum conjunto ou espaço (em muitos casos se consideram várias realizações ao mesmo tempo). O verdadeiro poder da teoria de grupos surge quando se combinam estes dois pontos de vista. É esta combinação que usaremos para formular os conceitos intuitivos de simetria e quebra de simetria em termos matemáticos precisos.

Uma simetria exata é descrita abstratamente por um grupo $G$ e, no contexto da teoria das representações lineares adotado neste trabalho, é realizada concretamente por um conjunto de matrizes que formam uma representação de $G$ em um espaço vetorial de dimensão finita $V$, escolhido de acordo com a aplicação que se tem em mente. O espaço vetorial $V$ representa o objeto que possui a simetria descrita pelo grupos $G$. A situação mais simples ocorre quando esta representação é irredutivel: isto significa, na terminologia usada em outras áreas da ciência diferentes da matemática (tais como física ou química), que o espaço vetorial $V$ é um multipleto sob $G$. Mais geralmente, assumiremos que toda representação considerada é completamente redutivel, o que significa que ela pode ser decomposta na soma direta de subrepresentações irredutíveis que formam um conjunto de multipletos sob $G$. O invariante mais importante de um multipleto é a sua dimensão (como espaço vetorial) e por isso, usa-se frequentemente a seguinte terminologia para efatizar a dimensão dos multipletos: um multipleto de dimensão um é chamado singleto, um multipleto de dimensão dois é chamado dubleto, um multipleto de dimensão três é chamado tripleto, um multipleto de dimensão quatro é chamado quadrupleto, etc..

Uma simetria quebrada é descrita fixando, além do mais, um subgrupo $H$ de $G$ que representa a simetria residual, i.e., aquela parte da simetria que permanece intacta durante a quebra. Então uma representação irredutível de $G$, quando restrita a $H$, se quebra em várias representações irredutíveis de $H$, isto é, um único multipleto sob $G$ se quebra em vários multipletos sob $H$ - um fenômeno comumente chamado de ramificação. Mais geralmente, a idéia de que a quebra de simetria frequentemente ocorre em vários estágios, e não de uma única vez, pode ser implementada supondo que $G$ vem junto com uma sequência de subgrupos $G_{1}, \ldots, G_{k}$ que formam uma cadeia descendente

$$
G \supset G_{1} \supset \ldots \supset G_{k}
$$

levando a uma sequência de ramificações sucessivas onde, em cada passo, uma representação irredutível do grupo anterior se quebra em várias representações irredutíveis do próximo grupo da cadeia. 
Finalmente, pode-se perguntar sobre o problema inverso, que é o seguinte. Dado apenas um conjunto de multipletos, encontrar um grupo $G$ e uma cadeia descendente de subgrupos $G_{1}, \ldots, G_{k}$ tal que o conjunto dado de multipletos pode ser arranjado em uma representação irredutível de $G$ e reproduzido por ramificação através da cadeia de subgrupos $G_{1}, \ldots, G_{k}$. Tal "abordagem espectroscópica" é a maneira como se identificam simetrias na teoria quântica.

No caso do código genético, é exatamente esta situação que encontramos, pois o código genético fornece uma distribuição de multipletos da seguinte forma. Definimos o espaço dos códons como sendo o espaço vetorial complexo $V$ que tem como base o conjunto dos códons apresentados na Tabela 1.1. O agrupamento dos códons em códons sinônimos induz naturlamente uma decomposição de $V$ em soma direta de subespaços: dois códons pertencem ao mesmo subespaço se e somente se representam o mesmo aminoácido. Agora queremos encontrar um grupo juntamente com uma cadeia descendente de subgrupos que forneça essa distribuição de multipletos através do processo de ramificação que explicamos acima. Este processo representaria então um histórico parcial da evolução do código genético, através de quebras de simetrias.

Para resolver este problema precisamos antes de mais nada escolher uma metodologia que torne o problema tratável. O primeiro passo é restringir a classe de grupos dentro da qual procuraremos um candidato para o grupo que representará a simetria primordial.

O problema foi tratado pela primeira vez com sucesso por Hornos \& Hornos [80] no contexto dos grupos de Lie compactos conexos. Esta classe de grupos foi escolhida por vários motivos, sendo o principal que as representações de dimensão finita dos grupos de Lie compactos conexos são todas completamente redutíveis. Como os grupos finitos têm a mesma propriedade, é natural estudar o problema nesta categoria, como já foi proposto em [80]. A estratégia geral para a análise das degenerescências no código genético é a seguinte:

(i) Encontrar, dentre todos os grupos finitos, aqueles que possuem representações irredutíveis de dimensão 64, chamadas representações de códons.

(ii) Para cada possibilidade obtida, analizar todos os subgrupos e tentar encontrar pelo menos um subgrupo que reproduz a distribuição de multipletos do código genético, isto é, que decompõe uma representação de códons em

- 3 sextupletos,

- 5 quadrupletos,

- 2 tripletos,

- 9 dubletos,

- 2 singletos. 
O grupo inicial $G$, em conjunto com sua representação de códons, representa a "simetria exata primordial" do modelo escolhido. Nesta fase, o código genético é completamente degenerado, isto é, todos os códons têm o mesmo significado e portanto ainda não codificam nenhum amonoácido. Com a primeira quebra de simetria surge o primeiro código genético, também chamado de "código genético primitivo", que já codifica alguns aminoácidos, mas que ainda não atingiu a forma final e portanto está sujeito a sofrer uma nova quebra de simetria e incorporar outros aminoácidos ao seu repertório. A hipótese de que a representação de códons seja irredutível reflete o caráter "primitivo" da simetria primordial, pois uma representação redutível é um objeto composto: podendo ser expressa como uma soma direta de representações irredutíveis, ela corresponde a um estágio posterior do processo e não ao estágio inicial. Um argumento semelhante pode ser aplicado ao próprio grupo inicial: suporemos que ele também seja "primitivo", no sentido de que não pode ser construído a partir de outros grupos. Isto nos leva à categoria dos grupos finitos simples - os "blocos fundamentais" da teoria dos grupos finitos. Ressaltamos que essa condição é imposta apenas sobre o grupo inicial; os subgrupos utilizados na quebra de simetria podem ser arbitrários.

Aqui é que surge a principal diferença entre a categoria dos grupos finitos e a dos grupos de Lie compactos conexos, que abreviaremos por grupos lcc. Na categoria dos grupos lcc, os subgrupos têm uma estrutura relativamente simples: são (a menos de um recobrimento finito) o produto direto de um toro (grupo lcc abeliano) e um grupo lcc semisimples, que por sua vez é (a menos de um recobrimento finito) o produto direto de um número finito de grupos lcc simples [23, 32]. Como as representações irredutíveis de um toro são unidimensionais [23], estes podem ser ignorados, e portanto basta considerar grupos lcc semisimples. A teoria das representações dos grupos lcc semisimples pode ser descrita inteiramente em termos da teoria das representações das álgebras de Lie semisimples complexas; assim toda a análise pode ser executada neste âmbito, isto é, na categoria das álgebras de Lie semisimples complexas e suas subalgebras semisimples. As subalgebras semisimples de uma álgebra semisimples qualquer podem ser construídas de maneira uniforme graças aos teoremas de Dynkin [47, 48]. Estes resultados classificam as subalgebras semisimples maximais de uma álgebra de Lie simples e por processo iterativo pode-se obter todas as subalgebras semisimples. A outra vantagem de se trabalhar com álgebras de Lie semisimples é que a teoria de representações destes objetos, criada por Élie Cartan e Hermann Weyl, vem com todas as ferramentas necessárias, que são as seguintes:

(i) Classificação das representações irredutíveis de todas as álgebras de Lie semisimples e fórmulas de dimensão $[20,56,62,82,101,147]$ que permitem determinar todas as álgebras de Lie semisimples que possuem representações de códons.

(ii) Tabelas das regras de ramificação, que descrevem como se decompõem as representações irredutíveis de uma álgebra de Lie semisimples sob restrição às suas subalgebras semisimples [117]. 
No caso dos grupos finitos simples a situação é bem diferente, pois como já comentamos esta categoria não é fechada com relação a subgrupos e não existem até hoje métodos para se construir todos os subgrupos de maneira uniforme, como no caso das álgebras de Lie semisimples. Existe apenas uma classificação dos subgrupos maximais [99] dos grupos finitos simples, com a exceção do grupo Monstro [121], mas isto não é suficiente para construir todos os subgrupos. A classificação das representações irredutíveis dos grupos finitos simples também não é completamente conhecida, pois ao contrário das álgebras de Lie semisimples para as quais existe uma teoria geral de representações em termos de pesos máximos, somente certas famílias de grupos finitos simples têm suas tabelas de caracteres completamente calculadas e os métodos são em geral completamente diferentes dependendo de cada família.

Por outro lado, grupos finitos podem ser abordados por métodos computacionais para resolver todos estes problemas. A teoria computacional dos grupos finitos está bastante avançada e conta com poderosos algoritmos [57] que tornam esta análise factível na categoria dos grupos finitos simples.

\subsection{Quebra Imperfeita de Simetria e Congelamento}

Quando um fenômeno admite simetrias, em geral, os modelos usados para o estudo deste fenômeno são idealizados: supõe-se que a simetria seja perfeita, mesmo quando é somente aproximada. Porém existem argumentos que suportam a relevância de tal aproximação: previsões baseadas em modelos com simetria aproximada diferem qualitativamente das previsões baseadas em modelos sem simetria alguma. Isso pode ser comprovado, por exemplo, em sistemas dinâmicos com uma simetria perturbada por pequenas imperfeições ou efeitos estocásticos, através de simulações numéricas.

O mesmo pode-se dizer de um processo de quebra de simetria, que também pode sofrer perturbações ou flutuações, de forma que a simetria residual não é perfeita. De fato, todos os modelos já obtidos para o código genético, incluindo o original de Hornos \& Hornos [80], não possuem um simetria residual perfeita.

Este tipo de imperfeição pode ser incorporado no esquema através de uma pequena generalização da definição de quebra de simetria. Considere uma cadeia de subgrupos

$$
G \supset G_{1} \supset \ldots \supset G_{k-1} \supset G_{k}
$$

que produz decomposições do espaço vetorial $V$ em subespaços irredutíveis sob cada um dos subgrupos $G_{i}, i=1, \ldots, k$. Na caso de uma quebra perfeita de simetria, a distribuição final de multipletos só depende do último subgrupo da cadeia, $G_{k}$ (a menos de conjugação). A generalização descrita a seguir implica que a distribuição final de multipletos depende dos últimos dois subgrupos da cadeia, $G_{k-1}$ e $G_{k}$ (a menos de conjugação). 
Para formular as regras que governam este processo de quebra imperfeita, lembremos primeiro que, em geral, a decomposição de uma representação completamente redutível de um grupo $G$ em um espaço vetorial $V$ em soma direta de subespaços irredutíveis não é única. No entanto, para cada subespaço irredutível $W$ de $V$, podemos definir $\hat{W}$ como a soma direta de todos os subespaços irredutíveis de $V$ que são equivalentes a $W$ sob a ação de $G$. Dizemos que $\hat{W}$ é a componente isotípica de $V$ correspondente a $W$. A utilidade deste conceito decorre do fato de que a decomposição de $V$ em componentes isotípicas é única, enquanto que a decomposição de cada componente isotípica em subespaços irredutíveis não é. Mais explicitamente, podemos escolher subespaços irredutíveis $W_{i}$ de $V(i=1, \ldots, n)$, tais que todo subespaço irredutível de $V$ é equivalente a exatamente um deles; então

$$
V=\hat{W}_{1} \oplus \ldots \oplus \hat{W}_{n} .
$$

Esta decomposição é chamada de decomposição isotípica de $V$ [60]. O número de subespaços irredutíveis em cada componente isotípica $\hat{W}_{i}$ é chamada de multiplicidade de $\hat{W}_{i}$.

Agora fixemos um par de subgrupos $G_{1}, G_{2}$ de $G$ sujeitos às seguintes condições:

$$
G \supset G_{1} \supset G_{2} \quad \text { e } G_{2} \text { é maximal em } G_{1} \text {. }
$$

A restrição da representação irredutível de $G$ em $V$ ao subgrupo $G_{1}$ produz uma decomposição de $V$ em subespaços $V_{i}^{1}(i=1, \ldots, r)$ irredutíveis sob $G_{1}$, enquanto que a restrição da representação irredutível de $G$ em $V$ ao subgrupo $G_{2}$ produz uma decomposição de $V$ em subespaços $V_{j}^{2}(j=1, \ldots, s)$ irredutíveis sob $G_{2}$. Mas a condição de que $G_{2} \subset G_{1}$ implica que o conjunto dos subespaços $V_{j}^{2}$ pode ser particionado em $r$ classes de equivalência indexadas pelos subespaços $V_{i}^{1}$, simplesmente dizendo que $V_{j_{1}}^{2}$ e $V_{j_{2}}^{2}$ estão na mesma classe de equivalência $i$ se e somente se $V_{j_{1}}^{2} \subset V_{i}^{1}$ e $V_{j_{2}}^{2} \subset V_{i}^{1}$. A condição de maximalidade de $G_{2}$ em $G_{1}$ implica que a subdivisão de cada um dos multipletos sob $G_{1}$ em vários multipletos sob $G_{2}$ é a mais branda possível: caso contrário poderia se inserir um grupo intermediário que produziria uma subdivisão intermediária.

Isso posto, podemos formalizar a noção de "congelamento". Nas condições acima descritas, diremos que um subespaço $V_{i}$ irredutível sob $G_{1}$ está congelado em $G_{2}$ se a partição de $V_{i}$ por restrição a $G_{2}$ for desconsiderada, isto é, apesar da ação de $G_{2}$ sobre $V_{i}$ ser redutível, este subespaço será mantido intacto como multipleto. Tal situação não pode ser descrita por um único subgrupo residual, mas por um par $\left(G_{1}, G_{2}\right)$ de subgrupos residuais. A regra principal é que o congelamento deve ser aplicado, ou não, a cada componente isotípica de $V$ sob $G_{1}$. Em outras palavras, cada multipleto sob $G_{1}$ tem duas opções: ou ele se quebra completamente sob a ação de $G_{2}$ ou ele fica completamente congelado sob a ação de $G_{2}$ e o mesmo deve então ocorrer com todos os outros multipletos na mesma componente isotípica. 
Finalmente, consideramos uma cadeia de subgrupos

$$
G \supset G_{1} \supset \ldots \supset G_{k-1} \supset G_{k},
$$

onde $G_{i}$ é maximal em $G_{i+1}$. Neste caso, o par que determina o congelamento é $\left(G_{k-1}, G_{k}\right)$, isto é, o congelamento só pode ocorrer durante a última quebra de simetria. Observe que escolhendo uma outra cadeia de subgrupos

$$
G \supset G_{1}^{\prime} \supset \ldots \supset G_{k-1}^{\prime} \supset G_{k},
$$

terminando no mesmo grupo residual $G_{k}$ mas tal que $G_{k-1}^{\prime}$ e $G_{k-1}$ não são conjugados, o resultado da quebra com congelamento poderá ser diferente para as duas cadeias, pois a distribuição final de multipletos depende também do penúltimo subgrupo, que determina como os multipletos podem ser congelados. É neste sentido generalizado de quebra de simetria que os modelos encontrados no contexto de grupos ou álgebras de Lie e de superalgebras de Lie reproduzem o código genético.

Obviamente, há uma certa arbitrariedade neste esquema, pois a escolha dos multipletos que serão congelados não pode ser formalizada dentro da teoria dos grupos subjacente ao modelo. Isto confere ao nosso esquema uma maior flexibilidade, mas por outro lado faz com que ele dependa de um justificativa externa para o congelamento e portanto não esteja completamente imerso no formalismo da teoria dos grupos. Esta restrição não é muito severa, pois não se espera realmente que seja possível construir modelos puramente matemáticos para fenômenos biológicos que, diferentemente dos fenômenos físicos, possuem regras muito menos rígidas. De qualquer modo, a interpretação deste congelamento deve ser procurada em outros âmbitos, esperando-se que novas idéias, de caráter matemático (sistemas dinâmicos, por exemplo) ou biológico, sejam adicionados ao modelo, conferindo-lhe maior completude. Porém, mesmo que ainda não podemos justificar o congelamento dentro da teoria dos grupos, podemos pelo menos descrevê-lo dentro deste formalismo. A idéia geral é que pode-se construir um operador linear no espaço da representação que tenha os espaços invariantes sob o grupo residual (ou sob o par de grupos residuais) como espaços próprios. Esta "descrição espectral" da distribuição de multipletos foi implementada no modelo baseado em álgebras de Lie utilizando-se certos operadores de Casimir na álgebra universal envolvente associada a álgebra de Lie final.

Finalmente, vale mencionar que, no que diz respeito à terminologia empregada, a noção matemática de congelamento aqui apresentada é motivada pelo significado literal da palavra "congelamento", que está associada à transição de fase do estado líquido para o estado sólido, sendo que o primeiro tem um grupo de simetria maior do que o segundo. Concretamente, quando esfriamos um balde de água até atingir a temperatura de zero graus Celsius, começa a se formar uma mistura de água e gelo. Nesse estado, trata-se de um sistema heterogêneo onde se misturam regiões com diferentes graus de simetria. A quebra de simetria que acompanha a transformação da água para o gelo é imperfeita ou incompleta, pois deixa de ser realizada nas regiões onde a água permanece líquida. 

CAPÍTUlo 2

\section{Grupos Finitos}

Nesta capítulo apresentaremos alguns tópicos da teoria dos grupos finitos, incluindo a teoria de estrutura dos grupos finitos, a teoria de extensões de grupos, a teoria de representações lineares e projetivas e a teoria de representações permutacionais e sua relação com subgrupos maximais. Todos estes assuntos são tratados em livros texto e portanto apresentaremos os resultados que nos interessam e indicaremos referências onde as demonstrações podem ser encontradas.

\subsection{Estrutura dos Grupos Finitos}

O resultado fundamental sobre a estrutura dos grupos finitos é o teorema de JordanHölder. Antes de enunciá-lo recordaremos algumas definições. Seja $G$ um grupo. Uma série de subgrupos

$$
G=G_{0} \supset G_{1} \supset \ldots \supset G_{r}
$$

é dita subnormal se cada $G_{i+1}$ é um subgrupo próprio normal de $G_{i}(i=0,1, \ldots, r-1)$. Os grupos quociente $G_{i} / G_{i+1}(i=0,1, \ldots, r-1)$ são chamados fatores da série. Um refinamento de uma série normal é uma nova série normal obtida inserido-se um número finito de subgrupos na série dada. Obviamente, todo grupo finito possui uma série normal de comprimento máximo, isto é, que não pode ser mais refinada, e terminando no grupo trivial:

$$
G=G_{0} \supset G_{1} \supset \ldots \supset G_{m}=\{1\} .
$$

Voltando ao caso geral, consideremos duas séries normais terminando no grupo trivial:

$$
\begin{aligned}
G & =G_{0} \supset G_{1} \supset \ldots \supset G_{r}=\{1\}, \\
G & =G_{0}^{\prime} \supset G_{1}^{\prime} \supset \ldots \supset G_{r^{\prime}}^{\prime}=\{1\} .
\end{aligned}
$$


Diremos que estas séries são equivalentes se $r=r^{\prime}$ e existe uma permutação dos índices $i=1, \ldots, r-1$, representada por $i \mapsto i^{\prime}$, tal que

$$
G_{i} / G_{i+1} \cong G_{i^{\prime}}^{\prime} / G_{i^{\prime}+1}^{\prime}
$$

Em outras palavras, os fatores de ambas são os mesmos, a menos de uma permutação dos índices.

Teorema 2.1.1 (Schreier) Seja G um grupo. Quaisquer duas séries normais de subgrupos terminando no grupo trivial possuem refinamentos equivalentes.

DemonstraÇÃo. Veja Lang [106], página 22.

Um grupo é dito simples se é não-trivial e não possui subgrupos normais além do grupo trivial $\{1\}$ e do próprio $G$.

O seguinte teorema é consequência do teorema de Schreier.

Teorema 2.1.2 (Jordan-Hölder) Sejam G um grupo e

$$
G=G_{0} \supset G_{1} \supset \ldots \supset G_{r}=\{1\}
$$

uma série normal tal que cada fator $G_{i} / G_{i+1}$ é simples. Então qualquer outra série normal de $G$ tendo a mesma propriedade é equivalente a esta. Em particular, ela tem comprimento máximo.

Demonstração. Veja Lang [106], página 22.

Uma série normal com comprimento máximo é chamada série de composição de $G$. Os fatores de uma série de composição de um grupo $G$, por serem simples, não podem ser mais reduzidos, e como são unicamente determinados por $G$, são invariantes de $G$. É neste sentido que os grupos finitos simples podem ser considerados os "blocos fundamentais" na teoria dos grupos finitos. Observe também que o teorema de Jordan-Hölder não afirma a existência de uma série de composição mas apenas a unicidade dos fatores simples (a menos de permutações). No caso em que $G$ é finito, porém, a existência de uma série de composição é imediata.

Isto posto, podemos nos perguntar até que ponto os invariantes simples determinam o grupo finito $G$. Este problema é chamado o "problema de extensão" que, dado dois grupos $N$ e $Q$, consiste em determinar quais são as possibilidades de se construir um novo grupo $G$ que satisfaça

$$
N \triangleleft G \quad \text { e } \quad Q \cong G / K,
$$

ou na linguagem de sequências exatas, classificar as sequências exatas curtas de grupos

$$
1 \longrightarrow N \stackrel{\iota}{\longrightarrow} G \stackrel{\pi}{\longrightarrow} Q \longrightarrow 1 \text {. }
$$


Neste caso, dizemos que $G$ é uma extensão de $Q$ por $N$ ou de $N$ por $Q$, de acordo com a conveniência. Na prática usamos as duas variações: se $Q$ é não-solúvel e $N$ é abeliano dizemos que $G$ é uma extensão de $Q$ por $N$, se $N$ é não-solúvel e $Q$ é solúvel dizemos que $G$ é uma extensão de $N$ por $Q$. O subgrupo normal $N$ é chamado núcleo da extensãa e o grupo $Q$ é chamado quociente da extensão. Podemos imaginar tal extensão como um "produto torcido", generalizando o produto direto $G=N \times Q$ entre $N$ e $Q$ que é a extensão trivial. De qualquer forma, $G$ opera sobre $N$ por conjugação e portanto temos um homomorfismo $G \rightarrow \operatorname{Aut}(N)$. Finalmente, dizemos que duas extensões $G_{1}$ e $G_{2}$ com o mesmo $N$ e o mesmo $Q$ são equivalentes se existem isomorfismos verticais como indicado no seguinte diagrama comutativo:

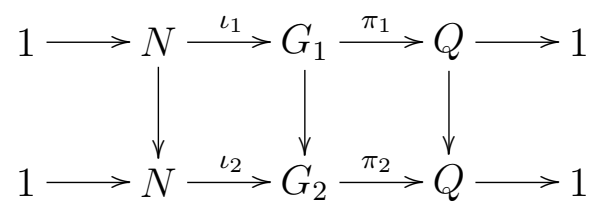

As flechas verticais externas são a aplicação identidade.

Agora podemos interpretar o teorema de Jordan-Hölder no contexto de extensões de grupos. Suponhamos que $G$ possui uma série de composição

$$
G=N_{0} \supset N_{1} \supset \ldots \supset N_{m-1} \supset N_{m}=\{1\},
$$

com os respectivos fatores

$$
N_{0} / N_{1}=Q_{1}, \ldots, N_{m-1} / N_{m}=Q_{m} .
$$

Obviamente, $N_{m-1}=Q_{m}$, pois $N_{m}=\{1\}$. No estágio anterior ocorre algo mais interessante, já que $N_{m-2} / N_{m-1}=Q_{m-1}$ e portanto $N_{m-2}$ é uma extensão de $N_{m-1}$ por $Q_{m-1}$. Se conseguirmos resolver o problema de extensão, podemos recuperar $N_{m-2}$ a partir de $N_{m-1}$ e $Q_{m-1}$, isto é, a partir de $Q_{m}$ e $Q_{m-1}$. Uma vez que temos $N_{m-2}$, podemos determinar $N_{m-3}$ de modo semelhante, usando que $N_{m-3} / N_{m-2}=Q_{m-2}$, e assim por diante, subindo na série de composição de $G$ até chegarmos em $N_{0}=G$. Podemos imaginar então que o grupo $G$ é o "produto torcido" dos grupos $Q_{i}$ e que o teorema de Jordan-Hölder nos diz quais são os grupos simples ocorrendo nesta "fatorização" de $G$, pois estes são unicamente determinados por $G$. Assim, podemos em tese construir todos os grupos finitos se soubermos determinar todos os grupos finitos simples e soubermos resolver o problema geral de extensão. Em particular, podemos construir todos os grupos finitos solúveis se soubermos resolver o problema geral de extensão, uma vez que conhecemos todos os grupos finitos simples abelianos: são os grupos cíclicos $\mathbb{Z}_{p}, p$ primo.

Uma solução do problema de extensão consiste em determinar as classes de equivalência de extensões de $N$ por $Q$. Uma resposta parcial foi obtida por Schreier (1926), que 
resolveu o problema de extensão no seguinte sentido: dado dois grupos finitos $N$ e $Q$ podemos construir as tabelas de multiplicação de todas as extensões $G$ de $N$ por $Q$ (veja [141]). Porém a solução de Schreier não providencia nenhum algoritmo para determinar quais delas são equivalentes. Uma solução geral do problema de extensão, no sentido de determinar as classes de equivalência de todas as extensões, ainda não é conhecida.

A ferramenta padrão para o estudo de extensões é a teoria de cohomologia de grupos [1]. Neste contexto, existem soluções completas do problema se nos restringirmos a certos tipos de extensões, por exemplo extensões com núcleo abeliano. Dentre as várias restrições que podemos impor sobre extensões de grupos, merecem destaque as extensões abelianas, em particular as extensões centrais, e as extensões cindidas.

Seja $G$ uma extensão de grupos com núcleo $N$ abeliano. Observe que, neste caso, o núcleo $N$ da extensão está contido no núcleo do homomorfismo $G \rightarrow \operatorname{Aut}(N)$ que portanto induz um homomorfismo $Q \rightarrow \operatorname{Aut}(N)$, isto é, $N$ é um $\mathbb{Z}$-módulo sobre $Q$. No caso especial quando $N$ estiver contido no centro de $G$ falamos de uma extensão central. Como veremos na próxima seção, extensões centrais têm estreita relação com a teoria de representações projetivas.

Uma extensão de grupos $G$ é chamada extensão cindida se existe um homomorfismo $\sigma: Q \rightarrow G$ tal que $\sigma \circ \pi=\mathrm{id}$. Como $\sigma$ é necessariamente injetor, podemos identificar $Q$ com sua imagem sob $\sigma$ e assim considerá-lo como subgrupo de $G$. O homomorfismo $\sigma$ é chamado cisão da sequência exata:

$$
1 \longrightarrow N \stackrel{\iota}{\longrightarrow} G \underset{\sigma}{\stackrel{\pi}{\rightleftarrows}} Q \longrightarrow 1
$$

Uma forma mais construtiva de se obter extensões cindidas é através do conceito de produto semidireto [1, pág. 11]. Considere dois grupos $N$ e $Q$ e suponha que seja dado um homomorfismo $\phi: Q \rightarrow \operatorname{Aut}(N)$, que podemos interpretar como uma operação (por automorfismos) de $Q$ sobre $N$ :

$$
\begin{array}{ccc}
Q \times N & \longrightarrow & N \\
(q, n) & \mapsto q \cdot n
\end{array}
$$

Então no produto cartesiano $N \times Q$ definimos o seguinte produto:

$$
\left(n_{1}, q_{1}\right)\left(n_{2}, q_{2}\right)=\left(n_{1}\left(q_{1} \cdot n_{2}\right), q_{1} q_{2}\right) .
$$

Este produto define uma estrutura de grupo em $N \times Q$ chamada produto semidireto de $N$ por $Q$ induzido por $\phi$ e denotada $N \rtimes_{\phi} Q$. Omitiremos o índice $\phi$ quando não houver perigo de confusão. Valem as seguintes propriedades [128]:

(i) As inclusões $N \rightarrow N \rtimes Q$ e $Q \rightarrow N \rtimes Q$ dadas, respectivamente, por $n \mapsto(n, 1)$ e $q \mapsto(1, q)$ são homomorfismos injetores de grupos, 
(ii) $N$ é normal em $N \rtimes Q$,

(iii) Se $\phi$ é o homomorfismo trivial então $N \rtimes Q$ se reduz ao produto direto de $N$ e $Q$, o que significa que $Q$ também é subgrupo normal,

(iv) o produto semidireto $N \rtimes Q$ é uma extensão cindida de $N$ com complemento $Q$.

Reciprocamente, pode-se provar que toda extensão cindida é isomorfa a um produto semidireto [128].

\subsection{Grupos de Recobrimento e Representações Projetivas}

Uma extensão central de um grupo $Q$ pelo grupo $Z$ é uma sequência exata

$$
1 \longrightarrow Z \stackrel{\iota}{\longrightarrow} G \stackrel{\pi}{\longrightarrow} Q \longrightarrow 1
$$

tal que $Z$ (que identificamos com sua imagem em $G$ ) está contido no centro $Z(G)$ de $G$. Também dizemos que o grupo $G$ é uma extensão central de $Q$ por $Z$ ou que o par $(G, Z)$ de grupos é uma extensão central de $Q$. Quando não precisamos ou não queremos especificar o subgrupo central $Z$, dizemos simplesmente que o grupo $G$ é uma extensão central de $Q$.

Uma extensão central é dita essencial ou um grupo de recobrimento de $Q$ se $Z$ está contido no subgrupo derivado $[G, G]$ de $G$. Recordamos que o comutador de dois elementos $x, y$ de um grupo $G$ é definido por $[x, y]=x^{-1} y^{-1} x y$ e que o grupo derivado de $G$ é o subgrupo normal $[G, G]$ gerado por todos estes comutadores. Um papel especial entre os grupos de recobrimento de um grupo $Q$ é desempenhado pelos grupos de recobrimento maximais definidos a seguir. Suponhamos que sejam dados uma outra extensão central essencial

$$
1 \longrightarrow Z^{\prime} \longrightarrow G^{\prime} \longrightarrow Q \longrightarrow 1 \text {. }
$$

junto com um homomorfismo $\varphi: G^{\prime} \rightarrow G$ de modo que o diagrama abaixo seja comutativo.

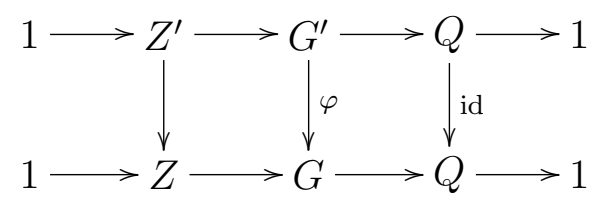

Dizemos que $G$ é um grupo de recobrimento maximal de $Q$ se $\varphi$ é um isomorfismo para toda extensão central essencial satisfazendo (2.1). Segue desta definição que, se $\alpha^{\prime}: G^{\prime} \rightarrow Q$ é um grupo de recobrimento qualquer, então existe um grupo de recobrimento maximal 
$\alpha: G \rightarrow Q$ e um homomorfismo sobrejetor $\beta: G \rightarrow G^{\prime}$ tal que $\alpha=\beta \circ \alpha^{\prime}$. Em outras palavras, todo grupo de recobrimento de $Q$ é o quociente de algum grupo de recobrimento maximal de $Q$ por algum subgrupo central.

A noção de grupo de recobrimento é particularmente transparente para grupos perfeitos. Lembramos que um grupo é dito perfeito se coincide com seu grupo derivado. É claro que se $G$ é uma extensão central de $Q$ e $G$ é perfeito então $Q$ também é. Reciprocamente, se $Q$ é perfeito então $G$ também é, desde que a extensão central seja essencial: esta é uma motivação para incluir a condição $Z \subset[G, G]$ na definição de grupo de recobrimento. Outro motivo é a observação de que na categoria de extensões centrais gerais (não essenciais) não existem objetos maximais.

A teoria de representações lineares de grupos é a uma das áreas mais importantes da teoria dos grupos, com aplicações dentro e fora da matemática. Há uma generalização desta teoria, chamada teoria de representações projetivas de grupos, que estende os resultados da teoria linear a uma classe mais ampla de ações de grupos. Os fundamentos desta teoria foram estabelecidos por Schur entre 1904 e 1907. Subsequentemente, em 1911, Schur aplicou essa teoria aos grupos simétricos e alternados.

Representações projetivas são também fundamentais na teoria quântica. Grosso modo, um sistema mecânico quântico é definido em termos de um espaço de Hilbert complexo $\mathscr{H}$ e uma álgebra de operadores lineares sobre $\mathscr{H}$ (não necessariamente contínuos e, neste caso, definidos em um subespaço denso de $\mathscr{H}$ ). Um estado quântico puro é representado por um subespaço unidimensional de $\mathscr{H}$, isto é, um elemento do espaço projetivo associado a $\mathscr{H}$. Quando o sistema admite um grupo de simetrias, este deve agir no espaço dos estados, o que leva naturalmente a considerar representações projetivas de dimensão infinita.

Nosso trabalho também necessita de alguns conceitos elementares desta teoria, que serão apresentados a seguir.

Seja $V$ um espaço vetorial complexo de dimensão finita. Uma representação projetiva (complexa) de um grupo $G$ em $V$ é uma aplicação $\pi: G \rightarrow G L(V)$ em conjunto com uma função $\omega: G \times G \rightarrow \mathbb{C}^{\times}$chamada o multiplicador da representação projetiva $\pi$, tal que $\omega(1,1)=1$ e para todo $g, h \in G$

$$
\pi(g) \pi(h)=\omega(g, h) \pi(g h) .
$$

Como as transformações lineares $\pi(g)$ são inversíveis, segue que, para todo $g \in G$,

$$
\omega(g, 1)=1=\omega(1, g) .
$$

Usando a associatividade da composição e da multiplicação do grupo em $\pi\left(g_{1}\right) \pi\left(g_{2}\right) \pi\left(g_{3}\right)$ obtemos que para todo $g_{1}, g_{2}, g_{3} \in G$

$$
\omega\left(g_{1}, g_{2} g_{3}\right) \omega\left(g_{2}, g_{3}\right)=\omega\left(g_{1}, g_{2}\right) \omega\left(g_{1} g_{2}, g_{3}\right) .
$$


Em geral, uma aplicação $\omega: G \times G \rightarrow \mathbb{C}^{\times}$satisfazando as condições $(2.2)$ e (2.3) é chamada um 2-cociclo de $G$. Para uso posterior, mencionamos que um 2-cociclo tomando valores nas $k$-ésimas raízes da unidade, para algum inteiro $k \geqslant 1$, é chamado um 2-cociclo especial de ordem $k$. Observamos também que uma representação linear de um grupo $G$ em um espaço vetorial de dimensão finita $V$, sendo um homomorfismo $G \rightarrow G L(V)$, pode ser vista como uma representação projetiva associada ao 2-cociclo trivial.

O termo "projetivo" neste contexto provém do seguinte fato. Dado um espaço vetorial complexo $V$, o espaço projetivo $\mathbb{P}(V)$ associado a $V$ é o conjunto das classes de equivalência $[v]$ de elementos não-nulos de $V$ sob a relação $v \sim u$ se e somente se $v=\lambda u$ para algum $\lambda \in \mathbb{C}^{\times}$. Um elemento $T \in G L(V)$ induz um operador $\hat{T}$ em $\mathbb{P}(V)$ por

$$
\hat{T}[v]=[T(v)],
$$

e este operador é um elemento do grupo geral projetivo $P G L(V)$, que é definido como o grupo quociente

$$
P G L(V)=G L(V) / \mathbb{C}^{\times} \cdot 1_{V} .
$$

Portanto, uma representação projetiva $\pi$ induz um homomorfismo $\hat{\pi}: G \rightarrow P G L(V)$ que, por abuso de linguagem, também é chamado uma representação projetiva de $G \mathrm{em} V$. No entanto, $\pi$ não é unicamente determinado por $\hat{\pi}$. De fato, podemos para todo $g \in G$ escolher um outro representante $\pi^{\prime}(g)$ de $\hat{\pi}(g)$ (com a mesma convenção de que $\pi^{\prime}(1)=1_{V}$ ); então

$$
\pi^{\prime}(g)=d(g) \pi(g),
$$

onde $d$ é uma função $d: G \rightarrow \mathbb{C}^{\times}$tal que $d(1)=1$. Sendo $\omega^{\prime}$ o 2 -cociclo associado a $\pi^{\prime}$, obtemos

$$
\omega^{\prime}(g, h)=d(g) d(h)(d(g h))^{-1} \omega(g, h) .
$$

Dois 2-cociclos relacionados desta forma são ditos cohomólogos. Denotamos a classe de cohomologia de um 2-cociclo $\omega$ por $[\omega]$.

Assim observamos que representações projetivas de $G$ (sobre $\mathbb{C}$ ) levam a considerar o segundo grupo de cohomologia de $G$ com coeficientes em $\mathbb{C}^{\times}, H^{2}\left(G, \mathbb{C}^{\times}\right)$. Este grupo é chamado o multiplicador de Schur de $G$ e denotado por $M(G)$. Ele foi introduzido por Schur, a quem se deve o seguinte resultado.

Teorema 2.2.1 (Schur) Para qualquer grupo finito $G$, o multiplicador de Schur $M(G)$ tem expoente 1 finito dividindo a ordem de $G$. Além disto, se uma classe de cohomologia tem ordem $k$ então existe um representante desta classe que é um cociclo especial de ordem $k$. Em particular, $M(G)$ é um grupo finito.

Demonstração. Veja Curtis \& Reiner [40], página 296.

\footnotetext{
${ }^{1} \mathrm{O}$ expoente de um grupo é o mínimo múltiplo comum das ordens dos seus elementos.
} 
Um grupo de representação ${ }^{2}$ (sobre $\mathbb{C}$ ) de um grupo finito $G$ é um grupo finito $H$ que é uma extensão central de $G$, tal que para qualquer espaço vetorial $V$ complexo de dimensão finita e qualquer representação projetiva $G \rightarrow G L(V)$ de $G$ em $V$ existe uma representação linear $H \rightarrow G L(V)$ de $H$ em $V$ tal que o diagrama

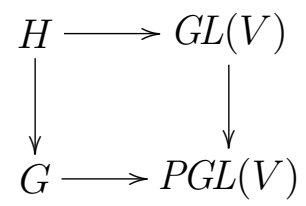

comuta. Em outras palavras, toda representação projetiva de $G$ pode ser levantada para uma representação linear de $H$.

O seguinte teorema, devido a Schur, prova que grupos de representação existem e fornece a sua relação com os grupos de recobrimento.

Teorema 2.2.2 (Schur) Seja $G$ um grupo finito com multiplicador de Schur $M(G)$. Todo grupo de representação de $G$ com centro $M(G)$ é um grupo de recobrimento maximal de $G$. Reciprocamente, todo grupo de recobrimento maximal de $G$ é um grupo de representação de $G$ e portanto tem centro igual a $M(G)$.

DemonstraÇÃo. Veja Curtis \& Reiner [40], página 300.

Então grupos de representação e grupos de recobrimento maximais são, essencialmente, os mesmos objetos, apenas vistos de maneira diferente. Ademais, como qualquer grupo de recobrimento é um quociente de algum grupo de recobrimento maximal, concluímos que qualquer grupo de recobrimento de um grupo finito $G$ é uma extensão central de $G$ por um grupo da forma $M=M(G) / M^{\prime}$.

Em geral, para grupos finitos, grupos de recobrimento maximais sempre existem mas não são únicos nem a menos de isomorfismo. No entanto, existem no máximo $|\operatorname{Hom}(G /[G, G], M(G))|$ classes de isomorfismo de grupos de recobrimento maximais [95]. Em particular, um grupo perfeito $G$ possui um único grupo de recobrimento maximal $\tilde{G}$, a menos de isomorfismo, com centro $M(G)$ que é funtorialmente associado a $G$ e denominado o grupo de recobrimento universal de $G$. A teoria de grupos de recobrimento de grupos perfeitos é muito semelhante a teoria de grupos de recobrimento de grupos de Lie, com o multiplicador de Schur no papel do grupo fundamental. A natureza funtorial da associação $G \rightarrow \tilde{G}$ implica, por exemplo, que $\operatorname{Aut}(\tilde{G})=\operatorname{Aut}(G)$ e que qualquer extensão central essencial de $\tilde{G}$ é trivial [19, pág. 121].

\footnotetext{
${ }^{2}$ Esta expressão é uma tradução literal do termo alemão "Darstellungsgruppe".
} 
No caso em que $G$ é um grupo finito qualquer, existe uma noção mais geral que a de isomorfismo, chamada isoclinismo, que é relevante para a teoria de grupos de recobrimento. Por definição, o comutador de dois elementos $x, y$ de um grupo $G$ pertence ao subgrupo derivado $[G, G]$ de $G$ e não é afetado quando multiplicamos $x$ ou $y$ por um elemento do centro $Z(G)$ de $G$. Portanto, podemos considerar o comutador em um grupo $G$ como sendo a aplicação

$$
\begin{aligned}
{[\cdot, \cdot]: \quad G / Z(G) \times G / Z(G) } & \longrightarrow \quad[G, G] \\
(x Z(G), y Z(G)) & \longmapsto x^{-1} y^{-1} x y
\end{aligned}
$$

Dois grupos $G$ e $H$ são ditos isoclínicos se eles possuem o mesmo comutador no seguinte sentido: existem isomorfismos $G / Z(G) \rightarrow H / Z(H)$ e $[G, G] \rightarrow[H, H]$ tais que o seguinte diagrama comuta

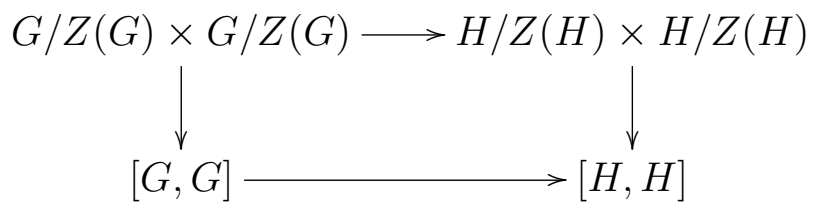

Por trás desta definição está a idéia de que $G$ e $H$ são isoclínicos se podemos aumentar seus centros até obter grupos isomorfos. Mais precisamente, pode-se provar que $G$ e $H$ são isoclínicos se e somente se ambos podem ser mergulhados em um grupo $K$ de modo que $K$ é gerado por $Z(K)$ e $G$ e também por $Z(K)$ e $H$ [19, pág. 131].

Assim obtemos um partição da classe dos grupos finitos em classes de isoclinismo, que é um relação de equivalência mais ampla do que as classes de isomorfismo. Por exemplo, todos os grupos abelianos pertencem à mesma classe de isoclinismo, a saber, a classe do grupo trivial.

Philip Hall introduziu a noção de isoclinismo para o estudo e para a classificação de $p$-grupos. Mas ela também é de grande importância na teoria de representações projetivas e multiplicadores de Schur, devido ao seguinte resultado.

Teorema 2.2.3 (Hall) Todos os grupos de recobrimento maximais de um grupo finito $G$ são isoclínicos.

DemonstraÇÃo. Veja Beyl \& Tape [19], página 139.

Já vimos que a teoria de representações projetivas pode ser reduzida à teoria de representações lineares por meio dos grupos de representação, ou equivalentemente dos grupos recobrimento maximais. O fato de que esta redução depende somente da classe de isoclinismo dos grupos de recobrimentos maximais é consequência do seguinte teorema. 
Teorema 2.2.4 Sejam $\hat{G}_{1}$ e $\hat{G}_{2}$ dois grupos de recobrimento maximais de um grupo finito $G$. Uma representação projetiva de $G$ pode ser levantada para uma representação linear de $\hat{G}_{1}$ se e somente se pode ser levantada para uma representação linear de $\hat{G}_{2}$. Toda representação irredutivel de $\hat{G}_{1}$ pode ser convertida em uma representação irredutível de $\hat{G}_{2}$ da mesma dimensão, na qual as matrizes que representam os elementos de $\hat{G}_{2}$ são múltiplos escalares das matrizes que representam os elementos de $\hat{G}_{1}$, e vice-versa. Em particular, dois grupos de recobrimento maximais $\hat{G}_{1}$ e $\hat{G}_{2}$ de um mesmo grupo finito $G$ tem o mesmo número de classes de equivalência de representações irredutíveis.

Demonstração. Veja Beyl \& Tape [19], página 173.

Portanto, para estudar representações projetivas, basta considerar um representante na classe de isoclinismo dos recobrimentos maximais. Veremos adiante que, em certos casos, existe um representante especial.

\subsection{Extensões por Grupos de Automorfismos}

Seja $G$ um grupo e $\operatorname{Aut}(G)$ seu grupo de automorfismos. O conjunto dos automorfismos internos $\operatorname{Inn}(G)$ é um subgrupo normal de $\operatorname{Aut}(G)$ e o quociente $\operatorname{Out}(G)=$ $\operatorname{Aut}(G) / \operatorname{Inn}(G)$ é chamado de grupo dos automorfismos externos. A ação $G \times G \rightarrow G$ de $G$ sobre si mesmo por conjugação, dada por $(g, h) \mapsto g h g^{-1}$, induz um homomorfismo $G \rightarrow \operatorname{Aut}(G)$ com imagem igual a $\operatorname{Inn}(G)$ e núcleo igual a $Z(G) ;$ portanto, $\operatorname{Inn}(G) \cong G / Z(G)$. Se $Z(G)=\{1\}$ então $G \cong \operatorname{Inn}(G)$, ou seja, $G$ pode ser visto como um subgrupo do seu grupo de automorfismos, e assim temos a sequência exata

$$
1 \longrightarrow G \stackrel{\iota}{\longrightarrow} \operatorname{Aut}(G) \stackrel{\pi}{\longrightarrow} \operatorname{Out}(G) \longrightarrow 1
$$

que exibe o grupo de automorfismos $\operatorname{Aut}(G)$ de $G$ como uma extensão de $G$ pelo seu grupo de automorfismos externos $\operatorname{Out}(G)$. Em particular, esta situação prevalece se $G$ é simples.

Um grupo $H$ é dito aproximadamente simples $^{3}$ se existe um grupo simples $G$ tal que $G<H<\operatorname{Aut}(G)$, em outras palavras, $H$ é uma extensão de um grupo simples $G$ por um subgrupo de $\operatorname{Out}(G)$. Um grupo $H$ é chamado quase-simples ${ }^{4}$ se $H$ for perfeito $(H=[H, H])$ e $G=H / Z(H)$ for um grupo simples, em outras palavras, $H$ é um grupo de recobrimento de um grupo simples $G$. Extensões de um grupo simples por um subgrupo de seu grupo de automorfismos externos também são chamadas extensões descendentes de $G$. Grupos de recobrimento de um grupo simples são também chamados de extensões ascendentes de G. Esta nomenclatura é usada em [36] e, desde então, tornou-se padrão,

\footnotetext{
${ }^{3}$ Esta expressão é tradução literal do termo original em inglês "almost simple".

${ }^{4}$ Esta expressão é tradução literal do termo original em inglês "quasi-simple".
} 
sendo que o original em inglês para extensões descendentes é "downward extensions" e para extensões ascendentes é "upward extensions".

A combinação destes dois tipos de extensão de um grupo simples $G$ proporciona uma família de grupos associados a $G$. Mais precisamente, os quocientes $M$ de $M(G)$ classificam as extensões ascendentes de $G$, geralmente denotadas por M.G e representadas por sequências exatas da forma

$$
1 \longrightarrow M \stackrel{\iota}{\longrightarrow} M . G \stackrel{\pi}{\longrightarrow} G \longrightarrow 1
$$

enquanto que os subgrupos $A$ de $\operatorname{Out}(G)$ classificam as extensões descendentes de $G$, denotadas por $G . A$ e representadas por sequências exatas da forma

$$
1 \longrightarrow G \stackrel{\iota}{\longrightarrow} G \cdot A \stackrel{\pi}{\longrightarrow} A \longrightarrow 1 \text {. }
$$

Podemos considerar não somente os recobrimentos de $G$ mas também os recobrimentos de suas extensões descendentes G.A, que definem apenas classes de isoclinismo de grupos de recobrimento, já que $G$.A não é necessariamente perfeito. Estas são genericamente chamadas de extensões mistas.

Em geral, nem todas as combinações M.G.A entre os dois tipos de extensão que parecem possíveis "a priori" existem na verdade, pois uma classe de isoclinismo do tipo M.G.A pode deixar de fazer sentido quando não existe nenhum grupo com esta estrutura. Isto ocorre, por exemplo, quando o multiplicador de Schur $M(G . A)$ é diferente do multiplicador de Schur $M(G)$ e o grupo $M$ é quociente de $M(G)$ mas não de $M(G . A)$. Mais especificamente, sabe-se que se $G$ é um grupo finito perfeito e $A$ é cíclico então $M(G . A)$ é um quociente de $M(G), M(G . A)=M(G) / M_{A}^{\prime}$, [95, pág. ?] e assim $M . G . A$ existirá apenas quando $M$ for o quociente de $M(G)$ por um subgrupo $M^{\prime}$ maior do que $M_{A}^{\prime}$.

Para grupos finitos simples $G$, a existência de extensões mistas do tipo M.G.A pode ser garantida sob hipóteses adicionais que se referem à existência e às propriedades de ações naturais de $A$ sobre $M$ e sobre $G$. Para poder formular estas hipóteses, observamos primeiro que existe uma ação natural de $\operatorname{Out}(G)$ sobre $M(G)$, definida da seguinte forma. Para um automorfismo $\phi$ de $G$ e um 2-cociclo $\omega: G \times G \rightarrow \mathbb{C}^{\times}$, pomos

$$
(\phi \cdot \omega)(g, h)=\omega\left(\phi^{-1}(g), \phi^{-1}(h)\right) \quad \text { para todo } g, h \in G \text {. }
$$

Esta lei de transformação define uma ação de $\operatorname{Aut}(G)$ sobre o conjunto dos 2-cociclos tal que se $\omega$ e $\omega^{\prime}$ são cociclos cohomólogos então $\phi \cdot \omega$ e $\phi \cdot \omega^{\prime}$ também são cociclos cohomólogos e portanto obtemos uma ação de $\operatorname{Aut}(G)$ sobre $M(G)$. Para obter uma ação de $\operatorname{Out}(G)$ sobre $M(G)$, precisamos do seguinte teorema. 
Teorema 2.3.1 Os automorfimos internos de $G$ operam trivialmente sobre $M(G)$.

Demonstração. Veja Suzuki [141], página 225.

Portanto, obtemos uma ação natural de $A \subset \operatorname{Out}(G)$ sobre $M=M(G) / M^{\prime}$ se e somente se $A$ deixar o subgrupo $M^{\prime}$ de $M(G)$ invariante. Por outro lado, uma ação natural de $A \subset \operatorname{Out}(G)$ sobre $G$ existe se somente se a sequência (2.6) cinde, o que significa que $A$ se torna um subgrupo de $\operatorname{Aut}(G)$ e a extensão descendente de $G$ por $A$ se torna um produto semidireto: $G \cdot A=G \rtimes A$. Sob estas hipóteses, podemos também definir uma ação de $A$ sobre $M . G$ da seguinte forma. Seja $\tilde{G}$ o grupo de recobrimento universal de $G$; como vimos anteriormente, $\operatorname{Aut}(\tilde{G})=\operatorname{Aut}(G)$ e a restrição desta ação a $Z(\tilde{G})=M(G)$ conicide com a ação definida acima [19, pág. 121]. Devido às hipóteses, $A \subset \operatorname{Out}(G)$ e $M^{\prime} \subset M(G)$ é invariante sob $A$, de forma que a ação de $A$ sobre $G$ induz uma ação de $A$ sobre $M . G=\tilde{G} / M^{\prime}$.

Suponhamos agora que, além das hipóteses já colocadas, a ação de $A$ sobre $M$ seja trivial. Neste caso, podemos construir explicitamente um grupo com estrutura M.G.A: é o produto semidireto $(M . G) \rtimes A$. Em geral, $Z((M . G) \rtimes A)$ seria apenas um subgrupo de $Z(M . G)$; porém devido à hipótese de que $A$ age trivialmente sobre $Z(M . G)=M$, temos $Z((M . G) \rtimes A)=Z(M . G)$ e assim

$$
\begin{aligned}
(M . G) \rtimes A / Z((M . G) \rtimes A) & =(M . G \rtimes A) / Z(M . G) \\
& =M \cdot G / Z(M . G) \rtimes A \\
& =G \rtimes A,
\end{aligned}
$$

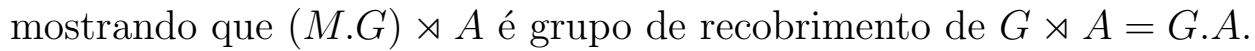

Observamos que quando a ação de $A$ sobre $M$ não for trivial, ainda pode-se construir o produto semidireto $(M . G) \rtimes A$ mas este deixa de ser um grupo de recobrimento de $G$.A, pois como $Z(M . G)$ não é centralizado por $A$, o centro de $(M . G) \rtimes A$ será menor do que o centro de $M . G$. No caso extremo, $(M . G) \rtimes A$ pode ter centro trivial e claramente não será extensão central. Isso ocorre, por exemplo, no caso do grupo de Suzuki $G=S z(8)$, que tem multiplicador de Schur $M(G)=\mathbb{Z}_{2} \times \mathbb{Z}_{2}$ e grupo de automorfismos externos $\operatorname{Out}(G)=\mathbb{Z}_{3}$. Portanto $G$ possui um recobrimento quádruplo universal $\tilde{G}$ e três recobrimentos duplos de tipo $\mathbb{Z}_{2} . G$ obtidos como fatores de $\tilde{G}$ pelos seus três subgrupos centrais de tipo $\mathbb{Z}_{2}$. Ademais, a sequência exata $(2.6)$ cinde e portanto $\operatorname{Out}(G) \subset \operatorname{Aut}(G)=\operatorname{Aut}(\tilde{G})$, mas $\operatorname{Out}(G)$ permuta os três subgrupos centrais de tipo $\mathbb{Z}_{2}$ de $\tilde{G}$. Então o produto semidireto $\tilde{G} \rtimes \operatorname{Out}(G)$ não é um grupo de recobrimento de $\operatorname{Aut}(G)$, pois tem centro trivial. Além disso, não existe nenhum grupo de estrutura $\mathbb{Z}_{2} \cdot G$. Out $(G)$, pois os subgrupos centrais de tipo $\mathbb{Z}_{2}$ de $\tilde{G}$ não são normais em $\tilde{G} \rtimes \operatorname{Out}(G)$. Devido a este fato, o automorfismo externo de ordem 3 de $G$ não pode ser levantado a nenhum dos recobrimentos duplos $\mathbb{Z}_{2} \cdot G$, porém este mesmo automorfismo induz isomorfismos entre os três recobrimentos duplos de $G$. Este exemplo também mostra que alguns grupos de recobrimento não são funtorialmente associados a $G$, mesmo quando $G$ for perfeito. 
Se a sequência exata (2.6) não cinde, surgem outras obstruções para a construção de extensões mistas, mesmo se $A$ age trivialmente sobre $M$. Por exemplo, o grupo alternado $G=A l t_{6}$ tem multiplicador de Schur $M(G)=\mathbb{Z}_{6}$ e grupo de automorfismos externos $\operatorname{Out}(G)=\mathbb{Z}_{2} \times \mathbb{Z}_{2}$. As três extensões de tipo $G$.A onde $A$ é um dos três subgrupos de tipo $\mathbb{Z}_{2}$ de $\operatorname{Out}(G)$ são diferentes: duas cindem e uma não. O recobrimento duplo $\mathbb{Z}_{2} \cdot G$ de $G$ está funtorialmente associado a $G$, pois $\mathbb{Z}_{6}$ só possui um subgrupo de ordem 3. Portanto todos os automorfismos de $G$ podem ser levantados a automorfismos de $\mathbb{Z}_{2} \cdot G$ e obviamente agem trivialmente sobre $M=\mathbb{Z}_{2}$. Pela construção anterior, obtemos dois grupos com estrutura $\mathbb{Z}_{2} \cdot G \cdot \mathbb{Z}_{2}$ que correspondem aos subgrupos $\mathbb{Z}_{2}$ de $\operatorname{Out}(G)$ tal que $G \cdot \mathbb{Z}_{2}$ cinde, porém não existe o grupo que corresponderia ao subgrupo $\mathbb{Z}_{2}$ tal que $G . \mathbb{Z}_{2}$ não cinde. Observe também que não existe nenhum grupo com estrutura $\mathbb{Z}_{2} \cdot G$. $\left(\mathbb{Z}_{2} \times \mathbb{Z}_{2}\right)$. Para maiores detalhes deste exemplo veja [36, pág. xxiv].

Em resumo, vimos que um grupo simples $G$ sempre vem acompanhado de um conjunto de (classes de isoclinismo de) extensões que são construídas a partir de (quocientes de) seu multiplicador de Schur $M(G)$ e de (subgrupos de) seu grupo de automorfismos externos $\operatorname{Out}(G)$. Tais grupos associados a $G$ serão conjuntamente chamados de satélites de $G$. 

CAPÍtulo 3

\section{Grupos Finitos Simples}

A teoria dos grupos finitos atingiu a sua maturidade com a finalização da classificação dos grupos finitos simples - os "blocos fundamentais" para a construção de todos os grupos finitos. O teorema de classificação dos grupos finitos simples que, segundo as últimas estimativas, ocupa 10.000 páginas impressas espalhadas ao longo de 500 artigos individuais, é o produto do esforço de várias gerações de matemáticos ao longo de mais de 100 anos. Pode-se dizer que este empreendimento começou em 1892, quando Otto Hölder levantou a seguinte questão em sua palestra no congresso internacional de matemáticos: "Es wäre von dem größten Interesse, wenn eine Übersicht der sämtlichen einfachen Gruppen von einer endlichen Zahl von Operationen gegeben werden könnte" ${ }^{1}$.

Um dos pioneiros desta área foi Richard Brauer, que começou o estudo dos grupos finitos simples no final da década de 40. Ele foi o primeiro a perceber a conexão entre a estrutura de um grupo e dos centralizadores de suas involuções (elementos de ordem 2), obtendo resultados qualitativos e quantitativos. Um exemplo do primeiro tipo é o teorema de Brauer-Fowler, que afirma que existe um número finito de grupos finitos simples com um centralizador de involução específico. Como exemplo do segundo tipo, Brauer provou que se o centralizador de uma involução em um grupo finito simples $G$ é isomorfo ao grupo geral linear em dimensão 2 sobre o corpo finito $\mathbb{F}_{q}$ de $q$ elementos, com $q$ impar, então ou $G$ é isomorfo ao grupo projetivo especial em dimensão 3 sobre $\mathbb{F}_{q}$ ou $q$ é igual a 3 e $G$ é isomorfo ao grupo de Mathieu $M_{11}$ de ordem $8 \cdot 9 \cdot 10 \cdot 11$. Este último resultado representa o ponto de partida para a classificação dos grupos finitos simples em termos da estrutura dos centralizadores de involuções. Além disso, ele exemplificou o fato de que conclusões de teoremas gerais de classificação necessariamente incluem grupos esporádicos como casos excepcionais. Nos anos que sucederam, Brauer foi essencialmente uma figura isolada trabalhando com grupos finitos simples - exceto pelo trabalho fundamental de Claude Chevalley, em 1955, sobre os grupos de tipo Lie, que teve considerável impacto na área.

\footnotetext{
1 "Seria de maior interesse se fosse possível dar uma descrição de toda a coleção de grupos finitos simples."
} 
O resultado isolado que, mais do que qualquer outro, abriu novas perspectivas na área dos grupos finitos simples e revelou o caminho para a sua classificação é o celebrado teorema de Walter Feit e John Thompson de 1962, que afirma que todo grupo finito de ordem impar é solúvel - um resultado expressível em apenas uma linha, porém com uma demonstração que ocupa um volume inteiro de 255 páginas do Pacific Journal of Mathematics [50].

Algum tempo depois, em 1965, surgiu o primeiro novo grupo esporádico depois de 100 anos: o grupo $J_{1}$ de Zvonimir Janko, que estimulou mais ainda o interesse da comunidade matemática na teoria dos grupos finitos simples. Os grupos esporádicos adquiriram este nome porque eles não são membros de nenhuma família infinita de grupos finitos simples. Em 1861, Emil Mathieu já havia descoberto os primeiros 5 grupos esporádicos, mas o grupo $J_{1}$ permaneceu desconhecido por um século, apesar do fato de que tem somente 175.560 elementos - um número pequeno para os padrões da teoria dos grupos finitos simples. Então numa rápida sucessão, ao longo dos 10 anos seguintes, mais 20 grupos esporádicos foram descobertos, o maior de todos sendo o grupo $F_{1}$ de Bernd Fischer e Robert Griess (de ordem aproximadamente $10^{54}$ ) e, por causa do tamanho, amplamente conhecido como o "Monstro".

No início de 1981, Daniel Gorenstein, um dos líderes do grupo de matemáticos que trabalhavam na classificação, anunciou que ela estava completa. Porém, por volta de 1986, Michael Aschbacher descobriu que o artigo de Geoff Mason que tratava de um dos casos que aparecem no problema de classificação (com mais de 800 páginas) estava incompleto em vários aspectos. Por volta de 1996, Aschbacher e Stephen Smith assumiram a tarefa de dar uma nova demonstração dos resultados enunciados no artigo de Mason. A publicação do artigo de Aschbacher e Smith será o marco final da demonstração do teorema de classificação dos grupos finitos simples.

Um sentimento frequentemente expresso pela comunidade matemática é que a abordagem atualmente empregada para classificar os grupos finitos simples seja inadequada nenhum teorema pode requerer uma demonstração de 10.000 páginas. Como a maioria dos grupos finitos simples são análogos finitos dos grupos de Lie, deveria ser possível construir uma geometria a partir de algumas propriedades internas adequadas de um grupo finito simples $G$ e então determinar $G$ a partir desta geometria. A final de contas, este é exatamente o método usado para a classificação das álgebras de Lie complexas simples (da qual se passa para a classificação dos grupos de Lie simples). Assim como existem 5 álgebras de Lie complexas excepcionais, poderia se imaginar que certas geometrias excepcionais levariam diretamente aos grupos esporádicos. ${ }^{2}$ De qualquer forma, o fato de que está além da capacidade humana apresentar uma argumentação razoavelmente fechada de vários milhares de páginas com exatidão absoluta, lança dúvidas sobre a validade da demonstração. De fato, existe um considerável número de "erros locais" em muitos dos artigos sobre grupos finitos simples.

\footnotetext{
${ }^{2}$ Um argumento heurístico de porque tal procedimento seria essencialmente equivalente à abordagem atual é apresentado em [65, pág. 25].
} 
Como pode-se garantir que nenhuma configuração que levaria a um novo grupo finito simples passou despercebida? A opinião geral dos especialistas em teoria dos grupos é que a demonstração do teorema de classificação tem boa exatidão e que com tantas pessoas trabalhando com grupos finitos simples nos últimos 35 anos e de diferentes perspectivas, qualquer configuração significativa teria surgido com frequência suficiente para não deixar de ser percebida. Enfim, ainda temos motivos para uma atitude cautelosa com respeito à completude da classificação dos grupos finitos simples.

Finalmente, devemos mencionar que desde o primeiro anúncio da finalização da demonstração, deu-se início a um movimento de revisão e redução do seu tamanho. Dado que, na época em que muitos dos artigos nesta área foram escritos, algumas das tećnicas mais poderosas ainda não estavam completamente elaboradas, o uso destes métodos permite reescrever as demonstrações dos resultados com maior precisão e menor tamanho. Estima-se que este processo de revisão possa reduzir o tamanho da prova por um fator de 3; uma redução maior necessitaria de idéias totalmente novas.

Mesmo com estas ressalvas, muitos resultados publicados nos últimos 20 anos usam a classificação dos grupos simples ou algumas de suas consequências, como por exemplo a conjectura de Schreier que afirma que o grupo de automorfismos externos de um grupo finito simples é solúvel. Atualmente, esta conjectura só pode ser demonstrada assumindo a classificação dos grupos finitos simples e verificando que cada grupo da lista tem grupo de automorfismos externos solúvel. A conjectura de Schreier, por sua vez, é usada de maneira crucial na demonstração do teorema de O'Nan-Scott, que determina a estrutura geral dos grupos de permutação primitivos, cuja principal consequência é o teorema de estrutura dos subgrupos maximais dos grupos simétricos e alternados.

Um outro fato interessante que decorre do teorema de classificação é que todo grupo finito simples é gerado por dois elementos, e na maioria dos casos pode-se construir este par de elementos de forma que um deles tenha ordem 2. Encontrar um conjunto mínimo de geradores é importante na utilização de métodos computacionais, pois em geral, a complexidade dos algoritmos depende diretamente do número de geradores.

O teorema de classificação também permite atacar problemas gerais na teoria dos grupos finitos que podem ser reduzidos a problemas sobre grupos finitos simples. Porém, quando se quer enfatizar o ceticismo com respeito ao teorema de classificação, usa-se o termo "grupos finitos simples conhecidos" para se referir aos grupos dados pela classificação. Assim os resultados que dependeriam da classificação e que, a princípio, valeriam para todos os grupos finitos, passam a valer pelo menos para os grupos finitos cujos fatores na série de composição são grupos finitos simples conhecidos.

Nas próximas seções apresentaremos uma descrição dos vários tipos de grupos finitos simples e o enunciado do teorema de classificação. 


\subsection{Grupos Alternados}

Os grupos alternados e simétricos são os primeiros exemplos de grupos finitos, tratados em qualquer disciplina introdutória sobre a teoria dos grupos. Por este motivo daremos apenas uma breve descrição destes grupos bem como algumas propriedades que necessitaremos mais adiante.

O grupo alternado $A l t_{n}$ é um subgrupo normal de índice 2 do grupo simétrico $S y m_{n}$ e portanto tem ordem $n ! / 2$. Seus elementos são chamados de permutações pares e caracterizados pelo fato de que têm um número par de ciclos de comprimento par. No que segue, suporemos sempre que $n \geqslant 5$, pois então o grupo alternado $A l t_{n}$ é simples.

O multiplicador de Schur de $A l t_{n}$ é

$$
M\left(A l t_{n}\right)= \begin{cases}\mathbb{Z}_{2} & \text { se } n \neq 6,7 \\ \mathbb{Z}_{6} & \text { se } n=6,7\end{cases}
$$

O grupo de recobrimento duplo de $A l t_{n}$ é denotado por $2 . A l t_{n}$. No caso em que $n=6,7$ ainda existem grupos de recobrimento com centros de ordem 3 e 6 , denotados respectivamente por 3. $A l t_{n}$ e $6 . A l t_{n}$.

O grupo de automorfismos externos de $A l t_{n}$ é

$$
\operatorname{Out}\left(A l t_{n}\right)=\left\{\begin{array}{cc}
\mathbb{Z}_{2} & \text { se } n \neq 6 \\
\mathbb{Z}_{2} \times \mathbb{Z}_{2} & \text { se } n=6
\end{array}\right.
$$

Em particular, $\operatorname{Aut}\left(A l t_{n}\right)=S y m_{n}=A l t_{n} .2$ para $n \neq 6$. Neste caso, Aut $\left(A l t_{n}\right)$ é um produto semidireto, pois qualquer transposição gera um subgrupo de ordem 2 que intersecta $A l t_{n}$ trivialmente. Como já foi mencionado antes, Aut $\left(A l t_{6}\right)$ é uma extensão não-cindida de $A l t_{6}$. No entanto, uma das extensões $A l t_{6} .2$ é $S y m_{6}$ e, pelo argumento anterior, também é um produto semidireto.

Quanto aos grupos simétricos $S y m_{n}$, seu multiplicador de Schur é igual a $\mathbb{Z}_{2}$, mas como não são grupos perfeitos, possuem dois grupos de recobrimento maximais duplos, denotados por 2. Sym $_{n}^{+}$e 2. Sym $_{n}^{-}$. No grupo de recobrimento $2 . S_{y m_{n}^{+}}$, os elementos que se projetam sobre as transposições têm ordem 2 enquanto que no grupo $2 . S y m_{n}^{-}$eles têm ordem 4. Dai segue que 2.Sym ${ }_{n}^{+}$é uma extensão cindida de $2 . A l t_{n}$ e $2 . S y m_{n}^{-}$é uma extensão não-cindida de 2. $A l t_{n}$. O grupo de automorfismos de $S y m_{n}$ é isomorfo ao próprio $S y m_{n}$, com exceção de Sym $_{6}$ que possui um grupo de automorfismos externos de ordem 2.

Os grupos 2.Sym $m_{n}^{+}$e $2 . S y m_{n}^{-}$não são isomorfos em geral, exceto quando $n=6$; neste caso, um isomorfismo entre os dois é induzido por um automorfismo externo de Sym $_{6}$. Por causa deste fato, nenhum automorfismo externo de $S_{y m}$ pode ser levantado aos seus recobrimentos duplos. 
O modo mais natural de construir os recobrimentos duplos de $A l t_{n}$ e de $S_{y m}$ é através da representação espinorial de dimensão $2^{n}$ do grupo ortogonal real $O(n-1)$ : o grupo $\operatorname{Sym}_{n}$ possui uma representação natural fiel de dimensão $n-1$ cujo levantamento aos grupos $\operatorname{Pin}^{+}(n-1)$ e $\operatorname{Pin}^{-}(n-1)$ proporciona realizações matriciais de 2. Sym $_{n}^{+}$e $2 . S y m_{n}^{-}$, respectivamente. Ademais, a mesma representação de dimensão $n-1$ de $S_{y} m_{n}$, quando restrita a $A l t_{n}$, proporciona um mergulho de $A l t_{n}$ em $S O(n-1)$ que por sua vez pode ser levantado a um mergulho de $2 . A l t_{n}$ em $\operatorname{Spin}(n-1)$. Estas representações de dimensão $2^{\left[\frac{n-1}{2}\right]}$ de $2 . A l t_{n}$ e $2 . S y m_{n}^{ \pm}$são chamadas de representações projetivas básicas de $A l t_{n}$ e $S y m_{n}$.

\subsection{Grupos Finitos de Tipo Lie}

Os grupos lineares, unitários, simpléticos e ortogonais são conjuntamente conhecidos como "grupos clássicos", no mínimo desde a publicação do livro de Hermann Weyl [154] que estuda estes grupos sobre o corpo dos números reais e complexos. Os mesmos grupos, quando definidos sobre um corpo finito, são - além dos grupos alternados - os exemplos mais elementares de grupos finitos simples. A referência mais importante sobre os grupos clássicos finitos ainda é o livro de Leonard Dickson [42], mas há também os tratamentos modernos de Emil Artin [7] e Jean Dieudonné [43, 44].

Esta classe de grupos foi generalizada, primeiro por Claude Chevalley [33] e depois por Robert Steinberg, Michio Suzuki, Remhak Ree e Jacques Tits, e hoje consiste de 16 famílias infinitas de grupos finitos simples que foram chamados conjuntamente de "grupos finitos de tipo Lie". Tal generalização faz uso da teoria das álgebras de Lie complexas simples e descreve de forma unificada os grupos clássicos sobre corpos finitos. A idéia principal se baseia no fato fundamental, descoberto por Chevalley, de que uma álgebra de Lie complexa simples possui uma base na qual todas as constantes de estrutura são números inteiros, permitindo assim definir o mesmo tipo de álgebra de Lie sobre os números inteiros e, consequentemente, sobre qualquer corpo.

Existem outros modos de se abordar os grupos de tipo Lie, dentre os quais destacamos também a construção via grupos algébricos afins, devida a Steinberg, e as definições axiomática (através do conceito de $B N$-pares) e geométrica (usando a noção de "buildings") de Tits. A primeira é importante na teoria de representações complexas de grupos de tipo Lie, desenvolvida por Pierre Deligne e George Lusztig, enquanto que a segunda e a terceira fornecem caracterizações dos grupos de tipo Lie que são fundamentais para a demonstração do teorema de classifcação.

Mesmo com o advento das definições modernas, as construções clássicas ainda são muito utilizadas, pois requerem como pré-requisito apenas algumas noções de álgebra linear sobre corpos finitos e levam diretamente à realização explícita dos grupos clássicos como grupos de matrizes, fato este que não é imediato na abordagem de Chevalley. 


\subsubsection{Grupos Clássicos}

Afim de descrever os grupos clássicos precisamos primeiro de alguns resultados sobre a estrutura dos corpos finitos [106]. O número de elementos (a ordem) $q$ de um corpo finito é sempre uma potência de um número primo, e para cada potência de um primo $q$ existe, a menos de isomorfismo, um único corpo finito com $q$ elementos, que denotaremos por $\mathbb{F}_{q}$; uma outra notação, devida a Dickson e muito empregada até hoje, é $G F(q)$. Estes corpos são frequentemente chamados de corpos de Galois.

Se $p$ é um número primo, o corpo $\mathbb{F}_{p}$ é simplesmente $\mathbb{Z} / p \mathbb{Z}$, o conjunto dos números inteiros módulo $p$ : estes corpos são chamados de corpos primos, pois qualquer corpo de característica $^{3} p \neq 0$ possui um subcorpo isomorfo a $\mathbb{F}_{p}$.

Para $q=p^{f}$, o corpo $\mathbb{F}_{q}$ pode ser construído como extensão a partir de $\mathbb{F}_{p}$, acrescentando-se as raízes de um polinômio irredutível de grau $f$ sobre $\mathbb{F}_{p}$. Da mesma forma como $\mathbb{F}_{p}$ é o anel de restos de divisão do anel $\mathbb{Z}$ dos inteiros pelo número primo $p, \mathbb{F}_{q}$ também pode ser considerado como um anel de restos de divisão: mais precisamente, dos restos de divisão do anel $\mathbb{F}_{p}[x]$ de polinômios numa indeterminada $x$ com coeficientes em $\mathbb{F}_{p}$ por um polinômio $P$ de grau $f$ mônico e irredutível. Assim as operações de soma e produto em $\mathbb{F}_{q}$ são obtidas a partir da soma e produto de polinômios em $\mathbb{F}_{p}[x]$, tomando o resto da divisão por $P$. Por exemplo, o corpo $\mathbb{F}_{4}$ pode ser obtido a partir do corpo $\mathbb{F}_{2}$ tomando-se $P(x)=x^{2}+x+1$, da mesma forma que escolhendo $P(x)=x^{2}+1$ permite obter $\mathbb{C}$ a partir de $\mathbb{R}^{4}$

Como $\mathbb{F}_{q}$ é um espaço vetorial de dimensão $f$ sobre $\mathbb{F}_{p}$, seu grupo aditivo é o produto direto de $f$ grupos cíclicos de ordem $p$. O seu grupo multiplicativo $\mathbb{F}_{q}^{\times}$é cíclico de ordem $q-1$, e um gerador deste grupo é chamado uma raiz primitiva de $\mathbb{F}_{q}$. Um exemplo de raiz primitiva é a classe de equivalência do polinômio $x$. Existem exatamente $\Phi(q-1)$ raízes primitivas, onde $\Phi$ denota a função de Euler, que conta o número $\Phi(n)$ de inteiros positivos estritamente menores que $n$ e sem divisores comuns com $n$.

O grupo de automorfismos de $\mathbb{F}_{q}$ é cíclico de ordem $f$; seus elementos são conhecidos como automorfismos de Frobenius, $\lambda \mapsto \lambda^{r}\left(r=1, p, p^{2}, \ldots, p^{f-1}\right)$. Os subcorpos de $\mathbb{F}_{q}$ são os corpos $\mathbb{F}_{r}$ para os quais $r$ é uma potência de $p$, e cada destes subcorpos é o corpo fixado pelo automorfismo de Frobenius correspondente.

\footnotetext{
${ }^{3}$ Se para um corpo $\mathbb{K}$, existe um inteiro positivo $n$ tal que $n \cdot 1=0$, onde $n \cdot 1$ significa $1+\ldots+1$ com $n$ somandos, então o menor dentre estes inteiros é a característica de $\mathbb{K}$. Se não existe nenhum inteiro positivo com esta propriedade então diz-se que $\mathbb{K}$ tem característica 0 . Se a característica de um corpo $\mathbb{K}$ é diferente de zero então ela é necessariamente um número primo.

${ }^{4}$ Sobre $\mathbb{F}_{2}$, o polinômio $P(x)=x^{2}+1$ é redutível, já que $x^{2}+1=(x+1)^{2}$.
} 


\section{Grupos Lineares}

Consideremos primeiro o espaço de todas as transformações lineares de $\mathbb{K}^{n}$ em $\mathbb{K}^{n}$, que identificamos com as matrizes $n \times n$ com entradas em $\mathbb{K}$, onde $\mathbb{K}$ é um corpo qualquer, tendo-se em mente como exemplos $\mathbb{Q}, \mathbb{R}, \mathbb{C}$ e os $\mathbb{F}_{q}$. As transformações não-singulares formam um grupo $G L_{n}(\mathbb{K})$, chamado de grupo linear geral. O centro $Z\left(G L_{n}(\mathbb{K})\right)$ de $G L_{n}(\mathbb{K})$ consiste dos múltiplos escalares da identidade. O grupo quociente $G L_{n}(\mathbb{K}) / Z\left(G L_{n}(\mathbb{K})\right)$ é o grupo projetivo geral $P G L_{n}(\mathbb{K})$. Ele opera sobre o espaço projetivo de dimensão $n-1$ associado a $\mathbb{K}^{n}$. Em particular, para $n=1$, temos que $G L_{1}(\mathbb{K})=\mathbb{K}^{\times}$. Quando $\mathbb{K}=\mathbb{F}_{q}$, usamos as notações $G L_{n}(q)$ e $P G L_{n}(q)$ para o grupo geral linear e para o grupo projetivo geral, respectivamente. As transformações de determinante 1 formam um subgrupo normal $S L_{n}(\mathbb{K})$, chamado de grupo linear especial. O grupo quociente $G L_{n}(\mathbb{K}) / S L_{n}(\mathbb{K})$ é isomorfo ao grupo multiplicativo de elementos não-nulos de $\mathbb{K}$. O centro $Z\left(S L_{n}(\mathbb{K})\right)$ de $S L_{n}(\mathbb{K})$ consiste dos múltiplos escalares da identidade com determinante 1 . O grupo quociente $S L_{n}(\mathbb{K}) / Z\left(S L_{n}(\mathbb{K})\right)$ é o grupo projetivo especial $P S L_{n}(\mathbb{K})$. Em particular, para $n=1$, temos que $S L_{1}(\mathbb{K})$ é isomorfo ao grupo das raizes da unidade do corpo $\mathbb{K}$. Quando $\mathbb{K}=\mathbb{F}_{q}$, o grupo especial linear é denotado por $S L_{n}(q)$ e o grupo projetivo especial é denotado por $P S L_{n}(q)$. O grupo $P S L_{n}(q)$ é simples para todo $n \geqslant 2$, com as exceções de $P S L_{2}(2)=S_{3}$ e $P S L_{2}(3)=A_{4}$ [5, pág. 169].

\section{Grupos Simpléticos}

Suponhamos agora que $\mathbb{K}^{n}$ esteja equipado com uma forma bilinear antisimétrica $\omega$ nãodegenerada. Então $n$ é necessariamente par, $n=2 m$, e prova-se [144, pág. 69] que a forma $\omega$ pode ser representada, com respeito a uma base adequadamente escolhida, pela matriz

$$
J_{2 m}=\left(\begin{array}{cc}
0 & 1_{m} \\
-1_{m} & 0
\end{array}\right) .
$$

As transformações que preservam $\omega$, representadas por matrizes $A$ tais que $A^{t} J_{2 m} A=J_{2 m}$, têm determinante 1 [5, pág. 139] e formam um subgrupo $S p_{2 m}(\mathbb{K})$ de $S L_{2 m}(\mathbb{K})$, chamado de grupo simplético. O centro $Z\left(S p_{2 m}(\mathbb{K})\right)$ de $S p_{2 m}(\mathbb{K})$ é $\{1,-1\}$ [5, pág. 140] e portanto é trivial se $\mathbb{K}$ tem característica 2. O grupo quociente $S p_{2 m}(\mathbb{K}) / Z\left(S p_{2 m}(\mathbb{K})\right)$ é o grupo projetivo simplético $P S p_{2 m}(\mathbb{K})$. Em particular, para $m=1$, temos

$$
S p_{2}(\mathbb{K})=S L_{2}(\mathbb{K}), \quad P S p_{2}(\mathbb{K})=P S L_{2}(\mathbb{K}) .
$$

Quando $\mathbb{K}=\mathbb{F}_{q}$, o grupo simplético é denotado por $S p_{2 m}(q)$ e o grupo projetivo simplético é denotado por $P S p_{2 m}(q)$. Os grupos projetivos simpléticos são simples, com a exceção de $P S p_{2}(2)=S_{3}, P S p_{4}(2)=S_{6}$ e $P S p_{2}(3)=A_{4}[5$, pág. 173]. 


\section{Grupos Unitários}

A definição dos grupos unitários requer que o corpo $\mathbb{K}$ admita um automorfismo $\lambda \mapsto \bar{\lambda}$ de ordem 2. No caso dos corpos de Galois, isto implica que $\mathbb{K}$ deve ser da forma $\mathbb{F}_{q^{2}}$ para alguma potência $q$ de número primo: então o automorfismo é dado por $\bar{\lambda}=\lambda^{q}$, sendo $\mathbb{F}_{q}$ o subcorpo fixado. Sob esta hipótese, suponhamos que $\mathbb{K}^{n}$ esteja equipado com uma forma hermitiana $\langle.,$.$\rangle , com respeito ao automorfismo \lambda \mapsto \bar{\lambda}$, não-degenerada. Quando $\mathbb{K}$ é um corpo finito, prova-se [10, pág. 88] que a forma $\langle.,$.$\rangle pode ser representada, com respeito$ a uma base adequadamente escolhida, pela matriz identidade. As transformações que preservam $\langle.,$.$\rangle , representadas por matrizes A$ tais que $\bar{A}^{t} A=1$, formam um subgrupo $U_{n}(\mathbb{K})$ de $G L_{n}(\mathbb{K})$, chamado de grupo unitário. As transformações unitárias de determinante 1 formam um subgrupo $S U_{n}(\mathbb{K})$ de $U_{n}(\mathbb{K})$, chamado de grupo especial unitário. O centro $Z\left(U_{n}(\mathbb{K})\right)$ de $U_{n}(\mathbb{K})$ consiste dos múltiplos escalares $\lambda 1$ da identidade com $\bar{\lambda} \lambda=1$. O centro $Z\left(S U_{n}(\mathbb{K})\right)$ de $S U_{n}(\mathbb{K})$ é a intersecção de $S U_{n}(\mathbb{K})$ com o centro de $U_{n}(\mathbb{K})$. Os grupos quociente $U_{n}(\mathbb{K}) / Z\left(U_{n}(\mathbb{K})\right)$ e $S U_{n}(\mathbb{K}) / Z\left(S U_{n}(\mathbb{K})\right)$ são, respectivamente, o grupo projetivo unitário $P U_{n}(\mathbb{K})$ e o grupo projetivo especial unitário $P S U_{n}(\mathbb{K})$. Em particular, para $n=1$, o grupo unitário $U_{1}(\mathbb{K})$ é isomorfo ao grupo dos elementos $\lambda$ de $\mathbb{K}$ tais que $\bar{\lambda} \lambda=1 \mathrm{e}$ portanto é abeliano, enquanto que para $n=2$, temos [99, pág. 43]

$$
S U_{2}(\mathbb{K})=S p_{2}(\mathbb{K}), \quad P S U_{2}(\mathbb{K})=P S p_{2}(\mathbb{K}) .
$$

Quando $\mathbb{K}=\mathbb{F}_{q^{2}}$, os grupos unitários correspondentes são denotados por $U_{n}(q), S U_{n}(q)$, $P U_{n}(q)$ e $P S U_{n}(q)$. Os grupos projetivos especiais unitários são simples, com a exceção de $P S U_{2}(2)=S_{3}, P S U_{3}(2)=\left(\mathbb{Z}_{3} \times \mathbb{Z}_{3}\right) \rtimes Q_{8}$ e $P S U_{2}(3)=A_{4}$, onde $Q_{8}$ é o grupo quaterniônico $\{ \pm 1, \pm i, \pm j, \pm k\}$ [99, pág. 43]. Além disto, temos ainda o isomorfismo $\mathrm{PSU}_{4}(2)=\mathrm{PSp}_{4}(3)$.

\section{Grupos Ortogonais}

Para descrever a última família de grupos clássicos precisamos de algumas noções da teoria das formas quadráticas e formas bilineares simétricas sobre corpos finitos, pois quando a característica do corpo é 2 estes conceitos deixam de ser equivalentes, sendo que neste caso, considera-se a noção de forma quadrática como primária e a de forma bilinear simétrica como secundária.

Uma forma quadrática $Q$ em um espaço vetorial $V$ sobre um corpo $\mathbb{K}$ é uma função $Q: V \rightarrow \mathbb{K}$ que é homogênea de grau 2, isto é, satisfaz $Q(\lambda v)=\lambda^{2} Q(v)$, e tal que

$$
(u, v)=Q(u+v)-Q(u)-Q(v)
$$

define uma forma bilinear simétrica sobre $V$. Quando a característica de $\mathbb{K}$ é diferente de 2, vale

$$
Q(v)=\frac{1}{2}(v, v),
$$


mostrando que a forma quadrática é completamente determinada pela forma bilinear simétrica associada e que toda forma quadrática provém de uma única forma bilinear simétrica, por restrição à diagonal. Ambas as afirmações são falsas em característica 2. Por exemplo, neste caso a forma bilinear simétrica associada a uma forma quadrática também é alternada, pois $(v, v)=2 Q(v)=0$.

Esta dificuldade se propaga na teoria inteira, implicando que em característica 2, torna-se necessário especificar se os termos padrão tais como posto, nulidade, nãodegenerescência, isotropia, etc. se referem à forma quadrática $Q$ ou à forma bilinear simétrica $(.,$.$) associada. Por exemplo, o núcleo de (.,$.$) é o subespaço de todos os vetores u$ tais que $(u, v)=0$ para todo $v \in V$ e o núcleo de $Q$ é o subespaço de todos os vetores $v$ no núcleo de $(.,$.$) para os quais Q(v)=0$. O posto e a nulidade de $(.,$.$) ou Q$ são, respectivamente, a dimensão e a codimensão do seu núcleo em $V$. Dizemos que (.,.) ou $Q$ é nãa-degenerada quando sua nulidade é 0 . Um subespaço $U$ de $V$ é chamado isotrópico com respeito a $(.,$. se $\left(u_{1}, u_{2}\right)=0$ para todo $u_{1}, u_{2} \in U$ e isotrópico com respeito a $Q$ se, além disso, vale $Q(u)=0$ para todo $u \in U$. O índice $\boldsymbol{d e} \boldsymbol{W} \boldsymbol{i t t}$ de $(.,$.$) ou de Q$ é o máximo das dimensões dos subespaços isotrópicos de $V$ com respeito a $(.,$.$) ou Q$, respectivamente.

O resultado fundamental desta teoria é o teorema de Witt [10, pág. 81], que afirma que todos os subespaços maximais isotrópicos com respeito a (.,.) ou a $Q$ possuem a mesma dimensão, igual ao índice de Witt correspondente. Em particular, o índice de Witt não pode exceder $\frac{1}{2} n$, onde $n$ é a dimensão de $V$. Dizemos que $(.,$.$) ou Q$ tem índice máximo se seu índice de Witt for $\frac{1}{2} n$ para $n$ par e $\frac{1}{2}(n-1)$ para $n$ impar. Em geral, os grupos ortogonais definidos a seguir dependem da escolha da forma quadrática, sendo distintos para formas de índice de Witt diferente. Por exemplo, quando $\mathbb{K}=\mathbb{R}$, as formas quadráticas são classificadas por seu índice de Witt, de acordo com o teorema de inércia de Sylvester. Por outro lado, quando $\mathbb{K}=\mathbb{C}$, todas as formas quadráticas não-degeneradas são equivalentes. Para corpos finitos $\mathbb{K}=\mathbb{F}_{q}$, a classificação depende da paridade da dimensão $n$ de $V$ e da característica de $\mathbb{K}$. Quando $n=2 m+1$ é impar, todas as formas quadráticas não-degeneradas têm índice de Witt $m$ (o valor máximo) e podem ser representadas, com respeito a uma base adequadamente escolhida, por [144, pág. 139]

$$
Q(v)=\sum_{i=1}^{m} v_{i} v_{i+m}+\kappa v_{n}^{2},
$$

com $\kappa \in \mathbb{F}_{q}$. Quando $n=2 m$ é par, as formas quadráticas não-degeneradas são de dois tipos: o tipo $(+)$ com índice de Witt $m$ (o valor máximo) e o tipo $(-)$ com índice de Witt $m-1$, podendo ser representadas, com respeito a uma base adequadamente escolhida, por [144, pág. 139]

$$
Q(v)=\sum_{i=1}^{m} v_{i} v_{i+m}
$$


e por

$$
Q(v)=\sum_{i=1}^{m-1} v_{i} v_{i+m}+v_{n-1}^{2}+v_{n-1} v_{n}+\kappa v_{n}^{2},
$$

com $\kappa \in \mathbb{F}_{q}$, respectivamente.

Voltando momentaneamente ao caso de um corpo $\mathbb{K}$ geral, suponhamos agora que $\mathbb{K}^{n}$ esteja equipado com uma forma quadrática $Q$ não-degenerada. As transformações que preservam $Q$ têm determinante \pm 1 [144, pág. 137] e formam um subgrupo $O_{n}(\mathbb{K})$ de $G L_{n}(\mathbb{K})$, chamado de grupo ortogonal. As transformações ortogonais de determinante 1 formam um subgrupo normal $S O_{n}(\mathbb{K})$ de $O_{n}(\mathbb{K})$, chamado de grupo especial ortogonal. O centro $Z\left(O_{n}(\mathbb{K})\right)$ de $O_{n}(\mathbb{K})$ é $\{1,-1\}$ e portanto é trivial quando $\mathbb{K}$ tem característica 2 . O centro $Z\left(S O_{n}(\mathbb{K})\right)$ de $S O_{n}(\mathbb{K})$ é a intersecção de $Z\left(O_{n}(\mathbb{K})\right)$ com $S O_{n}(\mathbb{K})$ e quando $\mathbb{K}$ tem característica $\neq 2$ contém -1 somente quando $n$ é par. Os grupos quociente $O_{n}(\mathbb{K}) / Z\left(O_{n}(\mathbb{K})\right)$ e $S O_{n}(\mathbb{K}) / Z\left(S O_{n}(\mathbb{K})\right)$ são, respectivamente, o grupo projetivo ortogonal $P O_{n}(\mathbb{K})$ e o grupo projetivo especial ortogonal $P S O_{n}(\mathbb{K})$. Em particular, para $n=1$, o grupo ortogonal $O_{n}(\mathbb{K})$ possui apenas dois elementos, enquanto que para $n=2$, ele é isomorfo ao grupo diedral [144, pág. 139]. Portanto, suporemos daqui em diante que $n \geqslant 3$.

Quando $\mathbb{K}=\mathbb{F}_{q}$, os grupos ortogonais correspondentes não dependem do valor de $\kappa$ [10, pág. 88] e portanto podem ser denotados simplesmente por $O_{2 m+1}(q), S O_{2 m+1}(q)$, $P O_{2 m+1}(q)$ e $P S O_{2 m+1}(q)$ em dimensão impar e $O_{2 m}^{ \pm}(q), S O_{2 m}^{ \pm}(q), P O_{2 m}^{ \pm}(q)$ e $P S O_{2 m}^{ \pm}(q)$ em dimensão par. Os grupos projetivos especiais ortogonais não são simples em geral, mas cada um deles possui um certo subgrupo normal que é simples se $n \geqslant 5$, a menos de algumas exceções. A definição deste subgrupo depende da característica do corpo base requerendo distinguir os casos quando esta é 2 ou $\neq 2$.

Discutiremos primeiro o caso em que $\mathbb{K}=\mathbb{F}_{q}$ é um corpo finito de característica 2; portanto $q=2^{l}$. Como já foi observado, quando a característica de $\mathbb{K}$ é 2 , a forma bilinear simétrica associada a uma forma quadrática também é alternada, ou equivalentemente, é antisimétrica. Em particular, os grupos ortogonais $O_{2 m}^{ \pm}\left(2^{l}\right)$ são subgrupos de $S p_{2 m}\left(2^{l}\right)$. Como vimos anteriormente, $-1=1$ implica que $O_{2 m}^{ \pm}\left(2^{l}\right)=S O_{2 m}^{ \pm}\left(2^{l}\right)$ e $O_{2 m+1}\left(2^{l}\right)=S O_{2 m+1}\left(2^{l}\right)$, em conformidade com o fato de que todo elemento de um grupo simplético tem determinante 1. Quando $n=2 m+1$ é impar, a forma bilinear $(.,$.$) associada à forma quadrática Q$ usada para definir $O_{2 m+1}\left(2^{l}\right)$ é degenerada, com núcleo unidimensional $\operatorname{ker}(Q)$. No entanto, ela induz uma forma bilinear não-degenerada em $\mathbb{K}^{2 m+1} / \operatorname{ker}(Q) \cong \mathbb{K}^{2 m}$ e mostra-se então que $O_{2 m+1}\left(2^{l}\right) \cong S p_{2 m}\left(2^{l}\right)$ [144, pág. 143]. Assim definimos

$$
\Omega_{2 m+1}\left(2^{l}\right)=O_{2 m+1}\left(2^{l}\right)=S p_{2 m}\left(2^{l}\right)=P S p_{2 m}\left(2^{l}\right) .
$$

Quando $n=2 m$ é par, os grupos ortogonais $O_{2 m}^{ \pm}\left(2^{l}\right)$ não são isomorfos a nenhum outro tipo de grupo clássico previamente definido. Com a exeção de $\Omega_{4}^{+}(2)$, definimos

$$
\Omega_{2 m}^{ \pm}\left(2^{l}\right)=\left[O_{2 m}^{ \pm}\left(2^{l}\right), O_{2 m}^{ \pm}\left(2^{l}\right)\right] .
$$


Prova-se então que $\Omega_{2 m}^{ \pm}\left(2^{l}\right)$ é o único subgrupo de índice 2 de $S O_{2 m}^{ \pm}\left(2^{l}\right)=O_{2 m}^{ \pm}\left(2^{l}\right)$. O grupo $\mathrm{O}_{4}^{+}(2)$ possui três subgrupos de índice 2 , sendo dois isomorfos a $S_{3} m_{3} \times S y m_{3}$ e o terceiro isomorfo a $\mathbb{Z}_{3}^{2} \rtimes \mathbb{Z}_{4}$, porém nenhum deles é o subgrupo derivado. É possível dar uma definição diferente dos grupos $\Omega_{2 m}^{+}\left(2^{l}\right)$ que coincide com a dada anteriormente e proporciona o grupo $\Omega_{4}^{+}(2)$ como um dos grupos Sym $_{3} \times$ Sym $_{3}$ [99, pág. 30].

Agora passamos ao caso em que $\mathbb{K}$ é um corpo finito de característica $\neq 2$. Para tanto, precisamos de mais algumas definições. Um vetor $v \in V$ não-isotrópico produz uma transformação ortogonal $s_{v}$ chamada de reflexãa em $v$, definida por

$$
s_{v}(u)=\frac{(u, v)}{Q(v)} v \text {. }
$$

O teorema de Cartan-Dieudonné afirma que todo elemento do grupo ortogonal em $n$ dimensões pode ser escrito como um produto de no máximo $n$ reflexões [144, pág. 157]. Seja agora $\mathbb{F}_{q}^{\times 2}=\left\{\lambda^{2}: \lambda \in \mathbb{F}_{q}^{\times}\right\}$o subgrupo dos quadrados no grupo multiplicativo $\mathbb{F}_{q}^{\times}$de $\mathbb{F}_{q}$. Como $q$ é impar, $\mathbb{F}_{q}^{\times} / \mathbb{F}_{q}^{\times 2}$ tem ordem 2. Definimos as aplicações $N: O_{2 m+1}(q) \rightarrow \mathbb{F}_{q}^{\times} / \mathbb{F}_{q}^{\times 2}$ e $N: O_{2 m}^{ \pm}(q) \rightarrow \mathbb{F}_{q}^{\times} / \mathbb{F}_{q}^{\times 2}$ pondo

$$
N(A)=Q\left(v_{1}\right) Q\left(v_{2}\right) \ldots Q\left(v_{i}\right) \quad \bmod \mathbb{F}_{q}^{\times 2} \quad \text { se } A=s_{v_{1}} \ldots s_{v_{n}} .
$$

Mostra-se então que $N(A)$ não depende da representação de $A$ como produto de reflexões e que $N$ é um homomorfismo sobrejetor [10, pág. 98] chamado de norma espinorial. Agora definimos

$$
\Omega_{2 m+1}(q)=\operatorname{ker}(N) \quad \text { e } \quad \Omega_{2 m}^{ \pm}(q)=\operatorname{ker}(N) .
$$

É claro que estes grupos têm índice 2 em $S O_{2 m+1}(q)$ e $S O_{2 m}^{ \pm}(q)$, respectivamente. Na verdade, estes são os únicos subgrupos de índice 2 e quando $n \geqslant 5$ cada um coincide com o correspondente subgrupo derivado do grupo ortogonal.

Os grupos $\Omega_{2 m+1}(q)$ e $\Omega_{2 m}^{ \pm}(q)$ são chamados de grupos ortogonais reduzidos e seus quocientes $P \Omega_{2 m+1}(q)$ e $P \Omega_{2 m}^{ \pm}(q)$ pelos respectivos centros são chamados de grupos projetivos ortogonais reduzidos. ${ }^{5}$ Nota-se que a passagem ao quociente é desnecessária exceto quando $n$ é par $(n=2 m)$ e $q$ é impar. Estes grupos projetivos são simples se $m \geqslant 5$, com a única exceção de $\Omega_{5}(2)=S p_{4}(2)=S_{6}$. Para $m \leqslant 6$, ainda temos os seguintes isomorfismos [99, pág. 43] (compare com os isomorfismos excepcionais entre as álgebras de Lie simples complexas de dimensão baixa):

$$
\begin{array}{ccc}
P S p_{2}(q)=P \Omega_{3}(q)=P S L_{2}(q), & P \Omega_{5}(q)=P S p_{4}(q), & P \Omega_{4}^{+}(q)=P S L_{2}(q) \times P S L_{2}(q), \\
P \Omega_{6}^{+}(q)=P S L_{4}(q), & P \Omega_{4}^{-}(q)=P S L_{2}\left(q^{2}\right), & P \Omega_{6}^{-}(q)=P S U_{4}(q) .
\end{array}
$$

\footnotetext{
${ }^{5}$ Aparentemente não há consenso na literatura quanto a esta terminologia. As notações $\Omega$ e $P \Omega$ se devem a Dieudonné, que definiu $\Omega_{n}(q)$ como sendo o subgrupo derivado de $S O_{n}(q)$. A definição que adotamos aqui para $q$ impar é devida a Artin e permite obter os grupos "corretos" (no sentido de Chevalley) para $n$ pequeno. Para $n \geqslant 5$ as duas definições coincidem [10].
} 


\subsubsection{Grupos de Chevalley}

O pré-requisito fundamental para entender a construção dos grupos de Chevalley é o teorema de Chevalley sobre a existência de certas bases especiais, hoje chamadas de bases de Chevalley, em álgebras de Lie complexas simples. As bases normalmente empregadas na teoria de álgebras de Lie complexas simples, conhecidas como bases de Cartan-Weyl, gozam de várias propriedades importantes, sendo uma delas o fato de que as constantes de estrutura com respeito a esta base são números racionais. A observação de Chevalley, de que é possível renormalizar os vetores de uma base de Cartan-Weyl de modo que todas as constantes de estrutura se tornem inteiros, permitiu que se desse início à teoria dos grupos de tipo Lie.

Sejam $\mathfrak{g}$ uma álgebra de Lie simples sobre $\mathbb{C}, \mathfrak{h}$ uma subalgebra de Cartan, $\Delta$ o sistema de raizes de $\mathfrak{g}$ com respeito a $\mathfrak{h}, \Pi$ um sistema de raizes simples em $\Delta$,

$$
\mathfrak{g}=\mathfrak{h} \oplus \bigoplus_{\alpha \in \Delta} \mathfrak{g}_{\alpha}
$$

a decomposição de $\mathfrak{g}$ em espaços-raíz com respeito a $\mathfrak{h}$ e $(.,$.$) a forma bilinear padrão sobre \mathfrak{g} .{ }^{6}$ Denotamos por $H_{\alpha}$ a co-raíz correspondente à raíz $\alpha$, definida pela condição de que, para todo $H \in \mathfrak{h}$,

$$
\left(H_{\alpha}, H\right)=\frac{2 \alpha(H)}{(\alpha, \alpha)} .
$$

A construção de uma base de Cartan-Weyl é efetuada escolhendo, para cada raíz $\alpha$ positiva, um gerador $E_{\alpha}$ em $\mathfrak{g}_{\alpha}$ e em seguida definindo o gerador $E_{-\alpha}$ em $\mathfrak{g}_{-\alpha}$ tal que satisfaça a condição de normalização

$$
\left(E_{\alpha}, E_{-\alpha}\right)=\frac{2}{(\alpha, \alpha)} .
$$

Então valem as seguintes regras de comutação

$$
\begin{array}{rlc}
{\left[H_{\alpha}, H_{\beta}\right]} & =0, \\
{\left[H_{\alpha}, E_{\beta}\right]} & =a_{\alpha, \beta} E_{\beta}, \\
{\left[E_{\alpha}, E_{-\alpha}\right]} & =H_{\alpha}, \\
{\left[E_{\alpha}, E_{\beta}\right]} & =N_{\alpha, \beta} E_{\alpha+\beta},
\end{array}
$$

onde

$$
a_{\alpha, \beta}=\frac{2(\alpha, \beta)}{(\beta, \beta)}
$$

\footnotetext{
${ }^{6}$ Segundo Kac [92], forma bilinear padrão é a única forma bilinear invariante sobre $\mathfrak{g}$, necessariamente proporcional á forma de Killing, na qual as raizes longas têm comprimento $\sqrt{2}$.
} 
e onde $N_{\alpha, \beta}=0$ se $\alpha+\beta \notin \Delta$. O teorema de Chevalley afirma que é possível renormalizar os geradores $E_{\alpha}$ de tal forma que estas relações continuem válidas, mas com constantes de estrutura $N_{\alpha, \beta}$ inteiros. De fato, o módulo de $N_{\alpha, \beta}$ é determinado pela condição de que a $\alpha$-série passando por $\beta$ se inicia em $\beta-\left(\left|N_{\alpha, \beta}\right|-1\right) \alpha$. A única ambiguidade que permanece reside na escolha dos sinais das constantes de estrutura, que também não é completamente arbitrária mas está sujeita a restrições que não especificaremos aqui.

Para toda raíz $\alpha$, a aplicação ad $E_{\alpha}$ é uma derivação nilpotente de $\mathfrak{g}$, isto é, vale $\left(\operatorname{ad} E_{\alpha}\right)^{n}(\mathfrak{g})=0$ para $n$ suficientemente grande. Se $\zeta \in \mathbb{C}$ então $\operatorname{ad}\left(\zeta E_{\alpha}\right)=\zeta$ ad $E_{\alpha}$ também é uma derivação nilpotente de $\mathfrak{g}$. $\operatorname{Logo}, \exp \left(\zeta\right.$ ad $\left.E_{\alpha}\right)$ é um automorfismo de g. Vamos escrever

$$
x_{\alpha}(\zeta)=\exp \left(\zeta \text { ad } E_{\alpha}\right) .
$$

Segue das regras de comutação (3.1) que cada um dos automorfismos $x_{\alpha}(\zeta)$ transforma os elementos de uma base de Chevalley em uma combinação linear de elementos desta base cujos coeficientes são potências inteiras não-negativas de $\zeta$ multiplicadas por números inteiros.

Fixemos de agora em diante uma base de Chevalley $B=\left\{H_{\alpha}, \alpha \in \Pi ; E_{\alpha}, \alpha \in \Delta\right\}$ de $\mathfrak{g}$ e denotaremos por $\mathfrak{g}_{\mathbb{Z}}$ o subconjunto de $\mathfrak{g}$ formado pelas combinações lineares dos elementos da base $B$ com coeficientes inteiros. Segue das regras de comutação (3.1) que o comutador de dois elementos da base $B$ é um elemento de $\mathfrak{g}_{\mathbb{Z}}$; portanto $\mathfrak{g}_{\mathbb{Z}}$ é uma álgebra de Lie sobre o anel dos inteiros, ${ }^{7}$ chamada de $\mathbb{Z}$-forma de $\mathfrak{g}$. A partir desta, podemos construir, para todo corpo $\mathbb{K}$, uma álgebra de Lie $\mathfrak{g}_{\mathbb{K}}$ sobre $\mathbb{K}$. Como espaço vetorial sobre $\mathbb{K}$

$$
\mathfrak{g}_{\mathbb{K}}=\mathbb{K} \otimes_{\mathbb{Z}} \mathfrak{g}_{\mathbb{Z}} .
$$

Portanto, os elementos de $\mathfrak{g}_{\mathbb{K}}$ podem ser escritos como

$$
\sum_{\alpha \in \Pi} \lambda_{\alpha}\left(1 \otimes H_{\alpha}\right)+\sum_{\alpha \in \Delta} \mu_{\alpha}\left(1 \otimes E_{\alpha}\right)
$$

$\operatorname{com} \lambda_{\alpha}, \mu_{\alpha} \in \mathbb{K}$. Definindo

$$
\bar{H}_{\alpha}=1 \otimes H_{\alpha}, \quad \bar{E}_{\alpha}=1 \otimes E_{\alpha} .
$$

vemos que $\bar{B}=\left\{\bar{H}_{\alpha}, \alpha \in \Pi ; \bar{E}_{\alpha}, \alpha \in \Delta\right\}$ é uma base de $\mathfrak{g}_{\mathbb{K}}$. Ademais, se $X$ e $Y$ são dois elementos da base $B$ então o comutador em $\mathfrak{g}_{\mathbb{K}}$ definido por

$$
[1 \otimes X, 1 \otimes Y]=1 \otimes[X, Y]
$$

e estendido por bilinearidade, torna $\mathfrak{g}_{\mathbb{K}}$ uma álgebra de Lie sobre $\mathbb{K}$. As constantes de estrutura de $\mathfrak{g}_{\mathbb{K}}$ com respeito à base $\bar{B}$ são as mesmas constantes de estrutura de $\mathfrak{g}$ com

\footnotetext{
${ }^{7}$ A definição de álgebra de Lie sobre um anel comutativo é análoga à definição sobre um corpo, trocando-se espaço vetorial por módulo.
} 
respeito à base $B$, interpretadas como elementos do subcorpo primo ${ }^{8}$ de $\mathbb{K}$. Vale observar também que, apesar da construção de $\mathfrak{g}_{\mathbb{K}}$ a partir de uma álgebra de Lie $\mathfrak{g}$ simples sobre $\mathbb{C}$, a álgebra de Lie $\mathfrak{g}_{\mathbb{K}}$ pode não ser simples. (Por exemplo, a álgebra de Lie $\mathfrak{s l}(2, \mathbb{K})$ é solúvel se $\mathbb{K}$ tiver característica 2.)

Tendo introduzido a álgebra de Lie $\mathfrak{g}_{\mathbb{K}}$, podemos definir automorfismos de $\mathfrak{g}_{\mathbb{K}}$ análogos aos automorfismos $x_{\alpha}(\zeta)$ de $\mathfrak{g}$. Seja $A_{\alpha}(\zeta)$ a matriz de $x_{\alpha}(\zeta)$ com respeito à base $B$. Os coeficientes de $A_{\alpha}(\zeta)$ são da forma $a \zeta^{i}$, com $a \in \mathbb{Z}$ e $i \geqslant 0$. Seja $t$ um elemento de $\mathbb{K}$ e $\bar{A}_{\alpha}(t)$ a matriz obtida de $A_{\alpha}(\zeta)$ substituindo cada coeficiente $a \zeta^{i}$ por $\bar{a} t^{i}$, onde $\bar{a}$ é o elemento do subcorpo primo de $\mathbb{K}$ correspondente a $a \in \mathbb{Z}$. Definimos $\bar{x}_{\alpha}(t)$ como sendo a aplicação linear de $\mathfrak{g}_{\mathbb{K}}$ sobre si mesmo, representada pela matriz $\bar{A}_{\alpha}(t)$ com respeito à base $\bar{B}$. Mostra-se então que $\bar{x}_{\alpha}(t)$ é um automorfismo de $\mathfrak{g}_{\mathbb{K}}$ para todo $t \in \mathbb{K}$.

Para simplificar a notação vamos escrever $H_{\alpha}$ para $\bar{H}_{\alpha}, E_{\alpha}$ para $\bar{E}_{\alpha}, x_{\alpha}(t)$ para $\bar{x}_{\alpha}(t)$ e $A_{\alpha}(t)$ para $\bar{A}_{\alpha}(t)$. Essa omissão das barras não leva a inconsistências, já que os objetos originais $H_{\alpha}, E_{\alpha}, x_{\alpha}(t)$ e $A_{\alpha}(t)$ são casos especiais de $\bar{H}_{\alpha}, \bar{E}_{\alpha}, \bar{x}_{\alpha}(t)$ e $\bar{A}_{\alpha}(t)$ quando tomamos $\mathbb{K}=\mathbb{C}$.

Definição 3.2.1 Sejam $\mathfrak{g}$ uma álgebra de Lie simples sobre $\mathbb{C}$ e $\mathbb{K}$ um corpo qualquer. O grupo de Chevalley ou mais precisamente grupo de Chevalley adjunto associado a $\mathfrak{g}$ sobre o corpo $\mathbb{K}$ é o grupo de automorfismos da álgebra de Lie $\mathfrak{g}_{\mathbb{K}}$ gerado por $x_{\alpha}(t)$ para todo $\alpha \in \Delta$ e todo $t \in \mathbb{K}$ :

$$
G(\mathbb{K})=\left\langle x_{\alpha}(t) \in \operatorname{Aut}\left(\mathfrak{g}_{\mathbb{K}}\right) \mid \alpha \in \Delta, t \in \mathbb{K}\right\rangle .
$$

A priori, a definição de $G(\mathbb{K})$ depende da escolha de uma base de Chevalley para a construção da álgebra $\mathfrak{g}_{\mathbb{K}}$ e dos automorfismos $x_{\alpha}(t)$. O fato de que a definição de $G(\mathbb{K})$ não depende desta escolha é, essencialmente, consequência do teorema do isomorfismo para álgebras de Lie simples sobre $\mathbb{C}$.

A terminologia introduzida na definição acima é motivada pelo fato de que, quando $\mathbb{K}=\mathbb{C}$, o grupo $G(\mathbb{C})$ é o grupo de Lie complexo $\operatorname{Int}(\mathfrak{g})$ dos automorfismos internos da álgebra de Lie $\mathfrak{g}$, isomorfo ao grupo $\operatorname{Ad}(G)$, onde $G$ é qualquer grupo de Lie conexo que tem $\mathfrak{g}$ como álgebra de Lie. Mais geralmente, se $\mathbb{K}$ é um corpo algebricamente fechado, $G(\mathbb{K})$ é um grupo algébrico linear sobre $\mathbb{K}$ com álgebra de Lie $\mathfrak{g}_{\mathbb{K}}$. Outra notação que empregaremos sistematicamente no que segue utiliza os rótulos de Cartan, tanto para indicar o grupo de Chevalley como a álgebra de Lie sobre a qual este age: se $X_{r}$ é o rótulo de Cartan de $\mathfrak{g}$ escrevemos $\left(X_{r}\right)_{\mathbb{K}}$ ao invés de $\mathfrak{g}_{\mathbb{K}}$ e $X_{r}(\mathbb{K})$ ao invés de $G(\mathbb{K})$. Quando $\mathbb{K}=\mathbb{F}_{q}$, escrevemos simplesmente $X_{r}(q)$ ao invés de $X_{r}(\mathbb{K})$.

\footnotetext{
${ }^{8} \mathrm{O}$ subcorpo primo de um corpo qualquer $\mathbb{K}$ é isomorfo a $\mathbb{Q}$ se $\mathbb{K}$ tiver característica 0 ou é isomorfo a $\mathbb{F}_{p}$ se $\mathbb{K}$ tiver característica $p$.
} 
Aplicando a construção de Chevalley às séries clássicas $A_{r}, B_{r}, C_{r}$ e $D_{r}$, obtemos as seguintes identificações com os grupos clássicos considerados na seção anterior:

$$
\begin{array}{cc}
A_{r}(q)=P S L_{r+1}(q) & , \quad B_{r}(q)=P \Omega_{2 r+1}(q), \\
C_{r}(q)=P S p_{2 r}(q) & , \quad D_{r}(q)=P \Omega_{2 r}^{+}(q),
\end{array}
$$

enquanto que as álgebras excepcionais proporcionam novos grupos simples:

$$
G_{2}(q), \quad F_{4}(q), \quad E_{6}(q), \quad E_{7}(q), \quad E_{8}(q) .
$$

Os grupos de Chevalley que acabamos de construir são chamados de adjuntos, pois utilizamos a representação adjunta de $\mathfrak{g}$ na sua construção. No entanto, todo o processo pode ser estendido a outras representações de $\mathfrak{g}$, o que leva a outros tipos de grupos de Chevalley. Mais precisamente, os grupos de Chevalley adjuntos sempre têm centro trivial, enquanto que os outros tipos são grupos de recobrimento do grupo adjunto. Em particular, existe sempre uma representação que fornece um (único a menos de isomorfismos) grupo de Chevalley (formalmente) simplesmente conexo; os outros tipos de grupo de Chevalley são quocientes por algum subgrupo central do grupo simplesmente conexo. Por exemplo, no caso de $A_{r}$, a álgebra de Lie das matrizes complexas de traço nulo, o grupo de Chevalley adjunto é $\operatorname{PSL}(r+1, \mathbb{K})$, enquanto que o grupo de Chevalley simplesmente conexo é $S L(r+1, \mathbb{K})$, obtido a partir da representação padrão de dimensão $r+1$ de $A_{r}$. Observamos que, no caso complexo, os grupos de Chevalley formalmente simplesmente conexos são exatamente os grupos de Lie simplesmente conexos (no sentido topológico).

Assim como os grupos unitários $U(n)$ são obtidos a partir de $G L(n, \mathbb{C})$, existem variantes finitas desta construção para os grupos de Chevalley. A teoria geral foi desenvolvida por Robert Steinberg, que não apenas construiu os grupos mas também descreveu a sua estrutura interna. Para definir estes "grupos torcidos", consideramos a situação análoga no caso complexo. O grupo $S U(n)$ consiste das matrizes complexas unimodulares $A \in S L(n, \mathbb{C})$ tais que $\bar{A}^{t} A=1$. De maneira mais algébrica podemos interpretar $S U(n)$ como o subgrupo de $S L(n, \mathbb{C})$ dos pontos fixos sob o automorfismo de $S L(n, \mathbb{C})$ de ordem 2 dado por $A \mapsto\left(\bar{A}^{t}\right)^{-1}$. Este por sua vez é composto de dois outros automorfismos de ordem 2. O primeiro é um "automorfismo de corpo", obtido pela aplicação da conjugação complexa $\lambda \mapsto \bar{\lambda}$ a cada entrada da matriz $A$. O segundo é um "automorfismo de grafo", obtido do automorfismo externo $X \mapsto-X^{t}$ de $\mathfrak{s l}(n, \mathbb{C})$ que corresponde à única simetria do diagrama de Dynkin de $A_{n-1}$.

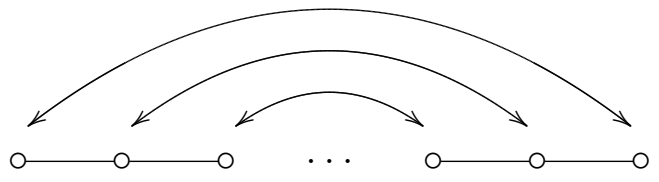


Observamos que estes dois automorfismos também podem ser considerados separadamente mas assim não levam à definição de uma nova classe de grupos, pois o subgrupo dos pontos fixos sob o automorfismo de corpo é $S L(n, \mathbb{R})$, enquanto que o subgrupo dos pontos fixos sob o automorfismo de grafo é $S O(n, \mathbb{C})$.

Foi demonstrado por Steinberg que este processo pode ser aplicado aos grupos de Chevalley sobre corpos quaisquer quando o diagrama de Dynkin subjacente possui simetrias não-triviais, o que ocorre para $A_{r}(r \geqslant 2), D_{r}(r \geqslant 4)$ e $E_{6}$. Assim ele obteve análogos finitos ${ }^{2} A_{r}(q),{ }^{2} D_{r}(q)$ e ${ }^{2} E_{6}(q)$ dos grupos de Lie correspondentes, onde no lugar da conjugação complexa (que é um automorfismo de ordem 2 de $\mathbb{C}$ ) usa-se o automorfismo de Frobenius de ordem 2 do corpo de Galois $\mathbb{F}_{q^{2}}$. Em particular, ${ }^{2} A_{r}(q)=P S U_{r+1}(q)$ e ${ }^{2} D_{r}(q)=P \Omega_{2 r}^{-}(q)$; note que o primeiro é um subgrupo de $A_{r}\left(q^{2}\right)=P S L_{r+1}\left(q^{2}\right)$ e o segundo é um subgrupo de $D_{r}\left(q^{2}\right)=P \Omega_{2 r}^{+}\left(q^{2}\right)$.

O diagrama de Dynkin $D_{4}$ é o único que possui uma simetria de ordem 3. Como $\mathbb{C}$ não possui automorfismos de ordem 3, não é possível utilizar este automorfismo de grafo para construir grupos torcidos complexos como nos casos anteriores. No entanto, o corpo de Galois $\mathbb{F}_{q^{3}}$ possui um automorfismo de Frobenius de ordem 3; tomando-se o produto deste automorfismo com o automorfismo de grafo de ordem 3 de $D_{4}$ pode-se construir um grupo torcido, do mesmo modo que antes, chamado de grupo torcido de trialidade de $D_{4}(q)$ e denotado por ${ }^{3} D_{4}(q)$ que é um subgrupo de $D_{4}\left(q^{3}\right)$.

Todos estes grupos torcidos são chamados de variações de Steinberg dos grupos de Chevalley ou grupos de Chevalley torcidos.

Finalmente, devido a certas degenerescências nas constantes de estrutura, as três famílias $B_{2}\left(2^{n}\right), G_{2}\left(3^{n}\right)$ e $F_{4}\left(2^{n}\right)$ possuem um tipo "extra" de automorfismo de grafo de ordem 2 que não foi levado em conta pela teoria anterior, induzido por simetrias do grafo de Coxeter. ${ }^{9}$ Foi Remhak Ree que observou que estes automorfismos poderiam ser usados para obter uma variação da construção de Steinberg, tomando como automorfismo de ordem 2 o produto do "automorfismo extra de grafo" com um automorfismo induzido pelo grupo de Galois do corpo $\mathbb{F}_{p^{n}}$, com as restrições de que $p$ seja igual ao número de arestas múltiplas no grafo e que $n$ seja impar. Desta forma, ele construiu três novas famílias de grupos simples, denotadas por ${ }^{2} B_{2}\left(2^{2 l+1}\right),{ }^{2} G_{2}\left(3^{2 l+1}\right)$ e ${ }^{2} F_{4}\left(2^{2 l+1}\right)$. É interessante notar que os grupos ${ }^{2} B_{2}\left(2^{2 l+1}\right)$ já haviam sido construídos anteriormente por Michio Suzuki através de uma abordagem totalmente diferente e por isto são também denotados por $S z\left(2^{2 l+1}\right)$. O último passo foi dado por Jacques Tits, que mostrou que ${ }^{2} F_{4}(2)$ não é simples mas que seu subgrupo derivado $T={ }^{2} F_{4}(2)^{\prime}$, de índice 2 e denominado grupo de Tits, é simples e não é isomorfo a nenhum outro grupo simples conhecido.

\footnotetext{
${ }^{9} \mathrm{O}$ grafo de Coxeter é obtido do diagrama de Dynkin desconsiderando a orientação das arestas múltiplas e portanto no caso de $B_{2}, G_{2}$ e $F_{4}$ possui simetrias adicionais, trocando as raizes simples curtas com as raizes simples longas.
} 
Os grupos finitos de tipo Lie consistem dos grupos de Chevalley, com as variações de Steinberg, Suzuki-Ree e Tits, juntamente com todos os seus grupos de recobrimento. A análise combinada de Chevalley, Steinberg, Suzuki, Ree e Tits fornece o seguinte resultado.

Teorema 3.2.1 Seja $G$ um grupo de tipo Lie na forma adjunta, isto é, com $Z(G)=\{1\}$. Então $G$ é simples, exceto quando ocorre uma das seguintes situações:

(i) $G=A_{1}(2)=$ Sym $_{3}, A_{1}(3)=$ Alt $_{4},{ }^{2} A_{2}(2)=\mathbb{Z}_{3}^{2} \rtimes Q_{8}$ ou ${ }^{2} B_{2}(2)=\mathbb{Z}_{5} \rtimes \mathbb{Z}_{4} ;$ nestes casos, $G$ é solúvel,

(ii) $G=B_{2}(2)=$ Sym $_{6}$,

(iii) $G=G_{2}(2),|G:[G, G]|=2$, e $[G, G]={ }^{2} A_{2}(3)$.

(iv) $G={ }^{2} G_{2}(3),|G:[G, G]|=3, e[G, G]=A_{1}(8)$.

(v) $G={ }^{2} F_{4}(2),|G:[G, G]|=2$, e $[G, G]=T$ é simples.

Está implícito neste enunciado a exclusão das famílias $B_{1}, C_{1}, C_{2}, D_{2}, D_{3}$ e ${ }^{2} D_{3}$ por causa dos seguintes isomorfismos (a álgebra de Lie $D_{1}$ não é simples):

$$
\begin{array}{cccc}
C_{1}(q)=B_{1}(q)=A_{1}(q), & C_{2}(q)=B_{2}(q), & D_{2}(q)=A_{1}(q) \times A_{1}(q), \\
D_{3}(q)=A_{3}(q), & { }^{2} D_{2}(q)=A_{1}\left(q^{2}\right), & { }^{2} D_{3}(q)={ }^{2} A_{3}(q) .
\end{array}
$$

Além disto, tem-se que

$$
B_{n}\left(2^{l}\right)=C_{n}\left(2^{l}\right)
$$

Existem isomorfismos entre alguns grupos de tipo Lie de ordem baixa:

$$
A_{1}(4)=A_{1}(5), \quad A_{1}(7)=A_{2}(2), \quad B_{2}(3)={ }^{2} A_{3}(2) .
$$

Também tem-se que três grupos de tipo Lie são isomorfos a grupos alternados:

$$
A_{1}(4)=A_{1}(5)=\text { Alt }_{5}, A_{1}(9)=\text { Alt }_{6}, A_{3}(2)=\text { Alt }_{8} .
$$

Estes isomorfismos mostram que alguns grupos finitos de tipo Lie de posto ${ }^{10}$ baixo e alguns grupos finitos simples de ordem baixa possuem várias "identidades" diferentes. Este fato é um dos principais responsáveis pela dificuldade da demonstração do teorema de classificação, mas por outro lado, ele esclarece o comportamento irregular de alguns (mas não todos) grupos finitos simples. Por exemplo, o isomorfismo $A_{1}(9)=A l t_{6}$ explica porque o multiplicador de Schur e o grupo de automorfismos do grupo $A l t_{6}$ não seguem o padrão dos grupos alternados $A l t_{n}$, para $n \geqslant 8$. Já o multiplicador de Schur de $A l t_{7}$ não tem nenhuma razão especial para ser diferente.

\footnotetext{
${ }^{10} \mathrm{O}$ posto de um grupo finito de tipo Lie é definido como sendo o posto da álgebra de Lie complexa associada.
} 


\begin{tabular}{|c|c|c|}
\hline$G(q)$ & Grupo Clássico & Ordem de $G(q)$ \\
\hline$A_{n}(q), n \geqslant 1$ & $P S L_{n+1}(q)$ & $\frac{1}{(n+1, q-1)} q^{\left(\begin{array}{c}n+1 \\
2\end{array}\right)} \prod_{i=2}^{n+1}\left(q^{i}-1\right)$ \\
\hline$B_{n}(q), n \geqslant 2$ & $P \Omega_{2 n+1}(q)$ & $\frac{1}{(2, q-1)} q^{n^{2}} \prod_{i=1}^{n}\left(q^{2 i}-1\right)$ \\
\hline$C_{n}(q), n \geqslant 3$ & $P S p_{2 n}(q)$ & $\frac{1}{(2, q-1)} q^{n^{2}} \prod_{i=1}^{n}\left(q^{2 i}-1\right)$ \\
\hline$D_{n}(q), n \geqslant 4$ & $P \Omega_{2 n}^{+}(q)$ & $\frac{1}{\left(4, q^{n}-1\right)} q^{n(n-1)}\left(q^{n}-1\right) \prod_{i=1}^{n-1}\left(q^{2 i}-1\right)$ \\
\hline$E_{6}(q)$ & & $\begin{array}{c}\frac{1}{(3, q-1)} q^{36}\left(q^{12}-1\right)\left(q^{9}-1\right)\left(q^{8}-1\right) \\
\cdot\left(q^{6}-1\right)\left(q^{5}-1\right)\left(q^{2}-1\right)\end{array}$ \\
\hline$E_{7}(q)$ & & $\begin{aligned} \frac{1}{(2, q-1)} q^{63}\left(q^{18}-1\right)\left(q^{14}-1\right)\left(q^{12}-1\right) \\
\quad \cdot\left(q^{10}-1\right)\left(q^{8}-1\right)\left(q^{6}-1\right)\left(q^{2}-1\right)\end{aligned}$ \\
\hline$E_{8}(q)$ & & $\begin{array}{l}q^{120}\left(q^{30}-1\right)\left(q^{24}-1\right)\left(q^{20}-1\right)\left(q^{18}-1\right) \\
\quad \cdot\left(q^{14}-1\right)\left(q^{12}-1\right)\left(q^{8}-1\right)\left(q^{2}-1\right)\end{array}$ \\
\hline$F_{4}(q)$ & & $q^{24}\left(q^{12}-1\right)\left(q^{8}-1\right)\left(q^{6}-1\right)\left(q^{2}-1\right)$ \\
\hline$G_{2}(q)$ & & $q^{6}\left(q^{6}-1\right)\left(q^{2}-1\right)$ \\
\hline${ }^{2} A_{n}(q), n \geqslant 2$ & $P S U_{n+1}(q)$ & $\frac{1}{(n+1, q+1)} q^{\left(\begin{array}{c}n+1 \\
2\end{array}\right)} \prod_{i=2}^{n+1}\left(q^{i}-(-1)^{i}\right)$ \\
\hline${ }^{2} D_{n}(q), n \geqslant 4$ & $P \Omega_{2 n}^{-}(q)$ & $\frac{1}{\left(4, q^{n}+1\right)} q^{n(n-1)}\left(q^{n}+1\right) \prod_{i=1}^{n-1}\left(q^{2 i}-1\right)$ \\
\hline${ }^{2} E_{6}(q)$ & & $\begin{array}{c}\frac{1}{(3, q-1)} q^{36}\left(q^{12}-1\right)\left(q^{8}-1\right)\left(q^{6}-1\right) \cdot \\
\cdot\left(q^{2}-1\right)\left(q^{9}+1\right)\left(q^{5}+1\right)\end{array}$ \\
\hline${ }^{3} D_{4}(q)$ & & $q^{12}\left(q^{6}-1\right)\left(q^{2}-1\right)\left(q^{8}+q^{4}+1\right)$ \\
\hline${ }^{2} B_{2}\left(2^{2 l+1}\right)$ & & $q^{2}(q-1)\left(q^{2}+1\right)$ \\
\hline${ }^{2} F_{4}\left(2^{2 l+1}\right)$ & & $q^{12}\left(q^{4}-1\right)(q-1)\left(q^{6}+1\right)\left(q^{3}+1\right)$ \\
\hline${ }^{2} G_{2}\left(3^{2 l+1}\right)$ & & $q^{3}(q-1)\left(q^{3}+1\right)$ \\
\hline
\end{tabular}

Tabela 3.1: Grupos finitos de tipo Lie com suas ordens. (Aqui $(a, b)$ denota o maior divisor comum entre $a$ e $b$.) 
As ordens dos grupos de tipo Lie estão apresentadas na Tabela 3.1. As fórmulas que aparecem na terceira coluna da tabela podem ser obtidas a partir de uma fórmula universal para a ordem dos grupos de Chevalley e uma outra para a ordem dos grupos de Chevalley torcidos, que só depende do sistema de raízes da álgebra de Lie complexa simples associada [30]. Observe que os grupos $B_{n}(q)$ e $C_{n}(q)$ tem a mesma ordem, mas só são isomorfos quando $\mathbb{F}_{q}$ tem característica $2[144]$.

O multiplicador de Schur de cada um dos grupos de tipo Lie é o produto direto de um grupo abeliano D chamado de multiplicador diagonal e um grupo abeliano E chamado de multiplicador extraordinário. Segundo um teorema de Steinberg [39, 136], o multiplicador diagonal é um grupo cuja ordem não é divisível pela característica do corpo finito subjacente e estende o grupo adjunto ao correspondente grupo simplesmente conexo, em particular ele é igual ao centro do grupo simplesmente conexo. O multiplicador extraordinário é sempre um $p$-grupo ${ }^{11}$ (onde $p$ é a característica do corpo finito subjacente) e é trivial a menos de um número finito de casos. Assim, o grupo simplesmente conexo é o recobrimento universal a menos de um número finito de casos onde o posto do grupo e o número de elementos do corpo são baixos.

Quanto ao grupo de automorfismos externos, um outro teorema de Steinberg afirma que qualquer automorfismo de um grupo de tipo Lie é o produto de um automorfismo interno, um "automorfismo diagonal", um "automorfismo de corpo" e um "automorfismo de grafo". Por exemplo, as matrizes diagonais em $G L_{n}(q)$ de determinante diferente de 1 definem, por conjugação, "automorfismos diagonais" de $S L_{n}(q)$. Os "automorfismos de corpo" são induzidos pelos automorfismos de Frobenius do corpo $\mathbb{F}_{q}$ quando aplicados às entradas das matrizes que formam o grupo. Finalmente, os "automorfismos de grafo" são induzidos por simetrias do diagrama de Dynkin ou do grafo de Coxeter da álgebra de Lie associada. É claro que os automorfismos diagonais formam um grupo abeliano D (este grupo é igual ao multiplicador diagonal) enquanto que os automorfismos de corpo formam um grupo cíclico $\mathrm{F}$ de ordem $f$, onde $q=p^{f}$ ( $p$ primo) para os grupos de Chevalley da forma $X_{r}(q)$, $q^{t}=p^{f}$ ( $p$ primo) para os grupos torcidos de Chevalley da forma ${ }^{t} X_{r}(q)$ e $f=2 l+1$ para os grupos de Suzuki-Ree da forma ${ }^{t} X_{r}\left(p^{2 l+1}\right)(p=2$ ou 3). Por outro lado, os automorfismos de grafo determinam um grupo $\mathrm{G}$ de ordem 1 ou 2 , exceto no caso de $D_{4}$ cujo grupo de automorfismos de grafo é $S_{y m_{3}}$. Em geral, o grupo de automorfismos externos Out $(G)$ de um grupo de tipo Lie $G$ é um grupo solúvel com um subgrupo normal DF, onde D é abeliano e F é cíclico, e $\mathrm{G}=\operatorname{Out}(G) / \mathrm{DF}=1, \mathbb{Z}_{2}$ ou $\operatorname{Sym}_{3}$.

Os multiplicadores de Schur e os grupos de automorfismos externos dos grupos de tipo Lie estão apresentados na Tabela 3.2. (Numa entrada do tipo "H para ..." está subentendido que $H=1$ em todos os outros casos.)

\footnotetext{
${ }^{11} \mathrm{Um} p$-grupo finito é um grupo finito cuja ordem é uma potência do número primo $p$.
} 


\begin{tabular}{|c|c|c|c|c|}
\hline$G(q)$ & $\mathrm{D}$ & G & & $E$ \\
\hline \multirow[t]{2}{*}{$A_{1}(q)$} & $\mathbb{Z}_{(2, q-1)}$ & 1 & $\mathbb{Z}_{2}$ & para $A_{1}(4)$ \\
\hline & & & $\mathbb{Z}_{3}$ & para $A_{1}(9)$ \\
\hline \multirow[t]{3}{*}{$A_{n}(q), n \geqslant 2$} & $\mathbb{Z}_{(n+1, q-1)}$ & $\mathbb{Z}_{2}$ & $\mathbb{Z}_{2}$ & para $A_{2}(2)$ \\
\hline & & & $\mathbb{Z}_{4} \times \mathbb{Z}_{4}$ & para $A_{2}(4)$ \\
\hline & & & $\mathbb{Z}_{2}$ & para $A_{3}(2)$ \\
\hline \multirow[t]{3}{*}{${ }^{2} A_{n}(q), n \geqslant 2$} & $\mathbb{Z}_{(n+1, q+1)}$ & 1 & $\mathbb{Z}_{2}$ & para ${ }^{2} A_{3}(2)$ \\
\hline & & & $\mathbb{Z}_{3} \times \mathbb{Z}_{3}$ & para ${ }^{2} A_{3}(3)$ \\
\hline & & & $\mathbb{Z}_{2} \times \mathbb{Z}_{2}$ & para ${ }^{2} A_{5}(2)$ \\
\hline$B_{2}(q)$ & $\mathbb{Z}_{(2, q-1)}$ & $\mathbb{Z}_{2}$ para $p=2$ & $\mathbb{Z}_{2}$ & para $B_{2}(2)$ \\
\hline${ }^{2} B_{2}(q)$ & 1 & 1 & $\mathbb{Z}_{2} \times \mathbb{Z}_{2}$ & para ${ }^{2} B_{2}(2)$ \\
\hline \multirow[t]{2}{*}{$B_{n}(q), n \geqslant 3$} & $\mathbb{Z}_{(2, q-1)}$ & 1 & $\mathbb{Z}_{2}$ & para $B_{3}(2)$ \\
\hline & & & $\mathbb{Z}_{3}$ & para $B_{3}(3)$ \\
\hline$C_{n}(q), n \geqslant 3$ & $\mathbb{Z}_{(2, q-1)}$ & 1 & $\mathbb{Z}_{2}$ & para $C_{3}(2)$ \\
\hline$D_{4}(q)$ & $\mathbb{Z}_{\left(2, q^{4}-1\right)}^{2}$ & $\mathrm{Sym}_{3}$ & $\mathbb{Z}_{2} \times \mathbb{Z}_{2}$ & para $D_{4}(2)$ \\
\hline${ }^{3} D_{4}(q)$ & 1 & 1 & & \\
\hline$D_{n}(q), n \geqslant 5$ impar & $\mathbb{Z}_{\left(4, q^{n}-1\right)}$ & $\mathbb{Z}_{2}$ & & \\
\hline$D_{n}(q), n \geqslant 6$ par & $\mathbb{Z}_{\left(2, q^{n}-1\right)}^{2}$ & $\mathbb{Z}_{2}$ & & \\
\hline${ }^{2} D_{n}(q), n \geqslant 4$ & $\mathbb{Z}_{\left(4, q^{n}+1\right)}$ & 1 & & \\
\hline$E_{6}(q)$ & $\mathbb{Z}_{(3, q-1)}$ & $\mathbb{Z}_{2}$ & & \\
\hline${ }^{2} E_{6}(q)$ & $\mathbb{Z}_{(3, q+1)}$ & $\mathbb{Z}_{2}$ & $\mathbb{Z}_{2} \times \mathbb{Z}_{2}$ & para ${ }^{2} E_{6}(2)$ \\
\hline$E_{7}(q)$ & $\mathbb{Z}_{(2, q-1)}$ & 1 & & \\
\hline$E_{8}(q)$ & 1 & 1 & & \\
\hline$F_{4}(q)$ & 1 & $\mathbb{Z}_{2}$ para $p=2$ & $\mathbb{Z}_{2}$ & para $F_{4}(2)$ \\
\hline${ }^{2} F_{4}(2)^{\prime}$ & 1 & 2 & & \\
\hline${ }^{2} F_{4}(q)$ & 1 & 1 & & \\
\hline \multirow[t]{2}{*}{$G_{2}(q)$} & 1 & $\mathbb{Z}_{2}$ para $p=3$ & $\mathbb{Z}_{3}$ & para $G_{2}(3)$ \\
\hline & & & $\mathbb{Z}_{2}$ & para $G_{2}(4)$ \\
\hline${ }^{2} G_{2}(q)$ & 1 & 1 & & \\
\hline
\end{tabular}

Tabela 3.2: Grupos finitos de tipo Lie com seus multiplicadores de Schur e seus grupos de automorfismos externos. (Aqui $(a, b)$ denota o maior divisor comum entre $a$ e $b$.) 


\subsection{Grupos Esporádicos}

Os grupos finitos simples apresentados nas seções anteriores ocorrem naturalmente em séries infinitas, mas esta regra geral não vale para todos os grupos finitos simples. As exceções são conhecidas como os grupos esporádicos, um termo originalmente usado por Burnside [25] para se referir aos grupos de Mathieu, que formam uma "mini-série" de 5 grupos.

Um dos aspectos mais curiosos da teoria dos grupos esporádicos é que em alguns casos a "descoberta" de um novo grupo esporádico $G$ não chegou a uma construção explícita de $G$, mas se reduziu a uma "forte evidência" da existência de um grupo $G$ com um certo conjunto de propriedades, tais como: a ordem de $G$, a estrutura de certos subgrupos chamados subgrupos locais ${ }^{12}$, a tabela de caracteres de $G$, alguns caracteres modulares, etc. O princípio matemático por trás desta "construção por convicção" é o seguinte: se a investigação de um grupo $G$ tendo certas propriedades não leva a nenhuma contradição mas sim a uma estrutura interna "compatível", então existe um grupo $G$ com estas propriedades. Apesar do crédito maior (inclusive o direito de nomear o grupo) ser usualmente dado ao "descobridor", a existência do grupo foi frequentemente estabelecida por outros, ou pelo menos com a ajuda de outros, e com intervalos variando de alguns meses até alguns anos.

Existem 26 grupos esporádicos, que ainda não estão definitivamente organizados sob um único ponto de vista. O maior de todos eles é o "Monstro" de Fischer-Griess. ${ }^{13}$ Dentre os 26 grupos esporádicos, 20 estão envolvidos nele como subquocientes e formam, segundo Robert Griess [73], a "Happy Family", que é naturalmente dividida em 3 gerações.

A primeira geração é composta dos 5 grupos de Mathieu: $M_{11}, M_{12}, M_{22}, M_{23}$ e $M_{24}$. Na busca de grupos de permutações de alto grau de transitividade, Emil Mathieu (por volta de 1860) descobriu dois grupos 5 -transitivos ${ }^{14}$ de graus 12 e 24, respectivamente, e denotados $M_{12}$ e $M_{24}$. Em seguida, ele definiu $M_{11}$ e $M_{23}$ como os subgrupos de estabilidade de um ponto em $M_{12}$ e $M_{24}$, respectivamente, e $M_{22}$ como o subgrupo de estabilidade de um ponto em $M_{23}$. Geradores de cada um deles encontram-se em [65, pág. 79] e os detalhes de sua construção podem ser vistos em [73]. Cada um destes grupos é simples, e todos são subgrupos de $M_{24}$. Estruturalmente, o fato mais notável a seu respeito é que, além dos grupos alternados e dos grupos simétricos, eles são os únicos grupos de permutações que são 4- e 5-transitivos. Mais notável ainda é o fato de que levou quase 100 anos para que se descobrisse outro grupo esporádico.

\footnotetext{
${ }^{12}$ Um subgrupo $H$ de um grupo $G$ é chamado de subgrupo local se $H$ é o normalizador de um subgrupo de $G$ cuja ordem é uma potência de um número primo $p$.

${ }^{13}$ Estima-se que o número de elementos do Monstro é da mesma ordem de grandeza que o número de partículas elementares no planeta Jupiter.

${ }^{14} \mathrm{Um}$ grupo de permutações $G$ em um conjunto $\Omega$ é dito $k$-transitivo se quaisquer duas $k$-uplas ordenadas de elementos de $\Omega$ podem ser transformadas uma na outra por um elemento de $G$.
} 
A segunda geração consiste dos 3 grupos de Conway $\mathrm{Co}_{1}, \mathrm{Co}_{2}$ e $\mathrm{Co}_{3}$, juntamente com os grupos $H S$ de Higman-Sims, $M c L$ de McLaughlin, $H J$ de Hall-Janko (também denotado por $J_{2}$ ) e $S u z$ de Suzuki. Todos estes grupos podem ser obtidos como subgrupos do grupo de automorfismos $\operatorname{Aut}\left(\Lambda_{0}\right)$ de um curioso reticulado $\Lambda_{0}$ de dimensão 24 chamado de "reticulado de Leech", que se originou a partir da teoria de empacotamento de esferas e foi estudado extensivamente por John Conway em 1969.

Um reticulado $\Lambda$ em $\mathbb{R}^{n}$ é o conjunto de todas as combinações lineares com coeficientes inteiros de $n$ vetores linearmente independentes $v_{1}, \ldots, v_{n}$, dos quais exigimos também que o produto escalar $\left(v_{i}, v_{j}\right)$ seja um inteiro para todo $1 \leqslant i, j \leqslant n .{ }^{15}$ Em particular, $\Lambda$ é um grupo abeliano. O reticulado $\Lambda$ é dito integral (racional) se existe uma base ortonormal de vetores $e_{1}, \ldots, e_{n}$ em $\mathbb{R}^{n}$ tal que as coordenadas de cada $v_{i}$ com respeito aos $e_{k}$ são números inteiros (racionais). Ademais, $\Lambda$ é dito unimodular se a matriz de mudança de base dos $e_{k}$ para os $v_{i}$ tem determinante 1 . O grupo de automorfismos $\operatorname{Aut}(\Lambda)$ de um reticulado $\Lambda \mathrm{em}$ $\mathbb{R}^{n}$ é o subgrupo do grupo de rotações de $\mathbb{R}^{n}$ que deixa $\Lambda$ invariante.

O reticulado de Leech $\Lambda_{0}$ é um reticulado racional unimodular em $\mathbb{R}^{24}$ e seu grupo de automorfismos é denotado por $C o_{0}$. Este grupo, por sua vez, é perfeito e possui um único subgrupo normal - o seu centro, que é de ordem 2. O grupo $C o_{1}$ é definido como o quociente de $C o_{0}$ pelo seu centro e portanto é um grupo simples que tem $C o_{0}$ como recobrimento duplo. Os grupos $\mathrm{Co}_{2}$ e $\mathrm{Co}_{3}$ são obtidos como subgrupos estabilizadores de certos subreticulados de $\Lambda_{0}$. Por outro lado, os grupos $H S, M c L, H J$ e $S u z$ foram originalmente descobertos e construídos de forma completamente diferente. Posteriormente, Conway notou que eles também ocorrem naturalmente como subgrupos ou subquocientes de $\mathrm{Co}_{0}$. Por exemplo, $H S$ e $M c L$ (mais precisamente, $\operatorname{Aut}(M c L)$ ) podem ser obtidos do mesmo modo que $\mathrm{Co}_{2}$ e $\mathrm{Co}_{3}$, escolhendo-se subreticulados adequados. Já os grupos $S u z$ e $H J$ (que é subgrupo de $S u z$ ) são subquocientes de $C o_{0}$. Desta forma, todos os 7 grupos estão envolvidos em $C o_{1}$. Se John Conway tivesse estudado o reticulado de Leech cinco anos antes, ele teria descoberto 7 novos grupos esporádicos, ao invés de 3.

Um fato interessante é que o grupo de Mathieu $M_{24}$ tem um papel fundamental na construção do reticulado de Leech, e por consequência, todos os outros grupos de Mathieu aparecem naturalmente como subgrupos de $C o_{0}$. Portanto, a primeira geração está incluída na segunda. Todas estas informações encontram-se, com os devidos detalhes, em [73].

A terceira geração é formada pelos 8 grupos esporádicos que estão envolvidos no Monstro, denotado por $M$. São eles: os 3 grupos de Fischer $F i_{22}, F i_{23}$ e $F i_{24}^{\prime}$, o grupo $H e$ de Held, o grupo $H N$ de Harada-Norton, o grupo $T h$ de Thompson e o grupo $B M$ de Fischer. ${ }^{16}$ Os grupos $H e, H N$, Th e $B M$ têm nomes alternativos $F_{7}, F_{5}, F_{3}$ e $F_{2}$, respectivamente,

\footnotetext{
${ }^{15}$ Em muitas instâncias, o termo "reticulado" é empregado sem esta condição de integralidade sobre os produtos escalares.

${ }^{16}$ Esta notação para o grupo de Fischer se deve ao seu apelido "Baby-Monster".
} 
pois podem ser construídos como centralizador em $M$ de classes de conjugação de ordens 7, 5, 3 e 2, respectivamente. Como $M$ é o centralizador de 1 ele também é denotado por $F_{1}$. Os grupos $F i_{22}, F i_{23}$ e $F i_{24}^{\prime}$ fazem parte de uma classe de grupos chamados grupos de 3-transposições. ${ }^{17}$ Eles ocorrem como os únicos grupos esporádicos no teorema de Fischer, que classifica os grupos finitos de 3-transposições que são aproximadamente simples [12].

Pelo fato de que o grupo $C o_{1}$ está envolvido em $M$, segue que as duas gerações anteriores também estão envolvidas em $M$. Mais informações sobre $M$ e seus "filhotes" podem ser encontradas em [71].

Os 6 grupos esporádicos restantes não estão envolvidos em $M$ e portanto não fazem parte da "Happy Family" [71, 157]: são chamados em [73] de "Parias". São eles: a "minisérie" dos 3 grupos de Janko $J_{1}, J_{3}$ e $J_{4}$, o grupo $L y$ de Lyons, o grupo $R u$ de Rudvalis e o grupo $O^{\prime} N$ de O'Nan.

Dizemos que um grupo transitivo de permutações tem posto $r$ se o subgrupo de estabilidade tem $r$ órbitas. Um grupo transitivo de permutações é 2-transitivo se e somente se tem posto 2 [10] e portanto os grupos de permutações de posto 3 são o próximo estágio além da situação $k$-transitiva. Por outro lado, sabe-se que várias classes de grupos finitos simples podem ser realizados como grupos de permutações de posto 3, como por exemplo, os grupos clássicos, os grupos alternados e simétricos e os grupos de Mathieu. No entanto, a consequência mais importante que decorre do fato de que um grupo $G$ pode ser realizado como um grupo de permutações de posto 3 é que a partir desta representação de $G$ pode-se construir um grafo $\Gamma$ de tal forma que o grupo $G$ age transitivamente nos vértices de $\Gamma$ e transforma arestas em arestas [10]. Portanto $G$ é um subgrupo de Aut $(\Gamma)$, ou em outras palavras, $G$ possui uma "geometria" natural associada. Ademais, se sabemos "a priori" que um determinado grupo é isomorfo a um grupo de permutações de posto 3, podemos em certos casos "favoráveis" construir o grupo $G$ partindo de um grafo apropriado [65].

O grupo $H J=J_{2}$, por ter uma representação permutacional de posto 3 , foi o primeiro grupo esporádico a ser construído por este método, o que motivou a procura de novos grupos esporádicos por esta abordagem. Numa rápida sucessão, formam descobertos e construídos mais 4 novos grupos esporádicos com representação permutacional de posto 3: o grupo $M c L$ de McLaughlin, o grupo $H S$ de Higman-Sims, o grupo Suz de Suzuki e o grupo $R u$ de Rudvalis. Os grupos de Fischer $F i_{22}, F i_{23}$ e $F i_{24}^{\prime}$, que já haviam sido descobertos, também foram construídos a partir de representações permutacionais de posto 3. Deste modo, vemos que o grupo $R u$ compartilha uma propriedade importante com 8 grupos da "Happy Family". Mais informações sobre grupos esporádicos com representação permutacional de posto 3 encontram-se em [73, pág. 125].

\footnotetext{
${ }^{17}$ Uma classe de conjugação $D$ de ordem 2 em um grupo é chamada uma classe de $p$-transposições, onde $p$ é um número primo impar, se o produto de quaisquer dois elementos de $D$ tem ordem 1,2 ou $p$.
} 
Por outro lado, os grupos $J_{1}, J_{3}$ e $J_{4}$, o grupo $L y$ de Lyons e o grupo $O^{\prime} N$ de O'Nan, juntamente com o grupo $H e$ de Held, o grupo de $H N$ de Harada-Norton, o grupo Th de Thompson, o grupo $B M$ de Fischer e o grupo $M$ de Fischer-Griess não possuem representações permutacionais de posto 3 e portanto não possuem nenhuma "geometria" natural associada que pudesse ser usada para construí-los. Estes grupos foram descobertos através de variações do método tradicional de Brauer de análise do centralizador de involuções [65, pág. 86], que produziu uma série de propriedades de cada um deles. A idéia básica para construí-los era usar estas propriedades para tentar mostrar que deveria existir alguma representação matricial ou permutacional do grupo em questão. Por exemplo, o grupo $J_{1}$ foi explicitamente exibido, pelo próprio Janko, como um subgrupo de $G L_{7}(11)$, gerado por duas matrizes de ordens 5 e 7 , respectivamente [65, pág. 84].

Já para a construção dos outros grupos, foi necessário o uso de computadores, dando inicio assim à teoria de grupos computacional. O pioneiro nesta área foi Charles Sims, que desenvolveu algoritmos para construir e realizar cálculos com grupos de permutações usando computadores. Com esta abordagem, foi possível construir os grupos $J_{3}, L y, O^{\prime} N$, He e $B M$ como grupos de permutações. A construção do grupo $R u$ também necessitou de alguns cálculos computacionais, devido ao grande número de elementos. Os grupos $J_{4}, H N$ e $T h$ foram construídos como grupos de matrizes sobre corpos finitos, também com o auxilio de computadores. Finalmente, o grupo $M$ construído por Robert Griess [71] numa "tour de force", como o grupo de automorfismos de uma álgebra não-associativa de dimensão 196.884, também produziu construções não-computacionais dos grupos $B M, H N$, Th e $H e$.

Atualmente, todos os grupos esporádicos já foram construídos de maneira nãocomputacional, utilizando sofisticados métodos combinatórios-geométricos [87, 88] que têm grande potencial para fornecer uma teoria capaz de descrever todos os grupos esporádicos de forma uniforme. Apesar disto, os esforços empregados nas construções computacionais resultaram em poderosos algoritmos de álgebra computacional que hoje se encontram à disposição em forma de pacotes especializados [57] e na montagem de um banco de dados com centenas de representações permutacionais e matriciais explícitas de vários grupos finitos simples, incluindo todos os grupos esporádicos. Este banco de dados, chamado "Atlas of Group Representations", funciona online através da Internet e fornece os geradores dos grupos nos formatos adequados para serem utilizados nos pacotes de álgebra computacional [160]. Assim todos os grupos esporádicos também já foram construídos computacionalmente, incluindo o Monstro que é gerado por apenas duas matrizes $196882 \times 196882$ sobre $\mathbb{F}_{2}$, que necessitam, cada uma, de aproximadamente 5 gigabytes de memória para seu armazenamento e levam 45 horas para serem multiplicadas usando todos os recursos computacionais do Lehrstuhl D für Mathematik, RWTH Aachen. ${ }^{18}$

\footnotetext{
${ }^{18}$ A dificuldade para multiplicar dois elementos do Monstro não é causada por seu tamanho e sim pela falta de representações "pequenas"; por exemplo, o grupo simétrico $S_{y} m_{50}$ é muito maior que o Monstro e no entanto precisamos de apenas alguns minutos para multiplicar dois de seus elementos manualmente.
} 


\begin{tabular}{|c|c|c|c|c|}
\hline$G$ & $|G|$ & $M(G)$ & $\operatorname{Out}(G)$ & Nome \\
\hline$M_{11}$ & $2^{4} .3^{2} .5 .11$ & 1 & 1 & Mathieu \\
\hline$M_{12}$ & $2^{6} \cdot 3^{3} \cdot 5 \cdot 11$ & $\mathbb{Z}_{2}$ & $\mathbb{Z}_{2}$ & Mathieu \\
\hline$M_{22}$ & $2^{7} \cdot 3^{2} \cdot 5 \cdot 7 \cdot 11$ & $\mathbb{Z}_{12}$ & $\mathbb{Z}_{2}$ & Mathieu \\
\hline$M_{23}$ & $2^{7} \cdot 3^{2} \cdot 5 \cdot 7 \cdot 11 \cdot 23$ & 1 & 1 & Mathieu \\
\hline$M_{24}$ & $2^{10} \cdot 3^{7} \cdot 5 \cdot 7 \cdot 11 \cdot 23$ & 1 & 1 & Mathieu \\
\hline$H J=J_{2}$ & $2^{7} \cdot 3^{3} \cdot 5^{2} \cdot 7$ & $\mathbb{Z}_{2}$ & $\mathbb{Z}_{2}$ & Hall-Janko \\
\hline Suz & $2^{13} \cdot 3^{7} \cdot 5^{2} \cdot 7 \cdot 11 \cdot 13$ & $\mathbb{Z}_{6}$ & $\mathbb{Z}_{2}$ & Suzuki \\
\hline$H S$ & $2^{9} \cdot 3^{2} \cdot 5^{3} \cdot 7 \cdot 11$ & $\mathbb{Z}_{2}$ & $\mathbb{Z}_{2}$ & Higman-Sims \\
\hline$M c L$ & $2^{7} \cdot 3^{6} \cdot 5^{3} \cdot 7 \cdot 11$ & $\mathbb{Z}_{3}$ & $\mathbb{Z}_{2}$ & McLaughlin \\
\hline $\mathrm{Co}_{3}$ & $2^{10} \cdot 3^{7} \cdot 5^{3} \cdot 7 \cdot 11 \cdot 23$ & 1 & 1 & Conway \\
\hline $\mathrm{Co}_{2}$ & $2^{18} \cdot 3^{6} \cdot 5^{3} \cdot 7 \cdot 11 \cdot 23$ & 1 & 1 & Conway \\
\hline$C o_{1}$ & $2^{21} \cdot 3^{9} \cdot 5^{4} \cdot 7^{2} \cdot 11 \cdot 13.23$ & $\mathbb{Z}_{2}$ & 1 & Conway \\
\hline$F i_{22}$ & $2^{17} \cdot 3^{9} \cdot 5^{2} \cdot 7 \cdot 11.13$ & $\mathbb{Z}_{6}$ & $\mathbb{Z}_{2}$ & Fischer \\
\hline$F i_{23}$ & $2^{18} \cdot 3^{13} \cdot 5^{2} \cdot 7 \cdot 11 \cdot 13 \cdot 17.23$ & 1 & 1 & Fischer \\
\hline$F i_{24}^{\prime}$ & $2^{21} \cdot 3^{16} \cdot 5^{2} \cdot 7^{3} \cdot 11 \cdot 13 \cdot 17 \cdot 23 \cdot 29$ & $\mathbb{Z}_{3}$ & $\mathbb{Z}_{2}$ & Fischer \\
\hline$H e=F_{7}$ & $2^{10} \cdot 3^{3} \cdot 5^{2} \cdot 7 \cdot 13.17$ & 1 & $\mathbb{Z}_{2}$ & Held \\
\hline$H N=F_{5}$ & $2^{14} \cdot 3^{6} \cdot 5^{6} \cdot 7 \cdot 11 \cdot 19$ & 1 & $\mathbb{Z}_{2}$ & Harada-Norton \\
\hline$T h=F_{3}$ & $2^{1} 5.3^{1} 0.5^{3} \cdot 7^{2} \cdot 13 \cdot 19 \cdot 31$ & 1 & 1 & Thompson \\
\hline$B M=F_{2}$ & $2^{41} .3^{13} \cdot 5^{6} \cdot 7^{2} \cdot 11 \cdot 31 \cdot 17 \cdot 19.23 .31 .47$ & $\mathbb{Z}_{2}$ & 1 & Fischer \\
\hline$M=F_{1}$ & $\begin{array}{l}2^{46} \cdot 3^{20} \cdot 5^{9} \cdot 7^{6} \cdot 11^{2} \cdot 31^{3} \cdot 17 \\
.19 .23 .29 \cdot 31.41 .47 .59 .71\end{array}$ & 1 & 1 & Fischer-Griess \\
\hline$J_{1}$ & $2^{3} \cdot 3 \cdot 5 \cdot 7 \cdot 11.19$ & 1 & 1 & Janko \\
\hline$J_{3}$ & $2^{7} .3^{5} \cdot 5.17 .19$ & 1 & 1 & Janko \\
\hline$J_{4}$ & $2^{21} \cdot 3^{3} \cdot 5 \cdot 7 \cdot 11^{3} \cdot 23 \cdot 29 \cdot 31 \cdot 37.43$ & 1 & 1 & Janko \\
\hline$R u$ & $2^{14} \cdot 3^{3} \cdot 5^{3} \cdot 7 \cdot 13 \cdot 29$ & $\mathbb{Z}_{2}$ & 1 & Rudvalis \\
\hline$O^{\prime} N$ & $2^{9} \cdot 3^{4} \cdot 5 \cdot 7^{3} \cdot 11 \cdot 19 \cdot 31$ & $\mathbb{Z}_{3}$ & $\mathbb{Z}_{2}$ & O’Nan \\
\hline Ly & $2^{8} .3^{7} .5^{6} .7 .11 .31 .37 .67$ & 1 & 1 & Lyons \\
\hline
\end{tabular}

Tabela 3.3: Grupos esporádicos. 


\subsection{Classificação dos Grupos Finitos Simples}

O teorema de classificação dos grupos finitos simples tem o seguinte enunciado.

Teorema 3.4.1 (Classificação dos Grupo Finitos Simples) Seja G um grupo finito simples. Então $G$ é um dos seguintes grupos:

(i) um grupo cíclico de ordem prima,

(ii) um grupo alternado de grau $n \geqslant 5$,

(iii) um grupo finito de tipo Lie na forma adjunta, ou

(iv) um dos 26 grupos esporádicos.

Os grupos cíclicos de ordem prima são os únicos grupos simples abelianos e são obviamente determinados pela sua ordem. No caso dos grupos finitos simples não-abelianos, temos o teorema de Artin sobre as ordens dos grupos finitos simples [5, 6, 97] que afirma que para dois grupos finitos simples não-abelianos de mesma ordem ocorre exatamente uma das seguintes possibilidades

1) eles são isomorfos;

2) um deles é $A l t_{8}$ e o outro é $P S L_{3}(4)$, que são os únicos grupos finitos simples (a menos de isomorfismos) de ordem 20.160;

3) um deles é $B_{m}(q)$ e outro é $C_{m}(q)$, com $q$ impar, que são os únicos grupos finitos simples (a menos de isomorfismos) de ordem $\frac{1}{(2, q-1)} q^{n^{2}} \prod_{i=1}^{n}\left(q^{2 i}-1\right)$;

Em outras palavras, os grupos finitos simples são determinados pela sua ordem, a menos de algumas exceções.

Neste trabalho assumiremos a classificação dos grupos simples finitos e nossa investigação será realizada no contexto dos grupos finitos simples e seus satélites. 
Capítulo 4

\section{Representações de Códons}

A tarefa de determinar todas as representações de códons dos grupos finitos simples e suas extensões é factível devido ao teorema de classificação. Dentre os quatro tipos de grupos simples, os grupos cíclicos podem ser imediatamente descartados, pois todas as suas representações irredutíveis são unidimensionais. Para os casos restantes usaremos uma série de resultados gerais sobre dimensões de representações irredutíveis que podem ser encontrados na literatura, juntamente com as tabelas de caracteres de [36], que daqui em diante será citado como o ATLAS.

Com a exceção dos grupos esporádicos, os grupos finitos simples formam famílias infinitas, parametrizadas por um número natural $n$, no caso dos grupos alternados, e por dois números naturais $n$ e $q$, ou somente um número natural $q$, com a restrição de que $q$ deve ser uma potência de um número primo, no caso das 16 famílias de grupos simples do tipo Lie. A estratégia para determinar suas representações de códons é a mesma que a usada para as álgebras de Lie simples ou para as superalgebras clássicas básicas: fundamenta-se na observação de que a dimensão $d_{1}$ da representação irredutível não-trivial de menor dimensão possível cresce com $n$ e q; uma afirmação similar vale para a "segunda menor" dimensão $d_{2}$, a "terceira menor" dimensão $d_{3}$, etc.. ${ }^{1}$ Esta afirmação é justificada por fórmulas exatas ou pelo menos por cotas inferiores ${ }^{2}$ para $d_{1}, d_{2}, d_{3}, \ldots$ como funções de $n$ e $q$ (quando aplicável), que permitem impor limites superiores em $n$ e $q$ (quando aplicável) para que o grupo finito simples relevante ou uma de suas extensões possa ter alguma representação irredutível (não-trivial) de dimensão $\leqslant 64$. Com estes cortes, ficamos com um número finito de casos que podem ser analisados explicitamente com a ajuda das tabelas de caracteres do ATLAS, levando finalmente às representações apresentadas nas tabelas 4.1 e 4.6.

\footnotetext{
${ }^{1}$ Note que é possível que existam várias representações irredutíveis inequivalentes com dimensões $d_{1}, d_{2}$, $d_{3}, \ldots$; quando isto for o caso, o número de classes de equivalência de representações de cada uma destas dimensões será denotado por $N_{1}, N_{2}, N_{3}, \ldots$.

${ }^{2}$ Observamos que o número de grupos finitos simples e suas extensões ascendentes e descendentes que admitem representações fiéis de uma dada dimensão $n$ é finito devido a um teorema clássico de Jordan [86].
} 
O restante deste capítulo será dedicado à elaboração desses argumentos com os devidos detalhes.

\subsection{Representações, Caracteres e Extensões}

Nesta seção apresentaremos algumas considerações gerais sobre representações lineares e projetivas e seus caracteres. Por fim, estudaremos o seu comportamento com relação a extensões centrais essenciais e extensões por automorfismos externos.

Como já foi explicado no Capítulo 2, a teoria de representações projetivas pode ser reduzida à teoria de representações lineares por meio de um grupo de representação que é único, a menos de isoclinismos. Além disto, as classes de equivalência de representações projetivas irredutíveis, quando levantadas a dois grupos de recobrimento isoclínicos, são relacionadas de forma simples: uma é obtida da outra multiplicando-se os operadores representantes por números complexos apropriados. Em particular, a resposta à questão se existem representações irredutíveis de uma dada dimensão não depende da escolha do grupo de representação que será usado para levantar as representações.

Uma outra simplificação surge devido ao fato de que, quando uma representação projetiva de $G$ é levantada a uma representação linear de um grupo de representação $\tilde{G}$ de $G$, esta leva o centro de $\tilde{G}$ para um subgrupo finito de $\mathbb{C}^{\times}$que é necessariamente um grupo cíclico; portanto, o quociente de $\tilde{G}$ pelo núcleo da referida representação linear é um grupo de recobrimento $M . G$ de $G$ com $M$ cíclico no qual a representação projetiva original de $G$ também pode ser levantada. Assim, através dos caracteres das representações lineares irredutíveis de $G$ e de todos os grupos de recobrimento de $G$ da forma $\mathbb{Z}_{n} \cdot G$, as tabelas do ATLAS providenciam uma completa classificação de todas as representações irredutíveis tanto lineares quanto projetivas - de $G$, para um grande número de grupos finitos simples, assim como suas extensões por grupos cíclicos de automorfismos externos.

Existe também uma relação entre as representações - tanto lineares quanto projetivas - de um grupo finito $G$ e qualquer uma de suas extensões $G$.A por automorfismos externos. O resultado principal aqui é um teorema devido a Clifford (para representações lineares) e a Mackey (para representações projetivas), baseado unicamente no fato de que $G$ é um subgrupo normal de G.A: ele afirma que uma representação irredutível de $G$.A quando restrita a $G$ se decompõe na soma direta de um certo número $r$ de cópias de uma representação de $G$ que por sua vez é a soma direta de um certo número $s$ de representações irredutíveis de $G$ que são mutuamente inequivalentes mas relacionadas pela ação de um elemento de $A$ [95]; em particular, todas estas têm a mesma dimensão $d$, o que implica que a dimensão da representação original de $G . A$ é $r s d$. Reciprocamente, isto significa que as representações irredutíveis de $G$.A são obtidas por fusão de um certo número $s$ de representações de $G$, todas da mesma dimensão $d$, mutuamente inequivalentes mas relacionadas 
pela ação de um elemento de $A$, em uma única representação de $G$ de dimensão $s d$ que, repetida com uma certa multiplicidade $r$, pode ser finalmente estendida a uma representação irredutível de $G$.A de dimensão $r s d$. O caso $r=1$ é particularmente interessante e pode ser dividido em dois subcasos:

(i) $r=1$ e $s=1$.

Isto significa que quando a representação irredutível de $G$. $A$ é restrita a $G$ ela permanece irredutível, ou reciprocamente, que a representação irredutível de $G$ pode ser estendida a uma representação irredutível de G.A. Esta extensão não é única, mas as várias extensões inequivalentes podem ser classificadas pelo grupo $\operatorname{Hom}\left(A, \mathbb{C}^{\times}\right)$de homomorfismos de $A$ em $\mathbb{C}^{\times}$[95]. No ATLAS, esta situação é denominada "split case" (cisão), no sentido que uma extensão cinde a representação de $G$ em várias representações inequivalentes de G.A.

(ii) $r=1$ e $s>1$.

Isto significa que quando a representação irredutível de $G$. $A$ é restrita a $G$ ela cinde em $s$ representações mutuamente inequivalentes relacionadas pela ação de um elemento de $A$, ou reciprocamente, que $s$ representações mutuamente inequivalentes mas relacionadas pela ação de um elemento de $A$ fundem-se em uma única representação de G.A. No ATLAS, esta situação é denominada "fusion case" (fusão).

Ademais, existem vários resultados que impõem restrições sobre os possíveis valores de $r, s$ e $d$, dependendo da estrutura de $A$. Um destes resultados é o teorema de Conlon [95, pág. 276] que afirma que se $A$ é cíclico e $s=1$, então $r=1$, e assim recaímos no "split case". No que segue nos referiremos ao caso em que $r>1$ e $s>1$ como o "generalized fusion case".

Para nossa investigação o "split case" é de menor interesse que o "fusion case", já que uma representação irredutível de $G$.A que permanece irredutível sob restrição a $G$ pode ser detectada entre as representações irredutíveis de mesma dimensão de $G$, da qual ela foi obtida por extensão. Além disso, a classificação de todas as possíveis extensões é um exercício simples: dada uma delas qualquer outra é obtida usando-se um homomorfismo de $A$ em $\mathbb{C}^{\times}$[95, pág. 295]. Considerando o "fusion case" e o " generalized fusion case", podemos afirmar em primeiro lugar que se várias representações irredutíveis de $G$ (equivalentes ou não) fundem-se em uma extensão $G . A$ de $G$ por algum grupo $A$ de automorfismos externos então elas já devem fusionar, pelo menos parcialmente, em pelo menos uma extensão $G \cdot \mathbb{Z}_{n}$ de $G$ por algum subgrupo cíclico $\mathbb{Z}_{n}$ de $A$, e esta é uma informação que pode ser lida diretamente das tabelas do ATLAS. Finalmente, mencionamos que pelo fato de estarmos interessados em determinar as representações irredutíveis de dimensão 64, surgem severas restrições sobre os três números $r, s$ e $d$ : todos devem ser potências de 2 e no "fusion case" ou "generalized fusion case" devemos ter $s \geqslant 2$. Assim, o grupo $G$ deve admitir pelo menos duas 
representações inequivalentes de dimensão $d$ que fundem-se em pelo menos uma extensão $\mathbb{Z}_{n} \cdot G$ de $G$ por algum grupo de automorfismos externos de $G$ de ordem par $n=2 m$, com $d$ assumindo um dos valores $2,4,8,16$ ou 32 .

\subsection{Grupos Esporádicos}

O caso mais fácil é o dos grupos esporádicos, cujas tabelas de caracteres estão todas no ATLAS. O resultado é que apenas um grupo esporádico se qualifica, a saber o segundo grupo de Janko $J_{2}=H J$ : ele possui duas representações projetivas pseudo-reais de códons que sob extensão pelo grupo de automorfismos $\mathbb{Z}_{2}$ de $J_{2}$ fundem-se em uma representação projetiva pseudo-real irredutível de $J_{2} \cdot \mathbb{Z}_{2}$ de dimensão 128.

\subsection{Grupos Alternados}

A teoria de representações dos grupos alternados $A l t_{n}$ e dos grupos simétricos $S_{y m}$ é apresentada em vários livros-texto e portanto vamos nos restringir a alguns comentários a respeito de aspectos relevantes aos nossos propósitos. Primeiramente, observamos que, de acordo com as tabelas de caracteres do ATLAS, os três primeiros grupos alternados $\mathrm{Alt}_{5}, \mathrm{Alt}_{6}$ e $A t_{7}$ não admitem nenhuma reprsentação de códons, e o mesmo vale para as suas extensões por automorfismos. Portanto, podemos assumir, sem perda de generalidade, que $n \geqslant 8$; isto garante que tanto o multiplicador de Schur quanto o grupo de automorfismos externos de $A l t_{n}$ são iguais a $\mathbb{Z}_{2}$ :

$$
M\left(A l t_{n}\right)=\mathbb{Z}_{2} \quad, \quad \operatorname{Out}\left(A l t_{n}\right)=\mathbb{Z}_{2} \quad \text { para } n \geqslant 8 .
$$

Em particular, $S_{y m_{n}}=A l t_{n} \cdot \mathbb{Z}_{2}$ é a extensão máxima de $A l t_{n}$ por automorfismos externos. Como já foi visto antes, as representações irredutíveis de $A l t_{n}$ e de $S y m_{n}$ são relacionadas de uma das duas seguintes formas:

(i) por cisão: é quando uma representação irredutível de $A l t_{n}$ se estende a uma representação irredutível de $\operatorname{Sym}_{n}$ (em precisamente duas formas não equivalentes), ou reciprocamente, uma representação irredutível de $S_{y m}$ permanece irredutível quando restrita a $A l t_{n}$. A relação é 1 : 2 (uma representação irredutível cinde em duas de $\left.\operatorname{Sym}_{n}\right)$.

(ii) por fusão: é quando duas representações irredutíveis de $A l t_{n}$ se fundem para formar uma única representação irredutível de $S y m_{n}$, ou reciprocamente, uma representação irredutível de $\operatorname{Sym}_{n}$ cinde em duas representações irredutíveis quando restrita a $A l t_{n}$. A relação é $2: 1$ (duas representações irredutíveis se fundem em uma de $S y m_{n}$ ). 
Exatamente a mesma situação ocorre não apenas para representações lineares mas também para representações projetivas, que podem ser levantadas a representações lineares dos grupos de recobrimento duplo 2. Alt $_{n}$ e $2 . S y m_{n}^{ \pm}$(lembremos que o último vem em duas variações isoclínicas); isto acontece porque, da mesma forma que $A l t_{n}$ é o subgrupo derivado de $S y m_{n}$, $2 . A l t_{n}$ é o subgrupo derivado de $2 . S y m_{n}^{ \pm}$.

Para poder excluir a existência de representações de códons de $A l t_{n}$ e de $S y m_{n}$ a partir de um certo valor de $n$, é conveniente distinguir entre representações lineares e projetivas.

Começando pelas representações lineares, usamos um teorema que pode ser encontrado em [124] e afirma que as três menores dimensões de representações irredutíveis de $\operatorname{Sym}_{n}$ são

$$
\begin{gathered}
d_{1}\left(\text { Sym }_{n}\right)=n-1, \\
d_{2}\left(\operatorname{Sym}_{n}\right)=\frac{1}{2} n(n-3), \\
d_{3}\left(\operatorname{Sym}_{n}\right)=\frac{1}{2}(n-1)(n-2),
\end{gathered}
$$

se $n \geqslant 14$. O único número entre estes que pode assumir os valores 64 ou 128 é $d_{1}\left(S y m_{n}\right)$, e como a representação irredutível de $S_{y m_{129}}$ de dimensão 128 permanece irredutível quando restrita a $A l t_{129}$, concluímos que não existe representação linear de códons para $A l t_{n}$ e $S y m_{n}$ quando $n \geqslant 14$, exceto se $n=65$ : este é o caso onde a representação irredutível de menor dimensão providencia uma representação real de códons de $A l t_{65}$ que por extensão pelo grupo de automorfismos externos cinde em duas representações reais de códons de $S_{y m}{ }_{65}$. O fato de que este é um grupo muito grande pode ser verificado comparando a sua ordem

$$
2^{62} \cdot 3^{30} \cdot 5^{15} \cdot 7^{10} \cdot 11^{5} \cdot 17^{3} \cdot 19^{3} \cdot 23^{3} \cdot 29^{3} \cdot 31^{2} \cdot 37 \cdot 41 \cdot 43 \cdot 47 \cdot 53 \cdot 59 \cdot 61,
$$

que é um número de ordem $\sim 10^{93}$, com

$$
2^{46} \cdot 3^{20} \cdot 5^{9} \cdot 7^{6} \cdot 11^{2} \cdot 13^{3} \cdot 17 \cdot 19 \cdot 23 \cdot 29 \cdot 31 \cdot 41 \cdot 47 \cdot 59 \cdot 71,
$$

que é a ordem do grupo Monstro, o maior dos grupos esporádicos, que é um número de ordem "apenas" $\sim 10^{55}$.

Passando para as representações projetivas, usamos um teorema que pode ser encontrado em [152] e afirma que a dimensão de qualquer representação projetiva de $A l t_{n}$ e $S y m_{n}$ é divisível por uma potência de 2 , a saber $2^{[(n-s) / 2]}$ e $2^{[(n-s-1) / 2]}$, respectivamente, onde $s$ é o número de termos na decomposição de $n$ em potências de $2\left(n=2^{\omega_{1}}+\ldots+2^{\omega_{s}}\right)$, ou em outras palavras, o número de dígitos que, na representação binária de $n$, são iguais a 1. O seguinte lema implica que não existe representação de códons para $A l t_{n}$ e $S_{y m}$ se $n \geqslant 16$.

Lema 4.3.1 O número $n-s$ (definido acima) é uma função monotonamente crescente com respeito a $n$. 
Demonstração. Suponha que $n$ está no intervalo entre, digamos, a $k$-ésima e a $(k+1)$ ésima potência de $2\left(2^{k} \leqslant n<2^{k+1}\right)$, então sua representação binária consiste de um dígito 1 seguido por $k$ dígitos que são iguais a 1 ou 0 . Assumindo primeiro que $n \neq 2^{k+1}-1$ e portanto $n+1$ está no mesmo intervalo, a passagem de $n$ para $n+1$ requer distinguir dois casos: se $n$ é par, seu último dígito será convertido de 0 para 1, então $s$ aumenta por 1 e $n-s$ permanece constante, enquanto que se $n$ é impar, seu último dígito será convertido de 1 para 0 e algum dígito anterior (o último dentre aqueles que são iguais a 0 ) será convertido de 0 para 1 , então $s$ permanece constante e $n-s$ aumenta por 1 . Finalmente, quando $n=2^{k+1}-1$, passando de $n$ para $n+1$ faz com que $s$ diminua de $k+1$ para 1 e $n-s$ aumenta de $2^{k+1}-k-2$ para $2^{k+1}-1$.

Com estes cortes, é possível obter as informações restantes das tabelas de caracteres do ATLAS ou, nos casos $n=14$ e $n=15$, dos teoremas gerais sobre a representação projetiva básica dos grupos alternados e simétricos [79], para concluir o seguinte.

- Alt 8 tem uma representação de códons linear real e uma representação de códons projetiva pseudo-real, e ambas cindem: a primeira se estende a duas representações de códons lineares reais e a segunda se estende a duas representações de códons projetivas pseudo-reais de Sym $_{8}$.

- $A l t_{10}$ tem duas representações de códons projetivas reais que se fundem em uma representação irredutível projetiva real de $S_{y m} m_{10}$ de dimensão 128.

- $A l t_{13}$ tem duas representações irredutíveis projetivas pseudo-reais de dimensão 32 que se fundem em uma representação de códons projetiva pseudo-real de $S y m_{13}$.

- $A l t_{14}$ tem uma representação de códons projetiva pseudo-real que cinde: ela se estende a um par de representações de códons projetivas complexas conjugadas de Sym $_{14}$.

- $A l t_{15}$ tem um par de representações de códons projetivas complexas conjugadas que se fundem em uma representação irredutível projetiva real de Sym $_{15}$ de dimensão 128.

Este resultado está esquematicamente apresentado na Tabela 4.1. Ele coincide essencialmente com a lista apresentada pelos autores de [96], exceto pelas representações projetivas de $A l t_{8}, S y m_{8}$ e $A l t_{10}$ que não são a básica e, provavelmente por esta razão, não aparecem em [96].

Este resultado está de acordo com [18] onde são determinados todos os grupos alternados que possuem representações lineares cuja dimensão é uma potência de um número primo e com [113] onde são determinados todos os grupos alternados de ordem < 18 que possuem representações lineares e projetivas cuja dimensão é uma potência de um número primo. 


\begin{tabular}{|cccc|}
\hline$G$ & $|G|$ & $N_{l}$ & $N_{p}$ \\
\hline Alt $_{8}$ & 20.160 & 1 & 1 \\
Alt $_{10}$ & 1.814 .400 & 0 & 2 \\
Alt $_{14}$ & 43.589 .145 .600 & 0 & 1 \\
Alt $_{15}$ & 653.837 .184 .000 & 0 & $2^{*}$ \\
Alt $_{65}$ & $65 ! / 2$ & 1 & 0 \\
\hline Sym $_{8}$ & 40.320 & 2 & 2 \\
Sym $_{13}$ & 6.227 .020 .800 & 0 & 1 \\
Sym $_{14}$ & 87.178 .291 .200 & 0 & $2^{*}$ \\
Sym $_{65}$ & $65 !$ & 2 & 0 \\
\hline
\end{tabular}

Tabela 4.1: Número de representações de códons lineares $N_{l}$ e projetivas $N_{p}$ dos grupos finitos simples: grupos alternados e grupos simétricos. (O símbolo $2^{*}$ indica um par de representações irredutíveis complexas conjugadas.)

\subsection{Grupos de Tipo Lie}

Devido aos isomorfismos execepcionais entre grupos finitos simples de ordem baixa, algumas restrições precisam ser impostas nos valores de $n$ e $q$ para excluir grupos que não são simples ou evitar repetições. Vamos explicitá-las aqui, para maior comodidade.

- $A_{1}(q): q \geqslant 7, q \neq 9$

De fato, $A_{1}(2)=$ Sym $_{3}$ e $A_{1}(3)=A l t_{4}$ são solúveis, enquanto que $A_{1}(4)=A l t_{5}$, $A_{1}(5)=A_{l} t_{5}$ e $A_{1}(9)=A l t_{6}$ já ocorreram entre os grupos alternados.

- $A_{2}(q): q \geqslant 3$

$A_{2}(2)=A_{1}(7)$ já aparece em uma série anterior.

- $A_{3}(q): q \geqslant 3$

$A_{3}(2)=A l t_{8}$ já ocorreu entre os grupos alternados. 
- $B_{2}(q): q \geqslant 3$

$B_{2}(2)=$ Sym $_{6}$ não é simples e seu subgrupo derivado (de índice 2) $B_{2}(2)^{\prime}=A_{l t}$ já ocorreu entre os grupos alternados.

- $C_{n}(q): q$ impar

Se $q$ é par e portanto uma potência de 2 , então $C_{n}(q)=B_{n}(q)$ já aparece em uma série anterior.

- ${ }^{2} A_{2}(q): q \geqslant 3$

${ }^{2} A_{2}(2)$ é solúvel.

- ${ }^{2} A_{3}(q): q \geqslant 3$

${ }^{2} A_{3}(2)=B_{2}(3)$ já aparece em uma série anterior.

- $G_{2}(q): q \geqslant 3$

$G_{2}(2)$ não é simples e seu subgrupo derivado (de índice 2) $G_{2}(2)^{\prime}={ }^{2} A_{2}(3)$ já aparece em uma série anterior.

- ${ }^{2} B_{2}(q): q \geqslant 8$

${ }^{2} B_{2}(2)$ é solúvel.

- ${ }^{2} F_{4}(q): q \geqslant 8$

${ }^{2} F_{4}(2)$ não é simples mas seu subgrupo derivado (de índice 2$)^{2} F_{4}(2)^{\prime}$ é um grupo simples e não faz parte de nunhuma outra série de grupos de tio Lie.

- ${ }^{2} G_{2}(q): q \geqslant 27$

${ }^{2} G_{2}(3)$ não é simples e seu subgrupo derivado (de índice 3$)^{2} G_{2}(3)^{\prime}=A_{1}(8)$ já aparece em uma série anterior.

No que segue, vamos primeiro aplicar as fórmulas das Tabelas 4.2-4.4 para determinar os grupos $G$ para os quais $d_{1}(G) \leqslant 64$, pois se $d_{1}(G)>64$, nem $G$ nem suas extensões por automorfismos externos possuem representações de códons. Dado que $d_{1}(G)$ é um polinômio em $q$ cujos expoentes são funções afins de $n$, uma desigualdade do tipo $d_{1}(G) \leqslant N$, onde $N$ é um número natural dado, impõe limites superiores em $q$ e em $n$, e então o conjunto de grupos a serem analisados é finito. Uma exigência mais forte é a de que $G$ tenha representações irredutíveis de dimensão $2^{k}$ onde $k$ assume os valores $1,2,3,4,5,6$, pois como foi mostrado na seção 2 , esta é uma condição necessária para que $G$ admita alguma extensão por automorfismos externos que tenha representações de códons.

Como veremos, isto reduz drasticamente o número de casos que devem ser analisados em detalhe. De fato, a maior parte dos casos pode ser resolvido consultando-se as tabelas de caracteres do ATLAS, enquanto que para os casos restantes, não cobertos pelo ATLAS, as informações necessárias podem ser obtidas da Tabela 4.5 que apresenta as três menores dimensões de representações irredutíveis. 


\begin{tabular}{|c|c|c|c|}
\hline$G$ & $d_{1}(G)$ & $N_{1}(G)$ & Condições \\
\hline$A_{1}(q)$ & $\begin{array}{c}q-1 \\
\frac{1}{2}(q-1) \\
3\end{array}$ & $\begin{array}{c}q / 2 \\
2 \\
4\end{array}$ & $\begin{array}{c}q \text { par, } q \geqslant 8 \\
q \text { impar, } q \neq 9 \\
\text { para } q=9\end{array}$ \\
\hline$A_{n}(q)(n \geqslant 2)$ & $\begin{array}{c}\frac{q\left(q^{n}-1\right)}{q-1} \\
26 \\
6\end{array}$ & $\begin{array}{l}1 \\
2 \\
6\end{array}$ & $\begin{array}{l}q \neq 2,3 \text { se } n=3 \\
q \neq 2,4 \text { se } n=2 \\
\text { para } n=3, q=3 \\
\text { para } n=2, q=4\end{array}$ \\
\hline$B_{2}(q)$ & $\begin{array}{l}\frac{1}{2} q(q-1)^{2} \\
\frac{1}{2}\left(q^{2}-1\right)\end{array}$ & $\begin{array}{l}1 \\
2\end{array}$ & $\begin{array}{c}q \text { par, } q \geqslant 4 \\
q \text { impar }\end{array}$ \\
\hline$B_{n}(q)(n \geqslant 3)$ & $\frac{q\left(q^{n-1}-1\right)\left(q^{n}-1\right)}{2(q+1)}$ & 1 & $\begin{array}{c}q \text { par, com } \\
q \geqslant 4 \text { se } n=3 \\
\text { para } n=3, q=2\end{array}$ \\
\hline$B_{n}(q)(n \geqslant 3)$ & $\begin{array}{c}\frac{q^{2 n}-1}{q^{2}-1} \\
\frac{q\left(q^{n-1}-1\right)\left(q^{n}-1\right)}{q^{2}-1} \\
27\end{array}$ & $\begin{array}{l}1 \\
2\end{array}$ & $\begin{array}{c}q \text { impar, } q \geqslant 5 \\
\text { para } n \geqslant 4, q=3 \\
\text { para } n=3, q=3\end{array}$ \\
\hline$C_{n}(q)(n \geqslant 3)$ & $\frac{1}{2}\left(q^{n}-1\right)$ & 2 & $q$ impar \\
\hline$D_{n}(q)(n \geqslant 4)$ & $\begin{array}{c}\frac{q\left(q^{n-2}+1\right)\left(q^{n}-1\right)}{q^{2}-1} \\
\frac{\left(q^{n-1}-1\right)\left(q^{n}-1\right)}{q^{2}-1} \\
260 \\
8\end{array}$ & $\begin{array}{l}2 \\
1 \\
6 \\
3\end{array}$ & $\begin{array}{ll} & q \geqslant 4 \\
& \\
\text { para } & n \geqslant 5, q=3 \\
\text { para } & n \geqslant 5, q=2 \\
\text { para } & n=4, q=3 \\
\text { para } & n=4, q=2\end{array}$ \\
\hline
\end{tabular}

Tabela 4.2: Dimensões mínimas e números de representações irredutíveis, lineares ou projetivas, para os grupos finitos de Chevalley não-torcidos (cf. Tabela II da Ref. [145]). 


\begin{tabular}{|c|c|c|c|}
\hline G & $d_{1}(G)$ & $N_{1}(G)$ & Condições \\
\hline${ }^{2} A_{n}(q)(n \geqslant 2)$ & $\begin{array}{l}\frac{q\left(q^{n}-1\right)}{q+1} \\
\frac{q^{n+1}-1}{q+1} \\
6\end{array}$ & $\begin{array}{l}q \\
4\end{array}$ & $\begin{array}{c}n \text { par, com } \\
q \geqslant 3 \text { se } n=2 \\
n \text { impar, com } \\
q \geqslant 4 \text { se } n=3 \\
\text { para } n=3, q=3\end{array}$ \\
\hline${ }^{2} D_{n}(q)(n \geqslant 4)$ & $\frac{q\left(q^{n-2}-1\right)\left(q^{n}+1\right)}{q^{2}-1}$ & 1 & \\
\hline
\end{tabular}

Tabela 4.3: Dimensões mínimas e números de representações irredutíveis, lineares ou projetivas, para os grupos finitos de Chevalley torcidos clássicos (cf. Tabela II da Ref. [145]).

\begin{tabular}{|c|c|c|}
\hline$G$ & $b(G)$ & Condições \\
\hline \hline$E_{6}(q)$ & $q^{9}\left(q^{2}-1\right)$ & \\
\hline$E_{7}(q)$ & $q^{15}\left(q^{2}-1\right)$ & \\
\hline$E_{8}(q)$ & $q^{27}\left(q^{2}-1\right)$ & \\
\hline$F_{4}(q)$ & $\frac{1}{2} q^{7}\left(q^{3}-1\right)(q-1)$ & $q$ par, $q \geqslant 4$ \\
\hline$G_{2}(q)$ & $q^{6}\left(q^{2}-1\right)$ & $q$ impar \\
\hline${ }^{2} E_{6}(q)$ & $q\left(q^{2}-1\right)$ & $q \geqslant 5$ \\
\hline${ }^{3} D_{4}(q)$ & $q^{9}\left(q^{2}-1\right)$ & \\
\hline${ }^{2} B_{2}(q)$ & $\sqrt{q / 2}(q-1)$ & $q=2^{2 l+1}, q \geqslant 32$ \\
\hline${ }^{2} F_{4}(q)$ & $\sqrt{q / 2} q^{4}(q-1)$ & $q=2^{2 l+1}, q \geqslant 8$ \\
\hline${ }^{2} G_{2}(q)$ & $q(q-1)$ & $q=3^{2 l+1}, q \geqslant 27$ \\
\hline
\end{tabular}

Tabela 4.4: Cotas inferiores para as dimensões de representações irredutíveis, lineares ou projetivas, para os grupos finitos de Chevalley não-clássicos (cf. Tabela I da Ref. [99]) 


\begin{tabular}{|c|c|c|c|c|}
\hline$G$ & $|G|$ & $d_{1}(G)$ & $d_{2}(G)$ & $d_{3}(G)$ \\
\hline \hline$A_{5}(2)=P S L_{6}(2)$ & 20.158 .709 .760 & 62 & 217 & 588 \\
$B_{2}(7)=P S p_{4}(7)$ & 138.297 .600 & 24 & 25 & 126 \\
$B_{2}(9)=P S p_{4}(9)$ & 1.721 .606 .400 & 40 & 41 & 288 \\
$B_{2}(11)=P S p_{4}(11)$ & 12.860 .654 .400 & 60 & 61 & 550 \\
$C_{3}(5)=P S p_{6}(5)$ & 228.501 .000 .000 .000 & 62 & 63 & 1240 \\
$C_{4}(3)=P S p_{8}(3)$ & 65.784 .756 .654 .489 .600 & 40 & 41 & 780 \\
${ }^{2} A_{3}(4)=P S U_{4}(4)$ & 1.018 .368 .000 & 51 & 52 & 221 \\
${ }^{2} A_{4}(3)=P S U_{5}(3)$ & 258.190 .571 .520 & 60 & 61 & 549 \\
${ }^{2} A_{6}(2)=P S U_{7}(2)$ & 227.787 .103 .272 .960 & 42 & 43 & 860 \\
\hline
\end{tabular}

Tabela 4.5: Três menores dimensões de representações irredutíveis, lineares ou projetivas, de alguns grupos clássicos (extraídas das Tabelas da Ref. [145]).

Feitas estas observações gerais, procederemos com a análise dos casos individuais. Começaremos investigando quais grupos finitos de tipo Lie possuem representações de códons, ou mais geralmente representações irredutíveis de dimensão $2^{k}$ onde $k$ assume um dos valores 1, 2, 3, 4, 5, 6. Em uma segunda etapa vamos analisar o que acontece com estas representações sob extensões por automorfismos externos.

- $A_{1}(q)(q \geqslant 7, q \neq 9)$ :

De acordo com a Tabela 4.2 , temos que $d_{1}\left(A_{1}(q)\right) \leqslant 64$ se e somente se $q \leqslant 64$ quando $q$ é par ou $q \leqslant 129$ quando $q$ é impar. Informações adicionais podem ser obtidas das tabelas genéricas de caracteres de $A_{1}(q)$ encontradas em [85, 116].

1) Se $q$ é par, então $q=2^{f}, A_{1}(q)$ tem multiplicador de Schur trivial e grupo de automorfismos externos $\mathbb{Z}_{f}$. Neste caso, $A_{1}(q)$ tem precisamente

- q/2 representações irredutíveis de dimensão $q-1$,

- 1 representação irredutível de dimensão $q$,

- q/2 - 1 representações irredutíveis de dimensão $q+1$, 
Isto mostra, em primeiro lugar, que existe apenas um valor par de $q, q=64$, para o qual $A_{1}(q)$ admite uma representação de códons. Para outros valores de $q$, ainda temos que considerar a possibilidade de obter uma representação de códons de alguma extensão de $A_{1}(q)$ por automorfismos externos, fusionando um certo número de representações irredutíveis de dimensão $r$ onde $r$ é $q-1$ ou $q+1$. É claro que isto obriga $r$ a ser um dos números 2, 4, 8, 16 ou 32 e portanto as possibilidades $r=q-1$ e $r=q+1$ estão descartadas. Tendo em vista que o grupo de automorfismos externos e todos os seus subgrupos são cíclicos, concluímos, pelo teorema de Conlon, que o resultado desejado só pode ser obtido fusionando várias representações irredutíveis inequivalentes de dimensão $q$ com $q$ assumindo um dos valores 8, 16, 32. Mas isto é impossível, pois existe apenas uma tal representação.

2) Se $q$ é impar, então $q=p^{f}$ onde $p$ é um número primo impar, $A_{1}(q)$ tem multiplicador de Schur $\mathbb{Z}_{2}$ e grupo de automorfismos externos $\mathbb{Z}_{2} \times \mathbb{Z}_{f}$. Neste caso, $A_{1}(q)$ tem precisamente

- 2 representações irredutíveis de dimensão $(q-1) / 2$,

- 2 representações irredutíveis de dimensão $(q+1) / 2$,

- $(q-1) / 2$ representações irredutíveis de dimensão $q-1$,

- 1 representação irredutível de dimensão $q$,

- $(q-3) / 2$ representações irredutíveis de dimensão $q+1$.

Isto mostra, em primeiro lugar, que existe apenas um valor impar de $q, q=127$, para o qual $A_{1}(q)$ admite uma representação de códons, que é projetiva. (De fato, outros valores para $q$ tais como 129, 65 ou 63 são proibidos pela condição de que $q$ deve ser uma potência de um número primo.) Para outros valores de $q$, ainda temos que considerar a possibilidade de obter uma representação de códons de alguma extensão de $A_{1}(q)$ por automorfismos externos, fusionando um certo número de representações irredutíveis de dimensão $r$ onde $r$ é $(q-1) / 2$ ou $(q+1) / 2$ ou $q-1$ ou $q$ ou $q+1$. É claro que isto obriga $r$ a ser um dos números $2,4,8,16$ ou 32 e portanto a possibilidade $r=q$ está descartada. Tendo em vista que $q$ deve ser uma potência de um número primo tal que $q \geqslant 7$ e $q \neq 9$, existem precisamente três soluções: $q=7, q=17$ e $q=31$. Todos estes valores para $q$ são números primos e portanto o grupo de automorfismos externos correspondente é o grupo cíclico $\mathbb{Z}_{2}$ o que, de acordo com o teorema de Conlon, implica que o resultado desejado só pode ser obtido fusionando duas representações irredutíveis inequivalentes de dimensão 32. Agora, as tabelas de caracteres do ATLAS mostram que $A_{1}(7)$ e $A_{1}(17)$ não possuem representações irredutíveis de dimensão 32 , enquanto que $A_{1}(31)$ possui várias delas, que porém são todas cindidas sob extensão a $A_{1}(31) \cdot \mathbb{Z}_{2}$. 
- $A_{n}(q)(n \geqslant 2)$ :

1) $n=2, q \geqslant 3$ :

De acordo com a Tabela 4.2 , temos que $d_{1}\left(A_{2}(q)\right) \leqslant 64$ se e somente se $q \leqslant 7$. De acordo com o ATLAS, $A_{2}(7)$ e $A_{2}(5)$ não possuem representações irredutíveis de dimensão $2^{k}$ com $1 \leqslant k \leqslant 6$. $A_{2}(4)$ possui 16 representações de códons, uma linear e 15 projetivas, além de duas representações irredutíveis de dimensão 8 que, sob extensão por algum subgrupo cíclico de seu grupo de automorfismos externos $D_{12}$, ou cindem ou fundem-se em uma representação irredutível de dimensão 16. Finalmente, $A_{2}(3)$ (cujo multiplicador de Schur é trivial) possui 4 representações irredutíveis de dimensão 16 que, sob extensão por seu grupo de automorfismos externos $\mathbb{Z}_{2}$, fundem-se em duas representações irredutíveis de dimensão 32.

2) $n=3, q \geqslant 3$ :

De acordo com a Tabela 4.2 , temos que $d_{1}\left(A_{3}(q)\right) \leqslant 64$ se e somente se $q=3$. De acordo com o ATLAS, $A_{3}(3)$ não possui representações irredutíveis de dimensão $2^{k}$ com $1 \leqslant k \leqslant 6$.

3) $n=4$ :

De acordo com a Tabela 4.2 , temos que $d_{1}\left(A_{4}(q)\right) \leqslant 64$ se e somente se $q=2$. De acordo com o ATLAS, $A_{4}(2)$ não possui representações irredutíveis de dimensão $2^{k}$ com $1 \leqslant k \leqslant 6$.

4) $n=5$ :

De acordo com a Tabela 4.2 , temos que $d_{1}\left(A_{5}(q)\right) \leqslant 64$ se e somente se $q=2$. De acordo com a Tabela $4.5, A_{5}(2)$ não possui representações irredutíveis de dimensão $2^{k}$ com $1 \leqslant k \leqslant 6$.

5) $n \geqslant 6$ :

De acordo com a Tabela 4.2 , temos que $d_{1}\left(A_{n}(q)\right)>64$ quando $n \geqslant 6$, para todos os valores de $q$.

- $B_{2}(q)(q \geqslant 3)$ :

De acordo com a Tabela 4.2 , temos que $d_{1}\left(B_{2}(q)\right) \leqslant 64$ se e somente se $q=4$ quando $q$ é par ou $q \leqslant 11$ quando $q$ é impar. Ademais, de acordo com a Tabela $4.5, B_{2}(11), B_{2}(9)$ e $B_{2}(7)$ não possuem representações irredutíveis de dimensão $2^{k}$ com $1 \leqslant k \leqslant 6$, e de acordo com o ATLAS, o mesmo é verdade para $B_{2}(5)$ e $B_{2}(4)$, enquanto que $B_{2}(3)$ tem duas representações de códons, uma linear e uma projetiva, além de duas representações irredutíveis de dimensão 4 que, sob extensão pelo seu grupo de automorfismos externos $\mathbb{Z}_{2}$, fundem-se em uma representação irredutível de dimensão 8. 
- $B_{n}(q)(n \geqslant 3, q$ par):

1) $n=3$ :

De acordo com a Tabela 4.2 , temos que $d_{1}\left(B_{3}(q)\right) \leqslant 64$ se e somente se $q=2$.

De acordo com o ATLAS, $B_{3}(2)$ possui duas representações de códons, ambas projetivas, além de uma representação irredutível de dimensão 8.

2) $n=4$ :

De acordo com a Tabela 4.2 , temos que $d_{1}\left(B_{4}(q)\right) \leqslant 64$ se e somente se $q=2$. De acordo com o ATLAS, $B_{4}(2)$ não possui representações irredutíveis de dimensão $2^{k} \operatorname{com} 1 \leqslant k \leqslant 6$.

3) $n \geqslant 5$ :

De acordo com a Tabela 4.2, temos que $d_{1}\left(B_{n}(q)\right)>64$ quando $n \geqslant 5$, para todos os valores pares de $q$.

- $B_{n}(q)(n \geqslant 3, q$ impar):

1) $n=3$ :

De acordo com a Tabela 4.2 , temos que $d_{1}\left(B_{3}(q)\right) \leqslant 64$ se e somente se $q=3$. De acordo com o ATLAS, $B_{3}(3)$ não possui representações irredutíveis de dimensão $2^{k} \operatorname{com} 1 \leqslant k \leqslant 6$.

2) $n \geqslant 4:$

De acordo com a Tabela 4.2, temos que $d_{1}\left(B_{n}(q)\right)>64$ quando $n \geqslant 4$, para todos os valores impares de $q$.

- $C_{n}(q)(n \geqslant 3, q$ impar):

1) $n=3$ :

De acordo com a Tabela 4.2 , temos que $d_{1}\left(C_{3}(q)\right) \leqslant 64$ se e somente se $q \leqslant 5$. De acordo com a Tabela $4.5, C_{3}(5)$ não possui representações irredutíveis de dimensão $2^{k}$ com $1 \leqslant k \leqslant 6$ e de acordo com o ATLAS o mesmo vale para $C_{3}(3)$.

2) $n=4$ :

De acordo com a Tabela 4.2 , temos que $d_{1}\left(C_{4}(q)\right) \leqslant 64$ se e somente se $q=3$. De acordo com a Tabela $4.5, C_{4}(3)$ não possui representações irredutíveis de dimensão $2^{k}$ com $1 \leqslant k \leqslant 6$.

3) $n \geqslant 5$ :

De acordo com a Tabela 4.2, temos que $d_{1}\left(C_{n}(q)\right)>64$ quando $n \geqslant 5$, para todos os valores impares de $q$. 
- $D_{n}(q)(n \geqslant 4)$ :

1) $n=4:$

De acordo com a Tabela 4.2 , temos que $d_{1}\left(D_{4}(q)\right) \leqslant 64$ se e somente se $q=2$. De acordo com o ATLAS, $D_{4}(2)$ não possui representações irredutíveis de dimensão $2^{k}$ com $1 \leqslant k \leqslant 6$, execeto por uma representação irredutível de dimensão 8 .

2) $n \geqslant 5$ :

De acordo com a Tabela 4.2, temos que $d_{1}\left(D_{n}(q)\right)>64$ quando $n \geqslant 5$, para todos os valores de $q$.

- ${ }^{2} A_{n}(q)(n \geqslant 2)$ :

1) $n=2, q \geqslant 3:$

De acordo com a Tabela 4.3 , temos que $d_{1}\left({ }^{2} A_{2}(q)\right) \leqslant 64$ se e somente se $q \leqslant 8$. De acordo com o ATLAS, ${ }^{2} A_{2}(8),{ }^{2} A_{2}(7)$ e ${ }^{2} A_{2}(5)$ não possuem representações irredutíveis de dimensão $2^{k}$ com $1 \leqslant k \leqslant 6 .{ }^{2} A_{2}(4)$ (cujo multiplicador de Schur é trivial) possui uma representação de códons. Finalmente, ${ }^{2} A_{2}(3)$ (cujo multiplicador de Schur é trivial) possui duas representações irredutíveis de dimensão 32 que, sob extensão por seu grupo de automorfismos externos $\mathbb{Z}_{2}$, fundem-se em uma representação de códons.

2) $n=3, q \geqslant 3$ :

De acordo com a Tabela 4.3 , temos que $d_{1}\left({ }^{2} A_{3}(q)\right) \leqslant 64$ se e somente se $q \leqslant 4$. De acordo com a Tabela $4.5,{ }^{2} A_{3}(4)$ não possui representações irredutíveis de dimensão $2^{k}$ com $1 \leqslant k \leqslant 6$ e de acordo com o ATLAS o mesmo vale para ${ }^{2} A_{3}(3)$.

3) $n=4$ :

De acordo com a Tabela 4.3 , temos que $d_{1}\left({ }^{2} A_{4}(q)\right) \leqslant 64$ se e somente se $q \leqslant 3$. De acordo com a Tabela $4.5,{ }^{2} A_{4}(3)$ não possui representações irredutíveis de dimensão $2^{k}$ com $1 \leqslant k \leqslant 6$ e de acordo com o ATLAS o mesmo vale para ${ }^{2} A_{4}(2)$.

4) $n=5$ :

De acordo com a Tabela 4.3, temos que $d_{1}\left({ }^{2} A_{5}(q)\right) \leqslant 64$ se e somente se $q=2$. De acordo com o ATLAS, ${ }^{2} A_{5}(2)$ não possui representações irredutíveis de dimensão $2^{k} \operatorname{com} 1 \leqslant k \leqslant 6$.

5) $n=6$ :

De acordo com a Tabela 4.3, temos que $d_{1}\left({ }^{2} A_{6}(q)\right) \leqslant 64$ se e somente se $q=2$. De acordo com a Tabela $4.5,{ }^{2} A_{6}(2)$ não possui representações irredutíveis de dimensão $2^{k}$ com $1 \leqslant k \leqslant 6$. 
6) $n \geqslant 7$ :

De acordo com a Tabela 4.3, temos que $d_{1}\left({ }^{2} A_{n}(q)\right)>64$ quando $n \geqslant 7$, para todos os valores de $q$.

- ${ }^{2} D_{n}(q)(n \geqslant 4)$ :

1) $n=4$ :

De acordo com a Tabela 4.3 , temos que $d_{1}\left({ }^{2} D_{5}(q)\right) \leqslant 64$ se e somente se $q=2$.

De acordo com o ATLAS, ${ }^{2} D_{4}(2)$ não possui representações irredutíveis de dimensão $2^{k} \operatorname{com} 1 \leqslant k \leqslant 6$.

2) $n \geqslant 5:$

De acordo com a Tabela 4.3, temos que $d_{1}\left({ }^{2} D_{n}(q)\right)>64$ quando $n \geqslant 5$, para todos os valores de $q$.

- $E_{n}(q)(n=6,7,8),{ }^{2} E_{6}(q)$ :

De acordo com a Tabela 4.4, estes grupos não possuem representações irredutíveis de dimensão $2^{k}$ com $1 \leqslant k \leqslant 6$.

- $F_{4}(q)$ :

De acordo com a Tabela 4.4, temos que $d_{1}\left(F_{4}(q)\right)>64$ quando $q \geqslant 3$. De acordo com o ATLAS, $F_{4}(2)$ não possui representações irredutíveis de dimensão $2^{k}$ com $1 \leqslant k \leqslant 6$.

- $G_{2}(q)(q \geqslant 3)$ :

De acordo com a Tabela 4.4 , temos que $d_{1}\left(G_{2}(q)\right)>64$ quando $q \geqslant 5$. De acordo com o ATLAS, $G_{2}(4)$ não possui representações irredutíveis de dimensão $2^{k}$ com $1 \leqslant k \leqslant 6$, enquanto que $G_{2}(3)$ possui duas representações de códons, ambas lineares.

- ${ }^{3} D_{4}(q)$ :

De acordo com a Tabela 4.4 , temos que $d_{1}\left({ }^{3} D_{4}(q)\right)>64$ quando $q \geqslant 3$. De acordo com o ATLAS, ${ }^{3} D_{4}(2)$ não possui representações irredutíveis de dimensão $2^{k}$ com $1 \leqslant k \leqslant 6$.

- ${ }^{2} B_{2}(q)\left(q=2^{2 l+1}\right.$ com $\left.l \geqslant 1\right)$ :

De acordo com a Tabela 4.4 , temos que $d_{1}\left({ }^{2} B_{2}(q)\right)>64$ quando $q \geqslant 32$. De acordo com o ATLAS, ${ }^{2} B_{2}(8)$ possui 4 representações de códons, uma linear e três projetivas.

- ${ }^{2} F_{4}(q)\left(q=2^{2 l+1} \operatorname{com} l \geqslant 1\right)$ :

De acordo com a Tabela 4.4, temos que $d_{1}\left({ }^{2} F_{4}(q)\right)>64$ quando $q \geqslant 8$. De acordo com o ATLAS, ${ }^{2} F_{4}(2)$ e o grupo de Tits ${ }^{2} F_{4}(2)^{\prime}$ não possuem representações irredutíveis de dimensão $2^{k}$ com $1 \leqslant k \leqslant 6$. 
- ${ }^{2} G_{2}(q)\left(q=3^{2 l+1} \operatorname{com} l \geqslant 1\right)$ :

De acordo com a Tabela 4.4, estes grupos não possuem representações irredutíveis de dimensão $2^{k}$ com $1 \leqslant k \leqslant 6$.

Passando para a segunda etapa, argumentamos como segue.

- $G=A_{1}(64)=P S L_{2}(64)$ :

O multiplicador de Schur de $G$ é trivial e o seu grupo de automorfismos externos é $\mathbb{Z}_{6}$. Em particular, $G$ é igual a $S L_{2}(64)$. Sua representação de códons identificada anteriormente é real e, por consequência do teorema de Conlon, deve cindir sob extensão por qualquer subgrupo cíclico de $\operatorname{Out}(G)$ : mais precisamente, ela se estende a duas representações reais de $G . \mathbb{Z}_{2}$, a uma representação real mais um par de representações complexas conjugadas de $G . \mathbb{Z}_{3}$ e duas representações reais mais dois pares de representações complexas conjugadas de $G \cdot \mathbb{Z}_{6}$.

- $G=A_{1}(127)=P S L_{2}(127)$ :

O multiplicador de Schur de $G$ é $\mathbb{Z}_{2}$ e o seu grupo de automorfismos externos é $\mathbb{Z}_{2}$. Em particular, o recobrimento universal de $G$ é $S L_{2}(127)$. Suas representações de códons identificadas anteriormente formam um par de representações projetivas complexas conjugadas que sob extensão por seu grupo de automorfismos externos $\mathbb{Z}_{2}$ fundem-se em uma representação projetiva real irredutível de $G \cdot \mathbb{Z}_{2}$ de dimensão 128 : isto segue do fato de que o automorfismo externo de $G$, que pode ser representado por conjugação pela matriz

$$
\left(\begin{array}{cc}
1 & 0 \\
0 & 126
\end{array}\right),
$$

permuta os caracteres destas duas representações, o que pode ser deduzido a partir das tabelas genéricas de caracteres de [85].

- $G=A_{2}(4)=P S L_{3}(4)$ :

O multiplicador de Schur de $G$ é $\mathbb{Z}_{3} \times \mathbb{Z}_{4} \times \mathbb{Z}_{4}$ e o seu grupo de automorfismos externos é $D_{12}$. Devido ao tamanho de $M(G)$ e de $\operatorname{Out}(G)$ este é o caso mais complicado a ser analisado. As informações necessárias para esta análise podem ser lidas no ATLAS, mas isto requer, como pré-requisito, um entendimento de quais são os quocientes cíclicos $M$ de $M(G)$, quais são os subgrupos cíclicos $A$ de $\operatorname{Out}(G)$ e finalmente quais extensões bicíclicas M.G.A são bem definidas. 
- Quocientes cíclicos de $M(G)$ :

O grupo $\mathbb{Z}_{3} \times \mathbb{Z}_{4} \times \mathbb{Z}_{4}$ possui 30 subgrupos dos quais 19 fornecem quocientes cíclicos. No ATLAS os quocientes cíclicos de $M(G)$ são denotados por $2,2^{\prime}, 2^{\prime \prime}$, $3,4_{1}, 4_{1}^{\prime}, 4_{1}^{\prime \prime}, 4_{2}, 4_{2}^{\prime}, 4_{2}^{\prime \prime}, 6,6^{\prime}, 6^{\prime \prime}, 12_{1}, 12_{1}^{\prime}, 12_{1}^{\prime \prime}, 12_{2}, 12_{2}^{\prime}, 12_{2}^{\prime \prime}$. Nesta notação, um número $N$ indica o grupo cíclico $\mathbb{Z}_{N}$ de ordem $N$, o índice inferior enumera famílias de quocientes cíclicos e o índice superior indica os membros individuais de cada família, que são quocientes por subgrupos permutados por um automorfismo externo de ordem 3.

- Subgrupos cíclicos de $\operatorname{Out}(G)$ :

O grupo $D_{12}$ é solúvel e tem 16 subgrupos. Dentre estes, 5 são normais, sendo um do tipo $\mathbb{Z}_{2}$, um do tipo $\mathbb{Z}_{3}$, um do tipo $\mathbb{Z}_{6}$ e dois do tipo $S y m_{3}$. O subgrupo de tipo $\mathbb{Z}_{2}$ é o centro de $D_{12}$. Dentre os subgrupos não-normais de $D_{12}$ há 6 subgrupos de ordem 2 que formam duas classes de conjugação e estes são os únicos subgrupos cíclicos não-normais de $D_{12}$. Então $D_{12}$ tem ao todo 9 subgrupos cíclicos que no ATLAS são denotados por $2_{1}, 2_{2}, 2_{2}^{\prime}, 2_{2}^{\prime \prime}, 2_{3}, 2_{3}^{\prime}, 2_{3}^{\prime \prime}, 3$ e 6 . Nesta notação, um número $N$ indica o grupo cíclico $\mathbb{Z}_{N}$ de ordem $N ; 2_{1}$ é o subgrupo central. O índice inferior indica uma classe de conjugação de subgrupos e, dentro de uma classe de conjugação, os grupos são distinguidos pelo índice superior.

- Extensões bicíclicas M.G.A de G:

De acordo com o ATLAS, extensões bicíclicas M.G.A de $G$ existem

(i) quando $M$ é trivial ou isomorfo a $\mathbb{Z}_{3}$; neste caso, $A$ pode ser qualquer subgrupo cíclico de $\operatorname{Out}(G)$.

(ii) quando $A$ é trivial ou isomorfo a $\mathbb{Z}_{2}$; neste caso, $M$ pode ser qualquer quociente cíclico de $M(G)$ se $A$ for o $\mathbb{Z}_{2}$ central.

Agora podemos usar as tabelas de caracteres do ATLAS para determinar o comportamento das várias representações de códons de $G$ sob extensão por um dos subgrupos cíclicos $A$ de $\operatorname{Out}(G)$ descritos acima. Em primeiro lugar, observa-se que a representação linear é real e cinde sob extensão por qualquer subgrupo cíclico $A \operatorname{de} \operatorname{Out}(G)$ : mais precisamente, ela se estende a duas representações reais de $G . \mathbb{Z}_{2}$ (onde $\mathbb{Z}_{2}$ indica qualquer um dos sete subgrupos cíclicos de ordem 2 de Out $(G)$ ), a uma representação real mais um par de representações complexas conjugadas de $G \cdot \mathbb{Z}_{3}$ e a duas representações reais mais dois pares de representações complexas conjugadas de $G . \mathbb{Z}_{6}$. Passando às 15 representações projetivas, três delas são reais e as outras 12 formam 6 pares de representações complexas conjugadas. Cada uma das três representações reais pode ser levantada a exatamente um dos três recobrimentos duplos $\mathbb{Z}_{2} \cdot G$ de $G$ (onde $\mathbb{Z}_{2}$ indica qualquer um dos três quocientes cíclicos de ordem 2 de $M(G)$ ) e cada uma destas representações cinde sob extensão por exatamente três dos 7 subgrupos cíclicos 
$A$ de ordem 2 de $\operatorname{Out}(G)$, a saber o central e um dos três membros de cada classe de conjugação, estendendo-se a duas representações reais de $\mathbb{Z}_{2} . G$.A; com respeito aos 4 subgrupos restantes, não existe a extensão bicíclica M.G.A correspondente. Do mesmo modo, cada um dos 6 pares de representações complexas conjugadas pode ser levantada a exatamente um dos 6 recobrimentos quádruplos $\mathbb{Z}_{4} \cdot G$ de $G$ (onde $\mathbb{Z}_{4}$ indica qualquer um dos 6 quocientes cíclicos de ordem 4 de $M(G)$ ) e cada um destes pares de representações fusiona em uma representação real de dimensão 128 de $\mathbb{Z}_{4} \cdot G \cdot A$ se $A$ é o centro de $\operatorname{Out}(G)$. Por outro lado, cada um destes 6 pares cinde, formando dois pares de representações complexas conjugadas, sob extensão por exatamente um dos 6 subgrupos cíclicos não-centrais $A$ de ordem $2 \operatorname{de} \operatorname{Out}(G)$; com respeito aos 5 subgrupos restantes, ainda existe um para o qual o par de representações complexas conjugadas fusiona sob extensão em uma representação real de dimensão 128 , enquanto que para os 4 restantes, não existe a extensão bicíclica M.G.A correspondente. Finalmente, nenhuma das representações projetivas de $G$ admite extensão a $G$. $A$ onde $A$ tem ordem 3 ou 6 - de acordo com o fato de que as extensões bicíclicas M.G.A correspondentes não existem quando $M$ tem ordem 2 ou 4.

- $G=B_{2}(3)=C_{2}(3)={ }^{2} A_{2}(3)$ :

O multiplicador de Schur de $G$ é $\mathbb{Z}_{2}$ e o seu grupo de automorfismos externos é $\mathbb{Z}_{2}$. Suas representações de códons identificadas anteriormente são uma representação linear real e uma representação projetiva pseudo-real, e ambas cindem sob extensão por seu grupo de automorfismos externos $\mathbb{Z}_{2}$ : a representação linear se estende a duas representações reais e a representação projetiva se estende a um par de representações complexas conjugadas de $G \cdot \mathbb{Z}_{2}$.

- $G={ }^{2} B_{2}(8)=S z(8)$ :

O multiplicador de Schur de $G$ é $\mathbb{Z}_{2} \times \mathbb{Z}_{2}$ e o seu grupo de automorfismos externos é $\mathbb{Z}_{3}$. Suas representações de códons identificadas anteriormente (uma linear e três projetivas) são todas reais. A representação linear cinde sob extensão por seu grupo de automorfismos externos $\mathbb{Z}_{3}$ : mais precisamente, ela se estende a uma representação real mais um par de representações complexas conjugadas de $G \cdot \mathbb{Z}_{3}$. As representações projetivas não admitem extensão - de acordo com o fato de que as extensões bicíclicas de tipo $M . G . A$ com $A=\mathbb{Z}_{3}$ e $M$ qualquer um dos quocientes de $M=\mathbb{Z}_{2} \times \mathbb{Z}_{2}$, que são todos isomorfos a $\mathbb{Z}_{2}$, não existem.

- $G={ }^{2} A_{2}(4)=P S U_{3}(4)$ :

O multiplicador de Schur de $G$ é trivial e o seu grupo de automorfismos externos é $\mathbb{Z}_{4}$. Em particular, $G$ é igual a $S U_{3}(4)$. Sua representação de códons identificada anteriormente é real e, como consequência do teorema de Conlon, deve cindir sob extensão por qualquer subgrupo cíclico $A$ do grupo de automorfismos externos $\mathbb{Z}_{4}$ : mais precisa- 
mente, ela se estende a duas representações reais de $G \cdot \mathbb{Z}_{2}$ e a duas representações reais mais um par de representações complexas conjugadas de $G . \mathbb{Z}_{4}$.

- $G=C_{3}(2)=B_{3}(2)$ :

O multiplicador de Schur de $G$ é $\mathbb{Z}_{2}$ e o seu grupo de automorfismos externos é trivial. Suas representações de códons identificadas anteriormente formam um par de representações projetivas complexas conjugadas. Como seu grupo de automorfismos externos é trivial, o problema de extensão não se apresenta.

- $G=G_{2}(3)$ :

O multiplicador de Schur de $G$ é $\mathbb{Z}_{3}$ e o seu grupo de automorfismos externos é $\mathbb{Z}_{2}$. Suas representações de códons identificadas anteriormente formam um par de representações lineares complexas conjugadas e ambas cindem sob extensão ao grupo de automorfismo externos $\mathbb{Z}_{2}$ : elas se extendem a dois pares de representações complexas conjugadas de $G \cdot \mathbb{Z}_{2}$.

Estes resultados estão resumidos na Tabela 4.6, que juntamente com a Tabela 4.1 constitui o primeiro resultado fundamental desta tese. Ademais, ele está de acordo com [113] onde são determinados todos os grupos finitos simples de tipo Lie e esporádicos que possuem representações lineares e projetivas cuja dimensão é uma potência de um número primo.

Observamos também que nos casos em que o multiplicador de Schur não é cíclico que correspondem a dois casos da Tabela 4.6 - o número de representações de códons é, na verdade, menor do que o indicado na Tabela 4.6. No caso do grupo ${ }^{2} B_{2}(8)=S z(8)$, cujo multiplicador de Schur é $\mathbb{Z}_{2} \times \mathbb{Z}_{2}$, os três recobrimentos duplos são isomorfos (os isomorfismos são induzidos por automorfismos externos de ordem três) e portanto basta contar uma representação projetiva a invés de três. No caso do grupo $A_{2}(4)=P S L_{3}(4)$, cujo multiplicador de Schur é $\mathbb{Z}_{4} \times \mathbb{Z}_{4} \times \mathbb{Z}_{3}$, os três recobrimentos duplos são isomorfos e os seis recobrimentos quádruplos se dividem em duas classes de isomorfismos com três grupos em cada classe (os isomorfismos são induzidos por automorfismos externos de ordem três). A Tabela 4.6 indica que $A_{2}(4)=P S L_{3}(4)$ possui 15 representações porjetivas de códons, sendo que as três representações se levantam aos recobrimentos duplos (onde somente uma representação se levanta a somente um recobrimento duplo) e os seis pares de representações complexas conjugadas se levantam aos seis recobrimentos quádruplos (onde um par de representações complexas conjugadas se levanta a somente um recobrimento quádruplo). Com as identificações entre recobrimentos duplos e quádruplos que mencionamos anteriormente, basta contar uma representação projetiva que se levanta a um recobrimento duplo e dois pares de representações complexas conjugadas projetivas que se levantam a dois recobrimentos quádruplos diferentes, chegando a um total de cinco representações de códons projetivas. 


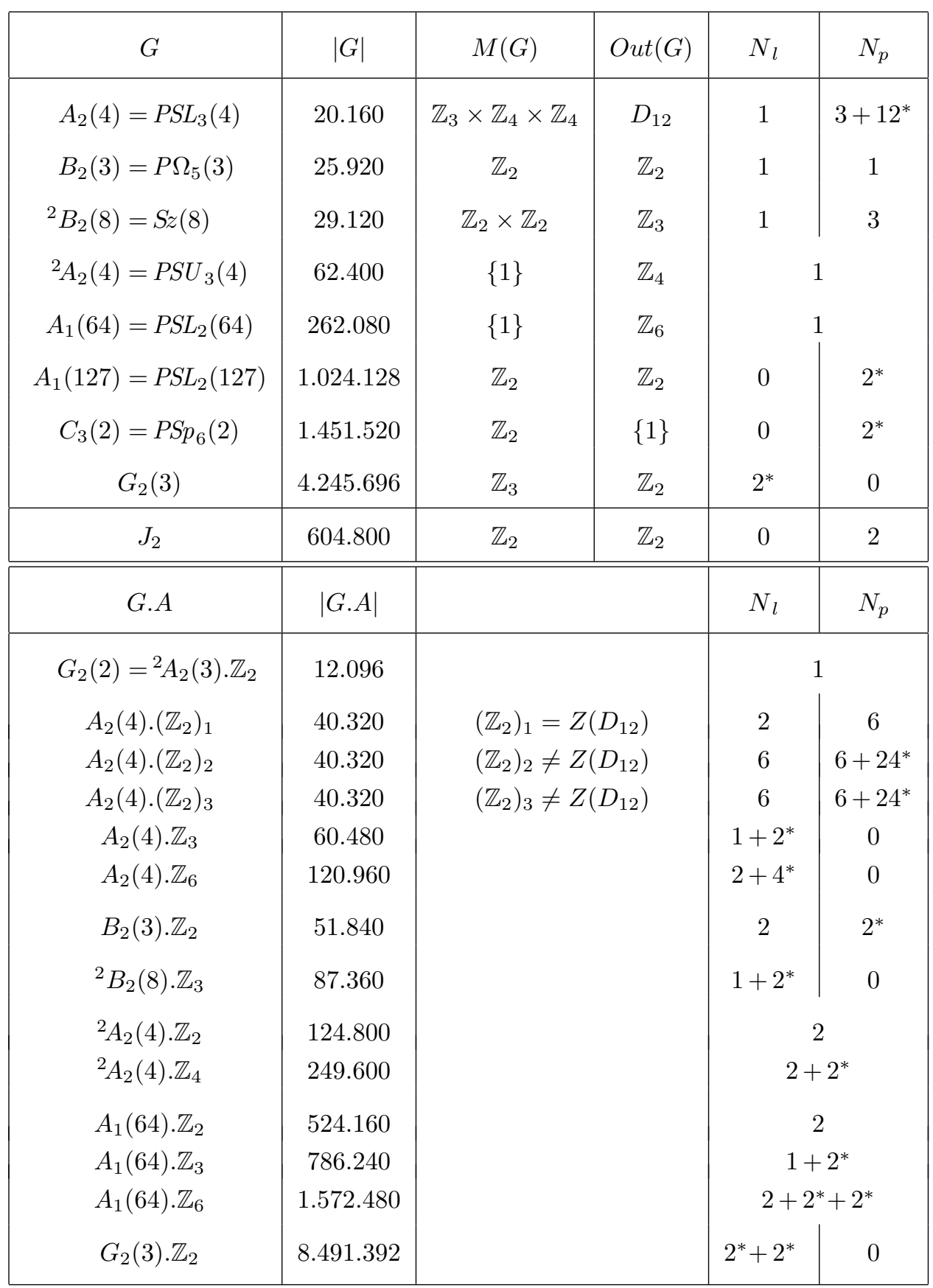

Tabela 4.6: Número de representações códons lineares $N_{l}$ e projetivas $N_{p}$ dos grupos finitos simples e de suas extensões por automorfismos externos: grupos de tipo Lie e grupos esporádicos. (O símbolo $n^{*}$ indica $n / 2$ pares de representações complexas conjugadas.) 

CAPÍtulo 5

\section{Regras de Ramificação}

Neste capítulo desenvolvemos a estratégia geral para calcular as regras de ramificação de uma representação irredutível de um grupo finito aos seus subgrupos. Esta tarefa só pode ser realizada com o auxílio de computadores. Como queremos analisar todos os grupos encontrados no capítulo anterior usando o mesmo procedimento, precisamos de uma metodologia uniforme que seja independente do tipo de grupo considerado. A ferramenta ideal para atacar este problema é o pacote $\mathrm{GAP}^{1}$ que reune os mais modernos algoritmos para o cálculo com grupos finitos em computadores.

O primeiro passo consiste em encontrar um meio de representar os grupos a serem estudados em um formato que possa ser lido pelo programa. O GAP trabalha tanto com grupos de permutações quanto com grupos de matrizes: basta fornecer um conjunto de geradores do grupo no devido formato. Na sua grande maioria, os grupos finitos de interesse são naturalmente definidos como grupos de matrizes e assim a primeira idéia seria adotar este ponto de vista. No entanto, os algoritmos mais eficientes disponíveis hoje em dia são para grupos de permutações. Portanto, nossa primeira tarefa é construir representações permutacionais dos grupos que queremos analisar.

Na primeira seção apresentaremos algumas noções teóricas sobre grupos de permutações e abordaremos a construção de representações permutacionais dos grupos finitos simples e suas extensões usando o GAP.

De posse das representações permutacionais, podemos passar para a próxima etapa que é a determinação das classes de conjugação de subgrupos de um grupo finito $G$. Como foi explicado no Capítulo 1, precisamos determinar também os pares $\left(H_{1}, H_{2}\right)$ de subgrupos de $G$ (a menos de conjugação) onde $H_{2}$ é maximal em $H_{1}$. Isto é equivalente ao problema de construir o reticulado de classes de conjugação de subgrupos de $G$ e será tratado na segunda seção.

\footnotetext{
${ }^{1}$ A abreviação GAP significa "Groups, Algorithms and Programming" [57].
} 
A terceira seção será dedicada à determinação das regras de ramificação, o que é feito através da teoria de caracteres. Nesta seção mostraremos como trabalhar com caracteres utilizando o GAP.

\subsection{Representações Permutacionais}

Todo grupo finito é isomorfo a um grupo de permutações. Esta afirmação, conhecida como o teorema de Cayley, é um dos resultados clássicos da teoria dos grupos finitos e é demonstrado exibindo-se um grupo finito de ordem $n$ como subgrupo de $S_{y m}$. Antes do advento do computador digital, o teorema de Cayley não tinha muita utilidade prática, pois é extremamente penoso executar cálculos manuais em grupos simétricos de ordem muito grande. A busca por construções explícitas de alguns grupos esporádicos como grupos de permutações deu grande impulso à pesquisa e ao desenvolvimento de métodos computacionais para cálculos em grupos de permutações. Atualmente, uma das áreas mais desenvolvidas na teoria computacional de grupos finitos é justamente a de grupos de permutações.

Apresentaremos algumas idéias básicas da teoria de representações permutacionais dos grupos finitos afim de estabelecer a terminologia que usaremos daqui em diante.

Uma representação permutacional de um grupo finito $G$ em $n$ pontos $\{1, \ldots, n\}$, também chamada representação permutacional de grau $n$, é um homomorfismo $\pi: G \rightarrow S_{\text {Sym }}$. Em outras palavras, uma representação permutacional corresponde a uma ação do grupo $G$ no conjunto $\{1, \ldots, n\}$, ou mais geralmente em um conjunto $X$ finito qualquer de $n$ elementos.

Isto permite estender as noções de órbita, subgrupo estabilizador, transitividade, etc. para a teoria de representações permutacionais. Duas representações permutacionais são ditas equivalentes se e somente se suas imagens são conjugadas em Sym $_{n}$.

Uma forma de se construir representações permutacionais transitivas é a seguinte. Seja $H$ um subgrupo de $G$ e seja $X=G / H$ o espaço quociente das classes laterais de $H$ em $G$; então definindo $\pi(g)\left(g^{\prime} H\right)=\left(g g^{\prime}\right) H$, obtemos uma representação permutacional transitiva de $G$ em $X$. O grau desta representação é o índice $[G: H]$ de $H$ em $G$ e o subgrupo estabilizador de uma classe lateral qualquer é conjugado a $H$. Pode-se provar que, reciprocamente, qualquer representação permutacional transitiva é equivalente a uma representação por multiplicação a esquerda nas classes laterais de algum subgrupo. Duas representações permutacionais transitivas de $G$ são equivalentes se e somente se algum (e portanto qualquer) subgrupo estabilizador de uma é conjugado em $G$ a algum (e portanto qualquer) subgrupo estabilizador da outra. Quando $H$ é o grupo trivial $\{1\}$ esta representação é chamada de representação regular a esquerda: é esta a representação usada na demonstração do teorema de Cayley. Finalmente, qualquer representação permutacional é a união disjunta 
de representações permutacionais transitivas, ou equivalentemente, é dada pela ação de $G$ na união de conjuntos de classes laterais $X=G / H_{1} \cup \ldots \cup G / H_{r}$, onde $H_{1}, \ldots, H_{r}$ são subgrupos de $G$. Neste caso, o grau da representação permutacional é a soma dos índices em $G$ dos subgrupos $H_{1}, \ldots, H_{r}$.

Se $\pi$ é uma representação permutacional de $G$ em $X$ o núcleo de $\pi$ é a intersecção de todos os grupos estabilizadores

$$
\operatorname{ker}(\pi)=\bigcap_{x \in X} G_{x}
$$

e se $\pi$ for transitiva, é o maior subgrupo normal de $G$ contido em $G_{x}$, para qualquer $x \in X$. Se $\pi$ for injetora $(\operatorname{ker}(\pi)=\{1\})$ então a representação $\pi$ é dita fiel ou efetiva. Neste caso, $G$ pode ser identificado com sua imagem em $S_{y m}$. A representação regular a esquerda é um exemplo de representação permutacional transitiva fiel.

Afim de realizar cálculos computacionas com um grupo finito $G$ devemos então construir uma representação permutacional fiel (de preferência transitiva) de $G$, e de menor grau possível, pois a eficiência dos algoritmos depende diretamente do grau da representação permutacional.

Denotamos por $p(G)$ o menor inteiro $n$ tal que $G$ possui uma representação permutacional fiel de grau $n$. No caso em que $G$ é simples, todas as representações são fiéis e portanto $p(G)$ será o índice do subgrupo maximal de $G$ de maior ordem. No entanto, precisamos também de representações permutacionais fiéis dos grupos de recobrimento de grupos finitos simples. Se $\hat{G}$ é um grupo de recobrimento de um grupo finito simples $G$ então todo subgrupo normal de $\hat{G}$, exceto ele próprio, está contido no seu centro $Z(\hat{G})$ e reciprocamente, todo subgrupo de $Z(\hat{G})$ é normal em $\hat{G}$. Assim, para construir representações permutacionais fiéis de $\hat{G}$ devemos considerar somente subgrupos que intersectam $Z(\hat{G})$ trivialmente.

Os subgrupos maximais de $\hat{G}$ não podem ser usados para construir representações permutacionais fiéis, devido ao seguinte fato.

Lema 5.1.1 Todo subgrupo maximal de uma extensão central essencial $G$ de um grupo finito contém o centro $Z(G)$ de $G$.

Demonstração. Isto pode ser mostrado considerando o subgrupo de Frattini $\Phi(G)$ de um grupo finito $G$, definido como a intersecção de todos os subgrupos maximais de $G$. $\Phi(G)$ é um subgrupo normal de $G$ (na verdade é invariante sob todos os automorfismos de $G$ ) e caracterizado pela seguinte propriedade: $g \in G$ é um elemento de $\Phi(G)$ se e somente se $g$ é um nãa-gerador de $G$, isto é, se $S$ é um subconjunto de $G$ tal que $\langle S, g\rangle=G$ então $\langle S\rangle=G$. Esta propriedade implica que $Z(G) \cap[G, G]$ é um subgrupo de $\Phi(G)$. Agora se $G$ é uma extensão central essencial de um grupo finito, então $Z(G) \subset[G, G]$ e portanto $Z(G) \subset \Phi(G)$, mostrando assim que $Z(G)$ está contido em cada subgrupo maximal de $G$. 
Este lema implica, em particular, que se $G$ é um grupo finito simples e $\gamma: \hat{G} \rightarrow G$ é um recobrimento então os subgrupos maximais de $\hat{G}$ são exatamente os grupos $\gamma^{-1}(H)$ com $H$ maximal em $G$. Também implica que, tipicamente, o grau da "menor" representação permutacional fiel de $\hat{G}$ é muito maior do que o grau da "menor" representação permutacional fiel de $G$.

Se $G$ é um grupo finito simples há informações detalhadas sobre a "menor" representação permutacional fiel de $G[114,115,148,149,150,151]$, que podem ser usadas para construí-la. Já para extensões ascendentes e descendentes de um grupo finito simples $G$ só é possível obter algumas informações qualitativas [14, 15, 103].

A definição abstrata de representação permutacional não esclarece o que significa ter um grupo de permutações em um computador. Isso depende do programa escolhido mas, em linhas gerais, um grupo de permutações é especificado por um conjunto de geradores $S=\left\{g_{1}, \ldots, g_{k}\right\}$, onde cada $g_{i}$ é uma permutação de $n$ pontos, geralmente escrita na forma de um produto de ciclos disjuntos. Por exemplo, o grupo $A l t_{8}$ é gerado pelas seguintes permutações em 8 pontos:

$$
\begin{gathered}
\mathrm{a}:=(1,2,3) ; \\
\mathrm{b}:=(2,3,4,5,6,7,8) ;
\end{gathered}
$$

Observe que esta é a representação permutacional natural de $A l t_{8}$, com subgrupo estabilizador Alt $_{7}$. Pode-se mostrar que esta é a representação permutacional fiel de menor grau de $A l t_{8}$. Já o seu recobrimento duplo $2 . A t_{8}$ é gerado pelas seguintes permutações em 240 pontos:

$$
\begin{aligned}
c:= & (1,2,3)(4,6,10)(5,8,14)(7,12,21)(9,16,28) \\
& (11,19,34)(13,23,40)(15,26,45)(17,30,51)(18,32,55) \\
& (20,36,61)(22,39,66)(24,41,69)(25,43,72)(27,46,77) \\
& (29,49,81)(31,53,87)(33,57,92)(35,50,83)(37,42,71) \\
& (38,64,105)(44,74,120)(47,68,111)(48,80,128)(52,85,133) \\
& (54,78,125)(56,90,138)(58,94,141)(59,96,143)(60,98,147) \\
& (62,101,151)(63,103,154)(65,106,159)(67,109,161)(70,114,168) \\
& (73,118,175)(75,121,179)(76,123,158)(79,126,93)(82,131,178) \\
& (84,88,95)(86,134,192)(89,137,194)(91,110,157)(97,145,162) \\
& (99,148,201)(100,150,205)(102,135,136)(104,156,208)(107,142,163) \\
& (108,160,177)(112,165,189)(113,167,216)(115,169,218)(116,171,211) \\
& (117,173,191)(119,176,129)(122,180,184)(124,172,152)(127,185,223) \\
& (130,187,195)(132,190,215)(139,197,233)(140,198,164)(144,200,209) \\
& (146,199,230)(149,203,206)(153,170,186)(155,207,234)(166,214,174) \\
& (181,220,229)(182,222,217)(183,224,212)(188,210,213)(193,204,225)
\end{aligned}
$$




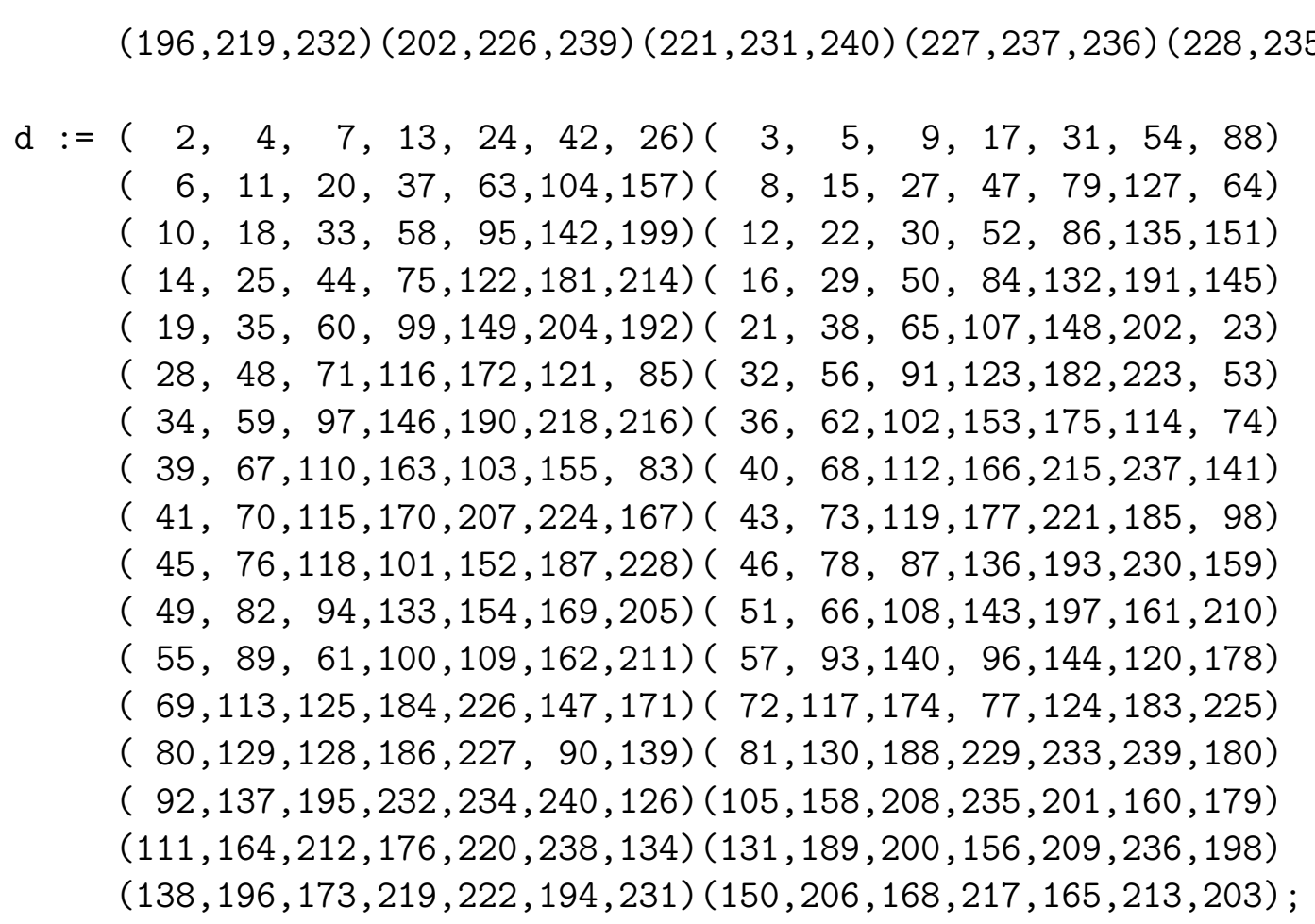

Esta representação corresponde à ação de $2 . A l t_{8}$ nas classes laterais de um subgrupo isomorfo a $P S L_{3}(2)$, que é um grupo simples de ordem 168 e portanto não intersecta o centro de $2 . A l t_{8}$. Finalmente, pode-se verificar que esta é a representação permutacional fiel de menor grau de 2. Alt $_{8}$.

Como já foi mencionado, a eficiência dos algoritmos para grupos de permutações depende diretamente do grau da representação permutacional, mas ela também depende do número de geradores usado para representar o grupo. Assim, para obter a máxima eficiência dos algoritmos, devemos construir os grupos que queremos estudar com o menor grau possível e com o menor número possível de geradores.

$\mathrm{Na}$ teoria computacional de grupos, a questão de encontrar um "bom" conjunto de geradores para um grupo é muito importante, principalmente no que concerne a checagem dos resultados e a reprodutibilidade dos cálculos. O problema é que o mesmo grupo pode ser representado por dois conjuntos independentes de geradores que não apresentam em geral nenhuma relação entre si, sendo que é impraticável obter um a partir do outro.

Não se espera que exista uma definição abstrata do que seria um "bom" conjunto de geradores de um dado grupo. No entanto, pode-se esperar que a proposta de um conjunto $\left\{g_{1}, \ldots, g_{r}\right\}$ de geradores para um determinado grupo $G$ seja acompanhada de um método para obter qualquer outro conjunto $\left\{h_{1}, \ldots, h_{s}\right\}$ de geradores de $G$ a partir deste. Isto significa que deve ser possível encontrar palavras $w_{1}, \ldots, w_{s}$ em $g_{1}, \ldots, g_{r}$ tais que 
$h_{j}=w_{j}\left(g_{1}, \ldots, g_{r}\right)$. Em geral, estes "geradores padrão" são especificados por certas propriedades estruturais, tais como suas ordens ou as ordens de suas classes de conjugação, de forma que um conjunto de geradores padrão é único a menos de automorfismos. Por exemplo, para certos grupos esporádicos, um conjunto de dois geradores padrão é fixado por três classes de conjugação: a primeira deve conter o primeiro gerador, a segunda deve conter o segundo gerador e a terceira deve conter o produto dos dois [158]. Outra propriedade útil, principalmente quando estamos trabalhando com grupos de recobrimento, é que os geradores do geupo de recobrimento sejam relacionados da forma mais simples possível com os geradores do grupo original. Por exemplo, os geradores de $A l t_{8}$ e de $2 . A l t_{8}$ que apresentamos acima são tais que a prescrição $a \mapsto c$ e $b \mapsto d$ define o homomorfismo de recobrimento 2.Alt $\rightarrow$ Alt $_{8}$.

Geradores padrão das representações permutacionais fiéis de menor grau (assim como de outros graus) para alguns grupos finitos simples e suas extensões estão disponíveis na Internet [160]. O GAP também possui uma biblioteca contendo todos os grupos finitos perfeitos de ordem até $10^{6}$ (a menos de algumas exceções), em particular ela contém todos os grupos quasi-simples de ordem até $10^{6}$. Além disto, o GAP possui funções que calculam automaticamente representações permutacionais fiéis (mas não necessariamente transitivas) destes grupos.

Utilizando estas fontes, conseguimos obter representações permutacionais transitivas fiéis de todos os grupos de tipo Lie e esporádicos e de seus grupos de recobrimento que possuem representações de códons. No caso dos grupos alternados e simétricos Alt $_{14}, A_{1} t_{15}$, $S_{y m_{13}}$ e $S y m_{14}$, foi possível encontrar representações matriciais fiéis dos seus recobrimentos duplos, mas a conversão destas em representações permutacionais transitivas fiéis mostrou-se além da capacidade computacional disponível. Além disto, segundo as estimativas apresentadas na Tabela 5.1, estas representações permutacionais seriam de grau tão alto que a maioria dos cálculos que precisamos executar nas próximas etapas se torna impraticável. O GAP armazena internamente uma permutação como uma lista das $n$ imagens dos inteiros $1, \ldots, n$ onde o "grau interno" $n$ da permutação é igual ao maior inteiro movido pela permutação. As imagens são todas armazenadas como inteiros de 16 bits ou 32 bits, dependendo se $n \leqslant 65536$ ou não. Isto significa que para uma representação permutacional de grau maior que 65536 , o consumo de memória será o dobro do consumo de para qualquer representação permutacional de grau menor que 65536, independentemente da ordem do grupo.

O resultado final desta etapa é que foi possível construir representações permutacionais de menor grau - ou pelo menos de um grau muito próximo do menor e, principalmente, menor que 65536 - de todos os grupos finitos simples e seus grupos de recobrimento cíclicos de ordem $<10^{10}$ que possuem representações de códons. Observamos também que podemos nos restringir aos grupos de recobrimento (nos casos em que o multiplicador de Schur é nãotrivial), pois as representações irredutíveis do grupo recoberto também são representações irredutíveis do grupo de recobrimento. 


\begin{tabular}{lcc}
\hline \multicolumn{1}{c}{$G$} & $|G|$ & $p(G)$ \\
\hline 2. Alt $_{5}$ & 120 & $=24$ \\
2. Alt $_{6}$ & 720 & $=80$ \\
2. Alt $_{7}$ & 5.040 & $=240$ \\
2. Alt $_{8}$ & 40.320 & $=240$ \\
2. Alt $_{9}$ & 362.880 & $=2.400$ \\
2. Alt $_{10}$ & 3.628 .800 & $=5.040$ \\
2. Alt $_{11}$ & 19.958 .400 & $\leqslant 60.480$ \\
2. Alt $_{12}$ & 479.001 .600 & $\leqslant 786.240$ \\
2. Alt $_{13}$ & 6.227 .020 .800 & $\leqslant 11.007 .360$ \\
2. Alt $_{14}$ & 87.178 .291 .200 & $\leqslant 165.110 .400$ \\
2. Alt $_{15}$ & 1.307 .674 .368 .000 & \\
\hline
\end{tabular}

Tabela 5.1: Estimativas para o grau mínimo de representações permutacionais fiéis dos grupos de recobrimento de alguns grupos alternados.

Passando às extensões por grupos de automorfismos externos, verificamos que para todos os grupos finitos simples e seus grupos de recobrimento $G$ que possuem representações de códons, o grupo de automorfismos de $G$ é um produto semidireto, ou seja, $\operatorname{Aut}(G)=\operatorname{Inn}(G) \rtimes \operatorname{Out}(G)$, usando o GAP para construir, em cada caso, um subgrupo $A$ de $\operatorname{Aut}(G) \operatorname{com} \operatorname{Inn}(G) \cap A=\{1\}$ e $\operatorname{Inn}(G) A=\operatorname{Aut}(G)$. Em muitos casos isto também pode ser mostrado de forma direta. Por exemplo, para os grupos esporádicos e os grupos alternados com $n \geqslant 8$, onde o grupo de automorfismos externos é $\mathbb{Z}_{2}$, observamos que se um grupo $G$ possui uma extensão do tipo $G . \mathbb{Z}_{2}$ então qualquer elemento de ordem 2 de $G . \mathbb{Z}_{2}$ que não está em $G$ gera um subgrupo $A$ isomorfo a $\mathbb{Z}_{2}$ que intersecta $G$ trivialmente e portanto satisfaz $G A=G \cdot \mathbb{Z}_{2}$. Examinando as tabelas de caracteres do ATLAS, constata-se então que todos os grupos mencionados acima possuem pelo menos uma classe de conjugação de ordem 2 que não está contida no subgrupo normal $G$. Para os grupos finitos de Chevalley nãotorcidos, existem resultados gerais, porém não completos, em relação à questão se o grupo de automorfismos é um produto semidireto ou não $[122,123]$. Nestes casos, verificamos que os resultados também estão de acordo.

Suponhamos agora que $G$ é um grupo finito simples tal que $\operatorname{Aut}(G)$ é um produto semidireto, $\operatorname{Aut}(G)=\operatorname{Inn}(G) \rtimes \operatorname{Out}(G)$, e que $\hat{G}$ é um grupo de recobrimento de $G$. Para construir, usando o GAP, uma representação permutacional transitiva fiel da maior extensão por automorfismos externos de $\hat{G}$ possível, a partir de uma representação permutacional transitiva fiel de $\hat{G}$, com subgrupo estabilizador $\hat{H}$, precisamos executar, sempre dentro desta representação permutacional, os seguintes passos: 

a) calcular o grupo $\operatorname{Aut}(\hat{G})$ de automorfismos de $\hat{G}$;
b) calcular o subgrupo $\operatorname{Inn}(\hat{G})$ de automorfismos internos de $\hat{G}$, que é isomorfo a $G$;
c) encontrar um subgrupo $\hat{A} \operatorname{de} \operatorname{Aut}(\hat{G})$ tal que $\operatorname{Inn}(\hat{G}) \cap \hat{A}=\{1\}$ e $\operatorname{Inn}(\hat{G}) \hat{A}=\operatorname{Aut}(\hat{G})$;
d) construir, com os dados acima, o grupo $\hat{G} \rtimes \hat{A}$;
e) identificar uma cópia de $\hat{G}$ dentro de $\hat{G} \rtimes \hat{A}$;
f) identificar uma cópia de $\hat{H}$ dentro de $\hat{G} \rtimes \hat{A}$;
g) calcular a ação de $\hat{G} \rtimes \hat{A}$ no conjunto das classes laterais $X=(\hat{G} \rtimes \hat{A}) / \hat{H}$.

Observe que este processo proporciona uma representação permutacional de $\hat{G} \rtimes \hat{A}$ de grau igual a $|\hat{A}|$ vezes o grau da representação permutacional de $\hat{G}$.

Vamos ilustrar esta construção usando o grupo 2. Alt $_{8}$, definido pelos geradores acima. Tendo introduzido os geradores $c$ e $d$, definimos o grupo 2.Alt 8 por

$$
\mathrm{g}:=\operatorname{Group}(\mathrm{c}, \mathrm{d}) \text {; }
$$

a) O grupo de automorfismos de $2 . A l t_{8}$, que é isomorfo a $S y m_{8}$, é calculado pelo comando

$$
\text { ag := AutomorphismGroup }(\mathrm{g}) \text {; }
$$

A saída deste comando deve ser um grupo gerado por três elementos.

b) O subgrupo dos automorfismos internos de $2 . A l t_{8}$, que é isomorfo a $A l t_{8}$, é calculado pelo comando

$$
\text { ig := InnerAutomorphismsAutomorphismGroup(ag); }
$$

A saída deste comando deve ser um grupo gerado por dois elementos.

c) Para encontrar um subgrupo complementar a $A l t_{8}$ dentro de $S_{y} m_{8}$, precisamos calcular as classes de conjugação de $S_{y} m_{8}$, o que é feito pelo comando

$$
\text { cc := ConjugacyClasses (ag); }
$$

Este comando deve produzir uma lista com 22 classes de conjugação. O seguinte comando imprime uma lista com as ordens dos representantes de cada uma das 22 classes de conjugação

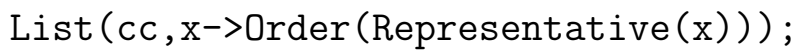


Vemos então que há 4 classes de conjugação de elementos de ordem 2. Agora, o comando

$$
\text { List (cc, } \mathrm{x}->\text { Representative( } \mathrm{x} \text { ) in ig); }
$$

imprime uma lista com as palavras "true" ou "false", indicando se a $i$-ésima classe de conjugação está ou não contida em $A l t_{8}$. O resultado mostra que dentre as quatro classes de elementos de ordem 2, duas estão contidas em $A l t_{8}$ e duas não. Precisamos de um representante de uma das duas classes que não estão contidas em $A l t_{8}$, o que pode ser feito pelo comando

$$
\mathrm{q}:=\text { Representative }(\mathrm{cc}[4]) \text {; }
$$

(observe que o número entre colchetes pode variar a cada seção). Com este elemento podemos construir o subgrupo complementar a $A l t_{8}$

$$
\text { a := } \operatorname{Subgroup}(\mathrm{ag},[\mathrm{q}]) \text {; }
$$

e testar se ele intersecta $A l t_{8}$ trivialmente

$$
\text { Size(Intersection(ig, a)); }
$$

Se tudo estiver correto, o resultado deste último comando deve ser 1. Podemos também verificar se o grupo de automorfismos de 2 . Alt 8 é realmente gerado pelos dois subgrupos que construímos

$$
\mathrm{ag}=\operatorname{Subgroup}(\mathrm{ag},[\mathrm{ig} \cdot 1, \mathrm{ig} \cdot 2, \mathrm{a} .1]) ;
$$

Se o resultado for "true" então conseguimos decompor o grupo de automorfismos de $2 . A l t_{8}$ no produto de dois subgrupos, sendo um deles normal, com intersecção trivial. Finalmente, para verificar que o produto semidireto obtido não é trivial, podemos testar se o complemento de $A l t_{8}$ é normal

\section{IsNormal $(\mathrm{ag}, \mathrm{a})$;}

O resultado "false" indica que $S y m_{8}$ é realmente um produto semidireto não-trivial.

d) $\mathrm{O}$ produto semidireto $2 . A l t_{8} \rtimes \mathbb{Z}_{2}$ é obtido pelo comando

$$
\text { s := SemidirectProduct (a, IdentityMapping }(a), g) \text {; }
$$


Esta função retorna um grupo isomorfo a $2 . A l t_{8} \rtimes \mathbb{Z}_{2}$ gerado por três permutações de 80.640 pontos, correspondendo à representação regular a esquerda de $2 . A l t_{8} \rtimes \mathbb{Z}_{2}$. Esta representação é inadequada para a maioria dos cálculos subsequentes; precisamos de uma representação permutacional fiel de grau menor. Os próximos comandos tem por objetivo construir uma representação permutacional fiel de $2 . A l t_{8} \rtimes \mathbb{Z}_{2}$ em 480 pontos.

e) $\mathrm{O}$ mergulho de $2 . A l t_{8}$ em $2 . A l t_{8} \rtimes \mathbb{Z}_{2}$ é obtido pelo seguinte comando

$$
\text { e := Embedding }(\mathrm{s}, 2) \text {; }
$$

Ele retorna um homomorfismo injetor 2. Alt $_{8} \rightarrow 2$. Alt $_{8} \rtimes \mathbb{Z}_{2}$.

f) A imagem dentro de $2 . A l t_{8} \rtimes \mathbb{Z}_{2}$ do subgrupo de etabilidade $\hat{H}$ da ação de 2 .Alt 8 que usamos em toda esta construção é calculado pelo comando

$$
\mathrm{h}:=\operatorname{Image}(\mathrm{e}, \operatorname{Stabilizer}(\mathrm{g}, 1)) \text {; }
$$

g) Agora basta calcular a ação de $2 . A l t_{8} \rtimes \mathbb{Z}_{2}$ no conjunto das classes laterais deste subgrupo

$$
\mathrm{k}:=\operatorname{Action}(\mathrm{s}, \operatorname{RightCosets}(\mathrm{s}, \mathrm{h}), \text { OnRight) }
$$

Este comando retorna um grupo isomorfo a $2 . A l t_{8} \rtimes \mathbb{Z}_{2}$ gerado por três permutações de 480 pontos.

Toda essa sequência de comandos pode ser colocada na forma de um programa que escreve o resultado final em um arquivo que pode ser lido novamente pelo GAP. Isto é útil e importamte pois, dependendo da ordem de $G$, o cálculo inteiro pode levar várias horas e até alguns dias. Felizmente, não é difícil colocar a saída dos resultados no formato de outros comandos do GAP. Por exemplo, para guardar em um arquivo as permutações que obtivemos no cálculo da representação permutacional de $2 . A l t_{8} \rtimes \mathbb{Z}_{2}$ em 480 pontos, usamos o seguinte comando

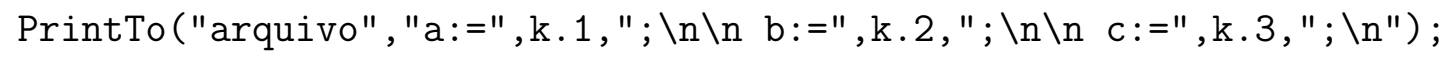

Assim, em uma nova seção do GAP, o grupo $2 . A l t_{8} \rtimes \mathbb{Z}_{2}$ pode ser definido diretamente pelos comandos

$$
\begin{aligned}
& \operatorname{Read}(" \operatorname{arquivo"}) ; \\
& \mathrm{g}:=\operatorname{Group}(\mathrm{a}, \mathrm{b}, \mathrm{c}) ;
\end{aligned}
$$

Deste modo, foi possível construir representações permutacionais de menor grau (ou de grau muito próximo do menor) de todos os grupos finitos simples, seus grupos de recobrimento e suas extensões por automorfismos externos de ordem $\leqslant 10^{10}$ que possuem representações de códons. 


\subsection{Classes de Conjugação de Subgrupos}

Para prosseguir com o cálculo das regras de ramificação de uma representação irredutível de um grupo $G$ precisamos determinar todos os subgrupos de $G$. Na verdade, precisamos apenas das classes de conjugação de subgrupos de $G$, pois as regras de ramificação com respeito a dois subgrupos conjugados são iguais.

Começamos recordando que o conjunto das classes de conjugação de um grupo $G$ possui uma relação de ordem parcial definida da seguinte forma. Sejam $H$ e $K$ subgrupos de $G$, então dizemos que $H$ é subconjugado a $K$ em $G$ se $H$ for conjugado em $G$ a um subgrupo de $K$. Passando para as classes de conjugação $[H]$ de subgrupos $H$ de $G$, temos então uma relação de ordem parcial: $[H] \preceq[K]$ se e somente se $H$ é subconjugado a $K$ em $G$. É claro que esta relação não depende da escolha dos representantes. O conjunto das classes de conjugação de subgrupos de $G$ munido desta relação de ordem parcial é chamado de reticulado das classes de conjugação de subgrupos e $G$.

No GAP, o conjunto das classes de conjugação de subgrupos de um grupo dado $G$ é calculado com o seguinte comando

$$
c:=\text { ConjugacyClassesSubgroups }(\mathrm{g}) \text {; }
$$

O resultado é a lista das classes de conjugação de subgrupos de $G$, a partir da qual podemos extrair uma lista de representantes através do comando

$$
r:=\operatorname{List}(c, i->\operatorname{Representative(i))} \text {; }
$$

Cada elemento desta lista é um subgrupo de $G$ dado em termos de um conjunto de geradores.

Este é, sem dúvida, um cálculo bastante pesado e portanto é necessário executálo através de um programa que escreve os resultados em arquivos que possam ser lidos posteriormente pelo GAP. Vale também mencionar que a otimização prévia da representação permutacional usada é fundamental, pois este comando também exige, além do tempo de processamento, muito espaço na memória.

O algoritmo usado pelo GAP para calcular as classes de conjugação de subgrupos é o método das extensões cíclicas que foi desenvolvido e implementado por Joachim Neubüser. Em linhas gerais, o método consiste em construir o reticulado de subgrupos de $G$ "camada por camada". Abstratamente, a k-ésima camada de subgrupos de $G$ é composta por todos os subgrupos $H$ de $G$ cuja série de composição tem comprimento $k$. Em particular, a primeira camada é composta pelos subgrupos simples, entre eles os grupos cíclicos de ordem prima. A partir destes, constroem-se por extensões cíclicas de ordem prima os subgrupos solúveis da segunda camada. Iterando o processo, obtêm-se todos os 
subgrupos solúveis de $G$ [27]. Para tratar do caso gera precisamos, de alguma forma, incluir os subgrupos perfeitos. Para tanto, observa-se que todos os subgrupos perfeitos de $G$ estão contidos em um único subgrupo perfeito maximal, chamado de resíduo perfeito de $G$, que pode ser obtido como o último elemento da série derivada de $G$ e portanto é normal. Tendose uma lista com todos os grupos perfeitos de ordem menor ou igual à ordem do resíduo perfeito de $G$, juntamente com algumas informações sobre sua estrutura e sobre quais são os grupos perfeitos nele contidos, pode-se adaptar o método das extensões cíclicas para incluir estes grupos nas camadas correspondentes e assim obter o reticulado de todos os subgrupos de $G[27]$.

Em resumo, a única limitação teórica para que o método das extensões cíclicas possa produzir todo o reticulado de subgrupos de um grupo $G$ dado é a ordem do resíduo perfeito de $G$. Como já foi mencionado, a biblioteca do GAP contém uma lista de todos os grupos perfeitos de ordem $\leqslant 10^{6}$, com algumas exceções; portanto a implementação do método das extensões cíclicas pelo GAP suporta grupos cujo resíduo perfeito pertence à lista de grupos perfeitos da biblioteca do GAP e, em particular, tem ordem $\leqslant 10^{6}$.

Dentre os grupos que possuem representações de códons existem seis cujo resíduo perfeito tem ordem acima de $10^{6}$; eles estão listados na Tabela 5.2.

\begin{tabular}{ccc}
\hline$G$ & $|G|$ & $\max \{|H|: H<G\}$ \\
\hline $2 . J_{2}$ & 1.209 .600 & 12.096 \\
$2 . A_{1}(127)$ & 2.048 .256 & 16.002 \\
$2 . C_{3}(2)$ & 2.903 .040 & 103.680 \\
2. Alt $_{10}$ & 3.628 .800 & 362.880 \\
$G_{2}(3)$ & 4.245 .696 & 12.096 \\
$G_{2}(3) \rtimes \mathbb{Z}_{2}$ & 8.491 .392 & 4.245 .696 \\
\hline
\end{tabular}

Tabela 5.2: Grupos que possuem representação de códons e cujo resíduo perfeito tem ordem acima de $10^{6}$. (A terceira coluna indica a ordem do maior subgrupo maximal de $G$.)

Os demais grupos estão dentro dos limites e o tempo de execução, nestes casos, é bastante satisfatório.

O tratamento dos seis grupos da Tabela 5.2 é baseado na observação de que, nos primeiros cinco casos, a ordem do maior subgrupo maximal é menor que a ordem do grupo por um fator de dez ou mais e portanto está dentro dos limites do algoritmo. Como todos estes grupos são recobrimentos ou extensões por automorfismos externos de grupos finitos simples, todos os seus subgrupos maximais são conhecidos e portanto pode-se aplicar o algoritmo a 
cada um dos seus subgrupos maximais, depois reunir todas as classes de conjugação de subgrupos obtidas e, por fim, eliminar as redundâncias, isto é, aquelas classes de conjugação de subgrupos que estão contidos em mais de um subgrupo maximal e por este motivo aparecem mais de uma vez.

Para colocar esta idéia em prática, precisamos obter, para um grupo $G$ representado como grupo de permutações, geradores explícitos de todos os seus subgrupos maximais. Para alguns grupos o ATLAS fornece informações de como obter os subgrupos maximais como normalizadores ou centralizadores de representantes de uma classe (ou várias classes) de conjugação. Contudo, é um fato conhecido que as informações contidas no ATLAS referentes aos subgrupos maximais são menos confiáveis do que outras, por exemplo as referentes às tabelas de caracteres, e portanto é necessário verificar os resultados em outras fontes. De fato, em alguns casos a lista de subgrupos maximais do ATLAS é incompleta ou apresenta subgrupos que não são maximais.

A classificação dos subgrupos maximais dos grupos alternados e simétricos se encontra em [108, 109], a dos grupos clássicos em [8, 99] e a dos grupos de Chevalley excepcionais do tipo $G_{2}$ em $[9,35,98]$. Com a ajuda do ATLAS e destas referências foi possível completar o cálculo do conjunto das classes de conjugação de subgrupos de quatro dos grupos da Tabela 5.2 .

Os dois casos restantes foram resolvidos de outra forma. No caso do grupo 2.J $J_{2}$, observamos que os seus subgrupos maximais são obtidos como imagem inversa dos subgrupos maximais de $J_{2}$ pelo homomorfismo quociente $2 . J_{2} \rightarrow J_{2}$ e como $J_{2}$ tem ordem 604.800 , os seus subgrupos maximais podem ser calculados pelo GAP. Finalmente, no caso do grupo $G_{2}(3) \rtimes \mathbb{Z}_{2}$ cujo subgrupo maximal de maior ordem é o subgrupo derivado $G_{2}(3)$ de $G_{2}(3) \rtimes \mathbb{Z}_{2}$ e portanto tem ordem acima dos limites do GAP, observamos em primeiro lugar que os subgrupos maximais de $G_{2}(3) \rtimes \mathbb{Z}_{2}$ que não estão contidos em $G_{2}(3)$ estão dentro dos limites do GAP - esta informação também pode ser obtida do ATLAS e verificada em [9, 35, 98] - e portanto podemos calcular as classes de conjugação de subgrupos contidos nestes subgrupos maximais, que junto com as classes de conjugação de subgrupos de $G_{2}(3)$ (que já foram calculadas anteriormente) podem ser usados para obter todas as classes de conjugação de subgrupos de $G_{2}(3) \rtimes \mathbb{Z}_{2}$.

A lista das classes de conjugação de subgrupos de $G$ é suficiente para a determinação das quebras de simetria perfeitas, mas como queremos também investigar as quebras de simetria imperfeitas, precisamos determinar os pares de subgrupos $(H, K)$ de $G$ onde $K$ é subgrupo maximal de $H$, ou seja, precisamos das relações de inclusão maximal entre as classes de conjugação de subgrupos de $G$. O método das extensões cíclicas gera estas informações durante sua execução e portanto representantes das classes de conjugação de subgrupos maximais de cada uma das classes de conjugação de subgrupos de $G$ podem ser obtidos imediatamente. Mais especificamente, a partir da lista $r$ de representantes das classes de 
conjugação de subgrupos de $G$ calculada anteriormente pelo GAP, o comando

$$
\mathrm{m}:=\operatorname{List}(\mathrm{r}, \mathrm{i}->\text { MaximalSubgroupClassReps (i)); }
$$

gera uma nova lista, do mesmo tamanho, cuja $i$-ésima entrada é uma lista com um representante de cada classe de conjugação de subgrupos maximais da $i$-ésima entrada de $r$. Esta informação pode ser simplificada, usando o fato de que cada subgrupo de $G$ é conjugado a um único subgrupo da lista $r$; portanto, podemos substiruir a lista m por uma lista de posições p cuja $i$-ésima entrada é a lista dos números $j_{1}, \ldots, j_{n_{i}}$ determinados pela condição de que $\mathrm{m}[\mathrm{i}][\mathrm{k}]$ é conjugado a $\mathrm{r}\left[\mathrm{j}_{\mathrm{k}}\right]$, para $1 \leqslant k \leqslant n_{i}$.

Uma das principais limitações deste método direto e simples para calcular as relações de inclusão maximal é o fato de que as listas $\mathrm{m}$ e p devem ser calculadas na mesma seção do GAP em que são calculadas as listas c e r, o que nem sempre é possível. Este problema ocorre exatamente para os seis grupos da Tabela 5.2, onde o cálculo do conjunto de classes de conjugação consome tanto espaço na memória que só pôde ser executado em várias seções distintas do GAP. Nestes casos, precisamos calcular as relações de inclusão maximal posteriormente, por força bruta, testando quais subgrupos da lista $r$ são subconjugados em $G$ a quais outros. É uma tarefa gigantesca que precisa ser otimizada, no sentido de fazer o menor número de testes de subconjugação possível.

A primeira otimização baseia-se na observação de que os grupos abelianos podem ser desconsiderados, pois estamos interessados em calcular, numa etapa posterior, regras de ramificação para subgrupos e como todas as representações irredutíveis de grupos abelianos são unidimensionais, eles não geram ramificações interessantes.

A parte mais dispendiosa do cálculo é o teste de subconjugação de $H$ em $K$ que requer construir a classe de conjugação de subgrupos de um dos grupos $H$ ou $K$ (de preferência a de menor tamanho) e testar se algum elemento da classe de conjugação de subgrupos construída contém ou está contido no outro subgrupo. A idéia básica para diminuir o número de testes de subconjugação é tentar calcular as relações de inclusão maximal sem ter que calcular todas as relações de inclusão.

Lembremos que a lista $r$ é ordenada de forma crescente com respeito à ordem dos subgrupos. Suponhamos que já calculamos todos os subgrupos maximais dos subgrupos $r[j]$ com $1 \leqslant j \leqslant i$, a menos de conjugação, o que permite determinar, por recursão, todos os subgrupos de $r[j]$ com $1 \leqslant j \leqslant i$, maximais ou não, a menos de conjugação. Para determinar quais são os subgrupos maximais de $r[i+1]$, a menos de conjugação, percorremos a lista $r$ truncada e na ordem oposta, isto é, começando em $r$ [i] até chegar em $r$ [1]. Felizmente, não é necessário executar o teste de subconjugação (de $r[j]$ em $r[i+1]$ ) para todo $i \geqslant j \geqslant 1$. De fato, podemos construir uma lista e de exeções que inicialmente é vazia. Quando encontramos o primeiro subgrupo $r\left[k_{1}\right]$ subconjugado a $r[i+1]$, é imediato que ele é maximal em 
$r$ [i+1]: portanto, anotamos sua posição na lista de relações de inclusão maximal e acrescentamos à lista e as posições dos subgrupos da lista $r$ que são subconjugados a $r\left[k_{1}\right]$ e já calculados anteriormente. Observe que se $j>k_{1}$ e $j$ pertence à lista e, então $\mathrm{r}$ [j] é claramente subconjugado a $r[i+1]$ mas deve ser eliminado por não ser maximal. Executando o teste de subconjugação apenas para os subgrupos $r[j]$ tais que $j$ não pertence à lista e, procedemos até encontrar o próximo subgrupo $r\left[k_{2}\right]$ que é subconjugado a $r[i+1]$, podendo concluir que ele também é maximal em $r[i+1]$ : portanto, anotamos sua posição na lista de relações de inclusão maximal e acrescentamos à lista e as posições dos subgrupos da lista $r$ que são subconjugados a $r\left[k_{2}\right]$ e já calculados anteriormente. Iterando este procedimento até chegar ao grupo $r$ [1], teremos concluído o cálculo dos subgrupos maximais de $r[i+1]$, a menos de conjugação. Por indução sobre $i$ obtemos a lista $\mathrm{p}$ das posições dos subgrupos maximais de cada subgrupo da lista $r$.

O argumento acima pode ser aplicado a qualquer lista ordenada de subgrupos não conjugados entre si, em particular, à lista de subgrupos não-abelianos. Mesmo com todas essas otimizações, o cálculo das relações de inclusão maximal foi o mais demorado de todos. O tempo de execução variou de alguns dias a algumas semanas. Por outro lado, o espaço de memória necessário para esta operação é pequeno. Desta forma conseguimos calcular, para todos os grupos quasi-simples e suas extensões por automorfismos externos de ordem $\leqslant 10^{10}$ que possuem representações de códons, não somente o conjunto das classes de conjugação de subgrupos mas também as relações de inclusão maximal.

Antes de passar para a próxima etapa, faremos alguns comentários finais. Em primeiro lugar, enfatizamos que o fato que tornou possível ultrapassar os limites do algoritmo do GAP foi que nos restringimos à categoria dos grupos finitos simples e seus satélites. Somente para esta categoria de grupos é que se tem informações tão detalhadas sobre a estrutura dos subgrupos maximais e como foi explicado, estas informações foram fundamentais para resolver o problema de calcular o reticulado dos subgrupos. Em segundo lugar, observamos que estes "recursos adicionais" (que se aplicam a uma categoria bastante restrita de grupos) elevaram por um fator de 10 o limite imposto pelo método das extensões cíclicas.

A principal crítica que se pode fazer ao método das extensões cíclicas é que ele trabalha "de baixo para cima", o que do ponto de vista teórico não é natural. Contudo, do ponto de vista construtivo ou computacional, ele é bem razoável, pois vai do mais simples - os subgrupos cíclicos de ordem prima, que são facilmente construídos - para o mais complicado. Afinal de contas, este algoritmo foi proposto em 1960, isto é, no mínimo vinte anos antes da classificação dos grupos finitos simples. De fato, é impossível calcular os subgrupos maximais de um grupo sem informações adicionais sobre uma parte do conjunto dos seus subgrupos. Recentemente, foram propostos novos métodos [28, 49] que trabalham "de cima para baixo" e, ao que tudo indica, podem ir razoavelmente além do limite imposto pelo método das extensões cíclicas. No entanto, estes métodos exigem que se tenha um banco de dados précalculados contendo todos os grupos de automorfismos de produtos diretos de grupos finitos 
simples, juntamente com todos seus subgrupos maximais, até uma certa ordem. Em resumo, se queremos inverter a direção do algoritmo, precisamos trocar os grupos finitos perfeitos por grupos de automorfismos de (produtos diretos de) grupos finitos simples. Este tipo de algoritmo se tornou viável somente na última década, quando as informações necessárias para compilar um banco de dados como mencionado acima foram disponibilizadas.

A seguir apresentamos uma tabela contendo alguns resultados de todos estes cálculos para os grupos finitos quasi-simples e suas extensões por automorfismos externos de ordem $\leqslant 10^{10}$ que possuem representação de códons. Nesta tabela aparecem 27 grupos, seguidos das seguintes informações:

- $|G|:$ ordem de $G$;

- $|\mathrm{RPF}|$ : grau da representação permutacional fiel de $G$ utilizada;

- \#CCS: número de classes de conjugação de subgrupos de $G$;

- \#CCSNA: número de classes de conjugação de subgrupos não-abelianos de $G$;

- \#CCSM: número de classes de conjugação de subgrupos maximais de $G$.

Todas as representações de códons que enumeramos no capítulo anterior aparecem, pelo menos uma vez, na tabela de caracteres de algum destes grupos.

A notação empregada para a descrição dos grupos da Tabela 5.3 é usada no ATLAS por ser mais compacta. As diferenças com a notação que vimos usando até agora são as seguintes:

- os grupos cíclicos $\mathbb{Z}_{n}$ são representados simplesmente por $n$;

- os recobrimentos cíclicos $\mathbb{Z}_{n} \cdot G$ de $G$ são denotados por n.G;

- os produtos semidiretos de $G$ por um grupo cíclico $\mathbb{Z}_{n}$ são denotados por $G: n$.

Finalmente, observamos que os recobrimentos e extensões por automorfismos externos distintos, porém com a mesma estrutura, são diferenciados por índices nos fatores cíclicos correspondentes. Por exemplo, o grupo $A_{2}(4)$ possui dois recobrimentos quádruplos distintos que são denotados por $4_{1} \cdot A_{2}(4)$ e $4_{2} \cdot A_{2}(4)$. 


\begin{tabular}{|c|c|c|c|c|c|}
\hline$G$ & $|G|$ & $|\mathrm{RPF}|$ & \#CCS & \# CCSNA & \# CCSM \\
\hline$G_{2}(2)$ & 12.096 & 63 & 100 & 72 & 5 \\
\hline 2. $A l t_{8}$ & 40.320 & 240 & 168 & 135 & 6 \\
\hline 2. Alt $t_{8}: 2$ & 80.640 & 480 & 329 & 279 & 7 \\
\hline $4_{1} \cdot A_{2}(4)$ & 80.640 & 224 & 279 & 234 & 9 \\
\hline $4_{1} \cdot A_{2}(4): 2_{3}$ & 161.280 & 224 & 360 & 286 & 6 \\
\hline $4_{2} \cdot A_{2}(4)$ & 80.640 & 224 & 284 & 233 & 9 \\
\hline $4_{2} \cdot A_{2}(4): 2_{2}$ & 161.280 & 224 & 609 & 508 & 6 \\
\hline 2. $A_{2}(4): 2_{1}$ & 80.640 & 224 & 330 & 257 & 10 \\
\hline$A_{2}(4): 3$ & 60.480 & 42 & 100 & 76 & 5 \\
\hline$A_{2}(4): 6$ & 120.960 & 42 & 143 & 109 & 6 \\
\hline 2. $B_{2}(3)$ & 51.840 & 80 & 162 & 120 & 5 \\
\hline 2. $B_{2}(3): 2$ & 103.680 & 240 & 492 & 430 & 6 \\
\hline $2 . S z(8)$ & 58.240 & 1.040 & 42 & 24 & 4 \\
\hline$S z(8): 3$ & 87.360 & 195 & 39 & 25 & 5 \\
\hline${ }^{2} A_{2}(4)$ & 62.400 & 65 & 34 & 20 & 4 \\
\hline${ }^{2} A_{2}(4): 2$ & 124.800 & 260 & 80 & 59 & 5 \\
\hline${ }^{2} A_{2}(4): 4$ & 249.600 & 260 & 120 & 94 & 5 \\
\hline$A_{1}(64)$ & 262.080 & 65 & 76 & 19 & 5 \\
\hline$A_{1}(64): 2$ & 524.160 & 390 & 127 & 72 & 6 \\
\hline$A_{1}(64): 3$ & 786.240 & 390 & 102 & 63 & 6 \\
\hline$A_{1}(64): 6$ & 1.572 .480 & 390 & 182 & 134 & 7 \\
\hline $2 . J_{2}$ & 1.209 .600 & 200 & 244 & 192 & 8 \\
\hline 2. $A_{1}(127)$ & 2.048 .256 & 256 & 51 & 31 & 5 \\
\hline 2. $C_{3}(2)$ & 2.903 .040 & 240 & 1.685 & 1.572 & 8 \\
\hline 2. Alt 10 & 3.628 .800 & 2.400 & 552 & 491 & 7 \\
\hline$G_{2}(3)$ & 4.245 .696 & 351 & 433 & 378 & 10 \\
\hline$G_{2}(3): 2$ & 8.491 .392 & 702 & 399 & 342 & 6 \\
\hline
\end{tabular}

Tabela 5.3: Grupos finitos quasi-simples e suas extensões por automorfismos externos de ordem $\leqslant 10^{10}$ que possuem representações de códons - representações permutacionais fiéis e classes de conjugação de subgrupos, de subgrupos não-abelianos e de subgrupos maximais. 


\subsection{Restrição de Caracteres e Ramificação}

Nesta última etapa, passamos ao estudo das representações de códons propriamente ditas, que é feito através da teoria de caracteres. Para tanto, precisamos explicar como o GAP calcula e manipula tabelas de caracteres.

Para calcular a tabela de caracteres de um grupo finito $G$ é preciso, antes de mais nada, determinar as classes de conjugação de $G$. Isto é feito pelo comando

cc := ConjugacyClasses (g);

que retorna uma lista contendo as classes de conjugação de $G$ parametrizadas por representantes. Dada uma classe de conjugação $C_{i}$ de $G$, consideremos os seguintes números: a ordem de um representante $g_{i}$ de $C_{i}$ e a ordem do centralizador $C_{G}\left(g_{i}\right)$ em $G$ de um representante $g_{i}$ de $C_{i}$ (que é equivalente ao número de elementos de $C_{i}$ pela relação $\left[G: C_{G}\left(g_{i}\right)\right]=\left|C_{i}\right|$ ). É claro que estes dois números não dependem da escolha do representante e portanto são invariantes básicos das classes de conjugação. Em geral, as classes de conjugação de um grupo são ordenadas por seus invariantes básicos: de forma crescente com respeito à ordem da classe de conjugação e entre as classes de mesma ordem, de forma decrescente com respeito à ordem do centralizador. Algumas classes de conjugação formam famílias caracterizadas pelo fato de que todos os subgrupos cíclicos gerados pelos elementos de uma mesma família de classes de conjugação são conjugados em $G$. As classes de conjugação de uma mesma família têm os mesmos invariantes básicos e portanto aparecem juntas na ordenação que definimos acima.

No GAP, o cálculo das classes de conjugação e de seus invariantes é executado automaticamente pela função usada para calcular a tabela de caracteres de $G$ :

$$
\mathrm{t}:=\text { CharacterTable }(\mathrm{g}) \text {; }
$$

A saída desta função é uma estrutura de dados especial que contém todos as informações que podem ser incluídas numa tabela de caracteres, tais como: a ordem das classes de conjugação, a ordem dos centralizadores das classes de conjugação, aplicações de $p$-potências, $p^{\prime}$-partes, etc. No entanto, esta função não calcula os caracteres irredutíveis de $G$. A razão pela qual a função que calcula os caracteres irredutíveis não é automaticamente acionada é que o tempo para sua execução pode ser muito grande. Ademais, certos cálculos com tabelas de caracteres não necessitam dos caracteres irredutíveis, como por exemplo a fusão das classes de conjugação de um subgrupo.

A idéia básica para calcular os caracteres irredutíveis de um grupo $G$ é devida a Burnside. Na álgebra de grupo $\mathbb{C} G$ de $G$, a soma $S_{C}$ dos elementos de uma classe de conjugação $C$ é um elemento do centro $Z(\mathbb{C} G)$; de fato, tomando estas somas para todas as 
classes de conjugação de $G$, obtemos uma base de $Z(\mathbb{C} G)$. Para uma classe de conjugação $C$ fixada, o produto $S_{C} S_{C_{i}}$ decompõe-se numa combinação linear de somas de classes $S_{C_{j}}$ cujos coeficientes com respeito às classes de conjugação $C_{i}$ definem uma matriz $M_{C}$. Como todas as somas de classes estão em $Z(\mathbb{C} G)$, as matrizes $M_{C_{i}}$ comutam e portanto são simultaneamente diagonalizáveis. Os caracteres irredutíveis são então calculados a partir destas formas diagonais. Para efetuar estes cálculos, precisamos das classes de conjugação de $G$ e dos coeficientes dos produtos entre as somas de classes. O método de Dixon-Schneider faz a diagonalização sobre corpos primos $\mathbb{Z}_{p}$ (onde $p$ é um número primo tal que o expoente de $G$ divide $p-1$ e $2 \sqrt{|G|}<p$ ) e o resultado é levantado para $\mathbb{C}$. A diagonalização é feita através de estratégias para selecionar um conjunto pequeno de matrizes $M_{C_{i}}$ afim de otimizar o cálculo da forma diagonal. O método de Dixon-Schneider é eficiente para grupos de ordem $<10^{9} \mathrm{e}$ com número de classes de conjugação da ordem de centenas [130]. Para grupos maiores, os caracteres irredutíveis podem ser calculados por indução de caracteres de subgrupos de $G$.

No GAP o cálculo dos caracteres irredutíveis é feito pelo comando

$$
\mathrm{x}:=\operatorname{Irr}(\mathrm{t})
$$

que executa o algoritmo de Dixon-Schneider e completa a estrutura de dados que armazena a tabela de caracteres com a lista dos caracteres irredutíveis.

Uma vez calculada a tabela de caracteres, podemos usar todo o arsenal de funções que o GAP oferece para manipulação de caracteres e, mais geralmente, de funções de classe sobre um grupo finito $G$. Para a determinação das regras de ramificação, precisamos da função que calcula a restrição de um caracter a um subgrupo $H$ de $G$. Contudo, para aplicar esta função é necessário calcular a tabela de caracteres de $H$ (ou, pelo menos, as classes de conjugação) e as fusões das classes de conjugação de $H$ com respeito a $G$, o que é feito pelo comando

\section{FusionConjugacyClasses $(h, g)$;}

Este comando retorna uma lista, chamada de aplicação de fusão entre $H$ e $G$, que contém na posição $i$ a posição da $i$-ésima classe de conjugação de $H$ na lista das classes de conjugação de $G$. Observe que cada classe de conjugação do subgrupo $H$ esta contida em somente uma classe de conjugação de $G$, por outro lado pode ocorrer que várias classes de conjugação de $H$ estão contidas na mesma classe de conjugação de $G$. É claro que a aplcação de fusão depende de um ordenação das classes de conjugação de ambos os grupos, mas uma vez fixadas estas ordenações, a aplicação de fusão é bem definida. Agora podemos restringir qualquer função de classe sobre $G$ ao subgrupo $H$, em particular podemos restringir o caracter de uma representação de códons, digamos x [13], ao subgrupo $H$ pelo comando

$\mathrm{y}:=$ RestrictedClassfunction $(\mathrm{x}[13], \mathrm{h})$; 
As regras de ramificação são obtidas decompondo a restrição de um caracter em constituintes irredutíveis pelo comando

$1:=$ ConstituentsOfCharacter $(\mathrm{y})$;

que retorna um lista com os caracteres irredutíveis de $H$ que compõem a restrição do caracter de $G$. Para a busca de esquemas que reproduzem o código genético só precisamos das dimensões e multiplicidades que aparecem na decomposição em representações irredutíveis da restrição de uma representação de códons a um subgrupo. As dimensões das representações dos constituintes irredutíveis são obtidos pelo comando

List (1, DegreeOfCharacter);

e as multiplicidades pelo comando

List ( $1, i->$ ScalarProduct $(y, i))$;

Estas informações podem ser arranjadas em uma matriz, chamada de matriz de ramificaçã o, de forma que as dimensões ocupam a primeira coluna, as multiplicidades a segunda coluna e as linhas sejam colocadas por ordem crescente de dimensão. Por exemplo, a matriz de ramificação do código genético é

$$
\left(\begin{array}{ll}
1 & 2 \\
2 & 9 \\
3 & 2 \\
4 & 5 \\
6 & 3
\end{array}\right)
$$

Desta forma, pode-se escrever um programa que percorre a lista de classes de conjugação de subgrupos de um grupo $G$ e calcula a matriz de ramificação para cada subgrupo da lista. Finalmente, podemos construir uma nova lista $\mathrm{b}$, do mesmo tamanho que a lista das classes de conjugação de subgrupos, cuja $i$-ésima entrada é a matriz de ramificação da $i$-ésima classe de conjugação de subgrupos.

Se executarmos este procedimento para cada representação de códons, teremos em mãos todas as informações necessárias para determinar se existe alguma quebra de simetria (na categoria dos grupos finitos simples e seus satélites) capaz de reproduzir a distribuição de multipletos do código genético. 


\subsection{Busca por Quebras de Simetria para o Código Genético}

Sejam $G$ um (satélite de um) grupo finito simples e $\pi$ uma representação de códons de $G$. Como a representação $\pi$ será fixada de agora em diante, não precisaremos mencionála quando nos referirmos aos multipletos que ela produz quando restrita a um subgrupo $H$ de $G$. Assim, por abuso de linguagem, falaremos apenas em multipletos de $H$.

A partir da lista das classes de conjugação de subgrupos de $G$ e da lista das matrizes de ramificação, podemos determinar se um subgrupo $H$ de $G$ reproduz a distribuição de multipletos do código genético: basta verificar se a matriz de ramificação de $H$ contém exatamente as dimensões e multiplicidades do código genético. Terminada esta busca, teremos a lista dos grupos (e respectivos subgrupos) que reproduzem a distribuição de multipletos do código genético através de uma quebra de simetria perfeita, isto é, sem congelamento.

Para determinar as quebras de simetria com congelamento que reproduzem a distribuição de multipletos do código genético, precisamos analisar, para cada subgrupo $H$ de $G$, a matriz de ramificação de $H$ e de seus subgrupos maximais. Aqui precisamos da lista de inclusões maximais que já deve ter sido calculada. Agora procuramos por pares $(H, K)$ de subgrupos de $G$ onde $K$ é subgrupo maximal de $H$ e a restrição da representação de códons de $G$, primeiro a $H$ e depois a $K$, reproduz a distribuição de multipletos do código genético com congelamento de alguns multipletos com respeito a $K$. Este congelamento só pode ser determinado analisando-se como os multipletos de $H$ quebram quando restritos a $K$ e portanto não pode ser obtida apenas a partir das matrizes de ramificação de $G$ para $H$ e de $G$ para $K$. A priori, o número de esquemas a serem analisados é assustador: é o produto do número de representações de códons de $G$ pelo número

$$
\sum_{[H] \in \operatorname{RS}(G)} m[H]
$$

de pares $(H, K)$ de subgrupos de $G$, onde $\operatorname{RS}(G)$ denota o reticulado das classes de conjugação $[H]$ de subgrupos $H$ de $G$ e $m[H]$ é o número de classes de conjugação de subgrupos maximais $K$ de $H$ (que só depende de $[H]$ ). No entanto, pode-se usar a informação fornecida pelas matrizes de ramificação para reduzir o número de pares de subgrupos que deverão ser analisados com maiores detalhes.

Há uma série de condições necessárias para que um par de subgrupos $(H, K)$ seja capaz de reproduzir a distribuição de multipletos do código genético através de uma quebra de simetria com congelamento. Muitas destas restrições já foram utilizadas na análise de cadeias de subalgebras de álgebras de Lie [81,3], reduzindo drasticamente o número de casos a serem analisados com maiores detalhes. Adaptando os critérios usados em [81, 3] à presente situação, introduzimos a seguinte terminologia. 
Um par de subgrupos $(H, K)$ de $G$ será dito admissivel para a representação de códons $\pi$ se $K$ é maximal em $H$ e

- o subgrupo $H$ tem menos que 21 multipletos e o subgrupo $K$ tem mais que 21 multipletos;

- o subgrupo $H$ tem no mínimo três multipletos de dimensão $\geqslant 6$ e no máximo dois multipletos de dimensão 1 e quatro multipletos de dimensão impar;

- o subgrupo $K$ tem no mínimo dois multipletos de dimensão 1 e nenhum multipleto de dimensão 5 ou de dimensão $\geqslant 7$.

- Se o subgrupo $K$ não tem nenhum multipleto de dimensão 3 então o subgrupo $H$ deve ter no mínimo dois multipletos de dimensão 3.

- Se o subgrupo $K$ não tem nenhum multipleto de dimensão 4 então o subgrupo $H$ deve ter no mínimo cinco multipletos de dimensão 4.

- Se o subgrupo $K$ não tem nenhum multipleto de dimensão 6 então o subgrupo $H$ deve ter no mínimo três multipletos de dimensão 6 .

Pode-se escrever então um programa que utiliza duas listas: a lista $\mathrm{p}$ das posições de inclusões maximais e a lista b de matrizes de ramificação, e aplicar estes critérios para determinar todos os pares admissíves de subgrupos.

Como as condições listadas acima são apenas necessárias, a questão se um par admissível $(H, K)$ de subgrupos realmente é capaz de reproduzir a distribuição de multipletos do código genético precisa de uma investigação mais aprofundada. Em primeiro lugar, é necessário que $K$ seja um subgrupo de $H$ e não somente subconjugado a $H$. No entanto, o representante adequado pode ser encontrado rapidamente usando o GAP. Basta então fazer a restrição da representação de códons ao subgrupo $H$, decompô-la em representações irredutíveis sob $H$ e restringir cada uma destas representações ao subgrupo $K$. Assim, obtemos as regras de ramificação para os multipletos de $H$ sob restrição a $K$. Com estas informações a disposição podemos, por inspeção direta de cada caso, decidir se é possível, ou não, congelar alguns multipletos de $H$ de forma correta e reproduzir as degenerescências do código genético.

Lembremos que os multipletos de $H$ dividem-se em componentes isotípicas e dois multipletos pertencem à mesma componente isotípica se e somente se têm o mesmo caracter. Então a seguinte condição deve ser satisfeita para que o congelamento seja correto.

- os multipletos de $H$ que pertencem à mesma componente isotípica ou devem ser todos congelados ou devem ser todos quebrados. 
Outro detalhe que deve ser observado é que se existe uma inclusão entre dois grupos que possuem representações de códons, digamos $G_{2} \subset G_{1}$, tal que a representação de códons de $G_{1}$ permanece irredutível quando restrita a $G_{2}$, então todos os pares admissíveis de subgrupos de $G_{2}$ também são pares admissíveis de subgrupos de $G_{1}$. Neste caso, os pares de subgrupos que já apareceram em $G_{2}$ não são considerados como pares de subgrupos de $G_{1}$, ou em outras palavras,

- o grupo "primordial" para um determinado par de subgrupos é sempre o menor grupo possível.

Finalmente, podemos reconstruir as cadeias de subgrupos que começam em $G$ e terminam em $H$, construindo assim os modelos de quebra de simetria para o código genético. Se existir uma única cadeia então o modelo fica completamente determinado pela dupla $(G, H)$ no caso de quebra de simetria sem congelamento e pela tripla $(G, H, K)$ no caso de quebra de simetria com congelamento.

A seguir apresentamos uma tabela contendo alguns resultados de todos estes cálculos para os grupos finitos quasi-simples e suas extensões por automorfismos externos de ordem $\leqslant 10^{10}$ que possuem representações de códons. Nesta tabela aparecem 27 grupos, seguidos das seguintes informações:

- $|G|:$ ordem de $G$;

- \#RC: o número de representações de códons de $G$ a menos de equivalência;

- \#PS: o número de pares de subgrupos de $G$;

- \#PAS: o número de pares de subgrupos de $G$ que são admissíveis para pelo menos uma das representações de códons de $G$.

A principal observação com respeito a esta tabela é que os críterios que utilizamos reduziram drasticamente a quantidade de dados gerada nos cálculos anteriores e já eliminaram 19 dos 27 grupos que possuem representações de códons. 


\begin{tabular}{|c|c|c|c|c|}
\hline$G$ & $|G|$ & $\# \mathrm{RC}$ & \#PS & \#PAS \\
\hline$G_{2}(2)$ & 12.096 & 1 & 162 & 1 \\
\hline 2. $A l t_{8}$ & 40.320 & 2 & 355 & 2 \\
\hline 2. Alt $t_{8}: 2$ & 80.640 & 4 & 889 & 2 \\
\hline $4_{1} \cdot A_{2}(4)$ & 80.640 & 4 & 737 & 0 \\
\hline $4_{1} \cdot A_{2}(4): 2_{3}$ & 161.280 & 8 & 816 & 0 \\
\hline $4_{2} \cdot A_{2}(4)$ & 80.640 & 4 & 735 & 0 \\
\hline $4_{2} \cdot A_{2}(4): 2_{2}$ & 161.280 & 8 & 1.791 & 0 \\
\hline 2. $A_{2}(4): 2_{1}$ & 80.640 & 4 & 713 & 0 \\
\hline$A_{2}(4): 3$ & 60.480 & 3 & 168 & 0 \\
\hline$A_{2}(4): 6$ & 120.960 & 6 & 249 & 0 \\
\hline 2. $B_{2}(3)$ & 51.840 & 2 & 283 & 1 \\
\hline 2. $B_{2}(3): 2$ & 103.680 & 4 & 1.454 & 19 \\
\hline $2 . S z(8)$ & 58.240 & 2 & 27 & 0 \\
\hline$S z(8): 3$ & 87.360 & 3 & 36 & 0 \\
\hline${ }^{2} A_{2}(4)$ & 62.400 & 1 & 27 & 0 \\
\hline${ }^{2} A_{2}(4): 2$ & 124.800 & 2 & 113 & 0 \\
\hline${ }^{2} A_{2}(4): 4$ & 249.600 & 4 & 206 & 0 \\
\hline$A_{1}(64)$ & 262.080 & 1 & 26 & 0 \\
\hline$A_{1}(64): 2$ & 524.160 & 2 & 153 & 0 \\
\hline$A_{1}(64): 3$ & 786.240 & 3 & 129 & 0 \\
\hline$A_{1}(64): 6$ & 1.572 .480 & 6 & 334 & 0 \\
\hline $2 . J_{2}$ & 1.209 .600 & 2 & 470 & 0 \\
\hline 2. $A_{1}(127)$ & 2.048 .256 & 2 & 43 & 0 \\
\hline $2 . C_{3}(2)$ & 2.903 .040 & 2 & 7.214 & 38 \\
\hline 2. Alt 10 & 3.628 .800 & 2 & 1.623 & 0 \\
\hline$G_{2}(3)$ & 4.245 .696 & 2 & 1.240 & 11 \\
\hline$G_{2}(3): 2$ & 8.491 .392 & 4 & 1.044 & 8 \\
\hline
\end{tabular}

Tabela 5.4: Grupos finitos quasi-simples e suas extensões por automorfismos externos de ordem $\leqslant 10^{10}$ que possuem representações de códons - representações de códons, pares de subgrupos e pares admissíveis de subgrupos. 


\section{Resultados e Perspectivas}

Neste capítulo apresentamos os resultados obtidos na análise das regras de ramificação dos grupos finitos simples e de suas extensões ascendentes e descendentes, que simplesmente chamamos de seus satélites, que possuem representações de códons.

A primeira questão refere-se à possibilidade de reproduzir a distribuição de multipletos do código genético através de quebras de simetria perfeitas, isto é, sem congelamento. O resultado da investigação é o seguinte.

Nenhum dos grupos finitos simples de tipo Lie e esporádicos e seus satélites ou dos grupos alternados e seus satélites com ordem $\leqslant 10^{10}$ reproduz a distribuição de multipletos do código genético através de uma quebra perfeita de simetria.

A segunda questão refere-se à possibilidade de reproduzir a distribuição de multipletos do código genético através de quebras de simetria imperfeitas, isto é, com congelamento. O resultado da investigação é o seguinte.

Entre os grupos finitos simples de tipo Lie e esporádicos e seus satélites e os grupos alternados e seus satélites com ordem $\leqslant 10^{10}$, existem três que reproduzem a distribuição de multipletos do código genético através de quebras de simetria imperfeitas.

A questão referente ao número de quebras distintas produzidas por estes grupos é mais complexa. Em princípio, os pares de subgrupos são classificados a menos de conjugação em $G$ e as representações de códons a menos de equivalência. No entanto, existem outros fatores que levam a identidades adicionais entre esquemas que a priori são considerados distintos. Por exemplo, representações de códons complexas conjugadas produzem as mesmas regras de ramificação, sob restrição a qualquer subgrupo. Portanto, de cada par de representações de códons complexas conjugadas, precisamos investigar apenas uma. Também é claro que quaisquer duas representações de códons de $G$ que coincidem sob restrição a $H$ produzem o mesmo esquema. 
Levando-se em conta todas estas identificações, apresentamos na seguinte tabela uma lista contendo: o número de representações de códons distintas (\#RCD), o número de pares de subgrupos (a menos de automorfismos) que reproduzem o código genético (\#PSCG) para pelo menos uma representação de códons e o número de esquemas realmente distintos de quebra de simetria que reproduzem o código genético (\#QSCG).

\begin{tabular}{ccccc}
\hline$G$ & $|G|$ & \#RCD & \#PSCG & \#QSCG \\
\hline $2 . B_{2}(3): 2$ & 103.680 & 3 & 9 & 12 \\
$2 . C_{3}(2)$ & 2.903 .040 & 1 & 1 & 1 \\
$G_{2}(3)$ & 4.245 .696 & 1 & 6 & 6 \\
\hline
\end{tabular}

Tabela 6.1: Grupos finitos simples e seus satélites que reproduzem as degenerescências do código genético através de quebra de simetria imperfeita.

No final deste capítulo apresentamos uma descrição detalhada dos grupos, dos pares de subgrupos, das cadeias de subgrupos associadas e das quebras de simetria indicados na Tabela 6.1.

Todos os cálculos computacionas foram realizados pelo GAP versão 4.3 para o sistema UNIX, por um processador Pentium III de $1 \mathrm{GHz}$, com memória RAM de 500 Mbytes e com sistema operacional Conectiva LINUX versão 7.0. A alta capacidade computacional e, principalmente, a grando quantidade de memória RAM desta máquina foram fundamentais para a realização dos cálculos.

A principal vantagem da abordagem algébrica que apresentamos é que, se for possível executá-la completamente, o resultado final é a classificação dos possíveis esquemas que podem servir para modelar o fenômeno estudado. Por outro lado, ela não diz nada sobre a interpretação destes modelos, ou seja, como relacionar a estrutura matemática subjacente com os processos que governam o comportameto do fenômeno modelado.

Essa interpretação deve levar em conta como os dados experimentais podem ser verificados no modelo. Por exemplo, fixando uma cadeia de subgrupos que produz um esquema de quebra de simetria de um determinado processo, os subgrupos da cadeia representam os estágios em que se deu o processo. No caso específico do código genético uma das questões mais importantes é sobre o número de aminoácidos utilizados pelo primeiro código genético que surgiu, chamada de "código genético primitivo". Existem vários argumentos indicando que o número de "aminoácidos primitivos" é 5 ou 6 . Nos modelos algébricos o número de "aminoácidos primitivos" é exatamente o número de multipletos do primeiro subgrupo da cadeia. Portanto, esquemas onde a primeira quebra de simetria produz 5 ou 6 multipletos têm maior chance de admitirem alguma interpretação e até fornecerem alguma previsão. 
Outro pré-requisito para obter uma interpretação é a "alocação de códons e aminoácidos" que consiste na distribuição dos códons e correspondentes aminoácidos nos multipletos gerados pela quebra. Há um certo grau de liberdade [81] para fazer esta distribuição, pois um esquema de quebra de simetria só reproduz o número de aminoácidos e o número de códons usado por cada aminoácido. É preciso acrescentar outras estuturas ao modelo, afim de diminuir as ambiguidades ou até mesmo fixar uma única alocação de códons e aminoácidos. Por exemplo, em [53] foram introduzidas regras para a alocação de códons e aminoácidos no modelo baseado no grupo de Lie $S p(6)$ que produzem uma alocação quase sem ambiguidades. Por outro lado, mostramos [4] que estas mesmas regras não podem ser aplicadas nos modelos baseados no grupo de Lie $G_{2}$.

Os resultados deste trabalho podem ser interpretados como a classificação dos grupos finitos simples e suas extensões ascendentes e descendentes que mergulham irredutivelmente no grupo de Lie $S U(64)$ (a menos de conjugação em $S U(64)$ ) e reproduzem o código genético $[74,75]$. Como os grupos finitos são grupos de Lie compactos de dimensão zero, os modelos discretos e contínuos para o código genético podem ser unificados em um único contexto, que inclui os grupos de Lie conexos de dimensão $\geqslant 1$ e os grupos de Lie desconexos de dimensão zero. A próxima extensão da classificação é a inclusão de todos os grupos de Lie compactos, conexos ou não.

Um outro tipo de questão se refere à origem da simetria do código genético e aos mecanismos que provocam a sua quebra. Acreditamos que estas questões podem ser tratadas pela teoria dos sistemas dinâmicos equivariantes dependendo de parâmetros externos e suas bifurcações [81]. Tais bifurcações ocorrem quando (pelo menos) um dos parâmetros é variado até ultrapassar um ponto crítico, o que em sistemas dinâmicos com simetrias é tipicamente acompanhado de uma quebra de simetria [59, 60]. Por outro lado, um sistema dinâmico com parâmetros externos associado a um esquema de quebra de simetria também necessita de uma interpretação: os parâmetros externos devem ser relacionados com algum parâmetro real do fenômeno que está sendo modelado. 


\subsection{Grupos para o código genético}

A notação empregada para a descrição dos subgrupos de cada cadeia é a mesma utilizada no ATLAS para a descrição dos subgrupos maximais. A idéia básica por trás desta notação é mostrar a estrutura dos subgrupos em termos de alguns subgrupos normais que se combinam na forma de extensões de grupos. Há várias possibilidades para um mesmo grupo, se ele não for simples. Procuramos a descrição mais simples possível e que ao mesmo tempo fornecesse alguma informação interessante.

Os três tipos básicos de extensões de grupos são denotadas da seguinte forma:

- $G \times H$, produto direto dos grupos $G$ e $H$;

- $G$ : $H$, produto semidireto dos grupos $G$ e $H$, onde $G$ é o subgrupo normal e $H$ é o complemento;

- $G . H$, extensão não-cindida de $G$ por $H$ ou $H$ por $G$, onde $G$ é o subgrupo normal e $H$ é o quociente.

Usamos também uma notação abreviada para alguns tipos de grupos:

- $n$, grupo cíclico de ordem $n$, onde $n$ é um número inteiro positivo;

- $p^{n}$, grupo abeliano elementar de ordem $p^{n}$, onde $p$ é um número primo;

- $p_{ \pm}^{1+2 n}$, grupo extraespecial: para cada número primo $p$ e inteiro positivo $n$ existem exatamento dois tipos $( \pm)$ de grupo extraespecial;

- $D_{n}$, grupo diedral de ordem $n$, onde $n$ é um número inteiro positivo par;

- $Q_{n}$, grupo quaterniônico ou dicíclico de ordem $n$, onde $n$ é um número inteiro positivo múltiplo de quatro.

Como as representações irredutíveis são descritas pelos respectivos caracteres, incluímos, para maior comodidade, as tabelas de caracteres de todos os grupos que aparecem nas cadeias, inclusive aquelas que também estão no ATLAS. Estas tabelas foram calculadas pelo GAP e estão apresentadas na mesma forma em que aparecem na tela. Nestas tabelas, as primeira linhas de cabeçalho indicam a ordem do centralizador das classes de conjugação decompostas em fatores primos e a última linha indica as ordens e os nomes das classes de conjugação. A notação compacta para números algébricos usada para representar os valores dos caracteres é a mesma do ATLAS, onde encontra-se a explicação completa de como interpretar esta notação. 


\subsubsection{Os Grupos}

\section{$B_{2}(3)$}

O grupo simples $B_{2}(3)$ é o grupo projetivo especial ortogonal reduzido $P \Omega_{5}(3)$ e, devido ao isomorfismo de álgebras de Lie $B_{2} \cong C_{2}$, também é o grupo projetivo simplético $\mathrm{PSp}_{4}(3)$. No primeiro caso, o prefixo "projetivo" pode ser omitido pois o centro de $\Omega_{5}(3)$ é trivial. O seu multiplicador de Schur é $\mathbb{Z}_{2}$ e seu grupo de automorfismos externos é $\mathbb{Z}_{2}$; portanto, existem as extensões $2 . B_{2}(3), B_{2}(3): 2$ e $2 . B_{2}(3): 2$. O modo mais natural de realizar o grupo de interesse, que é a extensão bicíclica $2 . B_{2}(3): 2$, é através da teoria das álgebras de Clifford e dos grupos espinoriais - que pode ser desenvolvida também sobre corpos finitos [10] - para mostrar que

$$
2 . B_{2}(3): 2 \cong \operatorname{Spin}_{5}(3) \text {. }
$$

Este grupo possui quatro representações de códons: duas representações fiéis complexas conjugadas e duas representações reais que se anulam sobre o seu centro e portanto descem para representações lineares do grupo especial ortogonal $\mathrm{SO}_{5}(3)$.

Os seguintes pares de subgrupos (a menos de conjugação) de $\operatorname{Spin}_{5}(3)$ reproduzem a distribuição de multipletos do código genético.

1) $\operatorname{Spin}_{5}(3) \supset Q_{8}:\left(3^{2}: 2^{2}\right) \supset Q_{8}:\left(3^{2} \times 2\right)$

2) $\operatorname{Spin}_{5}(3) \supset Q_{8}:\left(3^{2}: 2^{2}\right) \supset Q_{8}: D_{12}$

3) $\operatorname{Spin}_{5}(3) \supset Q_{8}:\left(3^{2}: 2^{2}\right) \supset 3^{2}: 2^{3}$

4) $\operatorname{Spin}_{5}(3) \supset Q_{8}:\left(3^{2}: 2\right) \supset Q_{8}: 3^{2}$

5) $\operatorname{Spin}_{5}(3) \supset Q_{8}:\left(3^{2}: 2\right) \supset Q_{8}: \operatorname{Sym}_{3}$

6) $\operatorname{Spin}_{5}(3) \supset Q_{8}:\left(3^{2}: 2\right) \supset 3^{2}: 2^{2}$

7) $\operatorname{Spin}_{5}(3) \supset Q_{8}:\left(3^{2}: 2\right) \supset Q_{8}: 3^{2}$

8) $\operatorname{Spin}_{5}(3) \supset Q_{8}:\left(3^{2}: 2\right) \supset Q_{8}: \operatorname{Sym}_{3}$

9) $\operatorname{Spin}_{5}(3) \supset Q_{8}:\left(3^{2}: 2\right) \supset 3^{2}: 2^{2}$

As duas representações de códons reias de $\operatorname{Spin}_{5}(3)$ quando restritas aos subgrupos $H$ dos pares de subgrupos 1-3 coincidem e da mesma maneira as duas representações fiéis complexas conjugadas de $\operatorname{Spin}_{5}(3)$ quando restritas aos subgrupos $H$ dos pares de subgrupos 1-3 também coincidem, mas esta restrição é diferente da obtida a partir das representações 
reais. Portanto cada um dos pares de subgrupos 1-3 gera dois esquemas de quebra de simetria distintos. As quatro representações de códons de $\operatorname{Spin}_{5}(3)$ coincidem quando restritas aos subgrupos $H$ dos pares de subgrupos 4-9. Portanto cada um deles gera um único esquema de quebra de simetria.

O grupo $\operatorname{Spin}_{5}(3)$ possui um grupo de automorfismos externos de ordem 2 que leva os pares de subgrupos 4, 5 e 6 em 7, 8 e 9, respectivamente. Isto faz com que as dimensões e multiplicidades dos esquemas de quebra de simetria entre dois pares que estão relacionados dessa forma sejam iguais, porém as representações subjacentes são diferentes.

As cadeias que podem ser construídas entre os grupos $\operatorname{Spin}_{5}(3)$ e $\left(Q_{8}: 3^{2}\right): 2^{2}$ são as seguintes:

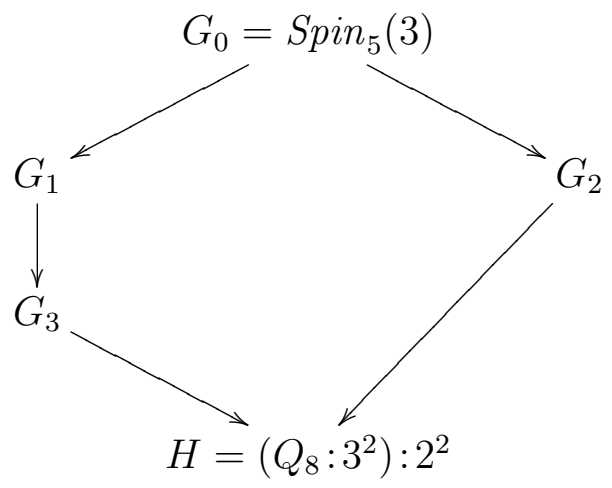

onde

- $\left|G_{1}\right|=2.304$

- $\left|G_{2}\right|=2.592$;

- $\left|G_{3}\right|=1.152$. 
As cadeias que podem ser construídas entre $\operatorname{Spin}_{5}(3)$ e $Q_{8}:\left(3^{2}: 2\right)$ são as seguintes:

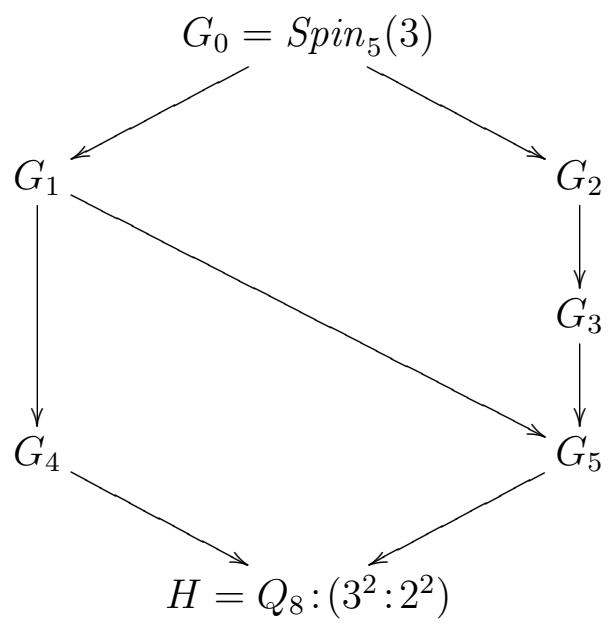

onde

- $\left|G_{1}\right|=2.592$;

- $\left|G_{2}\right|=2.304$;

- $\left|G_{3}\right|=1.152$;

- $\left|G_{4}\right|=1.296$;

- $\left|G_{5}\right|=288, G_{5}=Q_{8}:\left(3^{2}: 2^{2}\right)$ é o subgrupo $H$ dos pares de subgrupos 1-3.

\section{$C_{3}(2)$}

O grupo simples $C_{3}(2)$ é o grupo projetivo simplético $P S p_{6}(2)$ e, devido ao isomorfismo excepcional de grupos de tipo Lie $B_{n}\left(2^{m}\right) \cong C_{n}\left(2^{m}\right)$, também é o grupo projetivo especial ortogonal reduzido $P \Omega_{7}(2)$. Em ambos os casos, o prefixo "projetivo" pode ser omitido pois o centro de $S p_{6}(2)$ e de $\Omega_{7}(2)$ é trivial. O seu multiplicador de Schur é $\mathbb{Z}_{2}$ e seu grupo de automorfismos externos é trivial; portanto, existe somente a extensão ascendente $2 . C_{3}(2)$. O modo mais natural de realizá-la é através da teoria das álgebras de Clifford e dos grupos espinoriais - que pode ser desenvolvida também sobre corpos finitos [10] - para mostrar que

$$
\text { 2. } C_{3}(2) \cong \operatorname{Spin}_{7}(2) \text {. }
$$

Este grupo possui duas representações de códons fiéis complexas conjugadas. Nota-se que o grupo $\operatorname{Spin}_{5}(3)$ é subgrupo maximal (e o de maior ordem) de $\operatorname{Spin}_{7}(2)$ e que as duas 
representações de códons de $\operatorname{Spin}_{7}(2)$ permanecem irredutíveis sob restrição a este subgrupo: elas coincidem com as duas representações de códons fiéis de $\operatorname{Spin}_{5}(3)$ consideradas no item anterior. Portanto, devemos considerar apenas pares admissíveis $(H, K)$ de subgrupos de $\operatorname{Spin}_{7}(2)$ tais que $H$ não é subconjugado a $\operatorname{Spin}_{5}(3)$.

Com esta restrição, existe apenas um par de subgrupos (a menos de automorfismos) de $\operatorname{Spin}_{7}(2)$ que reproduz a distribuição de multipletos do código genético.

1) $\operatorname{Spin}_{7}(2) \supset\left(2^{2} \cdot 2^{4}\right): 3^{2} \supset Q_{8}:\left(3^{2} \times 2\right)$

As cadeias que podem ser construídas entre o grupo $\operatorname{Spin}_{7}(2)$ e $\left(2^{2} .2^{4}\right): 3^{2}$ são as seguintes:

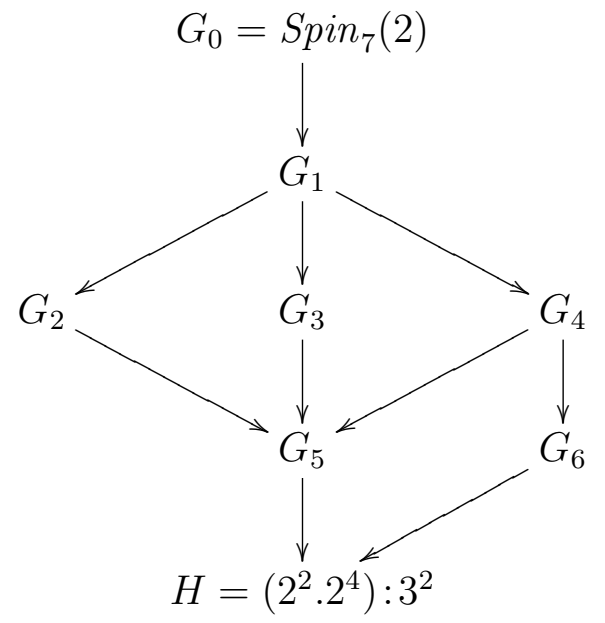

onde

- $\left|G_{1}\right|=9.216$;

- $\left|G_{2}\right|=\left|G_{3}\right|=\left|G_{4}\right|=4.608$, mas os três subgrupos são diferentes;

- $\left|G_{5}\right|=2.034$;

- $\left|G_{6}\right|=1.152$.

\section{$G_{2}(3)$}

O grupo simples $G_{2}(3)$ é naturalmente realizado como um subgrupo de $G L_{7}(3)$ e esta inclusão é induzida pela inclusão análoga do grupo de Lie complexo $G_{2}$ em $G L(7, \mathbb{C})$.

O grupo $G_{2}(3)$ possui duas representações de códons complexas conjugadas.

Os seguintes pares de subgrupos (a menos de automorfismos) de $G_{2}(3)$ reproduzem a distribuição de multipletos do código genético. 
1) $G_{2}(3) \supset Q_{8}:\left(3^{2}: 2\right) \supset Q_{8}: 3^{2}$

2) $G_{2}(3) \supset Q_{8}:\left(3^{2}: 2\right) \supset Q_{8}:$ Sym $_{3}$

3) $G_{2}(3) \supset Q_{8}:\left(3^{2}: 2\right) \supset 3^{2}: 2^{2}$

4) $G_{2}(3) \supset Q_{8}:\left(3^{2}: 2\right) \supset Q_{8}: 3^{2}$

5) $G_{2}(3) \supset Q_{8}:\left(3^{2}: 2\right) \supset Q_{8}:$ Sym $_{3}$

6) $G_{2}(3) \supset Q_{8}:\left(3^{2}: 2\right) \supset 3^{2}: 2^{2}$

O grupo $G_{2}(3)$ possui um grupo de automorfismos externos de ordem 2 que leva os pares de subgrupos 1,2 e 3 em 4, 5 e 6 , respectivamente. Isto faz com que as dimensões e multiplicidades dos esquemas de quebra de simetria entre dois pares que estão relacionados dessa forma sejam iguais, porém as representações subjacentes são diferentes.

As cadeias que podem ser construídas entre o grupo $G_{2}(3)$ e $Q_{8}:\left(3^{2}: 2\right)$ são as seguintes:

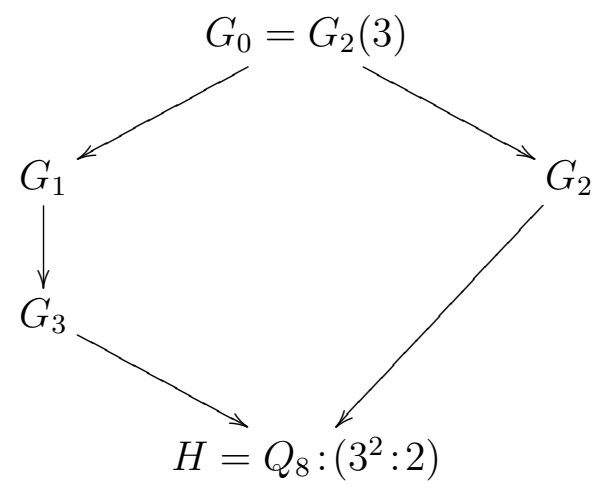

onde

- $\left|G_{1}\right|=11.664$

- $\left|G_{2}\right|=576$

- $\left|G_{3}\right|=1.296$.

\section{Nota:}

Geradores matriciais e permutacionais dos grupos $\operatorname{Spin}_{5}(3), \operatorname{Spin}_{7}(2)$ e $G_{2}(3)$, já no formato do GAP, podem ser obtidos pela internet, no site http://www . mat. bham.ac.uk/atlas/v2.0. 


\subsubsection{Os Esquemas de Quebra de Simetria}

\begin{tabular}{|c|cc|cc|cc|c|}
\hline$\#$ & Grupo $G$ & $|G|$ & Subgrupo $H$ & $|H|$ & Subgrupo $K$ & $|K|$ & Página \\
\hline 1 & $\operatorname{Spin}_{5}(3)$ & 103.608 & $Q_{8}:\left(3^{2}: 2^{2}\right)$ & 288 & $Q_{8}:\left(3^{2} \times 2\right)$ & 144 & 111 \\
2 & $\operatorname{Spin}_{5}(3)$ & 103.608 & $Q_{8}:\left(3^{2}: 2^{2}\right)$ & 288 & $Q_{8}: D_{12}$ & 96 & 112 \\
3 & $\operatorname{Spin}_{5}(3)$ & 103.608 & $Q_{8}:\left(3^{2}: 2^{2}\right)$ & 288 & $3^{2}: 2^{3}$ & 72 & 113 \\
4 & $\operatorname{Spin}_{5}(3)$ & 103.608 & $Q_{8}:\left(3^{2}: 2^{2}\right)$ & 288 & $Q_{8}:\left(3^{2} \times 2\right)$ & 144 & 114 \\
5 & $\operatorname{Spin}_{5}(3)$ & 103.608 & $Q_{8}:\left(3^{2}: 2^{2}\right)$ & 288 & $Q_{8}: D_{12}$ & 96 & 115 \\
6 & $\operatorname{Spin}_{5}(3)$ & 103.608 & $Q_{8}:\left(3^{2}: 2^{2}\right)$ & 288 & $3^{2}: 2^{3}$ & 72 & 116 \\
7 & $\operatorname{Spin}_{5}(3)$ & 103.608 & $Q_{8}:\left(3^{2}: 2\right)$ & 144 & $Q_{8}: 3^{2}$ & 72 & 117 \\
8 & $\operatorname{Spin}_{5}(3)$ & 103.608 & $Q_{8}:\left(3^{2}: 2\right)$ & 144 & $Q_{8}: S y m_{3}$ & 48 & 118 \\
9 & $\operatorname{Spin}_{5}(3)$ & 103.608 & $Q_{8}:\left(3^{2}: 2\right)$ & 144 & $3^{2}: 2^{2}$ & 36 & 119 \\
10 & $\operatorname{Spin}_{5}(3)$ & 103.608 & $Q_{8}:\left(3^{2}: 2\right)$ & 144 & $Q_{8}: 3^{2}$ & 72 & 120 \\
11 & $\operatorname{Spin}_{5}(3)$ & 103.608 & $Q_{8}:\left(3^{2}: 2\right)$ & 144 & $Q_{8}: S y m_{3}$ & 48 & 121 \\
12 & $\operatorname{Spin}_{5}(3)$ & 103.608 & $Q_{8}:\left(3^{2}: 2\right)$ & 144 & $3^{2}: 2^{2}$ & 36 & 122 \\
\hline 13 & $\operatorname{Spin}_{7}(2)$ & 2.903 .040 & $\left(2^{2} \cdot 2^{4}\right): 3^{2}$ & 576 & $Q_{8}:\left(3^{2} \times 2\right)$ & 144 & 123 \\
\hline 14 & $G_{2}(3)$ & 4.245 .696 & $Q_{8}:\left(3^{2}: 2\right)$ & 144 & $Q_{8}: 3^{2}$ & 72 & 124 \\
15 & $G_{2}(3)$ & 4.245 .696 & $Q_{8}:\left(3^{2}: 2\right)$ & 144 & $Q_{8}: S y m_{3}$ & 48 & 125 \\
16 & $G_{2}(3)$ & 4.245 .696 & $Q_{8}:\left(3^{2}: 2\right)$ & 144 & $3^{2}: 2^{2}$ & 36 & 126 \\
17 & $G_{2}(3)$ & 4.245 .696 & $Q_{8}:\left(3^{2}: 2\right)$ & 144 & $Q_{8}: 3^{2}$ & 72 & 127 \\
18 & $G_{2}(3)$ & 4.245 .696 & $Q_{8}:\left(3^{2}: 2\right)$ & 144 & $Q_{8}: S y m_{3}$ & 48 & 128 \\
19 & $G_{2}(3)$ & 4.245 .696 & $Q_{8}:\left(3^{2}: 2\right)$ & 144 & $3^{2}: 2^{2}$ & 36 & 129 \\
\hline & & & & & & \\
\hline
\end{tabular}

Tabela 6.2: Lista das Quebras de Simetria. 


\section{Quebra de Simetria 1}

\begin{tabular}{|c|c|c|c|c|c|}
\hline \multicolumn{2}{|c|}{$G=\operatorname{Spin}_{5}(3)$} & \multicolumn{2}{|c|}{$H=Q_{8}:\left(3^{2}: 2^{2}\right)$} & \multicolumn{2}{|c|}{$K=Q_{8}:\left(3^{2} \times 2\right)$} \\
\hline caracter & $d$ & caracter & $d$ & caracter & $d$ \\
\hline \multirow{32}{*}{$\begin{array}{l}\text { X.27 } \\
\text { X.28 }\end{array}$} & \multirow[t]{32}{*}{64} & \multirow[t]{2}{*}{ X.6 } & \multirow[t]{2}{*}{2} & X.7 & 1 \\
\hline & & & & X.13 & 1 \\
\hline & & X.13 & 2 & X.20 & 2 \\
\hline & & X.15 & 2 & X.20 & 2 \\
\hline & & \multirow[t]{2}{*}{ X.8 } & \multirow[t]{2}{*}{2} & X.9 & 1 \\
\hline & & & & X.17 & 1 \\
\hline & & \multirow[t]{2}{*}{ X.8 } & \multirow[t]{2}{*}{2} & X.9 & 1 \\
\hline & & & & X.17 & 1 \\
\hline & & \multirow[t]{2}{*}{ X.12 } & \multirow[t]{2}{*}{2} & X.11 & 1 \\
\hline & & & & $\mathrm{X} .15$ & 1 \\
\hline & & \multirow[t]{2}{*}{ X.22 } & \multirow[t]{2}{*}{4} & X.30 & 2 \\
\hline & & & & X.36 & 2 \\
\hline & & \multirow[t]{2}{*}{ X.24 } & \multirow[t]{2}{*}{4} & X.26 & 2 \\
\hline & & & & X.34 & 2 \\
\hline & & $\mathrm{X} .17$ & 3 & $\mathrm{X} .37$ & 3 \\
\hline & & X.18 & 3 & $\mathrm{X} .37$ & 3 \\
\hline & & \multirow[t]{2}{*}{ X.25 } & \multirow[t]{2}{*}{4} & X.28 & 2 \\
\hline & & & & $\mathrm{X} .32$ & 2 \\
\hline & & \multirow[t]{2}{*}{$\mathrm{X} .25$} & \multirow[t]{2}{*}{4} & $\mathrm{X} .28$ & 2 \\
\hline & & & & X.32 & 2 \\
\hline & & \multirow[t]{2}{*}{$\mathrm{X} .27$} & \multirow[t]{2}{*}{4} & X.22 & 2 \\
\hline & & & & X.24 & 2 \\
\hline & & \multirow[t]{2}{*}{ X.27 } & \multirow[t]{2}{*}{4} & X.22 & 2 \\
\hline & & & & X.24 & 2 \\
\hline & & \multirow[t]{2}{*}{ X.27 } & \multirow[t]{2}{*}{4} & X.22 & 2 \\
\hline & & & & X.24 & 2 \\
\hline & & \multirow[t]{2}{*}{ X.30 } & \multirow[t]{2}{*}{6} & X.39 & 3 \\
\hline & & & & X.41 & 3 \\
\hline & & X.30 & 6 & X.39 & 3 \\
\hline & & & & X.41 & 3 \\
\hline & & $\mathrm{X} .30$ & 6 & X.39 & 3 \\
\hline & & & & X.41 & 3 \\
\hline 1 subes & & 18 subes & os & 24 subesp & çOS \\
\hline
\end{tabular}




\section{Quebra de Simetria 2}

\begin{tabular}{|c|c|c|c|c|c|}
\hline \multicolumn{2}{|c|}{$G=\operatorname{Spin}_{5}(3)$} & \multicolumn{2}{|c|}{$H=Q_{8}:\left(3^{2}: 2^{2}\right)$} & \multicolumn{2}{|c|}{$K=Q_{8}: D_{12}$} \\
\hline caracter & $d$ & caracter & $d$ & caracter & $d$ \\
\hline \multirow{24}{*}{$\begin{array}{l}\text { X.27 } \\
\text { X.28 }\end{array}$} & \multirow[t]{24}{*}{64} & \multirow[t]{2}{*}{$\mathrm{X} .12$} & \multirow[t]{2}{*}{2} & X.1 & 1 \\
\hline & & & & X.3 & 1 \\
\hline & & $\mathrm{X} .8$ & 2 & X.6 & 2 \\
\hline & & X.8 & 2 & X.6 & 2 \\
\hline & & X.6 & 2 & X.6 & 2 \\
\hline & & $\mathrm{X} .13$ & 2 & X.7 & 2 \\
\hline & & $\mathrm{X} .15$ & 2 & X.9 & 2 \\
\hline & & \multirow[t]{2}{*}{$\mathrm{X} .25$} & \multirow[t]{2}{*}{4} & X.7 & 2 \\
\hline & & & & X.9 & 2 \\
\hline & & \multirow[t]{2}{*}{$\mathrm{X} .25$} & \multirow[t]{2}{*}{4} & X.7 & 2 \\
\hline & & & & X.9 & 2 \\
\hline & & $\mathrm{X} .17$ & 3 & X.11 & 3 \\
\hline & & $\mathrm{X} .18$ & 3 & $\mathrm{X} .12$ & 3 \\
\hline & & $\mathrm{X} .22$ & 4 & X.16 & 4 \\
\hline & & $\mathrm{X} .23$ & 4 & X.16 & 4 \\
\hline & & $\mathrm{X} .27$ & 4 & X.16 & 4 \\
\hline & & $\mathrm{X} .27$ & 4 & $\mathrm{X} .16$ & 4 \\
\hline & & $\mathrm{X} .27$ & 4 & $\mathrm{X} .16$ & 4 \\
\hline & & \multirow[t]{2}{*}{$\mathrm{X} .30$} & \multirow[t]{2}{*}{6} & X.11 & 3 \\
\hline & & & & $\mathrm{X} .12$ & 3 \\
\hline & & \multirow[t]{2}{*}{ X.30 } & \multirow[t]{2}{*}{6} & X.11 & 3 \\
\hline & & & & X.12 & 3 \\
\hline & & \multirow[t]{2}{*}{$\mathrm{X} .30$} & \multirow[t]{2}{*}{6} & X.11 & 3 \\
\hline & & & & $\mathrm{X} .12$ & 3 \\
\hline \multicolumn{2}{|l|}{1 subes } & \multicolumn{2}{|c|}{18 subespaços } & \multicolumn{2}{|c|}{24 subespaços } \\
\hline
\end{tabular}




\section{Quebra de Simetria 3}

\begin{tabular}{|c|c|c|c|c|c|}
\hline \multicolumn{2}{|c|}{$G=\operatorname{Spin}_{5}(3)$} & \multicolumn{2}{|c|}{$H=Q_{8}:\left(3^{2}: 2^{2}\right)$} & \multicolumn{2}{|c|}{$K=3^{2}: 2^{3}$} \\
\hline caracter & $d$ & caracter & $d$ & caracter & $d$ \\
\hline \multirow{34}{*}{$\begin{array}{l}\text { X.27 } \\
\text { X.28 }\end{array}$} & \multirow[t]{34}{*}{64} & \multirow[t]{3}{*}{ X.22 } & \multirow[t]{3}{*}{4} & X.7 & 1 \\
\hline & & & & X.8 & 1 \\
\hline & & & & X.17 & 2 \\
\hline & & X.6 & 2 & X.24 & 2 \\
\hline & & X.8 & 2 & $\mathrm{X} .13$ & 2 \\
\hline & & X.8 & 2 & X.13 & 2 \\
\hline & & X.12 & 2 & X.9 & 2 \\
\hline & & $\mathrm{X} .13$ & 2 & $\mathrm{X} .17$ & 2 \\
\hline & & $\mathrm{X} .15$ & 2 & $\mathrm{X} .17$ & 2 \\
\hline & & \multirow[t]{2}{*}{ X.24 } & \multirow[t]{2}{*}{4} & $\mathrm{X} .12$ & 2 \\
\hline & & & & X.20 & 2 \\
\hline & & \multirow[t]{2}{*}{ X.17 } & \multirow[t]{2}{*}{3} & X.1 & 1 \\
\hline & & & & X.24 & 2 \\
\hline & & \multirow[t]{2}{*}{ X.18 } & \multirow[t]{2}{*}{3} & X.2 & 1 \\
\hline & & & & $\mathrm{X} .24$ & 2 \\
\hline & & \multirow[t]{2}{*}{$\mathrm{X} .25$} & \multirow[t]{2}{*}{4} & X.16 & 2 \\
\hline & & & & X.20 & 2 \\
\hline & & \multirow[t]{2}{*}{$\mathrm{X} .25$} & \multirow[t]{2}{*}{4} & X.16 & 2 \\
\hline & & & & X.20 & 2 \\
\hline & & \multirow[t]{2}{*}{$\mathrm{X} .27$} & \multirow[t]{2}{*}{4} & $\mathrm{X} .12$ & 2 \\
\hline & & & & X.16 & 2 \\
\hline & & \multirow[t]{2}{*}{$\mathrm{X} .27$} & \multirow[t]{2}{*}{4} & X.12 & 2 \\
\hline & & & & X.16 & 2 \\
\hline & & \multirow[t]{2}{*}{ X.27 } & \multirow[t]{2}{*}{4} & X.12 & 2 \\
\hline & & & & X.16 & 2 \\
\hline & & \multirow[t]{3}{*}{ X.30 } & \multirow[t]{3}{*}{6} & X.9 & 2 \\
\hline & & & & X.13 & 2 \\
\hline & & & & X.21 & 2 \\
\hline & & \multirow[t]{3}{*}{ X.30 } & \multirow[t]{3}{*}{6} & X.9 & 2 \\
\hline & & & & X.13 & 2 \\
\hline & & & & $\mathrm{X} .21$ & 2 \\
\hline & & \multirow[t]{3}{*}{ X.30 } & 6 & X.9 & 2 \\
\hline & & & & X.13 & 2 \\
\hline & & & & X.21 & 2 \\
\hline 1 subesp & & 18 subes & $\mathrm{OS}$ & 24 subest & cos \\
\hline
\end{tabular}




\section{Quebra de Simetria 4}

\begin{tabular}{|c|c|c|c|c|c|}
\hline \multicolumn{2}{|c|}{$G=\operatorname{Spin}_{5}(3)$} & \multicolumn{4}{|c|}{$H=Q_{8}:\left(3^{2}: 2^{2}\right) \quad K=Q_{8}:\left(3^{2} \times 2\right)$} \\
\hline caracter & $d$ & caracter & $d$ & caracter & $d$ \\
\hline \multirow[t]{32}{*}{$\mathrm{X} .29=\overline{\mathrm{X} .30}$} & \multirow[t]{32}{*}{64} & \multirow[t]{2}{*}{$\mathrm{X} .5$} & \multirow[t]{2}{*}{2} & X.8 & 1 \\
\hline & & & & X.14 & 1 \\
\hline & & X.14 & 2 & X.19 & 2 \\
\hline & & X.16 & 2 & X.19 & 2 \\
\hline & & \multirow[t]{2}{*}{ X.7 } & \multirow[t]{2}{*}{2} & X.10 & 1 \\
\hline & & & & X.18 & 1 \\
\hline & & \multirow[t]{2}{*}{ X.7 } & \multirow[t]{2}{*}{2} & X.10 & 1 \\
\hline & & & & X.18 & 1 \\
\hline & & \multirow[t]{2}{*}{ X.9 } & \multirow[t]{2}{*}{2} & $\mathrm{X} .12$ & 1 \\
\hline & & & & X.16 & 1 \\
\hline & & \multirow[t]{2}{*}{$\mathrm{X} .21$} & \multirow[t]{2}{*}{4} & X.29 & 2 \\
\hline & & & & X.35 & 2 \\
\hline & & \multirow[t]{2}{*}{$\mathrm{X} .23$} & \multirow[t]{2}{*}{4} & $\mathrm{X} .25$ & 2 \\
\hline & & & & X.33 & 2 \\
\hline & & X.19 & 3 & $\mathrm{X} .38$ & 3 \\
\hline & & X.20 & 3 & X.38 & 3 \\
\hline & & \multirow[t]{2}{*}{ X.28 } & \multirow[t]{2}{*}{4} & $\mathrm{X} .27$ & 2 \\
\hline & & & & X.31 & 2 \\
\hline & & \multirow[t]{2}{*}{ X.28 } & \multirow[t]{2}{*}{4} & $\mathrm{X} .27$ & 2 \\
\hline & & & & X.31 & 2 \\
\hline & & \multirow[t]{2}{*}{ X.26 } & \multirow[t]{2}{*}{4} & X.21 & 2 \\
\hline & & & & $\mathrm{X} .23$ & 2 \\
\hline & & \multirow[t]{2}{*}{$\mathrm{X} .26$} & \multirow[t]{2}{*}{4} & X.21 & 2 \\
\hline & & & & $\mathrm{X} .23$ & 2 \\
\hline & & \multirow[t]{2}{*}{$\mathrm{X} .26$} & \multirow[t]{2}{*}{4} & X.21 & 2 \\
\hline & & & & $\mathrm{X} .23$ & 2 \\
\hline & & \multirow[t]{2}{*}{ X.29 } & \multirow[t]{2}{*}{6} & X.40 & 3 \\
\hline & & & & X.42 & 3 \\
\hline & & \multirow[t]{2}{*}{ X.29 } & 6 & X.40 & 3 \\
\hline & & & & $\mathrm{X} .42$ & 3 \\
\hline & & X.29 & 6 & $\mathrm{X} .40$ & 3 \\
\hline & & & & $\mathrm{X} .42$ & 3 \\
\hline 1 subespa & & 18 subes & & 24 subes & ços \\
\hline
\end{tabular}




\section{Quebra de Simetria 5}

\begin{tabular}{|c|c|c|c|c|c|}
\hline \multicolumn{2}{|c|}{$G=\operatorname{Spin}_{5}(3)$} & \multicolumn{2}{|c|}{$H=Q_{8}:\left(3^{2}: 2^{2}\right)$} & \multicolumn{2}{|c|}{$K=Q_{8}: D_{12}$} \\
\hline caracter & $d$ & caracter & $d$ & caracter & $d$ \\
\hline \multirow[t]{24}{*}{$\mathrm{X} .29=\overline{\mathrm{X} .30}$} & \multirow[t]{24}{*}{64} & \multirow[t]{2}{*}{ X.9 } & \multirow[t]{2}{*}{2} & X.3 & 1 \\
\hline & & & & $\mathrm{X} .4$ & 1 \\
\hline & & X.7 & 2 & $\mathrm{X} .5$ & 2 \\
\hline & & X.7 & 2 & $\mathrm{X} .5$ & 2 \\
\hline & & $\mathrm{X} .5$ & 2 & $\mathrm{X} .5$ & 2 \\
\hline & & X.14 & 2 & X.8 & 2 \\
\hline & & X.16 & 2 & X.10 & 2 \\
\hline & & \multirow[t]{2}{*}{ X.28 } & \multirow[t]{2}{*}{4} & X.8 & 2 \\
\hline & & & & X.10 & 2 \\
\hline & & \multirow[t]{2}{*}{$\mathrm{X} .28$} & \multirow[t]{2}{*}{4} & X.8 & 2 \\
\hline & & & & X.10 & 2 \\
\hline & & X.19 & 3 & X.13 & 3 \\
\hline & & X.20 & 3 & X.14 & 3 \\
\hline & & $\mathrm{X} .21$ & 4 & $\mathrm{X} .15$ & 4 \\
\hline & & $\mathrm{X} .23$ & 4 & X.15 & 4 \\
\hline & & X.26 & 4 & $\mathrm{X} .15$ & 4 \\
\hline & & $\mathrm{X} .26$ & 4 & $\mathrm{X} .15$ & 4 \\
\hline & & X.26 & 4 & $\mathrm{X} .15$ & 4 \\
\hline & & \multirow[t]{2}{*}{ X.29 } & \multirow[t]{2}{*}{6} & X.13 & 3 \\
\hline & & & & X.14 & 3 \\
\hline & & \multirow[t]{2}{*}{ X.29 } & \multirow[t]{2}{*}{6} & $\mathrm{X} .13$ & 3 \\
\hline & & & & X.14 & 3 \\
\hline & & \multirow[t]{2}{*}{ X.29 } & \multirow[t]{2}{*}{6} & X.13 & 3 \\
\hline & & & & X.14 & 3 \\
\hline \multicolumn{2}{|c|}{1 subespaço } & \multicolumn{2}{|c|}{18 subespaços } & \multicolumn{2}{|c|}{24 subespaços } \\
\hline
\end{tabular}




\section{Quebra de Simetria 6}

\begin{tabular}{|c|c|c|c|c|c|}
\hline \multicolumn{2}{|c|}{$G=\operatorname{Spin}_{5}(3)$} & \multicolumn{2}{|c|}{$H=Q_{8}:\left(3^{2}: 2^{2}\right)$} & \multicolumn{2}{|c|}{$K=3^{2}: 2^{3}$} \\
\hline caracter & $d$ & caracter & $d$ & caracter & $d$ \\
\hline \multirow{34}{*}{$\mathrm{X} .29=\overline{\mathrm{X} .30}$} & \multirow[t]{34}{*}{64} & \multirow[t]{3}{*}{$\mathrm{X} .21$} & \multirow[t]{3}{*}{4} & X.5 & 1 \\
\hline & & & & X.6 & 1 \\
\hline & & & & X.18 & 2 \\
\hline & & X.5 & 2 & X.23 & 2 \\
\hline & & X.7 & 2 & X.14 & 2 \\
\hline & & X.7 & 2 & X.14 & 2 \\
\hline & & X.9 & 2 & X.10 & 2 \\
\hline & & X.14 & 2 & X.18 & 2 \\
\hline & & X.16 & 2 & X.18 & 2 \\
\hline & & \multirow[t]{2}{*}{ X.24 } & \multirow[t]{2}{*}{4} & X.12 & 2 \\
\hline & & & & X.20 & 2 \\
\hline & & \multirow[t]{2}{*}{ X.19 } & \multirow[t]{2}{*}{3} & $\mathrm{X} .4$ & 1 \\
\hline & & & & X.23 & 2 \\
\hline & & \multirow[t]{2}{*}{ X.20 } & \multirow[t]{2}{*}{3} & X.3 & 1 \\
\hline & & & & X.23 & 2 \\
\hline & & \multirow[t]{2}{*}{ X.28 } & \multirow[t]{2}{*}{4} & X.15 & 2 \\
\hline & & & & X.19 & 2 \\
\hline & & \multirow[t]{2}{*}{ X.28 } & \multirow[t]{2}{*}{4} & X.15 & 2 \\
\hline & & & & X.19 & 2 \\
\hline & & \multirow[t]{2}{*}{ X.26 } & \multirow[t]{2}{*}{4} & X.11 & 2 \\
\hline & & & & X.15 & 2 \\
\hline & & \multirow[t]{2}{*}{ X.26 } & \multirow[t]{2}{*}{4} & X.11 & 2 \\
\hline & & & & X.15 & 2 \\
\hline & & \multirow[t]{2}{*}{ X.26 } & \multirow[t]{2}{*}{4} & X.11 & 2 \\
\hline & & & & X.15 & 2 \\
\hline & & \multirow[t]{3}{*}{ X.29 } & \multirow[t]{3}{*}{6} & X.10 & 2 \\
\hline & & & & X.14 & 2 \\
\hline & & & & X.22 & 2 \\
\hline & & \multirow[t]{3}{*}{ X.29 } & \multirow[t]{3}{*}{6} & X.10 & 2 \\
\hline & & & & X.14 & 2 \\
\hline & & & & X.22 & 2 \\
\hline & & \multirow[t]{3}{*}{ X.29 } & 6 & X.10 & 2 \\
\hline & & & & X.14 & 2 \\
\hline & & & & X.22 & 2 \\
\hline 1 subespaç & & 18 subes & ços & 24 subes & \\
\hline
\end{tabular}




\section{Quebra de Simetria 7}

\begin{tabular}{|c|c|c|c|c|c|}
\hline \multicolumn{2}{|c|}{$G=\operatorname{Spin}_{5}(3)$} & \multicolumn{2}{|c|}{$H=Q_{8}:\left(3^{2}: 2\right)$} & \multicolumn{2}{|c|}{$K=Q_{8}: 3^{2}$} \\
\hline caracter & $d$ & caracter & $d$ & caracter & $d$ \\
\hline \multirow{32}{*}{$\begin{array}{c}\mathrm{X} .29=\overline{\mathrm{X} .30} \\
\mathrm{X} .27 \\
\mathrm{X} .28\end{array}$} & \multirow[t]{32}{*}{64} & \multirow[t]{2}{*}{ X.3 } & \multirow[t]{2}{*}{2} & $\mathrm{X} .2$ & 1 \\
\hline & & & & X.3 & 1 \\
\hline & & X.7 & 2 & X.10 & 2 \\
\hline & & X.8 & 2 & X.10 & 2 \\
\hline & & \multirow[t]{2}{*}{ X.5 } & \multirow[t]{2}{*}{2} & X.4 & 1 \\
\hline & & & & X.7 & 1 \\
\hline & & \multirow[t]{2}{*}{ X.5 } & \multirow[t]{2}{*}{2} & X.4 & 1 \\
\hline & & & & X.7 & 1 \\
\hline & & \multirow[t]{2}{*}{ X.6 } & \multirow[t]{2}{*}{2} & X.5 & 1 \\
\hline & & & & X.9 & 1 \\
\hline & & \multirow[t]{2}{*}{ X.11 } & \multirow[t]{2}{*}{4} & X.11 & 2 \\
\hline & & & & X.12 & 2 \\
\hline & & \multirow[t]{2}{*}{$\mathrm{X} .14$} & \multirow[t]{2}{*}{4} & X.13 & 2 \\
\hline & & & & X.16 & 2 \\
\hline & & X.9 & 3 & X.19 & 3 \\
\hline & & X.10 & 3 & X.19 & 3 \\
\hline & & \multirow[t]{2}{*}{$\mathrm{X} .13$} & \multirow[t]{2}{*}{4} & X.14 & 2 \\
\hline & & & & X.18 & 2 \\
\hline & & \multirow[t]{2}{*}{ X.13 } & \multirow[t]{2}{*}{4} & X.14 & 2 \\
\hline & & & & X.18 & 2 \\
\hline & & \multirow[t]{2}{*}{ X.12 } & \multirow[t]{2}{*}{4} & X.15 & 2 \\
\hline & & & & X.17 & 2 \\
\hline & & \multirow[t]{2}{*}{ X.12 } & \multirow[t]{2}{*}{4} & X.15 & 2 \\
\hline & & & & X.17 & 2 \\
\hline & & \multirow[t]{2}{*}{$\mathrm{X} .12$} & \multirow[t]{2}{*}{4} & X.15 & 2 \\
\hline & & & & $\mathrm{X} .17$ & 2 \\
\hline & & \multirow[t]{2}{*}{ X.15 } & \multirow[t]{2}{*}{6} & X.20 & 3 \\
\hline & & & & X.21 & 3 \\
\hline & & X.15 & 6 & X.20 & 3 \\
\hline & & & & X.21 & 3 \\
\hline & & X.15 & 6 & X.20 & 3 \\
\hline & & & & X.21 & 3 \\
\hline 1 subespac & & 18 subes & & 24 subest & ços \\
\hline
\end{tabular}




\section{Quebra de Simetria 8}

\begin{tabular}{|c|c|c|c|c|c|}
\hline \multicolumn{2}{|c|}{$G=\operatorname{Spin}_{5}(3)$} & \multicolumn{2}{|c|}{$H=Q_{8}:\left(3^{2}: 2\right)$} & \multicolumn{2}{|c|}{$K=Q_{8}: S y m_{3}$} \\
\hline caracter & $d$ & caracter & $d$ & caracter & $d$ \\
\hline \multirow{24}{*}{$\begin{array}{c}\mathrm{X} .29=\overline{\mathrm{X} .30} \\
\mathrm{X} .27 \\
\mathrm{X} .28\end{array}$} & \multirow[t]{24}{*}{64} & \multirow[t]{2}{*}{ X.6 } & \multirow[t]{2}{*}{2} & X.1 & 1 \\
\hline & & & & $\mathrm{X} .2$ & 1 \\
\hline & & X.3 & 2 & X.3 & 2 \\
\hline & & $\mathrm{X} .5$ & 2 & X.3 & 2 \\
\hline & & $\mathrm{X} .5$ & 2 & $\mathrm{X} .3$ & 2 \\
\hline & & X.7 & 2 & $\mathrm{X} .5$ & 2 \\
\hline & & X.8 & 2 & $\mathrm{X} .4$ & 2 \\
\hline & & \multirow[t]{2}{*}{$\mathrm{X} .13$} & \multirow[t]{2}{*}{4} & $\mathrm{X} .4$ & 2 \\
\hline & & & & $\mathrm{X} .5$ & 2 \\
\hline & & \multirow[t]{2}{*}{$\mathrm{X} .13$} & \multirow[t]{2}{*}{4} & $\mathrm{X} .4$ & 2 \\
\hline & & & & $\mathrm{X} .5$ & 2 \\
\hline & & X.9 & 3 & X.6 & 3 \\
\hline & & X.10 & 3 & X.7 & 3 \\
\hline & & X.11 & 4 & X.8 & 4 \\
\hline & & X.14 & 4 & X.8 & 4 \\
\hline & & X.12 & 4 & X.8 & 4 \\
\hline & & $\mathrm{X} .12$ & 4 & X.8 & 4 \\
\hline & & X.12 & 4 & X.8 & 4 \\
\hline & & \multirow[t]{2}{*}{$\mathrm{X} .15$} & \multirow[t]{2}{*}{6} & X.6 & 3 \\
\hline & & & & $\mathrm{X} .7$ & 3 \\
\hline & & \multirow[t]{2}{*}{$\mathrm{X} .15$} & \multirow[t]{2}{*}{6} & X.6 & 3 \\
\hline & & & & $\mathrm{X} .7$ & 3 \\
\hline & & \multirow[t]{2}{*}{ X.15 } & \multirow[t]{2}{*}{6} & X.6 & 3 \\
\hline & & & & X.7 & 3 \\
\hline \multicolumn{2}{|c|}{1 subespaço } & \multicolumn{2}{|c|}{18 subespaços } & \multicolumn{2}{|c|}{24 subespaços } \\
\hline
\end{tabular}




\section{Quebra de Simetria 9}

\begin{tabular}{|c|c|c|c|c|c|}
\hline \multicolumn{2}{|c|}{$G=\operatorname{Spin}_{5}(3)$} & \multicolumn{2}{|c|}{$H=Q_{8}:\left(3^{2}: 2\right)$} & \multicolumn{2}{|c|}{$K=3^{2}: 2^{2}$} \\
\hline caracter & $d$ & caracter & $d$ & caracter & $d$ \\
\hline \multirow{34}{*}{$\begin{array}{c}\mathrm{X} .29=\overline{\mathrm{X} .30} \\
\mathrm{X} .27 \\
\mathrm{X} .28\end{array}$} & \multirow[t]{34}{*}{64} & \multirow[t]{3}{*}{ X.11 } & \multirow[t]{3}{*}{4} & $\mathrm{X} .3$ & 1 \\
\hline & & & & X.4 & 1 \\
\hline & & & & X.6 & 2 \\
\hline & & X.3 & 2 & $\mathrm{X} .5$ & 2 \\
\hline & & $\mathrm{X} .5$ & 2 & X.11 & 2 \\
\hline & & X.5 & 2 & X.11 & 2 \\
\hline & & X.6 & 2 & X.8 & 2 \\
\hline & & X.7 & 2 & X.6 & 2 \\
\hline & & X.8 & 2 & X.6 & 2 \\
\hline & & \multirow[t]{2}{*}{ X.14 } & \multirow[t]{2}{*}{4} & $\mathrm{X} .7$ & 2 \\
\hline & & & & X.9 & 2 \\
\hline & & \multirow[t]{2}{*}{ X.9 } & \multirow[t]{2}{*}{3} & $\mathrm{X} .1$ & 1 \\
\hline & & & & $\mathrm{X} .5$ & 2 \\
\hline & & \multirow[t]{2}{*}{ X.10 } & \multirow[t]{2}{*}{3} & $\mathrm{X} .2$ & 1 \\
\hline & & & & $\mathrm{X} .5$ & 2 \\
\hline & & \multirow[t]{2}{*}{$\mathrm{X} .13$} & \multirow[t]{2}{*}{4} & X.9 & 2 \\
\hline & & & & $\mathrm{X} .10$ & 2 \\
\hline & & \multirow[t]{2}{*}{ X.13 } & \multirow[t]{2}{*}{4} & X.9 & 2 \\
\hline & & & & $\mathrm{X} .10$ & 2 \\
\hline & & \multirow{2}{*}{ X.12 } & \multirow[t]{2}{*}{4} & $\mathrm{X} .7$ & 2 \\
\hline & & & & $\mathrm{X} .10$ & 2 \\
\hline & & \multirow[t]{2}{*}{ X.12 } & \multirow[t]{2}{*}{4} & X.7 & 2 \\
\hline & & & & X.10 & 2 \\
\hline & & \multirow[t]{2}{*}{ X.12 } & \multirow[t]{2}{*}{4} & X.7 & 2 \\
\hline & & & & $\mathrm{X} .10$ & 2 \\
\hline & & \multirow[t]{3}{*}{$\mathrm{X} .15$} & \multirow[t]{3}{*}{6} & $\mathrm{X} .8$ & 2 \\
\hline & & & & X.11 & 2 \\
\hline & & & & $\mathrm{X} .12$ & 2 \\
\hline & & \multirow[t]{3}{*}{ X.15 } & \multirow[t]{3}{*}{6} & X.8 & 2 \\
\hline & & & & X.11 & 2 \\
\hline & & & & X.12 & 2 \\
\hline & & \multirow[t]{3}{*}{$\mathrm{X} .15$} & 6 & X.8 & 2 \\
\hline & & & & X.11 & 2 \\
\hline & & & & X.12 & 2 \\
\hline 1 subespac & & 18 subes & & 24 subesp & \\
\hline
\end{tabular}




\section{Quebra de Simetria 10}

\begin{tabular}{|c|c|c|c|c|c|}
\hline \multicolumn{2}{|c|}{$G=\operatorname{Spin}_{5}(3)$} & \multicolumn{2}{|c|}{$H=Q_{8}:\left(3^{2}: 2\right)$} & \multicolumn{2}{|c|}{$K=Q_{8}: 3^{2}$} \\
\hline caracter & $d$ & caracter & $d$ & caracter & $d$ \\
\hline \multirow{32}{*}{$\begin{array}{c}\mathrm{X} .29=\overline{\mathrm{X} .30} \\
\mathrm{X} .27 \\
\mathrm{X} .28\end{array}$} & \multirow[t]{32}{*}{64} & \multirow[t]{2}{*}{ X.3 } & \multirow[t]{2}{*}{2} & $\mathrm{X} .2$ & 1 \\
\hline & & & & $\mathrm{X} .3$ & 1 \\
\hline & & X.7 & 2 & X.10 & 2 \\
\hline & & X.8 & 2 & X.10 & 2 \\
\hline & & \multirow[t]{2}{*}{$\mathrm{X} .5$} & \multirow[t]{2}{*}{2} & X.4 & 1 \\
\hline & & & & X.7 & 1 \\
\hline & & \multirow[t]{2}{*}{ X.5 } & \multirow[t]{2}{*}{2} & X.4 & 1 \\
\hline & & & & X.7 & 1 \\
\hline & & \multirow[t]{2}{*}{ X.4 } & \multirow[t]{2}{*}{2} & $\mathrm{X} .5$ & 1 \\
\hline & & & & X.9 & 1 \\
\hline & & \multirow[t]{2}{*}{$\mathrm{X} .11$} & \multirow[t]{2}{*}{4} & X.11 & 2 \\
\hline & & & & X.12 & 2 \\
\hline & & \multirow[t]{2}{*}{$\mathrm{X} .13$} & \multirow[t]{2}{*}{4} & $\mathrm{X} .13$ & 2 \\
\hline & & & & X.16 & 2 \\
\hline & & $\mathrm{X} .9$ & 3 & X.19 & 3 \\
\hline & & X.10 & 3 & X.19 & 3 \\
\hline & & \multirow[t]{2}{*}{ X.13 } & \multirow[t]{2}{*}{4} & X.14 & 2 \\
\hline & & & & $\mathrm{X} .18$ & 2 \\
\hline & & \multirow[t]{2}{*}{$\mathrm{X} .13$} & \multirow[t]{2}{*}{4} & $\mathrm{X} .14$ & 2 \\
\hline & & & & $\mathrm{X} .18$ & 2 \\
\hline & & \multirow[t]{2}{*}{$\mathrm{X} .12$} & \multirow[t]{2}{*}{4} & $\mathrm{X} .15$ & 2 \\
\hline & & & & X.17 & 2 \\
\hline & & \multirow[t]{2}{*}{ X.12 } & \multirow[t]{2}{*}{4} & $\mathrm{X} .15$ & 2 \\
\hline & & & & X.17 & 2 \\
\hline & & \multirow[t]{2}{*}{$\mathrm{X} .14$} & \multirow[t]{2}{*}{4} & $\mathrm{X} .15$ & 2 \\
\hline & & & & $\mathrm{X} .17$ & 2 \\
\hline & & \multirow[t]{2}{*}{$\mathrm{X} .15$} & \multirow[t]{2}{*}{6} & X.20 & 3 \\
\hline & & & & X.21 & 3 \\
\hline & & X.15 & 6 & X.20 & 3 \\
\hline & & & & X.21 & 3 \\
\hline & & X.15 & 6 & X.20 & 3 \\
\hline & & & & X.21 & 3 \\
\hline 1 subespac & & 18 subes & & 24 subes & çOS \\
\hline
\end{tabular}




\section{Quebra de Simetria 11}

\begin{tabular}{|c|c|c|c|c|c|}
\hline \multicolumn{2}{|c|}{$G=\operatorname{Spin}_{5}(3)$} & \multicolumn{2}{|c|}{$H=Q_{8}:\left(3^{2}: 2\right)$} & \multicolumn{2}{|c|}{$K=Q_{8}: S m_{3}$} \\
\hline caracter & $d$ & caracter & $d$ & caracter & $d$ \\
\hline \multirow{24}{*}{$\begin{array}{c}\mathrm{X} .29=\overline{\mathrm{X} .30} \\
\mathrm{X} .27 \\
\mathrm{X} .28\end{array}$} & \multirow[t]{24}{*}{64} & \multirow[t]{2}{*}{ X.4 } & \multirow[t]{2}{*}{2} & X.1 & 1 \\
\hline & & & & $\mathrm{X} .2$ & 1 \\
\hline & & $\mathrm{X} .3$ & 2 & X.3 & 2 \\
\hline & & $\mathrm{X} .5$ & 2 & X.3 & 2 \\
\hline & & $\mathrm{X} .5$ & 2 & X.3 & 2 \\
\hline & & X.7 & 2 & $\mathrm{X} .5$ & 2 \\
\hline & & X.8 & 2 & X.4 & 2 \\
\hline & & \multirow[t]{2}{*}{ X.12 } & \multirow[t]{2}{*}{4} & X.4 & 2 \\
\hline & & & & $\mathrm{X} .5$ & 2 \\
\hline & & \multirow[t]{2}{*}{$\mathrm{X} .12$} & \multirow[t]{2}{*}{4} & X.4 & 2 \\
\hline & & & & $\mathrm{X} .5$ & 2 \\
\hline & & X.9 & 3 & X.6 & 3 \\
\hline & & X.10 & 3 & X.7 & 3 \\
\hline & & X.11 & 4 & X.8 & 4 \\
\hline & & X.13 & 4 & X.8 & 4 \\
\hline & & X.14 & 4 & X.8 & 4 \\
\hline & & X.14 & 4 & X.8 & 4 \\
\hline & & X.14 & 4 & X.8 & 4 \\
\hline & & \multirow[t]{2}{*}{$\mathrm{X} .15$} & \multirow[t]{2}{*}{6} & X.6 & 3 \\
\hline & & & & X.7 & 3 \\
\hline & & \multirow[t]{2}{*}{$\mathrm{X} .15$} & \multirow[t]{2}{*}{6} & X.6 & 3 \\
\hline & & & & $\mathrm{X} .7$ & 3 \\
\hline & & \multirow[t]{2}{*}{ X.15 } & \multirow[t]{2}{*}{6} & X.6 & 3 \\
\hline & & & & X.7 & 3 \\
\hline \multicolumn{2}{|c|}{1 subespaço } & \multicolumn{2}{|c|}{18 subespaços } & \multicolumn{2}{|c|}{24 subespaços } \\
\hline
\end{tabular}




\section{Quebra de Simetria 12}

\begin{tabular}{|c|c|c|c|c|c|}
\hline \multicolumn{2}{|c|}{$G=\operatorname{Spin}_{5}(3)$} & \multicolumn{2}{|c|}{$H=Q_{8}:\left(3^{2}: 2\right)$} & \multicolumn{2}{|c|}{$K=3^{2}: 2^{2}$} \\
\hline caracter & $d$ & caracter & $d$ & caracter & $d$ \\
\hline \multirow{34}{*}{$\begin{array}{c}\mathrm{X} .29=\overline{\mathrm{X} .30} \\
\mathrm{X} .27 \\
\mathrm{X} .28\end{array}$} & \multirow[t]{34}{*}{64} & \multirow[t]{3}{*}{ X.11 } & \multirow[t]{3}{*}{4} & X.3 & 1 \\
\hline & & & & X.4 & 1 \\
\hline & & & & X.6 & 2 \\
\hline & & X.3 & 2 & X.5 & 2 \\
\hline & & $\mathrm{X} .5$ & 2 & X.11 & 2 \\
\hline & & X.5 & 2 & X.11 & 2 \\
\hline & & X.4 & 2 & X.7 & 2 \\
\hline & & X.7 & 2 & X.6 & 2 \\
\hline & & X.8 & 2 & X.6 & 2 \\
\hline & & \multirow[t]{2}{*}{ X.13 } & \multirow[t]{2}{*}{4} & X.8 & 2 \\
\hline & & & & X.9 & 2 \\
\hline & & \multirow[t]{2}{*}{ X.9 } & \multirow[t]{2}{*}{3} & $\mathrm{X} .2$ & 1 \\
\hline & & & & $\mathrm{X} .5$ & 2 \\
\hline & & \multirow[t]{2}{*}{ X.10 } & \multirow[t]{2}{*}{3} & X.1 & 1 \\
\hline & & & & X.5 & 2 \\
\hline & & \multirow[t]{2}{*}{ X.12 } & \multirow[t]{2}{*}{4} & X.9 & 2 \\
\hline & & & & X.10 & 2 \\
\hline & & \multirow[t]{2}{*}{ X.12 } & \multirow[t]{2}{*}{4} & X.9 & 2 \\
\hline & & & & X.10 & 2 \\
\hline & & \multirow[t]{2}{*}{ X.14 } & \multirow[t]{2}{*}{4} & X.8 & 2 \\
\hline & & & & X.10 & 2 \\
\hline & & \multirow[t]{2}{*}{ X.14 } & \multirow[t]{2}{*}{4} & X.8 & 2 \\
\hline & & & & X.10 & 2 \\
\hline & & \multirow[t]{2}{*}{ X.14 } & \multirow[t]{2}{*}{4} & X.8 & 2 \\
\hline & & & & $\mathrm{X} .10$ & 2 \\
\hline & & \multirow[t]{3}{*}{$\mathrm{X} .15$} & \multirow[t]{3}{*}{6} & X.7 & 2 \\
\hline & & & & X.11 & 2 \\
\hline & & & & X.12 & 2 \\
\hline & & \multirow[t]{3}{*}{ X.15 } & \multirow[t]{3}{*}{6} & X.7 & 2 \\
\hline & & & & X.11 & 2 \\
\hline & & & & X.12 & 2 \\
\hline & & \multirow[t]{3}{*}{ X.15 } & 6 & X.7 & 2 \\
\hline & & & & X.11 & 2 \\
\hline & & & & X.12 & 2 \\
\hline 1 subespac & & 18 subes & Sos & 24 subest & ços \\
\hline
\end{tabular}




\section{Quebra de Simetria 13}

\begin{tabular}{|c|c|c|c|c|c|}
\hline \multicolumn{2}{|c|}{$G=\operatorname{Spin}_{7}(2)$} & \multicolumn{2}{|c|}{$H=\left(2^{2} .2^{4}\right): 3^{2}$} & \multicolumn{2}{|c|}{$K=Q_{8}:\left(3^{2} \times 2\right)$} \\
\hline caracter & $d$ & caracter & $d$ & caracter & $d$ \\
\hline \multirow[t]{32}{*}{$\mathrm{X} .12=\overline{\mathrm{X} .13}$} & \multirow[t]{32}{*}{64} & \multirow[t]{2}{*}{ X.26 } & \multirow[t]{2}{*}{2} & X.10 & 1 \\
\hline & & & & X.14 & 1 \\
\hline & & \multirow[t]{2}{*}{ X.24 } & \multirow[t]{2}{*}{2} & X.8 & 1 \\
\hline & & & & X.18 & 1 \\
\hline & & \multirow[t]{2}{*}{ X.11 } & \multirow[t]{2}{*}{2} & X.12 & 1 \\
\hline & & & & X.16 & 1 \\
\hline & & \multirow[t]{2}{*}{$\mathrm{X} .11$} & \multirow[t]{2}{*}{2} & X.12 & 1 \\
\hline & & & & X.16 & 1 \\
\hline & & \multirow[t]{2}{*}{ X.38 } & \multirow[t]{2}{*}{4} & X.24 & 2 \\
\hline & & & & X.32 & 2 \\
\hline & & \multirow[t]{2}{*}{ X.40 } & \multirow[t]{2}{*}{4} & X.20 & 2 \\
\hline & & & & X.34 & 2 \\
\hline & & \multirow[t]{2}{*}{$\mathrm{X} .42$} & \multirow[t]{2}{*}{4} & X.22 & 2 \\
\hline & & & & X.26 & 2 \\
\hline & & \multirow[t]{2}{*}{$\mathrm{X} .35$} & \multirow[t]{2}{*}{4} & X.24 & 2 \\
\hline & & & & X.28 & 2 \\
\hline & & \multirow[t]{2}{*}{$\mathrm{X} .35$} & \multirow[t]{2}{*}{4} & X.24 & 2 \\
\hline & & & & X.28 & 2 \\
\hline & & \multirow[t]{2}{*}{ X.36 } & \multirow[t]{2}{*}{4} & X.22 & 2 \\
\hline & & & & X.36 & 2 \\
\hline & & \multirow[t]{2}{*}{ X.36 } & \multirow[t]{2}{*}{4} & $\mathrm{X} .22$ & 2 \\
\hline & & & & $\mathrm{X} .36$ & 2 \\
\hline & & \multirow[t]{2}{*}{ X.37 } & \multirow[t]{2}{*}{4} & $\mathrm{X} .20$ & 2 \\
\hline & & & & X.30 & 2 \\
\hline & & X.43 & 6 & X.40 & 3 \\
\hline & & & & X.42 & 3 \\
\hline & & X.43 & 6 & $\mathrm{X} .40$ & 3 \\
\hline & & & & $\mathrm{X} .42$ & 3 \\
\hline & & $\mathrm{X} .45$ & 6 & X.38 & 3 \\
\hline & & & & X.42 & 3 \\
\hline & & X.46 & 6 & X.38 & 3 \\
\hline & & & & X.40 & 3 \\
\hline 1 subespa & & 16 subes & & 24 subesp & ços \\
\hline
\end{tabular}




\section{Quebra de Simetria 14}

\begin{tabular}{|c|c|c|c|c|c|}
\hline \multicolumn{2}{|c|}{$G=G_{2}(3)$} & \multicolumn{2}{|c|}{$K=Q_{8}:\left(3^{2}: 2\right)$} & \multicolumn{2}{|c|}{$H=Q_{8}: 3^{2}$} \\
\hline caracter & $d$ & caracter & $d$ & caracter & $d$ \\
\hline \multirow[t]{32}{*}{$\mathrm{X} .3=\overline{\mathrm{X} .4}$} & \multirow[t]{32}{*}{64} & \multirow[t]{2}{*}{ X.3 } & \multirow[t]{2}{*}{2} & X.2 & 1 \\
\hline & & & & X.3 & 1 \\
\hline & & \multirow[t]{2}{*}{$\mathrm{X} .5$} & \multirow[t]{2}{*}{2} & X.5 & 1 \\
\hline & & & & X.9 & 1 \\
\hline & & \multirow[t]{2}{*}{$\mathrm{X} .5$} & \multirow[t]{2}{*}{2} & $\mathrm{X} .5$ & 1 \\
\hline & & & & X.9 & 1 \\
\hline & & \multirow[t]{2}{*}{ X.6 } & \multirow[t]{2}{*}{2} & X.6 & 1 \\
\hline & & & & $\mathrm{X} .8$ & 1 \\
\hline & & X.7 & 2 & X.10 & 2 \\
\hline & & X.8 & 2 & X.10 & 2 \\
\hline & & \multirow[t]{2}{*}{ X.11 } & \multirow[t]{2}{*}{4} & X.11 & 2 \\
\hline & & & & X.12 & 2 \\
\hline & & \multirow[t]{2}{*}{$\mathrm{X} .14$} & \multirow[t]{2}{*}{4} & X.14 & 2 \\
\hline & & & & X.18 & 2 \\
\hline & & X.9 & 3 & X.19 & 3 \\
\hline & & X.10 & 3 & X.19 & 3 \\
\hline & & \multirow[t]{2}{*}{ X.12 } & \multirow[t]{2}{*}{4} & X.13 & 2 \\
\hline & & & & X.16 & 2 \\
\hline & & \multirow[t]{2}{*}{$\mathrm{X} .12$} & \multirow[t]{2}{*}{4} & $\mathrm{X} .13$ & 2 \\
\hline & & & & X.16 & 2 \\
\hline & & \multirow[t]{2}{*}{ X.12 } & \multirow[t]{2}{*}{4} & $\mathrm{X} .13$ & 2 \\
\hline & & & & X.16 & 2 \\
\hline & & \multirow[t]{2}{*}{ X.13 } & \multirow[t]{2}{*}{4} & X.15 & 2 \\
\hline & & & & $\mathrm{X} .17$ & 2 \\
\hline & & \multirow[t]{2}{*}{$\mathrm{X} .13$} & \multirow[t]{2}{*}{4} & $\mathrm{X} .15$ & 2 \\
\hline & & & & $\mathrm{X} .17$ & 2 \\
\hline & & \multirow[t]{2}{*}{$\mathrm{X} .15$} & \multirow[t]{2}{*}{6} & X.20 & 3 \\
\hline & & & & $\mathrm{X} .21$ & 3 \\
\hline & & $\mathrm{X} .15$ & 6 & X.20 & 3 \\
\hline & & & & X.21 & 3 \\
\hline & & X.15 & 6 & X.20 & 3 \\
\hline & & & & X.21 & 3 \\
\hline 1 subespa & & 18 subes & cos & 24 subesp & ços \\
\hline
\end{tabular}




\section{Quebra de Simetria 15}

\begin{tabular}{|c|c|c|c|c|c|}
\hline \multicolumn{2}{|c|}{$G=G_{2}(3)$} & \multicolumn{2}{|c|}{$H=Q_{8}:\left(3^{2}: 2\right)$} & \multicolumn{2}{|c|}{$K=Q_{8}: S m_{3}$} \\
\hline caracter & $d$ & caracter & $d$ & caracter & $d$ \\
\hline \multirow[t]{24}{*}{$\mathrm{X} .3=\overline{\mathrm{X} .4}$} & \multirow{24}{*}{64} & \multirow[t]{2}{*}{ X.6 } & \multirow[t]{2}{*}{2} & X.1 & 1 \\
\hline & & & & X.2 & 1 \\
\hline & & X.3 & 2 & X.3 & 2 \\
\hline & & $\mathrm{X} .5$ & 2 & X.3 & 2 \\
\hline & & $\mathrm{X} .5$ & 2 & X.3 & 2 \\
\hline & & X.7 & 2 & X.4 & 2 \\
\hline & & X.8 & 2 & $\mathrm{X} .5$ & 2 \\
\hline & & \multirow[t]{2}{*}{ X.14 } & \multirow[t]{2}{*}{4} & X.4 & 2 \\
\hline & & & & $\mathrm{X} .5$ & 2 \\
\hline & & \multirow[t]{2}{*}{ X.14 } & \multirow[t]{2}{*}{4} & X.4 & 2 \\
\hline & & & & X.5 & 2 \\
\hline & & X.9 & 3 & X.6 & 3 \\
\hline & & X.10 & 3 & X.7 & 3 \\
\hline & & X.11 & 4 & X.8 & 4 \\
\hline & & $\mathrm{X} .12$ & 4 & X.8 & 4 \\
\hline & & X.12 & 4 & X.8 & 4 \\
\hline & & X.12 & 4 & $\mathrm{X} .8$ & 4 \\
\hline & & X.13 & 4 & X.8 & 4 \\
\hline & & \multirow[t]{2}{*}{$\mathrm{X} .15$} & \multirow[t]{2}{*}{6} & X.6 & 3 \\
\hline & & & & X.7 & 3 \\
\hline & & \multirow[t]{2}{*}{$\mathrm{X} .15$} & \multirow[t]{2}{*}{6} & X.6 & 3 \\
\hline & & & & X.7 & 3 \\
\hline & & \multirow[t]{2}{*}{ X.15 } & \multirow[t]{2}{*}{6} & X.6 & 3 \\
\hline & & & & X.7 & 3 \\
\hline \multicolumn{2}{|c|}{1 subespaço } & \multicolumn{2}{|c|}{18 subespaços } & \multicolumn{2}{|c|}{24 subespaços } \\
\hline
\end{tabular}




\section{Quebra de Simetria 16}

\begin{tabular}{|c|c|c|c|c|c|}
\hline \multicolumn{2}{|c|}{$G=G_{2}(3)$} & \multicolumn{2}{|c|}{$H=Q_{8}:\left(3^{2}: 2\right)$} & \multicolumn{2}{|c|}{$K=3^{2}: 2^{2}$} \\
\hline caracter & $d$ & caracter & $d$ & caracter & $d$ \\
\hline \multirow[t]{34}{*}{$\mathrm{X} .3=\overline{\mathrm{X} .4}$} & \multirow[t]{34}{*}{64} & \multirow[t]{3}{*}{ X.11 } & \multirow[t]{3}{*}{4} & $\mathrm{X} .2$ & 1 \\
\hline & & & & X.3 & 1 \\
\hline & & & & X.6 & 2 \\
\hline & & X.3 & 2 & X.11 & 2 \\
\hline & & $\mathrm{X} .5$ & 2 & X.12 & 2 \\
\hline & & X.5 & 2 & X.12 & 2 \\
\hline & & X.6 & 2 & X.7 & 2 \\
\hline & & X.7 & 2 & X.9 & 2 \\
\hline & & X.8 & 2 & X.9 & 2 \\
\hline & & \multirow[t]{2}{*}{ X.13 } & \multirow[t]{2}{*}{4} & X.6 & 2 \\
\hline & & & & X.8 & 2 \\
\hline & & \multirow[t]{2}{*}{ X.9 } & \multirow[t]{2}{*}{3} & $\mathrm{X} .4$ & 1 \\
\hline & & & & X.11 & 2 \\
\hline & & \multirow[t]{2}{*}{ X.10 } & \multirow[t]{2}{*}{3} & X.1 & 1 \\
\hline & & & & X.11 & 2 \\
\hline & & \multirow[t]{2}{*}{ X.12 } & \multirow[t]{2}{*}{4} & X.8 & 2 \\
\hline & & & & X.10 & 2 \\
\hline & & \multirow[t]{2}{*}{ X.12 } & \multirow[t]{2}{*}{4} & X.8 & 2 \\
\hline & & & & X.10 & 2 \\
\hline & & \multirow[t]{2}{*}{ X.12 } & \multirow[t]{2}{*}{4} & X.8 & 2 \\
\hline & & & & X.10 & 2 \\
\hline & & \multirow[t]{2}{*}{ X.14 } & \multirow[t]{2}{*}{4} & X.6 & 2 \\
\hline & & & & X.10 & 2 \\
\hline & & \multirow[t]{2}{*}{ X.14 } & \multirow[t]{2}{*}{4} & X.6 & 2 \\
\hline & & & & X.10 & 2 \\
\hline & & \multirow[t]{3}{*}{ X.15 } & \multirow[t]{3}{*}{6} & X.5 & 2 \\
\hline & & & & X.7 & 2 \\
\hline & & & & X.12 & 2 \\
\hline & & \multirow[t]{3}{*}{ X.15 } & \multirow[t]{3}{*}{6} & $\mathrm{X} .5$ & 2 \\
\hline & & & & X.7 & 2 \\
\hline & & & & X.12 & 2 \\
\hline & & \multirow[t]{3}{*}{ X.15 } & 6 & $\mathrm{X} .5$ & 2 \\
\hline & & & & X.7 & 2 \\
\hline & & & & X.12 & 2 \\
\hline 1 subespa & & 18 subes & ços & 24 subest & ços \\
\hline
\end{tabular}




\section{Quebra de Simetria 17}

\begin{tabular}{|c|c|c|c|c|c|}
\hline \multicolumn{2}{|c|}{$G=G_{2}(3)$} & \multicolumn{2}{|c|}{$H=Q_{8}:\left(3^{2}: 2\right)$} & \multicolumn{2}{|c|}{$K=Q_{8}: 3^{2}$} \\
\hline caracter & $d$ & caracter & $d$ & caracter & $d$ \\
\hline \multirow{32}{*}{$\mathrm{X} .3=\overline{\mathrm{X} .4}$} & \multirow[t]{32}{*}{64} & \multirow[t]{2}{*}{ X.3 } & \multirow[t]{2}{*}{2} & X.6 & 1 \\
\hline & & & & X.8 & 1 \\
\hline & & \multirow[t]{2}{*}{ X.4 } & \multirow[t]{2}{*}{2} & X.5 & 1 \\
\hline & & & & X.9 & 1 \\
\hline & & \multirow[t]{2}{*}{$\mathrm{X} .4$} & \multirow[t]{2}{*}{2} & X.5 & 1 \\
\hline & & & & X.9 & 1 \\
\hline & & \multirow[t]{2}{*}{$\mathrm{X} .6$} & \multirow[t]{2}{*}{2} & $\mathrm{X} .2$ & 1 \\
\hline & & & & X.3 & 1 \\
\hline & & X.7 & 2 & X.10 & 2 \\
\hline & & X.8 & 2 & X.10 & 2 \\
\hline & & \multirow[t]{2}{*}{ X.11 } & \multirow[t]{2}{*}{4} & X.4 & 2 \\
\hline & & & & X.5 & 2 \\
\hline & & \multirow[t]{2}{*}{ X.12 } & \multirow[t]{2}{*}{4} & X.4 & 2 \\
\hline & & & & X.5 & 2 \\
\hline & & X.9 & 3 & X.19 & 3 \\
\hline & & X.10 & 3 & X.19 & 3 \\
\hline & & \multirow[t]{2}{*}{ X.13 } & \multirow[t]{2}{*}{4} & X.13 & 2 \\
\hline & & & & X.16 & 2 \\
\hline & & \multirow[t]{2}{*}{$\mathrm{X} .13$} & \multirow[t]{2}{*}{4} & X.13 & 2 \\
\hline & & & & X.16 & 2 \\
\hline & & \multirow[t]{2}{*}{ X.14 } & \multirow[t]{2}{*}{4} & X.11 & 2 \\
\hline & & & & X.12 & 2 \\
\hline & & \multirow[t]{2}{*}{ X.14 } & \multirow[t]{2}{*}{4} & X.11 & 2 \\
\hline & & & & X.12 & 2 \\
\hline & & \multirow[t]{2}{*}{ X.14 } & \multirow[t]{2}{*}{4} & X.11 & 2 \\
\hline & & & & X.12 & 2 \\
\hline & & \multirow[t]{2}{*}{ X.15 } & \multirow[t]{2}{*}{6} & X.20 & 3 \\
\hline & & & & X.21 & 3 \\
\hline & & X.15 & 6 & X.20 & 3 \\
\hline & & & & X.21 & 3 \\
\hline & & X.15 & 6 & X.20 & 3 \\
\hline & & & & X.21 & 3 \\
\hline 1 subesp & & 18 subes & & 24 subest & ÇOS \\
\hline
\end{tabular}




\section{Quebra de Simetria 18}

\begin{tabular}{|c|c|c|c|c|c|}
\hline \multicolumn{2}{|c|}{$G=G_{2}(3)$} & \multicolumn{2}{|c|}{$H=Q_{8}:\left(3^{2}: 2\right)$} & \multicolumn{2}{|c|}{$K=Q_{8}: S y m_{3}$} \\
\hline caracter & $d$ & caracter & $d$ & caracter & $d$ \\
\hline \multirow[t]{24}{*}{$\overline{\mathrm{X} .3=\overline{\mathrm{X} .4}}$} & \multirow[t]{24}{*}{64} & \multirow[t]{2}{*}{ X.6 } & \multirow[t]{2}{*}{2} & X.1 & 1 \\
\hline & & & & X.2 & 1 \\
\hline & & X.3 & 2 & X.3 & 2 \\
\hline & & $\mathrm{X} .4$ & 2 & $\mathrm{X} .3$ & 2 \\
\hline & & X.4 & 2 & $\mathrm{X} .3$ & 2 \\
\hline & & X.7 & 2 & X.4 & 2 \\
\hline & & X.8 & 2 & $\mathrm{X} .5$ & 2 \\
\hline & & \multirow[t]{2}{*}{ X.14 } & \multirow[t]{2}{*}{4} & $\mathrm{X} .4$ & 2 \\
\hline & & & & $\mathrm{X} .5$ & 2 \\
\hline & & \multirow[t]{2}{*}{ X.14 } & \multirow[t]{2}{*}{4} & $\mathrm{X} .4$ & 2 \\
\hline & & & & $\mathrm{X} .5$ & 2 \\
\hline & & $\mathrm{X} .9$ & 3 & X.6 & 3 \\
\hline & & X.10 & 3 & $\mathrm{X} .7$ & 3 \\
\hline & & X.11 & 4 & $\mathrm{X} .8$ & 4 \\
\hline & & $\mathrm{X} .12$ & 4 & X.8 & 4 \\
\hline & & X.13 & 4 & $\mathrm{X} .8$ & 4 \\
\hline & & X.13 & 4 & $\mathrm{X} .8$ & 4 \\
\hline & & X.13 & 4 & X.8 & 4 \\
\hline & & \multirow[t]{2}{*}{$\mathrm{X} .15$} & \multirow[t]{2}{*}{6} & X.6 & 3 \\
\hline & & & & X.7 & 3 \\
\hline & & \multirow[t]{2}{*}{$\mathrm{X} .15$} & \multirow[t]{2}{*}{6} & X.6 & 3 \\
\hline & & & & X.7 & 3 \\
\hline & & \multirow[t]{2}{*}{$\mathrm{X} .15$} & \multirow[t]{2}{*}{6} & X.6 & 3 \\
\hline & & & & X.7 & 3 \\
\hline \multicolumn{2}{|c|}{1 subespaço } & \multicolumn{2}{|c|}{18 subespaços } & \multicolumn{2}{|c|}{24 subespaços } \\
\hline
\end{tabular}




\section{Quebra de Simetria 19}

\begin{tabular}{|c|c|c|c|c|c|}
\hline \multicolumn{2}{|c|}{$G=G_{2}(3)$} & \multicolumn{2}{|c|}{$H=Q_{8}:\left(3^{2}: 2\right)$} & \multicolumn{2}{|c|}{$K=3^{2}: 2^{2}$} \\
\hline caracter & $d$ & caracter & $d$ & caracter & $d$ \\
\hline \multirow[t]{34}{*}{$\mathrm{X} .3=\overline{\mathrm{X} .4}$} & \multirow[t]{34}{*}{64} & \multirow[t]{3}{*}{ X.11 } & \multirow[t]{3}{*}{4} & $\mathrm{X} .2$ & 1 \\
\hline & & & & X.3 & 1 \\
\hline & & & & X.6 & 2 \\
\hline & & X.3 & 2 & $\mathrm{X} .5$ & 2 \\
\hline & & $\mathrm{X} .5$ & 2 & X.12 & 2 \\
\hline & & X.5 & 2 & X.12 & 2 \\
\hline & & X.6 & 2 & X.7 & 2 \\
\hline & & X.7 & 2 & X.6 & 2 \\
\hline & & X.8 & 2 & X.6 & 2 \\
\hline & & \multirow[t]{2}{*}{ X.14 } & \multirow[t]{2}{*}{4} & X.8 & 2 \\
\hline & & & & X.9 & 2 \\
\hline & & \multirow[t]{2}{*}{ X.9 } & \multirow[t]{2}{*}{3} & X.1 & 1 \\
\hline & & & & $\mathrm{X} .5$ & 2 \\
\hline & & \multirow[t]{2}{*}{ X.10 } & \multirow[t]{2}{*}{3} & X.4 & 1 \\
\hline & & & & X.5 & 2 \\
\hline & & \multirow[t]{2}{*}{$\mathrm{X} .13$} & \multirow[t]{2}{*}{4} & X.13 & 2 \\
\hline & & & & X.16 & 2 \\
\hline & & \multirow[t]{2}{*}{ X.13 } & \multirow[t]{2}{*}{4} & X.13 & 2 \\
\hline & & & & X.16 & 2 \\
\hline & & \multirow[t]{2}{*}{ X.14 } & \multirow[t]{2}{*}{4} & X.11 & 2 \\
\hline & & & & X.12 & 2 \\
\hline & & \multirow[t]{2}{*}{ X.14 } & \multirow[t]{2}{*}{4} & X.11 & 2 \\
\hline & & & & X.12 & 2 \\
\hline & & \multirow[t]{2}{*}{ X.14 } & \multirow[t]{2}{*}{4} & X.11 & 2 \\
\hline & & & & X.12 & 2 \\
\hline & & \multirow[t]{3}{*}{$\mathrm{X} .15$} & \multirow[t]{3}{*}{6} & X.7 & 2 \\
\hline & & & & X.11 & 2 \\
\hline & & & & X.12 & 2 \\
\hline & & \multirow[t]{3}{*}{ X.15 } & \multirow[t]{3}{*}{6} & X.7 & 2 \\
\hline & & & & X.11 & 2 \\
\hline & & & & X.12 & 2 \\
\hline & & \multirow[t]{3}{*}{$\mathrm{X} .15$} & 6 & X.7 & 2 \\
\hline & & & & X.11 & 2 \\
\hline & & & & X.12 & 2 \\
\hline 1 subespa & & 18 subes & & 24 subesp & \\
\hline
\end{tabular}




\subsubsection{As Tabelas de Caracteres}

Segue abaixo uma lista das tabelas de caracteres que foram usadas para determinar as cadeias que reproduzem a distribuição de multipletos do código genético.

\begin{tabular}{ccc}
\hline Grupo & Tabela & Página \\
\hline $\operatorname{Spin}_{5}(3)$ & 6.4 & 131 \\
$\operatorname{Spin}_{7}(2)$ & 6.5 & 132 \\
$G_{2}(3)$ & 6.6 & 133 \\
$\left(2^{2} \cdot 2^{4}\right): 3^{2}$ & 6.7 & 134 \\
$Q_{8}:\left(3^{2}: 2^{2}\right)$ & 6.8 & 135 \\
$Q_{8}:\left(3^{2}: 2\right)$ & 6.9 & 136 \\
$Q_{8}:\left(3^{2} \times 2\right)$ & 6.10 & 137 \\
$Q_{8}: D_{12}$ & 6.11 & 138 \\
$3^{2}: 2^{3}$ & 6.12 & 139 \\
$Q_{8}: 3^{2}$ & 6.13 & 140 \\
$Q_{8}:$ Sym $_{3}$ & 6.14 & 141 \\
$3^{2}: 2^{2}$ & 6.15 & 141 \\
\hline
\end{tabular}

Tabela 6.3: Lista das Tabelas de Caracteres. 


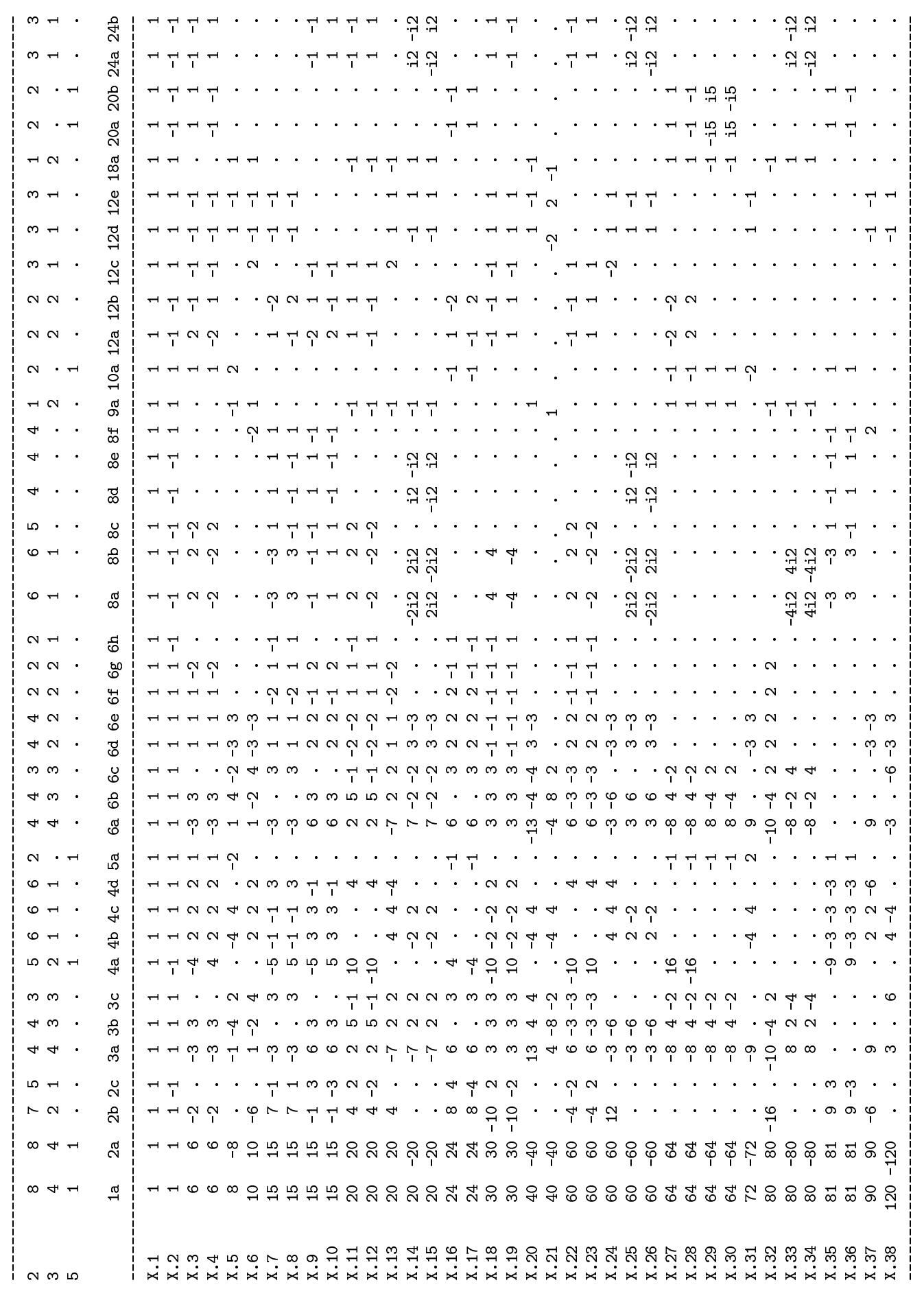

Tabela 6.4: Tabela de Caracteres do Grupo $\operatorname{Spin}_{5}(3)$. 


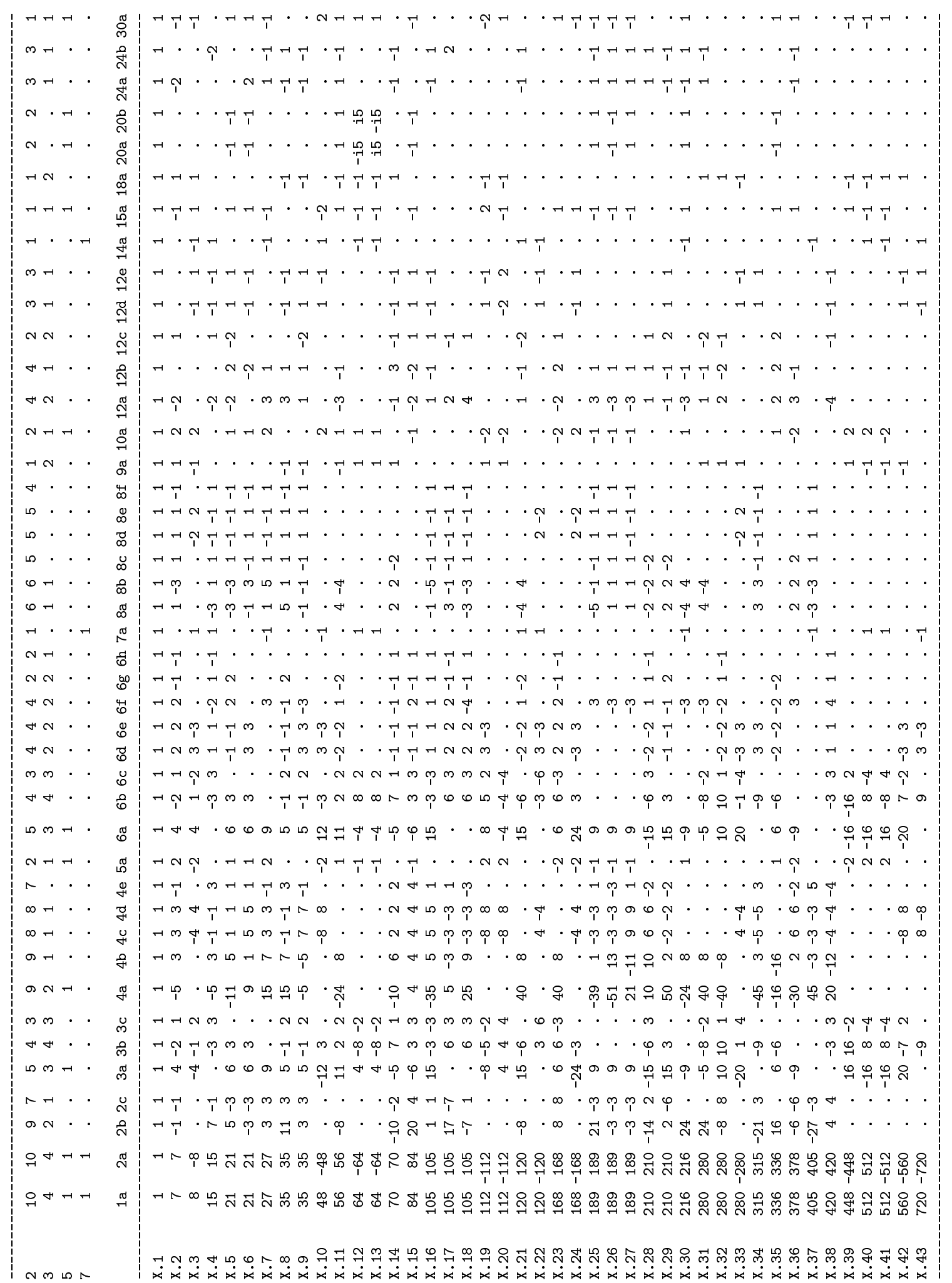

Tabela 6.5: Tabela de Caracteres do Grupo $\operatorname{Spin}_{7}(2)$. 


$\begin{array}{rlllllllllllllllllllllllllll}2 & 6 & 6 & 3 & 3 & . & 1 & 1 & 5 & 5 & 3 & 3 & 1 & 1 & . & 3 & 3 & . & . & . & 2 & 2 & . & . \\ 3 & 6 & 2 & 6 & 6 & 6 & 4 & 4 & 1 & 1 & 2 & 2 & 2 & 2 & . & . & . & 3 & 3 & 3 & 1 & 1 & . & . \\ 7 & 1 & . & . & . & . & . & . & . & . & . & . & . & . & 1 & . & . & . & . & . & . & . & . & . \\ 13 & 1 & . & . & . & . & . & . & . & . & . & . & . & . & . & . & . & . & . & . & . & . & 1 & 1\end{array}$

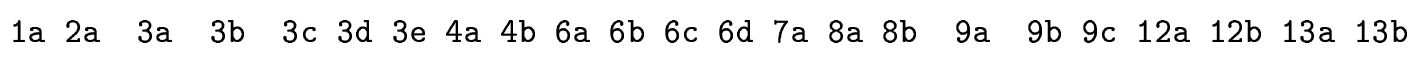

\begin{tabular}{|c|c|c|c|c|c|c|c|c|c|c|c|c|c|c|c|c|c|c|c|c|c|c|c|}
\hline X.1 & 1 & 1 & 1 & 1 & 1 & 1 & 1 & 1 & 1 & 1 & 1 & 1 & 1 & 1 & 1 & 1 & 1 & 1 & 1 & 1 & 1 & 1 & \\
\hline X. 2 & 14 & -2 & 5 & 5 & -4 & 2 & -1 & 2 & 2 & 1 & 1 & -2 & 1 & & • & 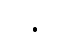 & -1 & -1 & 2 & -1 & 1 & 1 & \\
\hline .3 & 64 & . & -8 & -8 & 1 & 4 & -2 & . & . & . & . & . & . & 1 & . & . & b27 & $* *$ & 1 & . & . & -1 & 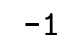 \\
\hline .4 & 64 & . & -8 & -8 & 1 & 4 & -2 & . & . & . & . & . & . & 1 & . & . & $* *$ & $\mathrm{~b} 27$ & 1 & . & 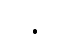 & -1 & 1 \\
\hline$X .5$ & 78 & -2 & -3 & -3 & -3 & -3 & 6 & 2 & 2 & 1 & 1 & 1 & -2 & 1 & 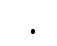 & - & . & . & 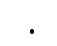 & -1 & -1 & - & \\
\hline $\mathrm{X} .6$ & 91 & 3 & -8 & 19 & 1 & 4 & -2 & 3 & -1 & . & 3 & 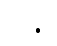 & . & . & -1 & 1 & 1 & 1 & -2 & . & -1 & 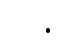 & \\
\hline .7 & 91 & 3 & 19 & -8 & 1 & 4 & -2 & -1 & 3 & 3 & . & . & . & . & 1 & -1 & 1 & 1 & -2 & -1 & & . & \\
\hline .8 & 91 & -5 & 10 & 10 & 10 & 1 & 1 & 3 & 3 & -2 & -2 & 1 & 1 & . & -1 & -1 & 1 & 1 & 1 & . & & 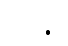 & \\
\hline X.9 & 104 & 8 & 14 & 14 & 5 & 2 & -1 & . & . & 2 & 2 & 2 & -1 & -1 & . & . & -1 & -1 & 2 & $\cdot$ & & . & \\
\hline$X .10$ & 168 & 8 & 6 & 6 & 6 & -3 & 6 & . & . & 2 & 2 & -1 & 2 & . & . & . & . & . & . & . & . & -1 & -1 \\
\hline X.11 & 182 & 6 & 20 & -7 & -7 & 2 & 2 & 2 & 2 & . & -3 & • & . & . & . & . & -1 & -1 & -1 & 2 & -1 & . & \\
\hline X.12 & 182 & 6 & -7 & 20 & -7 & 2 & 2 & 2 & 2 & -3 & • & • & • & 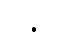 & . & . & -1 & -1 & -1 & -1 & 2 & ${ }^{\bullet}$ & \\
\hline$X .13$ & 273 & -7 & 30 & 3 & 3 & 3 & 3 & -3 & 1 & 2 & -1 & -1 & -1 & . & -1 & 1 & • & . & 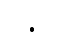 & . & 1 & • & \\
\hline$X .14$ & 273 & -7 & 3 & 30 & 3 & 3 & 3 & 1 & -3 & -1 & 2 & -1 & -1 & . & 1 & -1 & . & . & . & 1 & & . & \\
\hline X.15 & 448 & . & 16 & 16 & -11 & -2 & -2 & . & . & . & . & . & . & 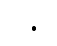 & . & - & 1 & 1 & 1 & 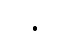 & • & b13 & \\
\hline $\mathrm{X} .16$ & 448 & . & 16 & 16 & -11 & -2 & -2 & . & . & . & . & . & 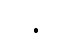 & & . & . & 1 & 1 & 1 & . & & $*$ & b13 \\
\hline X.17 & 546 & 2 & 6 & -21 & 6 & -3 & -3 & 6 & -2 & 2 & -1 & -1 & -1 & 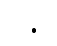 & . & 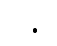 & 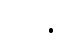 & . & $\cdot$ & . & 1 & & \\
\hline X.18 & 546 & 2 & -21 & 6 & 6 & -3 & -3 & -2 & 6 & -1 & 2 & -1 & -1 & . & . & . & $\cdot$ & . & . & 1 & & . & \\
\hline X.19 & 728 & -8 & 26 & -28 & -1 & -1 & -1 & . & . & -2 & 4 & 1 & 1 & & . & . & -1 & -1 & -1 & 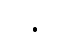 & & . & \\
\hline$X .20$ & 728 & -8 & -28 & 26 & -1 & -1 & -1 & . & . & 4 & -2 & 1 & 1 & . & . & . & -1 & -1 & -1 & 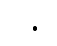 & & • & \\
\hline X.21 & 729 & 9 & 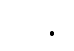 & • & . & . & . & -3 & -3 & . & . & 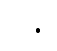 & . & 1 & -1 & -1 & . & . & . & . & 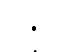 & 1 & \\
\hline X. 22 & 819 & 3 & 9 & 9 & 9 & . & . & -1 & -1 & -3 & -3 & . & . & . & 1 & 1 & 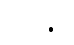 & . & . & -1 & -1 & 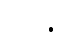 & \\
\hline X.23 & 832 & . & -32 & -32 & -5 & 4 & 4 & . & 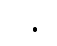 & . & . & 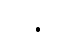 & 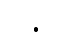 & -1 & . & . & 1 & 1 & 1 & . & . & 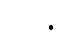 & \\
\hline
\end{tabular}

Tabela 6.6: Tabela de Caracteres do Grupo $G_{2}(3)$. 


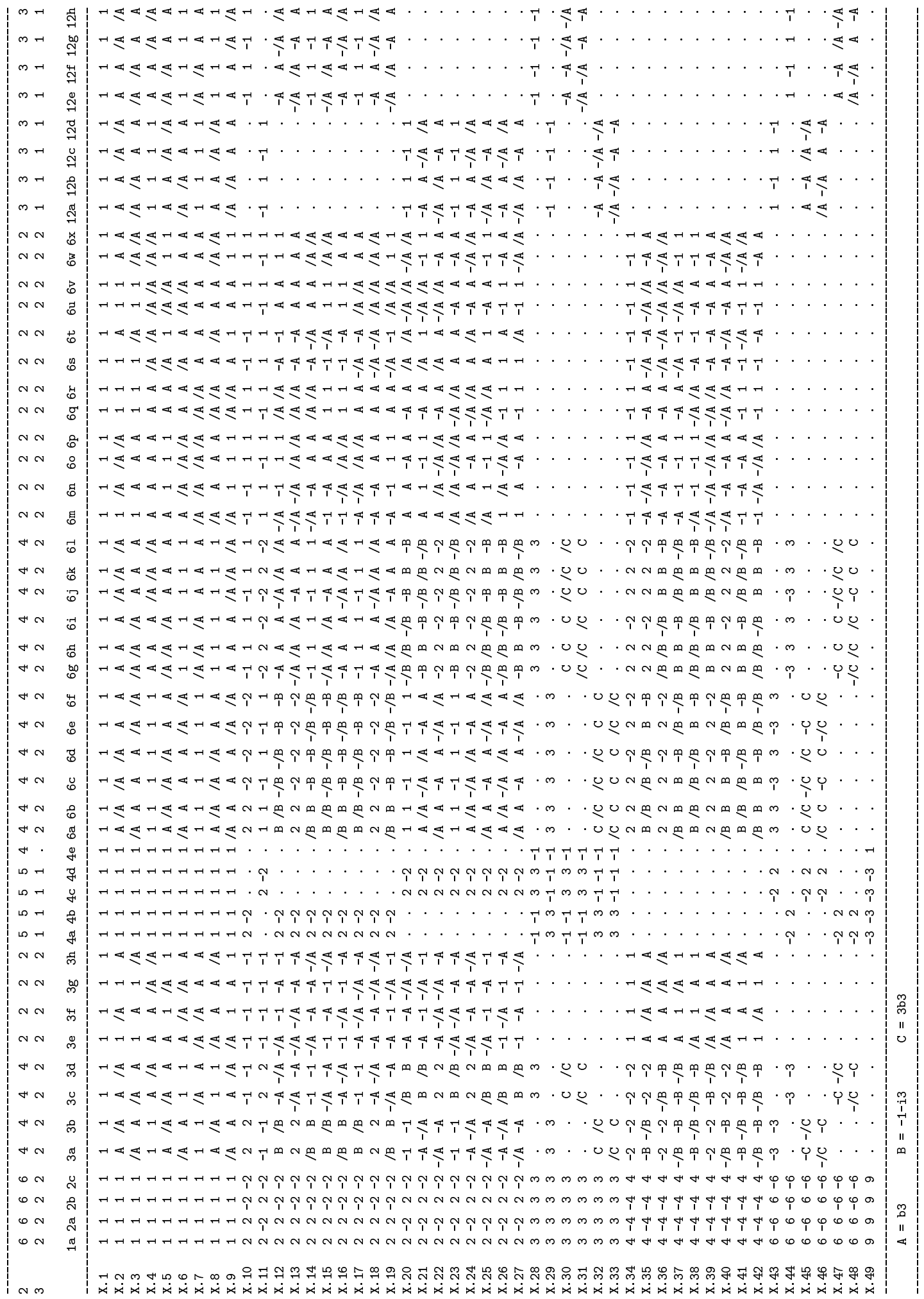

Tabela 6.7: Tabela de Caracteres do Grupo $\left(2^{2} \cdot 2^{4}\right): 3^{2}$. 


$\begin{array}{lllllllllllllllllllllllllllllll}2 & 5 & 5 & 5 & 5 & 3 & 3 & 4 & 2 & 2 & 2 & 4 & 4 & 4 & 4 & 4 & 2 & 2 & 2 & 2 & 2 & 2 & 2 & 2 & 2 & 4 & 4 & 4 & 4 & 3 & 3 \\ 3 & 2 & 2 & 2 & 2 & . & . & 2 & 2 & 2 & 2 & 1 & 1 & 2 & 2 & 2 & 2 & 2 & 2 & 2 & 2 & 2 & 2 & 2 & 2 & . & . & . & . & 1 & 1\end{array}$

1a 2a 2b 2c 2d 2e 3a 3b 3c 3d 4a 4b 6a 6b 6c 6d 6e 6f $6 \mathrm{~g} 6 \mathrm{~h} 6 \mathrm{i} 6 \mathrm{j} 6 \mathrm{k} 61$ 8a 8b 8c 8d 12a 12b

\begin{tabular}{|c|c|c|c|c|c|c|c|c|c|c|c|c|c|c|c|c|c|c|c|c|c|c|c|c|c|c|c|c|c|c|}
\hline .1 & 1 & 1 & 1 & 1 & 1 & 1 & 1 & 1 & 1 & 1 & 1 & & 1 & 1 & I & & 1 & 1 & 1 & 1 & 1 & & 1 & & 1 & 1 & 1 & 1 & & \\
\hline 2 & & 1 & 1 & 1. & -1 & -1 & 1 & 1 & 1 & 1 & 1 & & 1 & 1 & 1 & 1 & 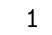 & 1 & & 1 & 1 & 1 & 1 & 1 & -1 & -1 & -1 & -1 & & \\
\hline 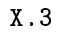 & & & -1 & -1 & -1 & 1 & 1 & 1 & 1 & 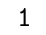 & -1 & & 1 & -1 & -1 & -1 & 1 & -1 & -1 & & -1 & & -1 & -1 & 1 & 1 & -1 & -1 & & \\
\hline 4 & & & -1 & -1 & 1 & -1 & 1 & 1 & 1 & 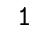 & -1 & & 1 & -1 & -1 & -1 & 1 & -1 & -1 & & -1 & 1 & -1 & -1 & -1 & -1 & 1 & & & \\
\hline .5 & & ? & -2 & -2 & & . & 2 & -1 & -1 & -1 & -2 & & 2 & -2 & -2 & 1 & -1 & 1 & 1 & -1 & 1 & -1 & 1 & 1 & & . & & & & \\
\hline 6 & & 2 & 2 & 2 & . & . & 2 & -1 & -1 & -1 & 2 & 2 & 2 & 2 & 2 & -1 & -1 & -1 & -1 & -1 & -1 & -1 & -1 & -1 & & & & & & \\
\hline .7 & & 2 & -2 & -2 & 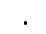 & . & -1 & -1 & -1 & 2 & -2 & ? & -1 & 1 & 1 & 1 & -1 & 1 & 1 & -1 & 1 & 2 & -2 & -2 & & & & $\cdot$ & & \\
\hline .8 & & 2 & 2 & 2 & . & . & -1 & -1 & -1 & 2 & 2 & 2 & -1 & -1 & -1 & -1 & -1 & -1 & -1 & -1 & -1 & 2 & 2 & 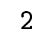 & & & & 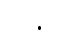 & 1 & \\
\hline 9 & & 2 & -2 & -2 & . & 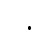 & -1 & 2 & -1 & -1 & -2 & 2 & -1 & 1 & 1 & -2 & 2 & -2 & 1 & -1 & 1. & -1 & 1 & & & & & 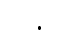 & & \\
\hline 1 & & 2 & -2 & -2 & . & . & -1 & -1 & 2 & -1 & -2 & ? & -1 & 1 & 1 & 1 & -1 & 1 & -2 & 2 & -2 & -1 & 1 & & & & & & & \\
\hline 1 & & 2 & 2 & 2 & . & . & -1 & -1 & 2 & -1 & 2 & ? & -1 & -1 & -1 & -1 & -1 & -1 & 2 & 2 & 2 & -1 & -1 & - & & & & & -1 & \\
\hline 1 & 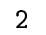 & 2 & 2 & 2 & . & - & -1 & 2 & -1 & -1 & 2 & 2 & -1 & -1 & -1 & 2 & 2 & 2 & -1 & -1 & -1 & -1 & -1 & -1 & & $\cdot$ & & & -1 & \\
\hline 1 & & -2 & -2 & 2 & . & . & 2 & -1 & -1 & -1 & . & . & -2 & -2 & 2 & -1 & 1 & 1 & 1 & 1 & -1 & 1 & -1 & 1 & $i 2$ & 2 & $-i 2$ & 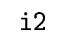 & & \\
\hline 1 & & -2 & 2 & -2 & . & . & 2 & -1 & -1 & -1 & . & . & -2 & 2 & -2 & 1 & 1 & -1 & -1 & 1 & 1 & 1 & 1 & -1 & -i2 & 2 & 2 & & & \\
\hline 1 & & -2 & -2 & 2 & . & . & 2 & -1 & -1 & -1 & . & . & -2 & -2 & 2 & -1 & 1 & 1 & 1 & 1 & -1 & 1 & -1 & 1 & 4 & $-i 2$ & i2 & - & & \\
\hline 1 & . & -2 & 2 & -2 & & . & 2 & -1 & -1 & -1 & 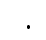 & . & -2 & 2 & -2 & 1 & 1 & -1 & -1 & 1 & 1 & 1 & 1 & -1 & 2 & $-i 2$ & $-i 2$ & i2 & & \\
\hline 17 & 3 & 3 & 3 & 3 & 1 & 1 & 3 & . & . & & -1 & -1 & 3 & 3 & 3 & . & 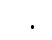 & . & 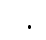 & $\cdot$ & . & ${ }^{\circ}$ & 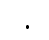 & ${ }^{\circ}$ & -1 & -1 & -1 & -1 & -1 & \\
\hline 18 & 3 & 3 & 3 & 3 & -1 & -1 & 3 & . & . & . & -1 & -1 & 3 & 3 & 3 & • & & . & ${ }^{\circ}$ & $\cdot$ & . & ${ }^{\circ}$ & $\cdot$ & 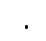 & & 1 & 1 & 1 & -1 & \\
\hline 1 & & 3 & -3 & -3 & -1 & 1 & 3 & . & . & . & 1 & -1 & 3 & -3 & -3 & • & $\cdot$ & . & $\cdot$ & $\cdot$ & . & ${ }^{\circ}$ & $\cdot$ & . & -1 & -1 & 1 & 1 & -1 & \\
\hline 20 & 3 & 3 & -3 & -3 & 1 & -1 & 3 & . & . & . & 1 & -1 & 3 & -3 & -3 & 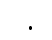 & & . & . & $\cdot$ & $\cdot$ & 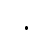 & . & & & 1 & -1 & -1 & -1 & \\
\hline 21 & 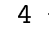 & -4 & 4 & -4 & $\cdot$ & . & 4 & 1 & 1 & 1 & . & $\cdot$ & -4 & 4 & -4 & -1 & -1 & 1 & 1 & -1 & -1 & -1 & -1 & 1 & & . & . & & & \\
\hline 22 & 4 & -4 & -4 & 4 & & ${ }^{\circ}$ & 4 & 1 & 1 & 1 & • & $\cdot$ & -4 & -4 & 4 & 1 & -1 & -1 & -1 & -1 & 1 & -1 & 1 & -1 & & $\cdot$ & • & & & \\
\hline 23 & & -4 & -4 & 4 & & . & -2 & 1 & 1 & -2 & • & . & 2 & 2 & -2 & 1 & -1 & -1 & -1 & -1 & 1 & 2 & -2 & & & • & & & & \\
\hline 24 & 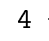 & -4 & 4 & -4 & $\cdot$ & . & -2 & 1 & 1 & -2 & • & . & 2 & -2 & 2 & -1 & -1 & 1 & 1 & -1 & -1 & 2 & 2 & -2 & & & & & & \\
\hline & 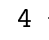 & -4 & -4 & 4 & & 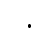 & -2 & -2 & 1 & 1 & • & $\cdot$ & 2 & 2 & -2 & -2 & 2 & 2 & -1 & -1 & 1 & -1 & 1 & -1 & & $\cdot$ & & & & \\
\hline & & -4 & 4 & -4 & 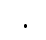 & - & -2 & 1 & -2 & 1 & & 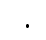 & 2 & -2 & 2 & -1 & -1 & 1 & -2 & 2 & 2 & -1 & -1 & 1 & & & & & & \\
\hline & 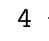 & -4 & -4 & 4 & & . & -2 & 1 & -2 & 1 & & • & 2 & 2 & -2 & 1 & -1 & -1 & 2 & 2 & -2 & -1 & 1 & -1 & & & & & & \\
\hline & & -4 & 4 & -4 & & . & -2 & -2 & 1 & 1 & & . & 2 & -2 & 2 & 2 & 2 & -2 & 1 & -1 & -1 & -1 & -1 & 1 & & & & & & \\
\hline & 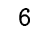 & 6 & -6 & -6 & & . & -3 & & & & 2 & -2 & -3 & 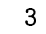 & 3 & & & & & & & & & & & & & & & \\
\hline 30 & 6 & 6 & 6 & 6 & & & -3 & & & & -2 & -2 & -3 & -3 & -3 & & & & & & & & & & & & & & & \\
\hline
\end{tabular}

Tabela 6.8: Tabela de Caracteres do Grupo $Q_{8}:\left(3^{2}: 2^{2}\right)$. 


\begin{tabular}{|c|c|c|c|c|c|c|c|c|c|c|c|c|c|c|c|c|c|}
\hline 2 & 4 & 4 & 2 & 3 & 1 & & & & 3 & 3 & 1 & 1 & 1 & 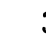 & & 3 & 2 \\
\hline 3 & 2 & 2 & . & 2 & 2 & & & 2 & 1 & 2 & 2 & 2 & 2 & & & . & 1 \\
\hline & $1 \mathrm{a}$ & $2 a$ & $2 b$ & $3 a$ & $3 b$ & 3 & & & $4 a$ & $6 a$ & $6 \mathrm{~b}$ & $6 c$ & $6 \mathrm{~d}$ & 8 & & $3 b$ & 12 \\
\hline X.1 & 1 & 1 & 1 & 1 & 1 & & & 1 & 1 & 1 & 1 & 1 & 1 & & & 1 & 1 \\
\hline X. 2 & 1 & 1 & -1 & 1 & 1 & & & 1 & 1 & 1 & 1 & 1 & 1 & - & & -1 & 1 \\
\hline X. 3 & 2 & 2 & . & 2 & -1 & - & & & 2 & 2 & -1 & -1 & -1 & & & ․ & 2 \\
\hline $\mathrm{X} .4$ & 2 & 2 & . & -1 & -1 & - & & 2 & 2 & -1 & -1 & 2 & -1 & & & $\cdot$ & -1 \\
\hline X.5 & 2 & 2 & . & -1 & -1 & 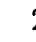 & & & 2 & -1 & -1 & -1 & 2 & & & . & -1 \\
\hline X. 6 & 2 & 2 & . & -1 & 2 & - & & & 2 & -1 & 2 & -1 & -1 & & & . & -1 \\
\hline X.7 & 2 & -2 & . & 2 & -1 & - & & & . & -2 & 1 & 1 & 1 & $-i$ & & 2 & \\
\hline X. 8 & 2 & -2 & . & 2 & -1 & - & & & . & -2 & 1 & 1 & 1 & i) & & 2 & \\
\hline X.9 & 3 & 3 & -1 & 3 & . & & & . & -1 & 3 & . & . & . & & & 1 & -1 \\
\hline X.10 & 3 & 3 & 1 & 3 & . & & & . & -1 & 3 & • & . & . & - & & -1 & -1 \\
\hline X.11 & 4 & -4 & . & 4 & 1 & & & 1 & . & -4 & -1 & -1 & -1 & & & . & \\
\hline X.12 & 4 & -4 & . & -2 & 1 & & & & . & 2 & -1 & 2 & -1 & & & . & . \\
\hline X.13 & 4 & -4 & . & -2 & 1 & - & & 1 & . & 2 & -1 & -1 & 2 & & & . & . \\
\hline X.14 & 4 & -4 & . & -2 & -2 & & & 1 & . & 2 & 2 & -1 & -1 & & & ${ }^{\circ}$ & • \\
\hline X.15 & 6 & 6 & . & -3 & • & & & & -2 & -3 & . & . & . & & & . & 1 \\
\hline
\end{tabular}

Tabela 6.9: Tabela de Caracteres do Grupo $Q_{8}:\left(3^{2}: 2\right)$. 


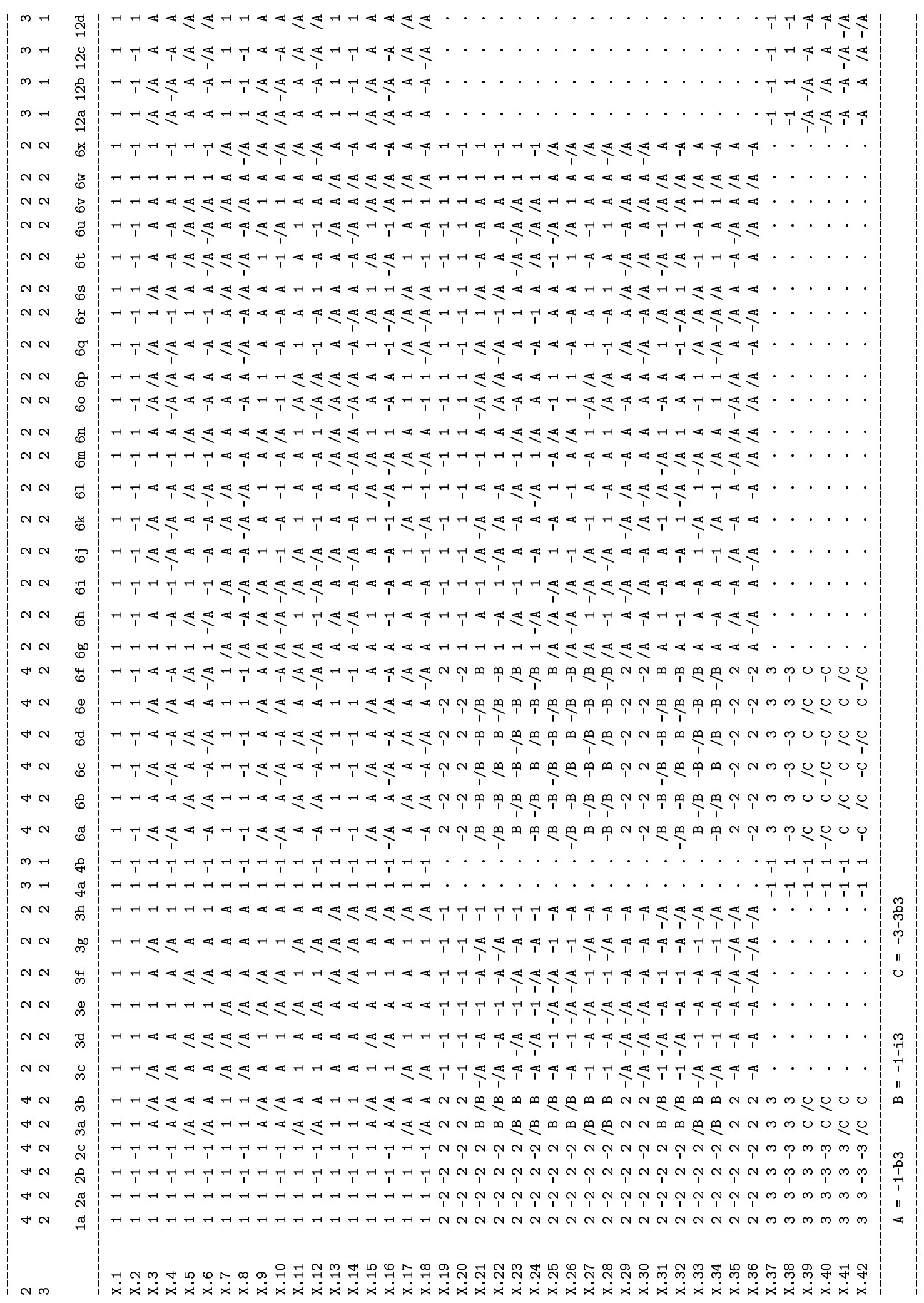

Tabela 6.10: Tabela de Caracteres do Grupo $Q_{8}:\left(3^{2} \times 2\right)$. 


$\begin{array}{lllllllllllllllll}2 & 5 & 5 & 5 & 5 & 3 & 3 & 2 & 4 & 4 & 2 & 2 & 2 & 4 & 4 & 4 & 4 \\ 3 & 1 & 1 & 1 & 1 & . & . & 1 & . & . & 1 & 1 & 1 & . & . & . & .\end{array}$

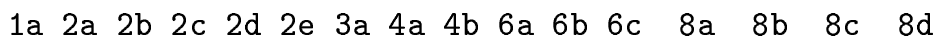

\begin{tabular}{|c|c|c|c|c|c|c|c|c|c|c|c|c|c|c|c|c|}
\hline$X .1$ & 1 & 1 & 1 & 1 & 1 & 1 & 1 & 1 & 1 & 1 & 1 & 1 & 1 & 1 & 1 & 1 \\
\hline X. 2 & 1 & 1 & -1 & -1 & -1 & 1 & 1 & -1 & 1 & -1 & 1 & -1 & 1 & 1 & -1 & -1 \\
\hline$X .3$ & 1 & 1 & 1 & 1 & -1 & -1 & 1 & 1 & 1 & 1 & 1 & 1 & -1 & -1 & -1 & -1 \\
\hline$X .4$ & 1 & 1 & -1 & -1 & 1 & -1 & 1 & -1 & 1 & -1 & 1 & -1 & -1 & -1 & 1 & 1 \\
\hline$X .5$ & 2 & 2 & -2 & -2 & . & . & -1 & -2 & 2 & 1 & -1 & 1 & . & . & . & \\
\hline$X .6$ & 2 & 2 & 2 & 2 & . & . & -1 & 2 & 2 & -1 & -1 & -1 & . & . & . & \\
\hline$X .7$ & 2 & -2 & -2 & 2 & . & . & -1 & . & . & -1 & 1 & 1 & $-i 2$ & i2 & i2 & $-i 2$ \\
\hline$X .8$ & 2 & -2 & 2 & -2 & . & . & -1 & . & . & 1 & 1 & -1 & $-i 2$ & i2 & $-i 2$ & i2 \\
\hline X. 9 & 2 & -2 & -2 & 2 & . & . & -1 & . & . & -1 & 1 & 1 & i2 & $-i 2$ & $-i 2$ & i2 \\
\hline$X .10$ & 2 & -2 & 2 & -2 & . & . & -1 & . & . & 1 & 1 & -1 & i2 & $-i 2$ & i2 & $-i 2$ \\
\hline X.11 & 3 & 3 & 3 & 3 & 1 & 1 & . & -1 & -1 & . & . & . & -1 & -1 & -1 & -1 \\
\hline X.12 & 3 & 3 & 3 & 3 & -1 & -1 & . & -1 & -1 & . & . & . & 1 & 1 & 1 & 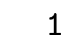 \\
\hline X.13 & 3 & 3 & -3 & -3 & -1 & 1 & 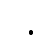 & 1 & -1 & . & 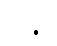 & . & -1 & -1 & 1 & 1 \\
\hline X.14 & 3 & 3 & -3 & -3 & 1 & -1 & . & 1 & -1 & • & . & . & 1 & 1 & -1 & -1 \\
\hline$X .15$ & 4 & -4 & 4 & -4 & . & . & 1 & . & . & -1 & -1 & 1 & . & . & . & \\
\hline $\mathrm{X} .16$ & 4 & -4 & -4 & 4 & . & . & 1 & . & . & 1 & -1 & -1 & . & . & . & \\
\hline
\end{tabular}

Tabela 6.11: Tabela de Caracteres do Grupo $Q_{8}: D_{12}$. 


$\begin{array}{lllllllllllllllllllllllll}2 & 3 & 3 & 3 & 3 & 3 & 3 & 3 & 3 & 2 & 2 & 2 & 2 & 2 & 2 & 2 & 2 & 2 & 2 & 2 & 2 & 2 & 2 & 2 & 2 \\ 3 & 2 & 2 & 2 & 2 & . & . & . & . & 2 & 2 & 2 & 2 & 2 & 2 & 2 & 2 & 2 & 2 & 2 & 2 & 2 & 2 & 2 & 2\end{array}$

1a $2 \mathrm{a} 2 \mathrm{~b} 2 \mathrm{c} 2 \mathrm{~d} 2 \mathrm{e} 2 \mathrm{f} 2 \mathrm{~g} 3 \mathrm{a} 3 \mathrm{~b} 3 \mathrm{c} 3 \mathrm{~d} 6 \mathrm{a} 6 \mathrm{~b} 6 \mathrm{c} 6 \mathrm{~d} 6 \mathrm{e} 6 \mathrm{f} 6 \mathrm{~g} 6 \mathrm{~h} 6 \mathrm{i} 6 \mathrm{j} 6 \mathrm{k} 6 \mathrm{l}$

\begin{tabular}{|c|c|c|c|c|c|c|c|c|c|c|c|c|c|c|c|c|c|c|c|c|c|c|c|c|}
\hline X. 1 & 1 & 1 & 1 & 1 & 1 & 1 & 1 & 1 & 1 & 1 & 1 & 1 & 1 & 1 & 1 & 1 & 1 & 1 & 1 & 1 & 1 & 1 & 1 & 1 \\
\hline .2 & 1 & 1 & 1 & 1 & -1 & -1 & -1 & -1 & 1 & 1 & 1 & 1 & 1 & 1 & 1 & 1 & 1 & 1 & 1 & 1 & 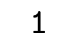 & - & 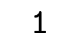 & \\
\hline$X .3$ & 1 & 1 & -1 & -1 & 1 & 1 & -1 & -1 & 1 & 1 & 1 & 1 & 1 & 1 & 1 & 1 & -1 & -1 & -1 & -1 & -1 & -1 & -1 & $\perp$ \\
\hline .4 & 1 & 1 & -1 & -1 & -1 & -1 & 1 & 1 & 1 & 1 & 1 & 1 & 1 & 1 & 1 & 1 & -1 & -1 & -1 & -1 & -1 & -1 & -1 & -1 \\
\hline .5 & 1 & -1 & 1 & -1 & -1 & 1 & -1 & 1 & 1 & 1 & 1 & 1 & -1 & -1 & -1 & -1 & 1 & -1 & 1 & -1 & -1 & 1 & -1 & \\
\hline .6 & 1 & -1 & 1 & -1 & 1 & -1 & 1 & -1 & 1 & 1 & 1 & 1 & -1 & -1 & -1 & -1 & 1 & -1 & 1 & -1 & -1 & 1 & -1 & \\
\hline$X .7$ & 1 & -1 & -1 & 1 & -1 & 1 & 1 & -1 & 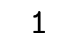 & 1 & 1 & 1 & -1 & -1 & -1 & -1 & -1 & 1 & -1 & 1 & 1 & -1 & 1 & -1 \\
\hline X. 8 & 1 & -1 & -1 & 1 & 1 & -1 & -1 & 1 & 1 & 1 & 1 & 1 & -1 & -1 & -1 & -1 & -1 & 1 & -1 & 1 & 1 & -1 & 1 & -1 \\
\hline .9 & 2 & 2 & 2 & 2 & . & 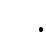 & . & . & -1 & -1 & -1 & 2 & -1 & -1 & -1 & 2 & -1 & -1 & -1 & -1 & 2 & 2 & -1 & -1 \\
\hline$X .10$ & 2 & 2 & -2 & -2 & • & & & . & -1 & -1 & -1 & 2 & -1 & -1 & -1 & 2 & 1 & 1 & 1 & 1 & -2 & -2 & 1 & \\
\hline X. 11 & 2 & -2 & 2 & -2 & . & . & . & . & -1 & -1 & -1 & 2 & 1 & 1 & 1 & -2 & -1 & 1 & -1 & 1 & -2 & 2 & 1 & -1 \\
\hline X.12 & 2 & -2 & -2 & 2 & . & . & . & . & -1 & -1 & -1 & 2 & 1 & 1 & 1 & -2 & 1 & -1 & 1 & -1 & 2 & -2 & -1 & 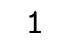 \\
\hline .13 & 2 & 2 & 2 & 2 & . & . & 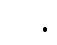 & . & 2 & -1 & -1 & -1 & 2 & -1 & -1 & -1 & 2 & 2 & -1 & -1 & -1 & -1 & -1 & -1 \\
\hline .14 & 2 & 2 & -2 & -2 & 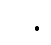 & 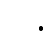 & & . & 2 & -1 & -1 & -1 & 2 & -1 & -1 & -1 & -2 & -2 & 1 & 1 & 1 & 1 & 1 & \\
\hline X.15 & 2 & -2 & 2 & -2 & 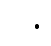 & • & 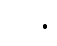 & ${ }^{\circ}$ & 2 & -1 & -1 & -1 & -2 & 1 & 1 & 1 & 2 & -2 & -1 & 1 & 1 & -1 & 1 & -1 \\
\hline X.16 & 2 & -2 & -2 & 2 & - & . & . & . & 2 & -1 & -1 & -1 & -2 & 1 & 1 & 1 & -2 & 2 & 1 & -1 & -1 & 1 & -1 & 1 \\
\hline X.17 & 2 & -2 & 2 & -2 & - & 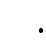 & 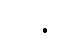 & • & -1 & -1 & 2 & -1 & 1 & 1 & -2 & 1 & -1 & 1 & 2 & -2 & 1 & -1 & 1 & -1 \\
\hline X.18 & 2 & -2 & -2 & 2 & . & & & & -1 & -1 & 2 & -1 & 1 & 1 & -2 & 1 & 1 & -1 & -2 & 2 & -1 & 1 & -1 & \\
\hline X.19 & 2 & -2 & 2 & -2 & 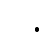 & 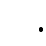 & 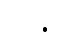 & . & -1 & 2 & -1 & -1 & 1 & -2 & 1 & 1 & -1 & 1 & -1 & 1 & 1 & -1 & -2 & 2 \\
\hline X. 20 & 2 & -2 & -2 & 2 & & & & . & -1 & 2 & -1 & -1 & 1 & -2 & 1 & 1 & 1 & -1 & 1 & -1 & -1 & 1 & 2 & -2 \\
\hline X. 21 & 2 & 2 & 2 & 2 & & & & & -1 & -1 & 2 & -1 & -1 & -1 & 2 & -1 & -1 & -1 & 2 & 2 & -1 & -1 & -1 & -1 \\
\hline X.22 & 2 & 2 & -2 & -2 & 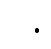 & . & & & -1 & -1 & 2 & -1 & -1 & -1 & 2 & -1 & 1 & 1 & -2 & -2 & 1 & 1 & 1 & . \\
\hline X.23 & 2 & 2 & 2 & 2 & & & & & -1 & 2 & -1 & -1 & -1 & 2 & -1 & -1 & -1 & -1 & -1 & -1 & -1 & -1 & 2 & 2 \\
\hline X. 24 & 2 & 2 & -2 & -2 & & & & & -1 & 2 & -1 & -1 & -1 & 2 & -1 & -1 & 1 & 1 & 1 & 1 & 1 & 1 & -2 & -2 \\
\hline
\end{tabular}

Tabela 6.12: Tabela de Caracteres do Grupo $3^{2}: 2^{3}$. 


\begin{tabular}{|c|c|c|c|c|c|c|c|c|c|c|c|c|c|c|c|c|c|c|c|c|c|}
\hline 2 & 3 & 3 & 3 & & 1 & 1 & 1 & 1 & 1 & 1 & 2 & 3 & 3 & 1 & 1 & 1 & 1 & 1 & 1 & $?$ & \\
\hline \multirow[t]{2}{*}{3} & 2 & 2 & 2 & 2 & 2 & 2 & 2 & 2 & 2 & 2 & 1 & 2 & 2 & 2 & 2 & 2 & 2 & 2 & 2 & 1 & \\
\hline & $1 \mathrm{a}$ & $2 a$ & $3 a$ & $3 b$ & $3 c$ & $3 d$ & $3 e$ & $3 f$ & $3 g$ & $3 \mathrm{~h}$ & $4 a$ & $6 a$ & $6 \mathrm{~b}$ & $6 c$ & $6 \mathrm{~d}$ & $6 e$ & $6 f$ & $6 \mathrm{~g}$ & $6 \mathrm{~h}$ & $12 \mathrm{a}$ & 1 \\
\hline$X .1$ & 1 & 1 & 1 & 1 & 1 & 1 & 1 & 1 & 1 & 1 & 1 & 1 & 1 & 1 & 1 & 1 & 1 & 1 & 1 & 1 & \\
\hline X. 2 & 1 & 1 & A & $/ \mathrm{A}$ & 1 & 1 & A & $\mathrm{A}$ & $/ A$ & $/ A$ & 1 & A & $/ \mathrm{A}$ & 1 & 1 & $\mathrm{~A}$ & A & $/ \mathrm{A}$ & $/ \mathrm{A}$ & A & /A \\
\hline X. 3 & 1 & 1 & $/ \mathrm{A}$ & $\mathrm{A}$ & 1 & 1 & $/ \mathrm{A}$ & $/ \mathrm{A}$ & A & A & 1 & $/ \mathrm{A}$ & $\mathrm{A}$ & 1 & 1 & $/ \mathrm{A}$ & $/ \mathrm{A}$ & $\mathrm{A}$ & $\mathrm{A}$ & $/ \mathrm{A}$ & \\
\hline$X .4$ & 1 & 1 & A & $/ \mathrm{A}$ & A & $/ \mathrm{A}$ & $/ \mathrm{A}$ & 1 & A & 1 & 1 & A & $/ \mathrm{A}$ & $\mathrm{A}$ & $/ \mathrm{A}$ & 1 & $/ \mathrm{A}$ & A & 1 & A & 1 \\
\hline X. 5 & 1 & 1 & $/ \mathrm{A}$ & A & A & $/ \mathrm{A}$ & 1 & A & 1 & $/ \mathrm{A}$ & 1 & $/ \mathrm{A}$ & A & A & $/ \mathrm{A}$ & A & 1 & 1 & $/ \mathrm{A}$ & $/ \mathrm{A}$ & \\
\hline X. 6 & 1 & 1 & 1 & 1 & A & $/ \mathrm{A}$ & A & $/ A$ & $/ \mathrm{A}$ & A & 1 & 1 & 1 & A & $/ \mathrm{A}$ & $/ A$ & A & $/ \mathrm{A}$ & $\mathrm{A}$ & 1 & \\
\hline$X .7$ & 1 & 1 & $/ \mathrm{A}$ & A & $/ \mathrm{A}$ & A & A & 1 & $/ \mathrm{A}$ & 1 & 1 & $/ \mathrm{A}$ & A & $/ \mathrm{A}$ & A & 1 & A & $/ \mathrm{A}$ & 1 & $/ \mathrm{A}$ & \\
\hline X. 8 & 1 & 1 & 1 & 1 & $/ \mathrm{A}$ & A & $/ \mathrm{A}$ & A & A & $/ \mathrm{A}$ & 1 & 1 & 1 & $/ \mathrm{A}$ & $\mathrm{A}$ & $\mathrm{A}$ & $/ \mathrm{A}$ & $\mathrm{A}$ & $/ A$ & 1 & \\
\hline X. 9 & 1 & 1 & A & $/ \mathrm{A}$ & $/ \mathrm{A}$ & A & 1 & $/ A$ & 1 & A & 1 & A & $/ \mathrm{A}$ & $/ A$ & A & $/ A$ & 1 & 1 & $\mathrm{~A}$ & A & 1 \\
\hline X. 10 & 2 & -2 & 2 & 2 & -1 & -1 & -1 & -1 & -1 & -1 & . & -2 & -2 & 1 & 1 & 1 & 1 & 1 & 1 & . & \\
\hline X. 11 & 2 & -2 & B & /B & -1 & -1 & $-/ A$ & $-/ A$ & $-A$ & $-A$ & . & $-B$ & $-/ B$ & 1 & 1 & $/ \mathrm{A}$ & $/ A$ & A & $\mathrm{A}$ & . & \\
\hline X. 12 & 2 & -2 & /B & B & -1 & -1 & $-A$ & $-A$ & $-/ A$ & $-/ A$ & . & $-/ B$ & $-B$ & 1 & 1 & A & A & $/ \mathrm{A}$ & $/ \mathrm{A}$ & . & \\
\hline X. 13 & 2 & -2 & 2 & 2 & $-A$ & $-/ A$ & $-A$ & $-/ A$ & $-/ A$ & $-A$ & . & -2 & -2 & A & $/ \mathrm{A}$ & $/ A$ & A & $/ \mathrm{A}$ & $\mathrm{A}$ & $\cdot$ & \\
\hline X. 14 & 2 & -2 & $/ \mathrm{B}$ & B & $-A$ & $-/ A$ & $-/ A$ & -1 & $-A$ & -1 & . & $-/ B$ & $-B$ & A & $/ \mathrm{A}$ & 1 & $/ \mathrm{A}$ & A & 1 & . & \\
\hline X. 15 & 2 & -2 & B & /B & $-A$ & $-/ A$ & -1 & $-A$ & -1 & $-/ A$ & . & $-B$ & $-/ B$ & A & $/ \mathrm{A}$ & $\mathrm{A}$ & 1 & 1 & $/ \mathrm{A}$ & . & \\
\hline X. 16 & 2 & -2 & /B & B & $-/ A$ & $-A$ & -1 & $-/ A$ & -1 & $-A$ & . & $-/ B$ & $-B$ & $/ A$ & A & $/ \mathrm{A}$ & 1 & 1 & A & $\cdot$ & \\
\hline X. 17 & 2 & -2 & B & $/ \mathrm{B}$ & $-/ A$ & $-A$ & $-A$ & -1 & $-/ A$ & -1 & . & $-B$ & $-/ B$ & $/ A$ & A & 1 & A & $/ \mathrm{A}$ & 1 & . & \\
\hline X. 18 & 2 & -2 & 2 & 2 & $-/ A$ & $-A$ & $-/ A$ & $-A$ & $-A$ & $-/ A$ & . & -2 & -2 & $/ \mathrm{A}$ & A & $\mathrm{A}$ & $/ \mathrm{A}$ & A & $/ \mathrm{A}$ & $\theta^{\circ}$ & \\
\hline X. 19 & 3 & 3 & 3 & 3 & • & . & . & . & . & 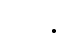 & -1 & 3 & 3 & . & . & . & . & . & . & -1 & - \\
\hline X. 20 & 3 & 3 & C & $/ \mathrm{C}$ & . & . & $\cdot$ & $\cdot$ & • & . & -1 & C & $/ C$ & . & . & . & . & . & . & $-A$ & $-/ A$ \\
\hline X. 21 & 3 & 3 & $/ \mathrm{C}$ & $\mathrm{C}$ & . & . & - & . & . & . & -1 & /C & C & . & . & . & . & . & . & $-/ A$ & - \\
\hline
\end{tabular}

Tabela 6.13: Tabela de Caracteres do Grupo $Q_{8}: 3^{2}$. 


\begin{tabular}{|c|c|c|c|c|c|c|c|c|}
\hline 2 & 4 & 4 & 2 & 1 & 3 & 1 & 3 & 3 \\
\hline 3 & 1 & 1 & - & 1 & 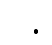 & 1 & . & \\
\hline & $1 \mathrm{a}$ & $2 \mathrm{a}$ & $2 b$ & $3 a$ & $4 a$ & $6 a$ & $8 a$ & $8 b$ \\
\hline 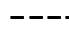 & -- & --- & $=-$ & -- & -1 & -- & -- & -- \\
\hline X.1 & 1 & 1 & 1 & 1 & 1 & 1 & 1 & 1 \\
\hline X. 2 & 1 & 1 & -1 & 1 & 1 & 1 & -1 & -1 \\
\hline X. 3 & 2 & 2 & • & -1 & 2 & -1 & . & . \\
\hline X. 4 & 2 & -2 & . & -1 & . & 1 & $-i 2$ & i2 \\
\hline X. 5 & 2 & -2 & . & -1 & . & 1 & i2 & $-i 2$ \\
\hline X. 6 & 3 & 3 & -1 & . & -1 & . & 1 & 1 \\
\hline$X .7$ & 3 & 3 & 1 & . & -1 & . & -1 & -1 \\
\hline X. 8 & 4 & -4 & . & 1 & . & -1 & . & . \\
\hline
\end{tabular}

Tabela 6.14: Tabela de Caracteres do Grupo $Q_{8}: S_{y m_{3}}$.

$\begin{array}{lllllllllllll}2 & 2 & 2 & 2 & 2 & 1 & 1 & 1 & 1 & 1 & 1 & 1 & 1 \\ 3 & 2 & 2 & . & . & 2 & 2 & 2 & 2 & 2 & 2 & 2 & 2\end{array}$

1a $2 \mathrm{a} 2 \mathrm{~b} 2 \mathrm{c} 3 \mathrm{a} 3 \mathrm{~b} 3 \mathrm{c} 3 \mathrm{~d} 6 \mathrm{a} 6 \mathrm{~b} 6 \mathrm{c} 6 \mathrm{~d}$

$\begin{array}{lrrrrrrrrrrrr}\text { X.1 } & 1 & 1 & 1 & 1 & 1 & 1 & 1 & 1 & 1 & 1 & 1 & 1 \\ \text { X.2 } & 1 & 1 & -1 & -1 & 1 & 1 & 1 & 1 & 1 & 1 & 1 & 1 \\ \text { X.3 } & 1 & -1 & 1 & -1 & 1 & 1 & 1 & 1 & -1 & -1 & -1 & -1 \\ \text { X.4 } & 1 & -1 & -1 & 1 & 1 & 1 & 1 & 1 & -1 & -1 & -1 & -1 \\ \text { X.5 } & 2 & 2 & . & . & -1 & -1 & -1 & 2 & -1 & -1 & -1 & 2 \\ \text { X.6 } & 2 & -2 & . & . & -1 & -1 & -1 & 2 & 1 & 1 & 1 & -2 \\ X .7 & 2 & 2 & . & . & -1 & -1 & 2 & -1 & -1 & -1 & 2 & -1 \\ X .8 & 2 & -2 & . & . & -1 & -1 & 2 & -1 & 1 & 1 & -2 & 1 \\ X .9 & 2 & -2 & . & . & 2 & -1 & -1 & -1 & -2 & 1 & 1 & 1 \\ X .10 & 2 & -2 & . & . & -1 & 2 & -1 & -1 & 1 & -2 & 1 & 1 \\ X .11 & 2 & 2 & . & . & -1 & 2 & -1 & -1 & -1 & 2 & -1 & -1 \\ \text { X.12 } & 2 & 2 & . & . & 2 & -1 & -1 & -1 & 2 & -1 & -1 & -1 \\ & & & & & & -1\end{array}$

Tabela 6.15: Tabela de Caracteres do Grupo $3^{2}: 2^{2}$. 

APÊNDICE A

\section{Número de Códigos Genéticos}

Do ponto de vista puramente combinatório, o número de códigos genéticos possíveis é simplesmente o número de possibilidades distintas de distribuir os aminoácidos (os significados) entre os 64 códons (os símbolos). O código genético padrão usa 20 aminoácidos e 1 sinal de terminação, mas em tese poderia usar qualquer número entre 1 e 64. É claro que um código genético com um único significado é extremamente degenerado, enquanto que um código genético com 64 significados e extremamente rígido.

Podemos então contar o número de códigos genéticos calculando primeiro o número de códigos genéticos com um número fixo $k$ de aminoácidos, com $k=1, \ldots, 64$.

Lembremos que uma particão não-ordenada de um conjunto finito $S$ é uma coleção de subconjuntos não-vazios de $S$ mutuamente disjuntos cuja união é $S$. O comprimento de uma partição não-ordenada é o número de subconjuntos que a compõem. Por exemplo, as partições do conjunto $\{1,2,3\}$ são:

$$
\begin{aligned}
&\{\{1\},\{2\},\{3\}\}, \\
&\{\{1\},\{2,3\}\}, \quad\{\{1,2\},\{3\}\}, \quad\{\{1,3\},\{2\}\}, \\
&\{\{1,2,3\}\} .
\end{aligned}
$$

O número de partições não-ordenadas de comprimento $k$ de um conjunto com $n$ elementos é dado pelo número de Stirling de segunda ordem $S_{2}(n, k)$ que é definido por

$$
x^{n}=\sum_{k=0}^{n} S_{2}(n, k) k !\left(\begin{array}{l}
x \\
k
\end{array}\right)
$$

e o número de todas as partições não-ordenadas de um conjunto de $n$ elementos é dado pelo número de Bell $B(n)$ que é definido por $B(n)=\sum_{k=0}^{n} S_{2}(n, k)$. 
Observamos agora que todas as partições não-ordenadas de comprimento $k$ do conjunto de 64 códons (que pode ser identificado com o conjunto $\{1, \ldots, 64\}$ ) correspondem a todas as possibilidades de dividir os 64 códons em $k$ grupos de códons tal que os códons pertencentes ao mesmo grupo tenham o mesmo significado. Como ainda temos a liberdade de distribuir os significados entre estes grupos, concluímos que o número de códigos genéticos com $k$ aminoácidos é igual a

$$
k ! \times S_{2}(64, k)
$$

e portanto o número total de códigos genéticos é igual a

$$
\sum_{k=1}^{64} k ! \times S_{2}(64, k) .
$$

Este cálculo pode ser feito no GAP pelo comando

$\operatorname{Sum}([1 \ldots 64], \mathrm{k}->$ Factorial $(\mathrm{k}) * \operatorname{NrPartitionsSet}([1 \ldots 64], \mathrm{k}))$;

cuja saída é

$14084191898344573685642048295231285651783905182088 \backslash$

34734403870775971211916384631776000167564122146475

Este número é da ordem de $10^{99}$ que é o número de códigos genéticos possíveis. Já o número de códigos genéticos com 20 aminoácidos e 1 sinal de terminação é da ordem de $10^{84}$ e é calculado pelo comando

Factorial (21)*NrPartitionsSet ([1..64], 21);

cuja saída é

$1510109515792918244116781339315785081841294 \backslash$

607960614956302330123544242628820336640000 


\section{Bibliografia}

[1] A. Adem \& R.J. Milgram, Cohomology of Finite Groups, Springer-Verlag, New York 1994.

[2] F. Antoneli, Subalgebras Maximais das Álgebras de Lie Semisimples, Quebra de Simetria e o Código Genético, Dissesrtação de Mestrado, IME-USP, São Paulo 1998.

[3] F. Antoneli, L. Braggion, M. Forger \& J.E.M. Hornos, Extending the Search for Symmetries in the Genetic Code, aceito para publicação no International Journal of Modern Physics.

[4] F. Antoneli, M. Forger, P.A. Gaviria \& J.E.M. Hornos, On Amino Acid and Codon Assignment in Algebraic Models for the Genetic Code em preparação

[5] E. Artin, The Orders of the Linear Groups, Comm. on Pure and Applied Math. 3(1955), 355-366.

[6] E. Artin, The Orders of the Classical Simple Groups, Comm. on Pure and Applied Math. 4(1955), 455-472.

[7] E. Artin, Geometric Algebra, Wiley Interscience, New York 1957.

[8] M. Aschbacher, On the Maximal Subgroups of the Finite Classical Groups, Invent. Math. 76(1984), 469-514.

[9] M. Aschbacher, Chevalley Groups of Type $G_{2}$ as the Group of a Trilinear Form, Journal of Algebra 109(1987), 193-259.

[10] M. Aschbacher, Finite Group Theory, Cambridge University Press, Cambridge 1994.

[11] M. Aschbacher, Sporadic Groups, Cambridge University Press, Cambridge 1994. 
[12] M. Aschbacher, 3-Transposition Groups, Cambridge University Press, Cambridge 1997.

[13] M. Aschbacher \& L. Scott, Maximal subgroups of finite groups, Journal of Algebra 92(1985), n $\mathrm{n}^{\circ} 1,44-80$.

[14] L. Babai, A.J. Goodman \& L.Pyber, On Faithful Permutation Representations of Small Degree, Comm. Algebra 21(1993), nº 5, 1587-1602.

[15] L. Babai, A.J. Goodman \& L.Pyber, Groups Without Faithful Transitive Permutation Representations of Small Degree, J. Algebra 195(1997), nº 1, 1-29.

[16] A.O. Barut \& R. Rạczka, Theory of Group Representations and Applications, 2nd edition, World Scientific, Singapore 1986.

[17] L. Barnett, S. Brenner, F.H.C. Crick \& R.J. Watts-Tobin, General Nature of the Genetic Code for Proteins, Nature 192(1961), 1227-1232.

[18] A. Balog, C. Bessenrodt, J.B. Olsson \& K. Ono, Prime Power Degree Representations of the Symmetric and Alternating Groups, J. London Math. Soc. (2) 64(2001) n ${ }^{\circ}$, 344-356.

[19] F.R. Beyl \& J. Tappe, Group Extensions, Represntations and the Schur Multiplicator, Lecture Notes in Mathematics 958, Springer-Verlag, Berlin 1982.

[20] N. Bourbaki, Lie Groups and Lie Algebras, Chapters 1-8, Hermann, Paris 1975.

[21] L. Braggion, Procura por Simetrias de Lie na evolução do Código Genético, Dissertação de Mestrado, ICMSC-USP, São Carlos 1998.

[22] J. Brinkman, Minimal Permutation Representations of the Two Double Covers of $S_{n}$, Proc. of the Edinburgh Math. Soc. 39(1996), 285-289.

[23] T. Bröcker \& T. tomDieck, Representations of Compact Lie Groups, 2nd printing, Springer-Verlag, New York 1995.

[24] K.S. Brown, Buildings, Springer-Verlag, New York 1989.

[25] W. Burnside, Theory of Groups of Finite Order, 2nd edition, Cambridge University Press, Cambridge 1911; reimpressão: Dover, New York 1955.

[26] M. Burrow, Representation Theory of Finite Groups, Dover, New York 1993.

[27] G. Butler, Fundamental Algorithms for Permutation Groups, Lecture Notes in Computer Science 559, Springer-Verlag, Berlin 1991. 
[28] J.J Cannon, B.C. Cox \& D.F. Holt, Computing the subgroups of a permutation group, "Computational algebra and number theory (Milwaukee, WI, 1996)", J. Symbolic Comput. 31(2001), n 1-2, 149-161.

[29] R.W. Carter, Finite Groups of Lie Type, Wiley Interscience, New York 1985.

[30] R.W. Carter, Simple Groups of Lie Type, Wiley Interscience, New York 1989.

[31] V. Chari \& A. Pressley, A Guide to Quantum Groups, Cambridge University Press, Cambridge 1994.

[32] C. Chevalley, Theory of Lie Groups, Princeton University Press, Princeton 1946.

[33] C. Chevalley, Sur Certain Grupes Simples, Tôhoku Math. J. 7(1955), 14-66.

[34] G. Cooperman, L. Finkelstein, M. Tselman \& B. York, Constructing Permutation Representations for Matrix Groups, J. Symbolic Computation 24(1997), 471-488.

[35] B.N. Cooperstein, Maximal Subgroups of $G_{2}\left(2^{n}\right)$, J. Algebra 70(1981), 23-36.

[36] J.H. Conway, R.T. Curtis, S.P. Norton, R.A. Parker \& R.A. Wilson, An ATLAS of Finite Groups, Clarendon Press, Oxford 1985.

[37] J.H. Conway \& S.P. Norton, Monstrous Moonshine, Bull. London Math. Soc. 11(1979), 308-339.

[38] F.H.C. Crick, The Origin of the Genetic Code, J. Mol. Biol. 38(1968), 367-379.

[39] C.W. Curtis, Chevalley Groups and Related Topics, em Finite Simple Groups, Proc. Instructional Conference of Oxford 1969, Academic Press, London 1972.

[40] C.W. Curtis \& I. Reiner, Methods of Representation Theory, volume I, Wiley Interscience 1981.

[41] F. Digne \& J. Michel, Representations of Finite Groups of Lie Type, Cambridge University Press, Cambridge 1991.

[42] L. E. Dickson, Linear Groups with an Exposition of the Galois Field Theory, Dover, New York 1958.

[43] J. Dieudonné, Sur les Groupes Classiques, Actualités Scientifiques et Industrielles 1040, Hermann, Paris 1948.

[44] J. Dieudonné, La Géométrie des Groupes Classiques, Ergebnisse der Mathematik und ihrer Grenzgebiete 5, Springer-Verlag, Berlin 1955. 
[45] J. Dixmier, Enveloping Algebras, Graduate Studies in Mathematics, Volume 11, American Mathematical Society, Providence RI 1996.

[46] L. Dornhoff, Group Representation Theory, Parts A \& B, Marcel Dekker, New York 1972.

[47] E.B. Dynkin, Semisimple subalgebras of semisimple Lie algebras, Mat. Sb. 30(1952), 349-462; English transl.: AMS Translations(2) 6(1957), 111-244.

[48] E.B. Dynkin, Maximal subgroups of classical groups, Trudy Moskov. Mat. Obshch. 1(1952), 39-166; English transl.: AMS Translations(2) 6(1957), 245-378.

[49] B. Eick \& A. Hulpke, Computing the maximal subgroups of a permutation group. I, "Groups and computation III (Columbus, OH, 1999)", 155-168,

[50] W. Feit \& J.G. Thompson, Solvability of Groups of Odd Order, Pacific J. Math. 13(1963), 775-1029.

[51] M. Forger, Symmetry breaking in the genetic code, $41^{\circ}$ Seminário Brasileiro de Análise, Campinas 1995.

[52] M. Forger, Invariant polynomials and Molien functions, J. Math. Phys. 39(1998), $\mathrm{n}^{\circ}$ 2, 1107-1141.

[53] M. Forger, J.E.M. Hornos \& Y.M.M. Hornos, Global aspects in the algebraic approach to the genetic code, Phys. Rev. E, 56(1997), 7078-7082.

[54] M. Forger \& S. Sachse, Lie Superalgebra and the Multiplet Structure of the Genetic Code I: Codon Representations, J. Math. Phys. 41(2000), 5407-5422.

[55] M. Forger \& S. Sachse, Lie Superalgebra and the Multiplet Structure of the Genetic Code II: Branching Schemes, J. Math. Phys. 41(2000), 5423-5444.

[56] W. Fulton \& J. Harris. Representation Theory: A First Course, Springer-Verlag, New York 1991.

[57] The GAP Group, GAP - Groups, Algorithms and Programming, Version 4.2, Aachen, St. Andrews 1999.

(http://www-gap.dcs.st-and.ac.uk/〜gap)

[58] M. Golubitsky \& D. Schaffer, Groups And Singularities in Bifurcation Theory I, Applied Mathematical Sciences 51, Springer-Verlag, New York 1985.

[59] M. Golubitsky, D. Schaffer \& I. Stewart, Groups And Singularities in Bifurcation Theory II, Applied Mathematical Sciences 69, Springer-Verlag, New York 1988. 
[60] M. Golubitsky \& I. Stewart, The Symmetry Perspective, Birkhäuser, Boston Massachusetts 2001.

[61] M. Golubitsky \& I. Melbourne A Symmetry Classification of Columns em "Bridges: Mathematical Connections in Art, Music, and Science", ed. Reza Sarhangi, Bridges Conference (1998) 209-223.

[62] R. Goodman \& N.R. Wallach, Representations and Invariants of the Classical Groups, Cambridge University Press, London 1998.

[63] M. Goto \& F.D. Grosshans, Semisimple Lie Algebras, Lecture Notes in Pure and Applaied Mathematics, Volume 38, Marcel Dekker, New York 1978.

[64] D. Gorenstein, Finite Groups, Harper \& Row, New York 1968.

[65] D. Gorenstein, Finite Simple Groups, Plenum Press, 1982.

[66] D. Gorenstein, The Classification of Finite Simple Groups, Plenum Press, 1983.

[67] D. Gorenstein, Classifying the Finite Simple Groups, Bull. Amer. Math. Soc 14(1986) $n^{\circ} 1,1-98$.

[68] D. Gorenstein, R. Lyons \& R. Solomon, The classification of the finite simple groups, Mathematical Surveys and Monographs, 40.1, American Mathematical Society, Providence RI 1994.

[69] D. Gorenstein, R. Lyons \& R. Solomon, The classification of the finite simple groups, Number 2. Part I. Chapter G. General group theory. Mathematical Surveys and Monographs, 40.2, American Mathematical Society, Providence RI 1996.

[70] D. Gorenstein, R. Lyons \& R. Solomon, The classification of the finite simple groups, Number 3. Part I. Chapter A. Almost simple $K$-groups, Mathematical Surveys and Monographs, 40.3, American Mathematical Society, Providence RI 1998.

[71] R.L. Griess Jr., The Friendly Giant, Invent. Math. 69(1982), 1-102.

[72] R.L. Griess Jr., Basic Conjugacy Theorems for $G_{2}$, Invent. Math. 121(1995), 257-277.

[73] R.L. Griess Jr., Twelve Sporadic Groups, Springer-Verlag, New York 1998.

[74] R.L. Griess Jr. \& A.J. Ryba, Finite Simple Groups Which Projectively Embed in an Excepcional Lie Group are Classified!, Bull. of the AMS 36(1999) n ${ }^{\circ}$ 1, 75-93.

[75] R.L. Griess Jr. \& A.J. Ryba, Classification of Finite Quasisimple Groups Which Embed in Exceptional Algebraic Groups, Journal of Group Theory 5(2002), 1-39. 
[76] M. Harris, A Universal Mapping Problem, Covering Groups and Automorphism Groups of Finite Groups, Rocky Mountain Journal of Mathematics 2(1977) vol. 7, 289-295.

[77] B. Hayes, The Invention of the Genetic Code, American Scientist 86(1998) n 1, 8-14.

[78] S. Helgason, Differential Geometry, Lie Groups and Symmetric Spaces, Academic Press, New York 1978.

[79] P.N. Hoffman \& J.F. Humphreys, Projective Representations of the Symmetric Groups, Oxford University Press, Oxford 1992.

[80] J.E.M. Hornos \& Y.M.M. Hornos, Algebraic Model for the Evolution of the Genetic Code, Phys. Rev. Lett. 71(1993), 4401-4404.

[81] J.E.M. Hornos, Y.M.M. Hornos \& M. Forger, Symmetry and Symmetry Breaking: An Algebraic Approach to the Genetic Code, Int. J. Mod. Phys. B 13(1999), 2795-2885.

[82] J.E. Humphreys, Linear Algebraic Groups, Springer-Verlag, New York 1981.

[83] J.E. Humphreys, Introduction to Lie Algebras and Representation Theory, 3rd printing, Springer-Verlag, New York 1994.

[84] J.E. Humphreys, Reflection Groups and Coxeter Groups, Cambridge University Press, Cambridge 1997.

[85] J.F. Humphreys, Projective Character Tables for the Finite Simple Groups of Order Less Than One Million, Communications in Algebra 7(1983) vol. 11, 725-751.

[86] I.M. Isaacs, Character Theory of Finite Groups, Dover, New York 1994.

[87] A.A. Ivanov, Geometry of Sporadic Groups I - Petersen and Tilde Geometries, Encyclopedia of Mathematics and its Applications, 76. Cambridge University Press, Cambridge 1999.

[88] A.A. Ivanov \& S.V. Shpectorov, Geometry of Sporadic Groups II - Representations and Amalgams, Encyclopedia of Mathematics and its Applications, 91. Cambridge University Press, Cambridge 2002.

[89] G. James \& M. Liebeck, Rpresentations and Characters of Groups, Cambridge University Press, Cambridge 1995.

[90] N. Jacobson, Lie Algebras, Dover Publications, New York 1997.

[91] D.L. Johnson, Minimal Permutation Representations of Finite Groups, Amer. J. Math. 93(1971), 857-866. 
[92] V.G. Kac, Infinite Dimensional Lie Algebras, 3rd edition, Cambridge University Press, Cambridge 19??.

[93] W.M. Kantor, Simple Groups in Computational Group Theory, "Proceedings of the International Congress of Mathematicians, Vol. II (Berlin, 1998)", Doc. Math. (1998), Extra Vol. II, 77-86.

[94] C. Kassel, Quantum Groups, Springer-Verlag, New York 1995.

[95] G. Karpilovsky, Projective Representations of Finite Groups, Marcel Dekker, New York 1985.

[96] R.D. Kent, M. Schlesinger \& B.G. Wybourne, Algebraic Approaches to the Genetic Code, Canad. J. Phys. 76(1998) 445-452.

[97] W. Kimmerle, R. Lyons, R. Sandling, \& D.N. Teague, Composition Factors from the Group Ring and Artin's Theorem on Orders of Simple Groups, Proc. London Math. Soc. 60(1990), 89-122.

[98] P.B. Kleidman, The Maximal Subgroups of the Chevalley Groups $G_{2}(q)$ with $q$ Odd, the Ree Groups ${ }^{2} G_{2}(q)$, and Their Automorphisms Groups, Journal of Algebra 117(1988), 30-71.

[99] P.B. Kleidman \& M.W. Liebeck, The Subgrup Structure of the Finite Classical Groups, Cambridge University Press, Cambridge 1990.

[100] W.S. Klug \& M.R. Cummings, Concepts of Genetics, 3rd edition, MacMillan, New York 1991.

[101] A.K. Knapp, Lie Groups Beyond an Introduction, Birkhäuser, Boston Massachusetts 1996.

[102] H. Kopka \& P.W. Daly, A Guide to $\operatorname{H}^{A} T_{E} X 2_{\varepsilon}$, 2nd edition, Addison-Wesley, Reading Massachusetts 1996.

[103] L.G. Kovács \& C.E. Praeger, On Minimal Faithful Permutation Representation of Finite Groups, Bull. Austral. Math Soc. 62(2000), n 2, 311-317.

[104] V. Landázuri, Cotas para los Caracteres de los Grupos de Chevalley, Revista Colombiana de Matemáticas 6(1972), 125-165.

[105] V. Landázuri \& G.M. Seitz, On the Minimal Degrees of Projective Representations of the Finite Chevalley Groups, Journal of Algebra 32 (1974), 418-443. 
[106] S. Lang, Algebra, 3nd edition, Addison-Wesley, Reading Massachusetts 1993.

[107] S. Lang, Linear Algebra, 3nd edition, Springer-Verlag, New York 1987.

[108] M.W. Liebeck, C.E. Praeger \& J. Saxl, A Classification of the Maximal Subgroups of the Finite Alternating and Symmetric Groups, Journal of Algebra 111(1987), 365-383.

[109] M.W. Liebeck, C.E. Praeger \& J. Saxl, On the O'Nan-Scott Theorem for Finite Primitive Permutation Groups, J. Austral. Math. Soc. (Series A) 44(1988), 389-396.

[110] A.L. Lehninger, D.L. Nelson \& M.M Cox, Principles of Biochemistry, 2nd edition, Worth Publ., New York 1993.

[111] B. Lewin, Genes V, Oxford University Press, Oxford 1994.

[112] J. Maddox, The genetic code by numbers, Nature 367(1994), 111.

[113] G. Malle \& A.E. Zalesskii, Prime Power Degree Representations of Quasi-simple Groups, Arch. Math. 77(2001), 461-468.

[114] V.D. Mazurov, Minimal Permutation Representations of the Thompson Simple Group, Algebra i Logika 27(1988) n ${ }^{\circ}$ 5, 562-580; English transl.: Algebra and Logic 27(1988) $\mathrm{n}^{\mathrm{o}} 5,350-361$.

[115] V.D. Mazurov, Minimal Permutation Representations of Finite Simple Classical Groups Special Linear, Symplectic and Unitary Groups, Algebra i Logika 32(1993) n 3, 267-287; English transl.: Algebra and Logic 32(1993) nº 3, 142-153.

[116] J. McKay, The Non-Abelian Simple Groups $G,|G|<10^{6}$ - Character Tables, Communications in Algebra 13(1979) vol 7, 1407-1445.

[117] W.G. McKay \& J. Patera, Tables of Dimensions, Indices and Branching Rules of Simple Lie Algebras, Lecture Notes in Pure and Applaied Mathematics, Volume 69, Marcel Dekker, New York 1981.

[118] G.O. Michler \& M. Weller, The Character Values of the Irreducible Constituents of a Transitive Permutation Representation, Arch. Math. (Basel) 78(2002) nº 6, 417-429.

[119] M.W. Nirenberg \& J.H. Matthaei, The Dependence of Cell-Free Protein Synthesis in E. Coli upon Naturally Occurring Or Synthetic Polyribonucleotides, Proc. Nat. Acad. Sci. USA 47(1961), 1588-1602.

[120] M.W. Nirenberg \& P. Leder, RNA Codewords and Protein Synthesis, Science 145 (1964), 1399-1407. 
[121] S.P. Norton \& R.A. Wilson, Anatomy of the Monster II, Proc. London Math. Soc (3) 84(2002) $\mathrm{n}^{\mathrm{o}} 3,581-598$.

[122] G.N. Pandya, On Automorphisms of Finite Simple Chevalley Groups, J. Number Theory 6(1974), 171-184..

[123] G.N. Pandya, Algebraic Groups and Automorphisms of Finite Simple Chevalley Groups, J. Number Theory 6(1974), 239-247.

[124] R. Rasala, On the Minimal Degrees of Characters of $S_{n}$, Journal of Algebra 45 (1977), 132-181.

[125] M. Ronan, Lectures on Buildings, Perspectives in Mathematics, volume 7, Academic Press, Boston Masschusetts 1989.

[126] L.A.B. San Martin, Álgebras de Lie, Editora da UNICAMP, Campinas 1999.

[127] H. Samelson, Notes on Lie Algebras, Springer-Verlag, New York 1990.

[128] W.R. Scott, Group Theory, Dover, New York 1987.

[129] G.M. Seitz \& A.E. Zalesskii, On the Minimal Degrees of Projective Representations of the Finite Chevalley Groups II, Journal of Algebra 158 (1993), 233-243.

[130] A. Seress, An Introduction to Computational Group Theory, Notices Amer. Math. Soc. 44(1997), $\mathrm{n}^{\circ}$ 6, 671-679.

[131] J.-P. Serre, Complex Semisimple Lie Algebras, Springer-Verlag, New York 1987.

[132] J.-P. Serre, Lie Algebra and Lie Groups, 2nd edition, Lecture Notes in Mathematics 1500, Springer-Verlag, New York 1992.

[133] R. Solomon, A Brief History of the Classification of the Finite Simple Groups, Bull. Amer. Math. Soc. 38(2001) no 3, 315-352.

[134] R. Steinberg, Variations on a Theme of Chevalley, Pacific J. Math. 91(1959), 875-891.

[135] R. Steinberg, Automorphisms of Classical Lie Algebras, Pacific J. Math. 11(1961), 1119-1129.

[136] R. Steinberg, Lectures on Chevalley Groups, Lecture Notes, Yale University, 1967-1968.

[137] S. Sternberg, Group Theory and Physics, Cambridge University Press, Cambridge 1994. 
[138] I. Stewart, Broken symmetry in the genetic code?, New Scientist (5 MArch 1994), 16.

[139] I. Stewart, Life's Other Secret, John Wiley \& Sons, Inc., New York 1998.

[140] L. Stryer, Biochemistry, 4th edition, Freeman \& Co., New York, 1995.

[141] M. Suzuki, Group Theory I, Springer-Verlag, New York 1982.

[142] M. Suzuki, Group Theory II, Springer-Verlag, New York 1985.

[143] K.I. Tahara, On the Second Cohomology Groups of Semidirect Products, Math. Z. 129(1972), 365-379.

[144] D.E. Taylor, The Geometry Of Classical Groups, Heldermann Verlag, Berlin 1992.

[145] P.H. Tiep \& A.E. Zalesskii, Minimal Characters of the Finite Classical Groups, Communications in Algebra 24(1996) vol. 6, 2093-2167.

[146] J. Tits, Buildings of Spherical Type and Finite BN-pairs, Lecture Notes in Mathematics 386, Springer-Verlag, Berlin 1974.

[147] V.S. Varadarajan, Lie Groups, Lie Algebras and Their Representations, SpringerVerlag, New York 1984.

[148] A.V. Vasil'ev, Minimal Permutation Representations of Finite Simple Exceptional Groups of Types $G_{2}$ and $F_{4}$, Algebra i Logika 35(1996) n ${ }^{\circ}$ 6, 663-684; English transl.: Algebra and Logic 35(1996) $\mathrm{n}^{\mathrm{o}}$ 6, 371-383.

[149] A.V. Vasil'ev, Minimal Permutation Representations of Finite Simple Exceptional Groups of Types $E_{6}, E_{7}$ and $E_{8}$, Algebra i Logika 36(1997) $n^{\circ}$ 5, 518-530; English transl.: Algebra and Logic 36(1997) nº 5, 302-310.

[150] A.V. Vasil'ev, Minimal Permutation Representations of Finite Simple Exceptional Groups of Twisted Type, Algebra i Logika 37(1998) n $n^{\circ}$ 1, 17-35; English transl.: Algebra and Logic 37(1998) $\mathrm{n}^{\mathrm{o}}$ 1, 9-20.

[151] A.V. Vasil'ev \& V.D. Mazurov, Minimal Permutation Representations of Finite Simple Ortogonal Groups, Algebra i Logika 33(1994) no 6, 603-627; English transl.: Algebra and Logic 33(1994) $\mathrm{n}^{\circ}$ 6, 337-350.

[152] A. Wagner, An Observation on the Degrees of Projective Representations of the Symmetric and Alternating Groups over an Arbitrary Field, Arch. Math. 29(1977) 583-589.

[153] G. Warner, Harmonic Analysis on Semi-Simple Lie Groups I \& II, Springer-Verlag, New York 1972. 
[154] H. Weyl, Classical Groups, Their Invariants and Representaitions, 2nd edition, Princeton University Press, Princeton 1946.

[155] H. Weyl, Simetria, EdUSP, São Paulo 1997.

[156] E.P. Wigner, The Unreasonable Effectiveness of Mathematicas in Natural Sciences, Comm. on Pure and Applied Math. 13(1960), 1-14.

[157] R.A. Wilson, Is $J_{1}$ a subgroup of the Monster?, Bull. London Math. Soc. 18(1986) $\mathrm{n}^{\circ}$ 4, 349-350.

[158] R.A. Wilson, Standard Generators for Sporadic Simple Groups, J. Algebra 184(1996) $n^{\circ} 2,505-515$.

[159] R.A. Wilson, Construction of Finite Matrix Groups, em "Computational Methods for Representations of Groups and Algebras", eds. P. Dräxler, G.O. Michler, C.M. Ringel, Euroconference in Essen (Germany) (1997) 61-84, Progress in Mathematics, volume 173, Birkhäuser Verlag, Basel 1999.

[160] R.A. Wilson et al., A World-Wide-Web Atlas Of Finite Group Representations, http://www. mat.bham.ac.uk/atlas/v2.0.

[161] D.P. Želobenko, Compact Lie Groups and Their Representations, Translations of Mathematical Monographs, Volume 40, American Mathematical Society, Providence, RI, 1973. 